JESÚS MARINO FALCÓN ROQUE

\title{
DESENVOLVIMENTO DE DIFERENTES TIPOS DE NANOCONTAINERS COM INIBIDOR DODECILAMINA ENCAPSULADO PARA ADITIVAÇÃO DE PRIMERS COM PROPRIEDADES DE AUTORREPARAÇÃO
}




\section{DESENVOLVIMENTO DE DIFERENTES TIPOS DE NANOCONTAINERS COM INIBIDOR DODECILAMINA ENCAPSULADO PARA ADITIVAÇÃO DE PRIMERS COM PROPRIEDADES DE AUTORREPARAÇÃO}

Tese apresentada à Escola Politécnica da Universidade de São Paulo para a obtenção do Titulo de Doutor em Engenharia 
Área de concentração:

Engenharia Química

Orientadora:

Prof. ${ }^{a}$ Dra. Idalina Vieira Aoki 
Este exemplar foi revisado e corrigido em relação à versão original, sob responsabilidade única do autor e com a anuência de seu orientador.

São Paulo, de fevereiro de 2015.

Assinatura do autor

Assinatura do orientador

Catalogação-na-publicação

Falcon Roque, Jesus Marino

Desenvolvimento de diferentes tipos de nanocontainers com inibidor dodecilamina encapsulado para aditivação de primers com propriedades de autorreparação / J.M. Falcon Roque. versão corr. -- São Paulo, 2015.

$194 \mathrm{p}$.

Tese (Doutorado) - Escola Politécnica da Universidade de São Paulo. Departamento de Engenharia Química.

1.Nanoconteiners 2.Sef-healing 3.Dodecilamina 4.Revestimentos 5.EIE 6.SVET I.Universidade de São Paulo. Escola Politécnica. Departamento de Engenharia Química II.t. 
Dedico este trabalho

à Deus, que sempre esta de meu lado e cuida de minha família, aos meus queridos pais, Jesús Falcón Handabaka e Amanda Roque Bedoya pelo apoio incondicional e porque sempre acreditaram em minha superação, ao meus queridos irmãos, Amanda e Eder que sempre estão pendentes de mim e iluminam meu caminho com suas orações, à minha esposa Liliana e meu filho Matheus, que são a razão de minha vida e meu existir. 


\section{AGRADECIMENTOS}

À querida Professora Dra. Idalina Vieira Aoki, mais uma vez obrigado pela paciência, apoio, colaboração, dedicação e orientação para a finalização deste trabalho. Agradeço também sua grande amizade e confiança depositada em mim. Aos Professores Hercílio Gomes de Melo, Augusto Câmara Neiva e Isabel Correia Guedes, obrigado pelo apoio e amizade.

À Professora Larissa Otubo do Instituto de Pesquisa de Energéticas Nucleares, obrigado pelo apoio na obtenção das micrografias no microscópio eletrônico de transmissão.

Ao Alfredo do Laboratório de Microscópio de Varredura pela obtenção das imagens no FEG.

Ao pessoal da Mettler Toledo, Fabio, Pierre e Alessandra pelo apoio nas análises.

À técnica do Laboratório Teresa, obrigado pelos conselhos, apoio e grande amizade.

Aos técnicos do Laboratório de Química Tecnológica Geral, Antônio Carlos e Joel. Aos técnicos do Laboratório de Bioquímica e Processos do Bloco 20, Orlinda e Andreia.

Ao pessoal do Laboratório do Bloco 22, Denise e Henry (o mariachi).

Ao pessoal do Laboratório de corrosão do IPT pelo apoio no jateamento das chapas.

Ao pessoal administrativo em especial a Elisete, Graça e Alexander.

Ao Tiago pela amizade e apoio no laboratório.

À minha turminha de bandejão e risada, Ernesto (o papuchin) e o Victor (o empresário) pelos gratos momentos.

Aos meus companheiros de trabalho do Laboratório de Eletroquímica e Corrosão, em especial à Rocio, Bruna, Fernando, Marcão e Beatriz. 


\section{RESUMO}

Nos últimos anos, as indústrias têm mostrado muito interesse em procurar sistemas de pinturas que possam ser mais eficientes na proteção do substrato metálico. Os sistemas comuns de pinturas criam uma barreira passiva sobre substrato que evita o contato com a água e outras espécies agressivas. No entanto, a degradação do revestimento pode ocorrer como consequência de fatores externos como radiação UV, temperatura ou ação mecânica. Por este motivo, pesquisadores têm buscado sistemas de pintura com proteção ativa que sejam capazes de se autorreparar (self-healing), levando o substrato a um tempo de vida em serviço mais prolongado. Uma maneira para atingir este efeito ativo é a incorporação de sistemas de nanocontainers ou nanorreservatórios com material ativo encapsulado (inibidores de corrosão) na matriz do revestimento. O objetivo deste trabalho é avaliar o efeito na resistência à corrosão do aço carbono ABNT 1020 numa solução de $\mathrm{NaCl} 0,01 \mathrm{~mol} / \mathrm{L}$ quando seja submetido a um prétratamento com camada de tinta alquídica aditivada com nanocontainers contendo o inibidor de corrosão dodecilamina. Três tipos de nanocontainers foram avaliados: 1) nanocontainers a base de nanopartículas de sílica revestida com diferentes camadas de polieletrólitos. 2) nanocontainers a base do mineral haloisita. 3) nanocontainers a base de uma sílica mesoporosa com arranjo ordenado hexagonal tipo SBA-15. Também foi estudada a cinética de liberação do inibidor dodecilamina dos diferentes tipos de nanocontainers usando a técnica de impedância eletroquímica. Os métodos eletroquímicos utilizados para avaliar a resistência a corrosão e o efeito de autorreparação ou self healing foram a técnica de varredura do eletrodo vibratório (SVET) e espectroscopia de impedância eletroquímica (EIS), obtidas em solução aerada de $\mathrm{NaCl} 0,01 \mathrm{~mol} / \mathrm{L}$ para chapas de aço carbono revestidas. Testes acelerados de corrosão numa câmara de névoa salina (SSC) foram realizados seguindo a norma ASTM B 117-11. As imagens de microscopia ótica, microscopia eletrônica de varredura e microscopia eletrônica de transmissão foram obtidas para conhecer a estrutura e morfologia dos

nanocontainers e o aspecto dos corpos de prova pintados. A caracterização da sílica mesoporosa foi realizada por termogravimetria (TGA), adsorção e dessorção 
de nitrogênio e difração de raios-X. Os estudos de cinética de liberação do inibidor foram realizados numa solução de $\mathrm{NaCl} 0,1 \mathrm{~mol} / \mathrm{L}$ a diferentes valores de $\mathrm{pH}(2,9$ e 6.2) e contendo $1 \% \mathrm{~m} / \mathrm{m}$ de nanocontainers carregados com inibidor dodecilamina, onde foi possível demonstrar que a pH 2 a velocidade de liberação do inibidor foi maior para os três tipos de nanocontainers estudados. Com relação aos resultados de espectroscopia de impedância eletroquímica (EIS) e técnica de varredura com eletrodo vibratório (SVET) para os corpos de prova revestidos com uma tinta alquídica contendo $10 \% \mathrm{~m} / \mathrm{m}$ de nanopartículas de sílica obtidas por Lb-L ou haloisita e $15 \% \mathrm{~m} / \mathrm{m}$ de sílica mesoporosa foi comprovado o efeito selfhealing da tinta pela liberação do inibidor dodecilamina encapsulado dentro da estrutura do nanocontainer. Este efeito também foi notado nos testes de névoa salina, onde o inibidor de corrosão é liberado pelo abaixamento do $\mathrm{pH}$ nas regiões anódicas ou de corrosão retardando o processo de corrosão na região do defeito.

Palavras-chave: nanocontainers, self-healing, dodecilamina, revestimentos, EIE, SVET. 


\section{ABSTRACT}

In the last years, the industries have shown much interest in searching painting systems that may be more effective in protecting the metallic substrate. Common painting systems create a passive barrier over the substrate that avoids contact with the water and other aggressive species. However, degradation of the coating may occur as a result of external factors such as UV radiation, temperature or mechanical action. For this reason, researchers have sought paint active protection systems that are able to self-repair (self-healing) leading to a longer lifetime of the substrate. One way to achieve this active effect is the incorporation of nanocontainer systems with encapsulated active material (corrosion inhibitors) to the coating matrix. The objective of this study is to evaluate the effect on corrosion resistance of carbon steel ABNT 1020 in aerated $0.1 \mathrm{~mol} / \mathrm{L} \mathrm{NaCl}$ solution when it is subjected to a pretreatment with alkyd paint layer doped with nanocontainers containing dodecylamine as corrosion inhibitor. Three types of nanocontainers were evaluated: 1) $\mathrm{SiO}_{2}$ nanoparticles coated with polyelectrolytes multilayers. 2) halloysite nanoparticles. 3) type SBA-15 mesoporous silica particles of. The kinetics of release of the inhibitor dodecylamine from the different types of nanocontainers was also determined indirectly using electrochemical impedance spectroscopy technique. Electrochemical measurements were performed to evaluate the self-healing effect of coated carbon steel panels after a provoked defect with scanning vibrating electrode technique (SVET) and electrochemical impedance spectroscopy (EIS), all measurements were performed in an aerated $\mathrm{NaCl} 0.01 \mathrm{~mol} / \mathrm{L}$ solution. Accelerated corrosion tests in salt spray chamber (SSC) were also carried out following the prescriptions of ASTM B 117-11 standard. The images from optical, scanning electron and transmission electron microscopy were obtained to show the morphology and structure of the nanocontainers and the aspect of coated samples. The characterization of mesoporous silica was made by transmission electron microscopy, thermogravimetry (TGA), adsorption/desorption of $\mathrm{N}_{2}$ and X-ray diffraction. Kinetic studies of the release of encapsulated corrosion inhibitor were performed in $\mathrm{NaCl} 0.1 \mathrm{~mol} / \mathrm{L}$ solution at different $\mathrm{pH}$ values $(2,9$ and 6.2) containing $1 \mathrm{wt}$. \% of dispersed nanocontainers loaded with dodecylamine inhibitor, and it was possible to confirm that at $\mathrm{pH} 2$ condition the release of inhibitor was more efficient in comparison to other $\mathrm{pH}$ conditions (9 and 6.2). On the other hand, the results obtained by electrochemical impedance spectroscopy (EIS) and scanning vibrating electrode technique (SVET) of the coated carbon steel panels with alkyd paint loaded with 10 wt. \% $\left(\mathrm{SiO}_{2}\right.$ nanoparticles or halloysite) and $15 \mathrm{wt}$ \% (mesoporous silica) has proven the self-healing effect by the release of corrosion inhibitor from nanocontainers on the defect area triggered by the $\mathrm{pH}$ decrease typical of anodic or corroding areas. This self-healing and protective effect was also noticed in salt spray tests, where the corrosion inhibitor was released slowing down the corrosion process on the defective region.

Key-words: nanocontainers, self-healing, dodecylamine, coatings. 


\section{SUMÁRIO}

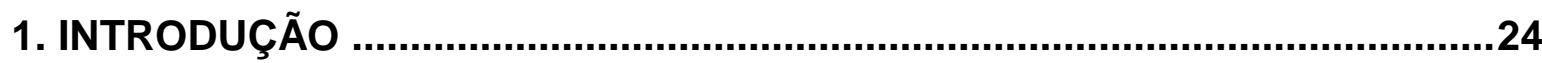

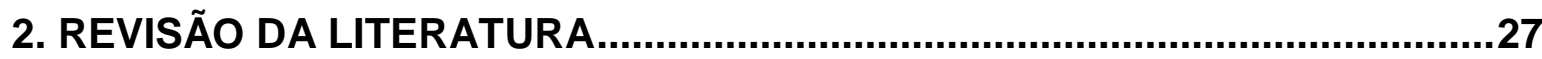

2.1 Inibidores de corrosão orgânicos que atuam por adsorção........................27

2.2 Aminas como inibidores de corrosão .......................................................31

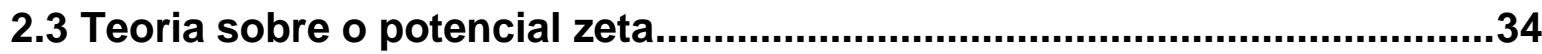

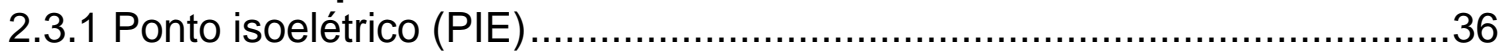

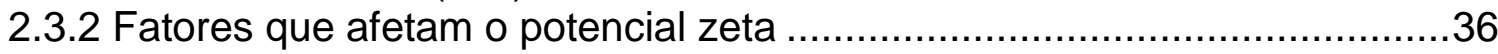

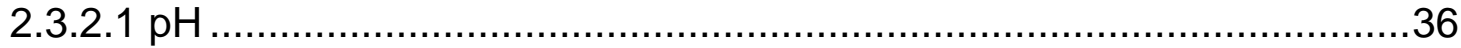

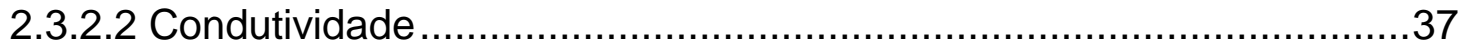

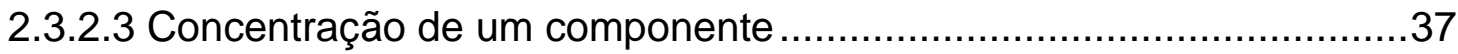

2.4 Teoria sobre polieletrólitos, formação, caracterização e aplicação...........37

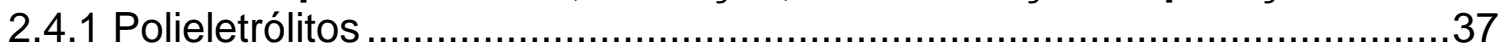

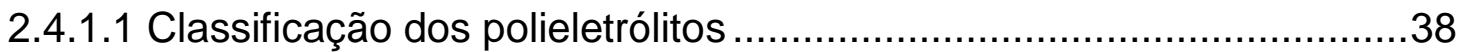

2.4.1.2 Parâmetros que afetam a ligação entre polieletrólitos ........................40

2.4.1.3 Formação de camadas de polieletrólitos ..........................................41

2.4.1.4 Mecanismos de adsorção para a formação de camadas....................42

2.4.2 Influência do pH nas propriedades de liberação dos polieletrólitos ............43

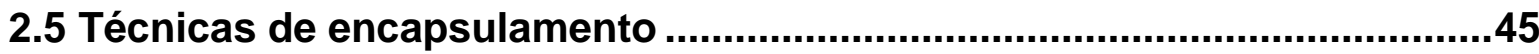

2.5.1 Encapsulamento em microcápsulas de paredes poliméricas ....................45

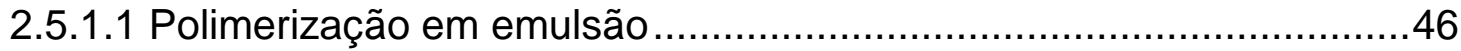

2.5.1.2 Polimerização em suspensão .........................................................46

2.5.1.3 Polimerização em emulsão e evaporação de solvente .........................47

2.6 Técnica de encapsulamento por Layer-by-Layer (L-b-L) ...........................48

2.7 Técnicas para avaliar a liberação dos inibidores de corrosão ..................52

2.7.1 Espectroscopia na região do infravermelho ......................................52

2.7.2 Medida indireta da liberação de inibidores encapsulados pela técnica de espectroscopia de impedância eletroquímica, EIE ............................................54

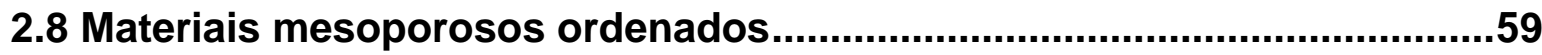

2.8.1 Mecanismo de formação da sílica mesoporosa ......................................62

2.8.2 Técnicas de caraterização de materiais mesoporosos ..............................63

2.8.2.1 Análise termogravimétrica (TGA/DTG) ……................................63

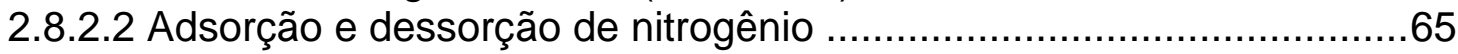

2.8.2.3 Método BET de adsorção de $\mathrm{N}_{2}$ para determinação da área superficial

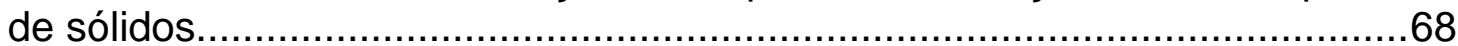

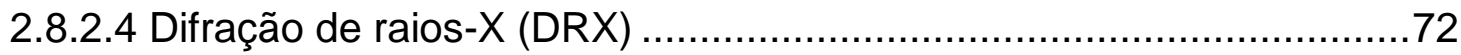

2.8.2.5 Microscopia eletrônica de transmissão (MET) ……............................75 
2.9 Avaliação do efeito self-healing ou autorreparação em camadas de tinta aditivadas com cápsulas contendo inibidores................................................78

2.9.1 Medidas de espectroscopia de impedância eletroquímica, EIE, em corpos

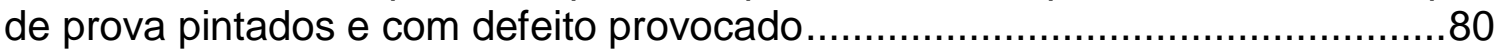

2.9.2 Técnica de varredura com eletrodo vibratório - SVET ............................84

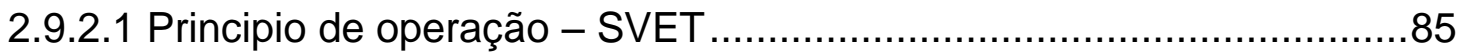

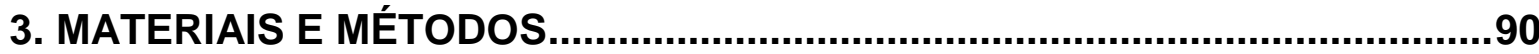

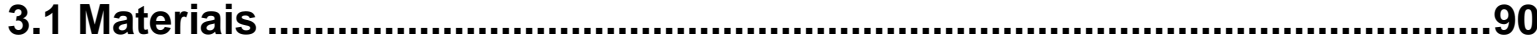

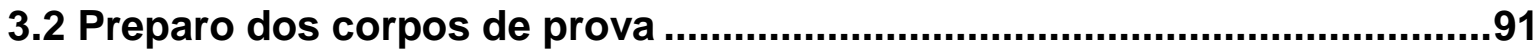

3.3 Preparo do inibidor de corrosão para encapsulamento...............................92

3.4 Preparo dos nanorreservatórios ou nanocontainers ...............................92

3.4.1 Nanorreservatórios feitos à base de nanoparticulas de sílica $\left(\mathrm{SiO}_{2}\right) \ldots \ldots . . .92$

3.4.2 Nanorreservatórios feitos à base de nanoparticulas de haloisita ..............93

3.4.3 Nanorreservatórios feitos à base de partículas de sílica mesoporosa ......94

3.5 Método de obtenção dos nanocontainers obtidos pelo método Layer-byLayer com dispersante PVA e método sem dispersante .................................94

3.6 Medidas de potencial zeta e tamanho de partícula ......................................94

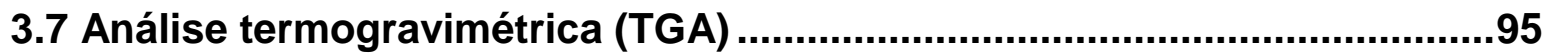

3.8 Caracterização por difração de raios-X ....................................................95

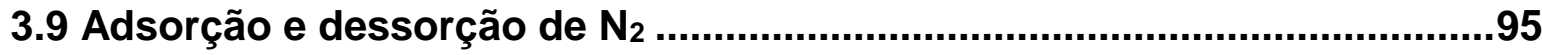

3.10 Microscopia eletrônica de transmissão (MET) ..........................................96

3.11 Caracterização morfológica dos nanocontainers por microscopia ótica

3.12 Caracterização morfológica dos nanocontainers por microscopia

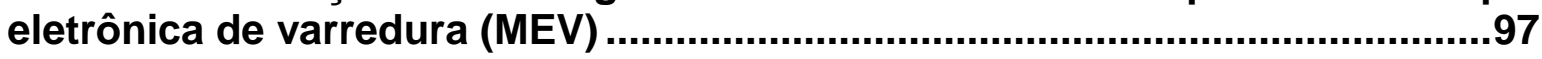

3.13 Caracterização morfológica dos nanocontainers por microscopia eletrônica de varredura por emissão de campo (MEV-FEG) .............................97

3.14 Preparo dos revestimentos aditivados com nanocontainers de sílica contendo dodecilamina obtidos pelo método Layer-by-Layer .........................97

3.15 Preparo dos revestimentos aditivados com nanocontainers de haloisita

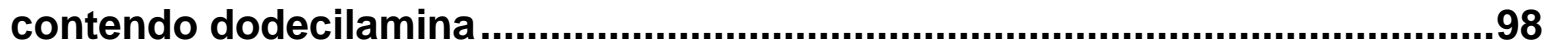


3.16 Preparo dos revestimentos aditivados com nanocontainers de sílica

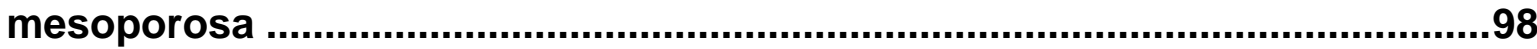

3.17 Preparo dos corpos de prova para a aplicação dos revestimentos contendo nanocontainers ..............................................................................98

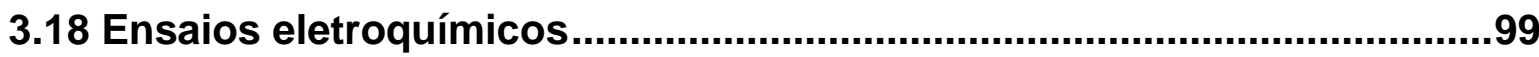

3.18.1 Medidas de espectroscopia de impedância eletroquímica, EIE ..............99

3.18.2 Medidas com o eletrodo vibratório, SVET …....................................100

3.19 Uso de uma sonda para análise na região do infravermelho para detectar a saída do inibidor dodecilamina dos nanocontainers obtidos pelo método Layer-by-Layer 101

3.20 Obtenção de corpos de prova pintados com tinta aditivada contendo os diferentes tipos de nanocontainers estudados carregados com inibidor de corrosão dodecilamina............................................................................102

3.21 Ensaios acelerados de corrosão em câmara de névoa salina................103

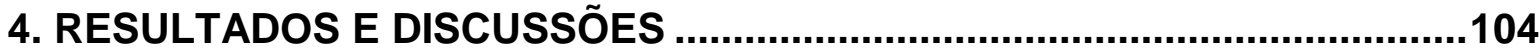

4.1 Curvas de tafel do inibidor dodecilamina sobre aço carbono ...................105

4.2 Caracterização da dodecilamina como inibidor de corrosão para aço carbono em meio neutro e em meio ácido ....................................................106

4.3 Caraterização morfológica e estrutural dos diferentes tipos de nanocontainers estudados ........................................................................109

4.3.1 Nanocontainers feitos à base de nanopartículas de sílica ....................110

4.3.1.1 Microscopia ótica (MO) .........................................................110

4.3.1.2 Potencial zeta e tamanho de partícula.......................................110

4.3.2 Nanocontainers feitos à base de nanopartículas de haloisita..................112

4.3.2.1 Análise termogravimétrica (TGA) ..............................................114

4.3.3 Nanocontainers feitos à base de partículas de sílica mesoporosa ..........116

4.3.3.1 Análise termogravimétrica (TGA) ...............................................116

4.3.3.2 Adsorção e dessorção de nitrogênio $\left(\mathrm{N}_{2}\right)$...................................119

4.3.3.3 Difração de raios-X ................................................................121

4.3.3.4 Microscopia eletrônica de varredura (MEV) .................................124

4.3.3.5 Microscopia eletrônica de transmissão (MET) .................................125

4.4 Avaliação por EIE da cinética de liberação do inibidor dodecilamina encapsulado sobre nanopartículas de sílica pela técnica L-b-L para diferentes valores de $\mathrm{pH}$ e diferentes formas de dispersar as partículas ....126 
4.4.1 Cinética de liberação do inibidor encapsulado de dentro dos nanocontainers de sílica $\left(\mathrm{SiO}_{2}\right)$.............................................................130 4.4.2 Estudo da liberação do inibidor para diferentes procedimentos de dispersão das nanopartículas de sílica durante a obtenção dos nanocontainers

4.4.2.1 Nanocontainers obtidos pelo método sem uso de dispersante PVA e sem uso de ultrassom ..............................................................................133 4.4.2.2 Nanocontainers obtidos pelo método com uso de dispersante PVA e de ultrassom 134

4.5 Estudo da liberação do inibidor dodecilamina encapsulado sobre nanopartículas de sílica usando uma sonda de análise na região do infravermelho 136

4.6 Avaliação por EIE da cinética de liberação do inibidor dodecilamina encapsulado sobre nanopartículas de haloisita para diferentes valores de $\mathrm{pH}$.

4.6.1 Cinética de liberação do inibidor encapsulado de dentro dos nanotubos de haloisita para diferentes $\mathrm{pHs}$ 144

4.7 Avaliação por EIE da cinética de liberação do inibidor dodecilamina encapsulado sobre partículas de sílica mesoporosa para diferentes valores de $\mathrm{pH}$. 145

4.7.1 Cinética de liberação do inibidor encapsulado de dentro das partículas de sílica mesoporosa. 149

4.8 Avaliação por EIE e por SVET do efeito de autorreparação de um revestimento alquídico aditivado com partículas de sílica contendo o inibidor dodecilamina encapsulado pelo método $L-b-L$ aplicado sobre $o$ aço carbono 152

4.8.1 Avaliação do efeito de autorreparação por espectroscopia de impedância

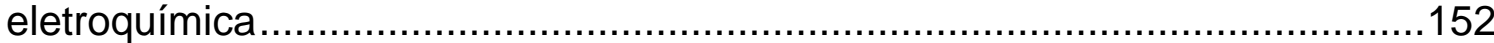
4.8.2 Técnica de varredura com eletrodo vibratório (SVET) .........................154

4.8.3 Ensaios acelerados em câmara de névoa salina ...................................159

4.9 Avaliação por EIE e por SVET do efeito de autorreparação de um revestimento alquídico aditivado com nanotubos de haloisita contendo o inibidor dodecilamina aplicado sobre aço carbono .....................................162

4.8.1 Medidas de espectroscopia de impedância eletroquímica (EIE) ..............162

4.9.2 Técnica de varredura com eletrodo vibratório (SVET) ..........................164

4.8.3 Ensaios em câmara de névoa salina................................................167

4.10 Avaliação por EIE e por SVET do efeito de autorreparação de um revestimento alquídico aditivado com partículas de sílica mesoporosa contendo o inibidor dodecilamina aplicado sobre $o$ aço carbono ................170

4.10.1 Medidas de espectroscopia de impedância eletroquímica (EIE) ...........170

4.10.2 Técnica de varredura com eletrodo vibratório (SVET) .........................172 
4.10.3 Ensaios acelerados em câmara de névoa salina ..............................176

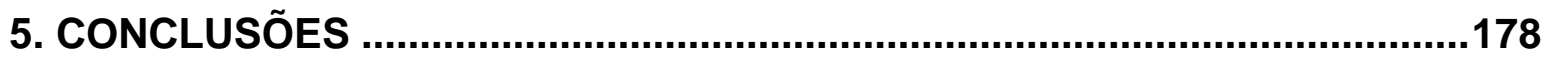

6. SUGESTÕES PARA TRABALHOS FUTUROS..........................................181

7. REFERÊNCIAS BIBLIOGRÁFICAS ......................................................182 


\section{LISTA DE FIGURAS}

Figura 2.1 Representação esquemática da formação e agregação de camadas de polieletrólitos (a) formação de um complexo primário (b) processo de formação dentro dos complexos internos (c) processo de ligação entre os complexos (VERMA; VERMA, 2013).

Figura 2.2 Etapas do processo de encapsulação de partículas pela técnica de polimerização em emulsão (FU et al.,2011).

Figura 2.3 Etapas do processo de encapsulação de uma fase oleosa pela técnica de polimerização por suspensão (CHAIYASAT; ISLAM; CHAIYASAT, 2013).

Figura 2.4 Etapas do processo de encapsulação pela técnica de evaporação de solvente (MISSIRLIS et al., 2006)....

Figura 2.5 Esquema mostrando as diferentes etapas para o encapsulamento de um agente ativo (inibidor de corrosão) pela técnica Layer-byLayer

Figura 2.6 Esquema mostrando os diferentes tipos de vibrações moleculares (SKOOG; HOLLER; NIEMAN, 2002).

Figura 2.7 Representação esquemática do (a) Diagrama de Nyquist e (b) Diagrama de Bode (ELECTROCHEMICAL [...], 2007).

Figura 2.8 Formula estrutural do P123 (KAVANOV et al., 2002).

Figura 2.9 Dualidade porosa da sílica mesoporosa tipo SBA-15 (GALARNEAU et al., 2001)

Figura 2.10 Microscopia eletrônica de varredura da sílica mesoporosa calcinada (ZHAO et al., 1998b)

Figura 2.11 Representação esquemática da síntese da sílica mesoporosa. (Adaptado do HATTON et al., 2005). 
Figura 2.12 Diagrama de um equipamento para análises termogravimétricas (DENARI, 2012).

Figura 2.13 Classificação das isotermas de adsorção e dessorção segundo IUPAC (NEIMARK; SING, 2008)

Figura 2.14 Tipos de hiterese (SING et al., 1985).....

Figura 2.15 Esquema representativo para a formulação da lei de Bragg (SKOOG; HOLLER; NIEMAM, 2002).

Figura 2.16 Difratograma de raios-X para a sílica mesoporosa calcinada (DHAR et al., 2005)......

Figura 2.17 Esquema de funcionamento de um microscópio de transmissão (ROA, 2008).

Figura 2.18 (A) Esquema do efeito self-healing de um revestimento protegido e (B) imagem de um primer contendo as nanopartículas de sílica dopadas com inibidor (SKORB et al., 2009).

Figura 2.19 Representação de Nyquist dos valores de impedância de um aço pintado com epóxi-oxido de ferro após diferentes tempos de imersão em solução $1 \mathrm{~mol} / \mathrm{L}$ de $\mathrm{NaCl}$ (a) após $1 \mathrm{~h}$ de imersão e (b) após $504 \mathrm{~h}$ de imersão (WOLYNEC, 2003).

Figura 2.20 Diagrama esquemático do (a) fluxo iônico gerado pelas regiões anódicas e (b) as respectivas correntes em diferença de potencial gerados (AKID; GARMA, 2004).

Figura 2.21 Diferentes tipos de resposta em função das intensidades de correntes detectadas pela SVET (AKID; GARMA, 2004).

Figura 2.22 Esquema de funcionamento do SVET

Figura 3.1 Fluxograma para a obtenção dos diferentes tipos de nanocontainers estudados.

Figura 3.2 Imagem ilustrativa do defeito artificial feito sobre a amostra pintada para a realização dos ensaios de SVET.

Figura 3.3 Foto ilustrativa do reator Easymax integrado com a sonda de infravermelho. 
Figura 3.4 Foto ilustrativa dos corpos de prova dentro da câmara de névoa salina e com as bordas protegidas com fita apropriada.

Figura 4.1 Curvas de Tafel para o aço carbono imerso numa solução de $\mathrm{NaCl}$ $0,1 \mathrm{~mol} / \mathrm{L}$ a pH $6.2 \mathrm{sem}$ inibidor e contendo $400 \mathrm{ppm}$ do inibidor dodecilamina.

Figura 4.2 Diagramas de Nyquist (a) e de Bode (b) obtidos para o aço carbono quando foi imerso durante $1 \mathrm{~h}$ numa solução de $\mathrm{NaCl} 0,1 \mathrm{~mol} / \mathrm{L}$ a pH $6.2 \mathrm{sem}$ inibidor e contendo diferentes concentrações do inibidor dodecilamina.

Figura 4.3 Diagramas de Nyquist (a) e de Bode (b) obtidos para o aço carbono quando foi imerso durante $1 \mathrm{~h}$ numa solução de $\mathrm{NaCl} 0,1 \mathrm{~mol} / \mathrm{L}$ a pH 2 sem inibidor e contendo diferentes concentrações do inibidor dodecilamina.

Figura 4.4 Imagens por $\mathrm{MO}$ das nanopartículas de sílica (L-b-L) contendo $\mathrm{O}$ inibidor dodecilamina.

Figura 4.5 (a) Medidas de potencial zeta dos nanocontainers: número de camadas de 0 , nanopartículas de $\mathrm{SiO}_{2}$ iniciais; $1, \mathrm{SiO}_{2} / \mathrm{PEI} ; 2$, $\mathrm{SiO}_{2} / \mathrm{PEI} / \mathrm{PSS} ; 3$, $\mathrm{SiO}_{2} / \mathrm{PEI} / \mathrm{PSS} /$ dodecilamina; 4, $\mathrm{SiO}_{2} / \mathrm{PEI} / \mathrm{PSS} /$ dodec ilamina/PSS; 5, $\mathrm{SiO}_{2} / \mathrm{PEI} / \mathrm{PSS} /$ dodecilamina/PSS/dodecilamina. Diâmetro dos nanocontainers vs número de etapas de deposição.

Figura 4.6 Imagens do MEV-FEG da haloisita sem inibidor antes (a) e depois do tratamento com ácido sulfúrico $2 \mathrm{~mol} / \mathrm{L}$ durante um tempo de 12 horas (b)

Figura 4.7 Curva termogravimétrica (TGA) para a haloisita sem inibidor dodecilamina.

Figura 4.8 Curva termogravimétrica (TGA) para haloisita com inibidor dodecilamina.

Figura 4.9 Curva termogravimétrica (TGA) para a sílica mesoporosa sem inibidor dodecilamina

Figura 4.10 Curva termogravimétrica (TGA) para a sílica mesoporosa com inibidor dodecilamina. 
Figura 4.11 Isotermas de adsorção e dessorção de $\mathrm{N}_{2}$ na sílica mesoporosa...........

Figura 4.12 Distribuição do raio de poro para a sílica mesoporosa......................... 120

Figura 4.13 Difração de raios-X para a sílica mesoporosa.................................... 122

Figura 4.14 Difração de raios- $X$ para a sílica mesoporosa calcinada considerando uma faixa maior de valores de $2 \theta$ varredura.

Figura 4.15 Imagens de MEV das nanopartículas de sílica mesoporosa para diferentes aumentos (a) 5000x e (b) 20000x.

Figura 4.16 Imagens de TEM da sílica mesoporosa (a) paralelo ao eixo dos poros e (b) perpendicular ao eixo dos poros.

Figura 4.17 Diagramas de Nyquist (a) e de Bode ((b) e (c)) para o aço carbono, para diferentes tempos de imersão numa solução de $\mathrm{NaCl} 0,1 \mathrm{~mol} / \mathrm{L}$ com $\mathrm{pH}=2$ contendo $1 \%$ em massa de nanopartículas de sílica com dodecilamina encapsulada por L-b-L

Figura 4.18 Diagramas de Nyquist (a) e de Bode ((b) e (c)) para o aço carbono, para diferentes tempos de imersão numa solução de $\mathrm{NaCl} 0,1 \mathrm{~mol} / \mathrm{L}$ com $\mathrm{pH}=6,2$ contendo $1 \%$ em massa de nanopartículas de sílica com dodecilamina encapsulada por L-b-L

Figura 4.19 Diagramas de Nyquist (a) e de Bode ((b) e (c)) para o aço carbono, para diferentes tempos de imersão numa solução de $\mathrm{NaCl} 0,1 \mathrm{~mol} / \mathrm{L}$ com $\mathrm{pH}=2$ contendo $1 \%$ em massa de nanopartículas de sílica com dodecilamina encapsulada por L-b-L

Figura 4.20 Cinética da cinética de liberação do inibidor a partir das nanopartículas de sílica (L-b-L) para diferentes tempos de imersão numa solução de $\mathrm{NaCl} 0,1 \mathrm{~mol} / \mathrm{L}$ para valores de $\mathrm{pH}=2,6,2$ e 9 usando como substrato uma chapa de aço carbono ABNT 1020 .

Figura 4.21 Diagramas de Nyquist (a) e de Bode (b) para o aço carbono em diferentes tempos de imersão numa solução de $\mathrm{NaCl} 0,1 \mathrm{~mol} / \mathrm{L}$ com $\mathrm{pH}=2$ e sem adição de nanocontainers.

Figura 4.22 Diagramas de Nyquist (a) e de Bode (b) para o aço carbono em diferentes tempos de imersão numa solução de $\mathrm{NaCl} 0,1 \mathrm{~mol} / \mathrm{L}$ com $\mathrm{pH}=2 \mathrm{com}$ adição de $1 \% \mathrm{~m} / \mathrm{m}$ de nanocontainers sem inibidor encapsulado. 
Figura 4.23 Diagramas de Nyquist para o aço carbono seguindo o primeiro tratamento sem dispersante e sem ultrassom em diferentes tempos de imersão numa solução de $\mathrm{NaCl} 0,1 \mathrm{~mol} / \mathrm{L}$ para $\mathrm{pH}=2$ e $\mathrm{pH}=6.2$ e contendo $1 \%$ em massa de nanocontainers.

Figura 4.24 Diagramas de Nyquist para o aço carbono seguindo o segundo tratamento com dispersante e com ultrassom em diferentes tempos de imersão numa solução de $\mathrm{NaCl} 0,1 \mathrm{~mol} / \mathrm{L}$ para $\mathrm{pH}=2$ e $\mathrm{pH}=6.2 \mathrm{e}$ contendo $1 \%$ em massa de nanocontainers.

Figura 4.25 Imagens dos nanocontainers de nanopartículas de sílica carregadas de dodecilamina por L-b-L obtidas por MEV.

Figura 4.26 Espectros de infravermelho para a dodecilamina, poliestirenosulfonado (PSS) e polietilenoimina (PEI) obtidos por subtração do espectro do solvente.

Figura 4.27 Gráfico 3D dos espectros obtidos da liberação da dodecilamina e dos polieletrólitos (PEI e PSS) em função do tempo (subtraído do solvente inicial)

Figura 4.28 Intensidade do pico de absorbância a $1596 \mathrm{~cm}^{-1}$ em função do tempo mostrando a liberação do inibidor de corrosão dodecilamina desde os nanocontainers a $\mathrm{pH} 2$

Figura 4.29 Diagramas de Nyquist (a) e de Bode ((b) e (c)) para o aço carbono, para diferentes tempos de imersão numa solução de $\mathrm{NaCl} 0,1 \mathrm{~mol} / \mathrm{L}$ com $\mathrm{pH}=2$ contendo $1 \%$ em massa de nanotubos de haloisita com dodecilamina encapsulada como inibidor de corrosão

Figura 4.30 Diagramas de Nyquist (a) e de Bode ((b) e (c)) para o aço carbono, para diferentes tempos de imersão numa solução de $\mathrm{NaCl} 0,1 \mathrm{~mol} / \mathrm{L}$ com $\mathrm{pH}=6,2$ contendo $1 \%$ em massa de nanotubos de haloisita com dodecilamina encapsulada como inibidor de corrosão

Figura 4.31 Diagramas de Nyquist (a) e de Bode ((b) e (c)) para o aço carbono, para diferentes tempos de imersão numa solução de $\mathrm{NaCl} 0,1 \mathrm{~mol} / \mathrm{L}$ com $\mathrm{pH}=6,2$ contendo $1 \%$ em massa de nanotubos de haloisita com dodecilamina encapsulada como inibidor de corrosão.

Figura 4.32 Curvas da cinética de liberação do inibidor desde a haloisita obtidas para diferentes tempos de imersão numa solução de $\mathrm{NaCl} 0,1 \mathrm{~mol} / \mathrm{L}$ para valores de $\mathrm{pH}=2,6,2$ e 9 usando como substrato uma chapa de aço carbono ABNT 1020. 
Figura 4.33 Diagramas de Nyquist (a) e de Bode ((b) e (c)) para o aço carbono, para diferentes tempos de imersão numa solução de $\mathrm{NaCl} 0,1 \mathrm{~mol} / \mathrm{L}$ com $\mathrm{pH}=2$ contendo $1 \%$ em massa de sílica mesoporosa com dodecilamina encapsulada.................................................................

Figura 4.34 Diagramas de Nyquist (a) e de Bode ((b) e (c)) para o aço carbono, para diferentes tempos de imersão numa solução de $\mathrm{NaCl} 0,1 \mathrm{~mol} / \mathrm{L}$ com $\mathrm{pH}=6,2$ contendo $1 \%$ em massa de sílica mesoporosa com dodecilamina encapsulada.

Figura 4.35 Diagramas de Nyquist (a) e de Bode ((b) e (c)) para o aço carbono, para diferentes tempos de imersão numa solução de $\mathrm{NaCl} 0,1 \mathrm{~mol} / \mathrm{L}$ com $\mathrm{pH}=9$ contendo $1 \%$ em massa de sílica mesoporosa com dodecilamina encapsulada

Figura 4.36 Curvas da cinética de liberação do inibidor desde a sílica mesoporosa obtidas para diferentes tempos de imersão numa solução de $\mathrm{NaCl}$ $0,1 \mathrm{~mol} / \mathrm{L}$ para valores de $\mathrm{pH} \mathrm{2,} \mathrm{6,2} \mathrm{e} 9$ usando como substrato uma chapa de aço carbono ABNT 1020 .

Figura 4.37 Comparação entre as curvas de cinética de liberação do inibidor dodecilamina desde os três tipos de nanocontainers obtidas para um tempo de imersão de até $16 \mathrm{~h}$ numa solução de $\mathrm{NaCl} 0,1 \mathrm{~mol} / \mathrm{L}$ para $\mathrm{pH} 2$, usando como substrato uma chapa de aço carbono ABNT 1020 .

Figura 4.38 Diagramas de Bode obtidos para as chapas de aço carbono revestidas com duas demãos de tinta alquídica e apenas a primeira camada aditivada com $0 \% \mathrm{~m} / \mathrm{m}$ e $10 \% \mathrm{~m} / \mathrm{m}$ de nanopartículas de sílica com dodecilamina encapsulada por L-b-L sem e com defeito provocado após diferentes tempos de imersão numa solução de $\mathrm{NaCl}$ $0,01 \mathrm{~mol} / \mathrm{L}$

Figura 4.39 Imagens do corpo de prova e mapas de densidade de corrente iônica obtidos para os CPs revestidos com duas demãos de tinta alquídica com defeito sem adição de nanopartículas de sílica para diferentes tempos de imersão em solução de $\mathrm{NaCl} 0,01 \mathrm{~mol} / \mathrm{L}$

Figura 4.40 Imagens do corpo de prova e mapas de densidade de corrente, obtidas para os CPs revestidos com duas demãos de tinta alquídica com defeito e apenas a primeira camada aditivada com $10 \%$ em massa de nanopartículas de sílica com dodecilamina encapsulada por L-b-L para diferentes tempos de imersão em solução de $\mathrm{NaCl} 0,01$ $\mathrm{mol} / \mathrm{L}$ 
Figura 4.41 Imagens dos corpos de prova lixados, pintados com duas demãos de alquídica e apenas a primeira camada aditivada com $0 \%, 10 \%$ e15 ; massa de nanopartículas de sílica com inibidor mina dodecila encapsulada por L-b-L após $0 \mathrm{~h}$ e $96 \mathrm{~h}$ de exposição na câmara de $r$ salina

Figura 4.42 Imagens dos corpos de prova jateados, pintados com duas demãos de tinta alquidíca aditivada com $0 \%, 10 \%$ e $15 \%$ em massa de nanopartículas de sílica com inibidor dodecilamina encapsulada por Lb-L após $0 \mathrm{~h}$ e $96 \mathrm{~h}$ de exposição na câmara de névoa salina.

Figura 4.43 Diagramas de Bode obtidos para as chapas de aço carbono revestidas com duas demãos de tinta alquídica e apenas a primeira camada aditivada com $0 \% \mathrm{~m} / \mathrm{m}$ e $10 \% \mathrm{~m} / \mathrm{m}$ de nanotubos de haloisita com dodecilamina encapsulada sem e com defeito provocado após diferentes tempos de imersão numa solução de $\mathrm{NaCl}$ $0,01 \mathrm{~mol} / \mathrm{L}$

Figura 4.44 Imagens do corpo de prova e mapas de densidade de corrente, obtidas para os CPs revestidos com duas demãos de tinta alquídica com defeito sem adição de nanotubos de haloisita para diferentes tempos de imersão em solução de $\mathrm{NaCl} 0,01 \mathrm{~mol} / \mathrm{L}$

Figura 4.45 Imagens do corpo de prova e mapas de densidade de corrente, obtidas para os CPs revestidos com duas demãos de tinta alquídica com defeito e apenas a primeira camada aditivada com $10 \% \mathrm{~m} / \mathrm{m}$ de nanotubos de haloisita com dodecilamina encapsulada para diferentes tempos de imersão em solução de $\mathrm{NaCl}$ 0,01 mol/L

Figura 4.46 Imagens dos corpos de prova lixados e pintados com duas demãos de tinta alquídica e apenas a primeira camada aditivada com $0 \%$ e $10 \%$ em massa de nanotubos de haloisita com dodecilamina encapsulada depois de $0 \mathrm{~h}$ e $720 \mathrm{~h}$ de exposição na câmara de névoa salina. 
Figura 4.47 Diagramas de Bode obtidos para as chapas de aço carbono revestidas com duas demãos de tinta alquídica e apenas a primeira camada aditivada com $0 \% \mathrm{~m} / \mathrm{m}$ e $15 \% \mathrm{~m} / \mathrm{m}$ de sílica mesoporosa com dodecilamina sem e com defeito provocado após diferentes tempos de imersão numa solução de $\mathrm{NaCl}$

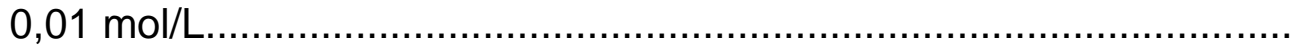

Figura 4.48 Imagens dos corpos de prova e mapas de densidade de correntes para as chapas de aço carbono revestidas com duas demãos de tinta alquídica com defeito sem adição de partículas de sílica mesoporosa com diferentes tempos de imersão em solução de $\mathrm{NaCl}$ $0,05 \mathrm{~mol} / \mathrm{L}$

Figura 4.49 Imagens dos corpos de prova e mapas de densidade de correntes para as chapas de aço carbono revestidas com duas demãos de tinta alquídica com defeito e apenas a primeira camada aditivada com 15 $\% \mathrm{~m} / \mathrm{m}$ de sílica mesoporosa contendo dodecilamina com diferentes tempos de imersão em solução de $\mathrm{NaCl}$ 0,05 mol/L

Figura 4.50 Imagens dos corpos de prova jateados pintados com duas demãos de tinta alquídica e apenas a primeira camada aditivada com $0 \%$ e $15 \%$ em massa de sílica mesoporosa com dodecilamina encapsulada depois de $0 \mathrm{~h}$ e $720 \mathrm{~h}$ de exposição na câmara de névoa salina. 


\section{LISTA DE TABELAS}

Tabela 2.1 Diferentes tipos de inibidores orgânicos classificados de acordo com o grupo funcional (INIBIDORES [...], 2005)

Tabela 2.2 Diferentes técnicas usadas na indústria de microencapsulamento (GHOSH, 2006).

Tabela 2.3 Principais fatores que podem influenciar nas medidas de TGA/DTG (DENARI, 2012).

Tabela 3.1 Medidas das espessuras das camadas em base seca e úmida para os corpos de prova revestidos usando nanocontainers a base de sílica $\left(\mathrm{SiO}_{2}\right) \mathrm{L}-\mathrm{b}-\mathrm{L}$

Tabela 3.2 Medidas das espessuras das camadas em base seca e úmida para os corpos de prova revestidos usando nanocontainers a base de nanotubos de haloisita.

Tabela 3.3 Medidas das espessuras das camadas em base seca e úmida para os corpos de prova revestidos usando nanocontainers a base de sílica mesoporosa.

Tabela 4.1 Valores de eficiência de inibição da dodecilamina para aço carbono em $\mathrm{NaCl} 0,1 \mathrm{~mol} / \mathrm{L}$ em $\mathrm{pH}$ 6,2 calculada a partir dos diagramas de impedância eletroquímica

Tabela 4.2 Valores de eficiência de inibição da dodecilamina para aço carbono em $\mathrm{NaCl} 0,1 \mathrm{~mol} / \mathrm{L}$ em $\mathrm{pH}$ 2,0 calculada a partir dos diagramas de impedância eletroquímica.

Tabela 4.3 Etapas das perdas de massa com suas perdas porcentuais para a haloisita sem inibidor dodecilamina 
Tabela 4.4 Etapas das perdas de massa com suas perdas porcentuais para a haloisita com inibidor dodecilamina

Tabela 4.5 Etapas das perdas de massa com suas perdas porcentuais para a sílica mesoporosa sem inibidor dodecilamina.

Tabela 4.6 Etapas das perdas de massa com suas perdas porcentuais para a sílica mesoporosa com inibidor dodecilamina.

Tabela 4.7 Características estruturais da sílica mesoporosa obtidas a partir dos dados de adsorção e dessorção de $\mathrm{N}_{2}$

Tabela 4.8 Valores de ângulo de $2 \theta$ com os índices de Miller, suas respectivas distâncias interplanares e o parâmetro mesoporoso 


\section{INTRODUÇÃO}

Durante as últimas décadas têm surgido várias propostas para proteger as superfícies dos metais contra o fenômeno da corrosão, o qual é um problema tecnologicamente importante para muitas indústrias. Recentes estudos sobre tecnologia e ciência da superfície provêem novas oportunidades sobre conceitos de engenharia moderna para a fabricação de revestimentos com propriedades de autorreparação ativa mediante a integração de partículas em nanoescala carregadas com componentes inibidores de corrosão ativos em filmes protetores clássicos, uma vez que existem alguns tipos de inibidores que não podem ser usados diretamente na formulação da pintura devido a possíveis interações com a matriz polimérica do revestimento.

A maioria dos sistemas de inibidores de corrosão é aplicada por adição direta aos meios agressivos e estes se adsorvem ou precipitam sobre as superfícies metálicas para criar uma barreira passiva protetora entre o metal e o meio agressivo, mas com os avanços da nanotecnologia, estas barreiras estão possuindo dupla funcionalidade, a saber: uma barreira física contra as espécies corrosivas e a outra de resposta ativa imediata para mudanças no ambiente local $(\mathrm{pH}$, temperatura, resistência iônica, etc). Sistemas de proteção ativa apontam para a recuperação das propriedades iniciais do revestimento ou substrato quando se tenha iniciado o processo de corrosão.

Atualmente, um novo conceito, baseado no uso de nanocontainers para o aumento do desempenho de sistemas de proteção ativa, tem-se tornado um assunto de grande importância no âmbito industrial, constituindo os chamados revestimentos inteligentes. Estes nanocontainers são carregados com inibidores de corrosão e consequentemente dispersados sobre revestimentos híbridos ou orgânicos oferecendo assim a possibilidade de liberação do material ativo de uma forma controlada, conseguindo-se assim deter as reações de corrosão sobre as zonas afetadas por defeitos, oferecendo assim uma eficiente habilidade de autorreparação para os revestimentos protetores. Um aspecto importante no projeto de novos revestimentos ativos é fazer nanocontainers que tenham as 
seguintes propriedades i) compatibilidade com os componentes da matriz polimérica, ii) que possam encapsular e manter o material ativo dentro de sua estrutura e iii) que as paredes possuam propriedades de permeabilidade que possam ser controladas por estímulos externos ou processo de corrosão, a fim de ativar a liberação controlada das espécies inibidoras encapsuladas. Existem muitas propostas já desenvolvidas para o projeto de sistemas de armazenagem tais como: nanocontainers poliméricos ou fibra de vidro, hidróxidos duplos lamelares ou materiais inorgânicos porosos (haloisita, montmorilonita, caulim, óxidos mesoporosos) e finalmente, os nanocontainers empregando multicamadas de polieletrólitos e inibidor de corrosão (método Layer-by-Layer).

Estes nanocontainers a base de materiais inorgânicos porosos como a haloisita, tem-se tornado provavelmente uma das melhores propostas devido a seu baixo custo e capacidade de encapsular uma variedade de agentes ativos dentro de sua estrutura de cilindro oco, seguido de sua retenção e liberação. Além de ser a haloisita um produto natural, de dimensões nanométricas e compatível com a maioria de sistemas de pinturas a base solvente e água, ela também não oferece riscos ao meio ambiente.

Estruturas de sílica mesoporosas são outro tipo de material que recentemente tem atraído muito a atenção como nanocontainers devido a sua alta estabilidade, biocompatibilidade, grande área de superfície, diâmetro de poro controlável e fácil superfície de funcionalização. Estas propriedades permitem armazenar o inibidor de corrosão nos poros de sua superfície e liberá-lo como resposta às mudanças de $\mathrm{pH}$ produzidas pelo processo de corrosão. Atualmente uma variedade de propostas químicas e físico-químicas têm sido empregadas para fabricar estes tipos de estruturas mesoporosas, surgindo assim a idéia de preparar materiais mesoporosos com estruturas ordenadas. Além disso, o tamanho dos mesoporos pode ser regulado por meio da escolha apropriada dos precursores. Materiais mesoporosos à base de sílica apresentam baixa toxicidade (são praticamente não tóxicos), baixa reatividade e podem ser modificados para se obter o tamanho do poro e geometria adequada para a adsorção de substâncias ativas como os inibidores de corrosão. 
O objetivo deste trabalho é avaliar as propriedades de autorreparação (selfhealing) de camadas de tinta alquídica aditivadas com diferentes tipos de nanocontainers carregados com o inibidor dodecilamina. Os três tipos de nanocontainers estudados foram: 1) nanocontainers à base de nanopartículas inertes de sílica $\left(\mathrm{SiO}_{2}\right)$ cobertas por diversas monocamadas permeáveis de polieletrólitos (poliestireno sulfonado e polietilenimina) e camadas do inibidor dodecilamina; 2) nanocontainers a base de nanotubos de haloisita e 3) nanocontainers a base de sílica mesoporosa com estrutura hexagonal ordenada. A morfologia dos nanocontainers foi estudada por microscopia eletrônica de varredura (MEV) e microscopia ótica (MO). A sílica mesoporosa sintetizada foi caracterizada por difração de raios- $X$, microscopia eletrônica de transmissão (MET), termogravimetria (TGA) e adsorção e dessorção de nitrogênio. Para comprovar o efeito de autorreparação dos revestimentos foram usadas técnicas eletroquímicas como espectroscopia impedância eletroquímica $(E I E)$ e técnica de varredura com eletrodo vibratório (SVET). Para dar suporte a estas técnicas eletroquímicas foram feitos também ensaios acelerados de corrosão em câmara de névoa salina seguindo a norma ASTM B-117. 


\section{REVISÃO DA LITERATURA}

\subsection{Inibidores de corrosão orgânicos que atuam por adsorção}

A corrosão é definida como o ataque destrutivo de um metal por reação química ou eletroquímica com seu meio. Em alguns casos, este ataque químico é acompanhado da deterioração física do material ou também chamada corrosão por erosão (UHLIG; REVIE, 1985). A importância prática da corrosão não reside só na perda de uma quantidade considerável de metais, mas é frequente que com perdas relativamente pequenas de metal estas possam causar danos irreparáveis, como o originado pelas formas localizadas de corrosão por pite e corrosão intergranular (ROBERGE, 2000).

Um dos métodos importantes para minimizar as perdas de corrosão é o uso de inibidores de corrosão, os quais são usados extensivamente em muitas aplicações industriais (SASTRI, 1998). Estes inibidores são substâncias ou misturas de substâncias que, quando adicionadas em concentrações adequadas, fazem decrescer ou eliminam efetivamente a corrosão (UHLIG; REVIE, 1985; GENTIL, 1996).

Dentre os diferentes tipos de inibidores de corrosão têm-se os inibidores de adsorção, os quais funcionam como películas protetoras formando uma barreira entre o metal e o meio agressivo e, dessa forma interferindo com a cinética do processo eletroquímico. Neste grupo estão incluídas substâncias orgânicas com grupos fortemente polares que dão lugar a películas por adsorção. Entre elas estão os colóides, sabões de metais pesados e moléculas com átomos de oxigênio, nitrogênio ou enxofre, podendo-se citar os aldeídos, aminas, compostos heterocíclicos nitrogenados, uréia e tiouréia substituídas (GENTIL, 1996).

Os inibidores orgânicos de adsorção foram classificados há muito tempo em inibidores dos tipos "O", "S" e "N", conforme sua atuação seja atribuída a moléculas com grupos funcionais contendo, respectivamente, átomos de oxigênio 
(grupos aldeído, álcool, ácido, cetona), enxofre e nitrogênio. Também alguns contendo fósforo ou arsênio são empregados, como é apresentado na Tabela 2.1.

Tabela 2.1 - Diferentes tipos de inibidores orgânicos classificados de acordo com o grupo funcional (INIBIDORES [...], 2005).

\begin{tabular}{|c|c|}
\hline Grupo funcional & Compostos \\
\hline "O" (-) & $\begin{array}{c}\text { Glicose, aldeídos (formaldeído), álcoois } \\
\text { (alcool propargílico) }\end{array}$ \\
\hline "S" (-) & Tiuoréias, sulfóxidos, mercaptanos \\
\hline "N" (+) & $\begin{array}{c}\text { Aminas (monoetanol amina, MEA, } \\
\text { dietanol amina, DEA, trietanol amina, } \\
\text { TEA, piridina, quinolina, morfolina, } \\
\text { poliaminas) e sais de amônio } \\
\text { quaternário }\end{array}$ \\
\hline $\mathrm{P}$ e As & Fosfonatos e arseno quaternários \\
\hline
\end{tabular}

Os inibidores do tipo $\mathrm{O}$ e $\mathrm{S}$, possuem grupos funcionais nos quais estes átomos têm quase sempre os elétrons disponíveis, de modo que facilmente conseguem se adsorver sobre superfícies carregadas positivamente, isto é, aquelas em que o metal está a um potencial acima do potencial de carga zero dele na solução. Já os inibidores do tipo $\mathrm{N}$ e os outros contendo fósforo e arsênio, produzem grupos com cargas positivas, pelo que se adsorvem mais facilmente sobre superfícies carregadas negativamente, ou seja, abaixo do potencial de carga nula.

Os inibidores do tipo S se adsorvem, em geral, fortemente. Às vezes esta adsorção é por compartilhamento de elétrons, como parece ser o caso da tiouréia, quando então a interação se dá em toda a superfície (regiões anódicas e catódicas).

Os inibidores tipo $\mathrm{N}$ ou $\mathrm{O}$ tendem, como um todo, a serem mais fracamente adsorvidos, de modo que são mais específicos em seus sítios de adsorção, em geral preferindo sítios anódicos. Um fator que influi na adsorção é o tamanho da molécula: por exemplo, aminas aromáticas se adsorvem deitadas sobre a superfície, com uma fraca força de adsorção do próprio anel benzênico; assim, 
quanto maior a área ocupada pelos carbonos dos anéis, maior é a inibição. Há o efeito estérico.

Aminas alifáticas se adsorvem pelo grupo amina e o restante da molécula fica ondulando em frente da superfície, aparentemente varrendo a superfície de modo a produzir efeitos estéricos mesmo em regiões catódicas vizinhas e assim funcionam como inibidores anódicos e catódicos (mistos) eficientes (INIBIDORES $[\ldots], 2005)$.

Saeed, Ali e Rahman (2003) testaram as hidroxilaminas cíclicas como inibidores de corrosão sobre aço carbono em meio ácido a $60{ }^{\circ} \mathrm{C}$ usando métodos gravimétricos e eletroquímicos. Os autores conseguiram obter eficiências altas de inibição usando concentrações de 400 ppm destes inibidores em solução de $\mathrm{HCl}$ $1,0 \mathrm{~mol} / \mathrm{L}$. Segundo os autores, a mais provável explicação para esta alta inibição é a forte adsorção destes compostos sobre a superfície do metal, a qual forma uma barreira física contra o meio agressivo. Outro resultado que eles encontraram foi que o ajuste dos dados experimentais pelo gráfico $\theta$ vs $\log C(p p m)$ obedece à isoterma de Temkin, o que indica que houve mais de uma camada adsorvida sobre a superfície do aço carbono. Desta forma, a excelente capacidade das hidroxilaminas em inibir a corrosão do aço carbono pode abrir caminho para sua exploração em aplicações industriais futuras.

Olivares et al. (2008) sintetizaram compostos alquilamidas a partir de $\alpha$ aminoácidos para testá-los como inibidores de corrosão para o aço carbono ABNT 1018 em meio de $\mathrm{HCl}$. Estes compostos foram: a) dodecilamida da tirosina (Tyr C12), b) dodecilamida da glicina (Gly C-12), c) octilamida da tirosina (Tyr C-8) e d) octilamida da glicina (Gly C-8). As técnicas utilizadas para avaliar a eficiência de inibição destes compostos foram curvas de polarização potenciodinâmica e medidas de perda de massa. Os resultados tirados das curvas de polarização potenciodinâmica mostraram que a eficiência de inibição apresenta a seguinte ordem: Tyr C-12 > Gly C-12 > Tyr C-8 > Gly C-8, já que tirosina possui uma cadeia 
mais longa em sua estrutura e, portanto, apresenta um maior grau de cobertura durante o processo químico de adsorção. $O$ ajuste dos resultados por um gráfico $\theta$ vs $\log \mathrm{C}(\mathrm{ppm})$ mostrou que o processo de adsorção obedece à isoterma de Temkin, o que indica a estabilidade do filme adsorvido sobre a superfície do aço carbono. Além disso, os valores de $\mathrm{K}$, constante de equilíbrio de adsorção e $\Delta \mathrm{G}$, energia livre de adsorção, junto com os baixos valores de velocidade de corrosão do aço na presença da tirosina indicam que eles são mais fortemente adsorvidos sobre a superfície do aço carbono em comparação com os outros compostos derivados da glicina.

Ashassi e Nabavi (2002) estudaram o efeito de inibição de diferentes tipos de aminas sobre o aço carbono, onde estas aminas foram dissolvidas numa mistura corrosiva de água e petróleo contendo ácido acético e cloreto de sódio. As aminas usadas neste estudo foram: a) etilenodiamina (EDA); b) hexilamina (HA); c) butilamina (BA); d) tert-butilamina (t-BA); e) propilamina (PA) e d) isopropilamina (i-PA). As técnicas utilizadas para avaliar o efeito de inibição destas aminas foram espectroscopia de impedância eletroquímica (EIS) e polarização cíclica. Os autores concluíram que entre as diferentes aminas estudadas, a isopropilamina (i-PA), tert-butilamina (t-BA) e etilenodiamina (EDA) apresentaram boas propriedades de inibição, mas a ação da etilenodiamina (EDA) foi mais efetiva em comparação com as outras aminas. Os autores explicaram também que a boa inibição da etilenodiamina (EDA) foi devido à adsorção de dois compostos intermediários, o primeiro envolvendo uma camada de hidróxido $\left(\mathrm{FeOH}^{-}\right)$ads e a outra envolvendo uma molécula complexa adsorvida de FeX ads, onde $\mathrm{X}$ é a molécula do inibidor.

Badiea e Kikkeri (2009) investigaram o efeito de inibição do benzoato de sódio (SB) e a 4-(feniloamino)benzenosulfonato (SPABS) sobre aço carbono em água industrial usando métodos gravimétricos, numa faixa de temperaturas de $30^{\circ} \mathrm{C}$ a $80^{\circ} \mathrm{C}$. Os autores demonstraram que aqueles compostos são eficientes inibidores atingindo valores de eficiência de 81,5 \% e 84,4 \% para o SB e SPABS, 
respectivamente. Esta eficiência de inibição é causada pela adsorção destes compostos sobre a superfície do aço carbono, que obedece ao modelo da isoterma de Freundlich. Além disso, os parâmetros termodinâmicos (energia livre de adsorção de $25,47 \mathrm{~kJ} \mathrm{~mol}^{-1}$ e $27,7 \mathrm{~kJ} \mathrm{~mol}^{-1}$, respectivamente) indicaram que adsorção destes compostos é uma adsorção química ou chamada também de quimissorção por serem valores acima de $25 \mathrm{~kJ} \mathrm{~mol}^{-1}$.

\subsection{Aminas como inibidores de corrosão}

O uso de aminas na inibição de corrosão do aço carbono é bem conhecido devido a sua moderada solubilidade em água, especialmente para compostos de baixo peso molecular (BRAUN; LOPEZ; VOLLMER, 1993; SZAUER; BRANDT, 1981). A presença de um heteroátomo no composto orgânico com ligações insaturadas origina um processo de adsorção sobre a superfície do aço carbono, que reduz a velocidade de corrosão do metal (BASTIDAS; POLO; CANO, 2000; SRHIRI; ETMAN; DABOSI, 1996). Embora o uso de aminas seja amplamente divulgado como inibidores de corrosão, seu mecanismo de inibição ainda não está muito bem explicado (BASTIDAS et al., 2000). É também conhecido que a eficiência de inibição geralmente aumenta com o número de átomos de carbono na cadeia da amina desde 9 a 12 carbonos (SRHIRI; ETMAN; DABOSI, 1996). Já um incremento adicional da cadeia acima deste valor leva só a um pequeno incremento na eficiência devido a um decréscimo na solubilidade e efeito estérico impedindo a adsorção. Esta efetividade das aminas como inibidores de corrosão pode ser estudada como uma função da densidade de elétrons do átomo doador na molécula do inibidor, a estrutura da molécula e o tamanho dela.

Bastidas, Polo e Cano (2000) estudaram o mecanismo de inibição da hexilamina e a dodecilamina para o aço carbono em meio ácido para diferentes concentrações dessas aminas. O mecanismo de inibição foi investigado através de isotermas de adsorção de Flory-Huggins (FH), Dhar-Flor-Huggins (DFH) e Bockris-Swinkels $(\mathrm{BH})$. Os autores encontraram que o mecanismo de adsorção de 
ambas as aminas sobre o aço carbono obedecia às isotermas de Flory-Huggins (FH) e Dhar-Flor-Huggins (DFH), onde uma molécula da hexilamina ou dodecilamina substituía três moléculas de água. Além disso, concluíram que eficiência de inibição da dodecilamina é mais alta em comparação com a hexilamina devido a seu maior peso molecular e a constante de dissociação para a dodecilamina, que é igual a 10,63, o que indica um maior caráter básico em comparação com outras aminas de cadeia menor, facilitando sua adsorção por quimissorção, onde há uma transferência parcial de elétrons da dodecilamina para o metal. Outro estudo foi feito por esses mesmos autores usando a tributilamina como inibidor de corrosão sobre aço carbono em meio de ácido clorídrico $2 \mathrm{~mol} / \mathrm{L}$, onde a tributilamina é adsorvida quimicamente sobre a superfície do aço carbono de acordo com a isoterma de Bockris-Swinkels $(\mathrm{BH})$ com uma molécula de tributilamina substituindo três moléculas de água. Além disso, os autores concluíram que a eficiência de inibição da tributilamina era maior quando a concentração do inibidor aumentava.

Srhiri, Etman e Dabosi (1996) estudaram a influência eletroquímica e físicoquímica como inibidor de corrosão dos alquilimidazóis sobre aço carbono usando como meio cloreto de sódio $3 \% \mathrm{~m} / \mathrm{m}$. Este estudo foi realizado usando técnicas eletroquímicas como curvas de polarização anódica e catódica, espectroscopia de impedância eletroquímica e técnicas gravimétricas para determinar os valores de densidade de corrente de corrosão equivalente. Os autores determinaram que a máxima eficiência de inibição foi atingida quando o número de átomos de carbono era onze. Uma baixa concentração de alquilimidazol $(0,01 \mathrm{~mol} / \mathrm{L})$ foi suficiente para alcançar uma considerável inibição da corrosão (92,3 \%). Já para um número de átomos de carbono ser menor ou igual a oito, foi necessária uma alta concentração do inibidor para conseguir um efeito comparável de inibição. No caso do número de átomos de carbono ser maior que doze, a camada adsorvida de moléculas de inibidor sobre a superfície do aço não fica muito estável e a eficiência de inibição resulta mais baixa. 
Damborenea, Bastidas e Vazquez (1997) investigaram as propriedades de adsorção e inibição de 4 diferentes aminas alifáticas sobre o aço carbono e em meio de ácido clorídrico $2 \mathrm{~mol} / \mathrm{L}$ para diferentes faixas de concentração $\left(10^{-1} \mathrm{~mol} / \mathrm{L}\right.$ a $\left.10^{-6} \mathrm{~mol} / \mathrm{L}\right)$ e temperatura $(278 \mathrm{~K}-308 \mathrm{~K})$. Estas aminas foram: hexilamina, octilamina, decilamina e dodecilamina. As propriedades de inibição destas aminas alifáticas foram explicadas com o uso de duas técnicas clássicas, gravimetria e medida de resistência de polarização linear. Os autores concluíram que a velocidade de corrosão aumenta pelo menos numa ordem de grandeza na faixa de temperatura testada e que este efeito é particularmente significativo para concentrações baixas de inibidores. Eles também encontraram que a eficiência de inibição do aço carbono aumentava à medida que o número de átomos na cadeia da amina aumentava de 6 a 12 carbonos e que o mecanismo de adsorção para as quatro aminas alifáticas testadas obedecia a isoterma de Frumkin.

Ayers e Hackerman (1962) usaram a piridina e seus derivados para inibir a corrosão do aço carbono em meio de $\mathrm{HCl} 6,0 \mathrm{~mol} / \mathrm{L}$ a $35^{\circ} \mathrm{C}$. Estes compostos foram: piridina, 3-picolina, 2-picolina, 4-picolina, 3,5-lutidina, 2,4-lutidina, 2,6lutidina, 2,4,6-colidina. As velocidades de corrosão do aço foram determinadas por análise colorimétrica do ferro liberado e complexado com ácido mercaptoacético, dentro de uma célula eletroquímica de três eletrodos contendo $\mathrm{HCl} \mathrm{6,0} \mathrm{mol/L.} \mathrm{Os}$ autores concluíram que a eficiência de inibição e o valor do potencial de corrosão aumentaram com a concentração para cada composto estudado. Além disso, explicaram que o mecanismo de inibição destes compostos orgânicos segue duas etapas: na primeira etapa o cátion é adsorvido fracamente na superfície e na segunda etapa este cátion adsorvido fracamente é transformado numa amina livre adsorvida fortemente sobre o substrato. Neste caso a inibição por quimissorção pode ocorrer ou pela estabilização do átomo de ferro na superfície da rede cristalina ou pela formação de um íon complexo insolúvel in situ. 


\subsection{Teoria sobre o potencial zeta}

Quase todos os materiais macroscópicos ou particulados adquirem uma carga elétrica superficial quando estão em contato com um líquido. O potencial zeta é um indicador dessa carga e é importante nos estudos de química de superfície, visto que pode ser usado para prever e controlar a estabilidade de suspensões ou emulsões coloidais (DALTIN, 2011). Dessa forma, o potencial zeta é uma propriedade física a qual é exibida por uma partícula quando está imersa num liquido, e com a medida deste valor é possível otimizar processos e aperfeiçoar formulações de emulsões e suspensões (HUNTER, 1981; ROSS; MORRISON, 1988). Sua magnitude é muito sensível às perturbações do meio, e serve como uma poderosa ferramenta para o controle de qualidade dos processos. $\mathrm{O}$ valor do potencial zeta está intimamente ligado ao $\mathrm{pH}$, sendo normalmente positivo em regiões ácidas, e negativo em regiões básicas. $\mathrm{O}$ valor de $\mathrm{pH}$ para o qual o potencial zeta possui valor nulo é denominado ponto isoelétrico (PIE), e a região em torno desse valor corresponde à região de menor estabilidade das suspensões do ponto de vista eletrostático (REED, 1995).

O potencial zeta é possivelmente umas das poucas grandezas relacionadas a fenômenos de superfície que podem ser diretamente investigadas por técnicas experimentais muito bem estabelecidas (ARAÚJO; PERES; BRANDÃO, 1990). Este potencial pode ser obtido a partir da velocidade de migração de partículas suspensas num meio fluido, em direção a um eletrodo de carga oposta, quando aplicada uma diferença de potencial entre dois eletrodos, sendo medido onde se unem a camada difusa e a de Stern. Alguns autores consideram como camada de Stern, aquele plano de cisalhamento onde são realizadas as determinações eletrocinéticas do potencial zeta (FUERSTENAU, 2004).

A determinação do potencial zeta é uma forma eficiente de controlar o comportamento do colóide, pois seu valor indica mudanças no potencial da superfície e as forças de repulsão dos colóides, sendo no tratamento de efluentes 
uma forma de se avaliar se o $\mathrm{pH}$ e a dosagem de coagulantes empregados estão sendo favoráveis na eficiência do processo.

A eletroforese é uma das técnicas mais utilizadas para a medição do potencial zeta. Por meio dela determina-se a mobilidade eletroforética das partículas no plano de cisalhamento. A mobilidade eletroforética e a relação entre a velocidade da partícula e o campo elétrico aplicado; é convertida em potencial zeta, a partir da relação Helmholtz-Smoluchowski (Equação 2.1) (DALTIN, 2011).

\section{$\zeta=4 \pi \eta V_{\mathrm{e}} / \varepsilon_{\mathrm{r}} \varepsilon_{0}$}

Equação 2.1

$\zeta=$ potencial zeta .

$\eta=$ viscosidade do meio de dispersão.

$\mathrm{V}_{\mathrm{e}}=$ mobilidade eletroforética.

$\varepsilon_{r}=$ constante dielétrica no meio

$\varepsilon_{0}=$ permissividade elétrica do ar $\left(8,854 \times 10^{-12} \mathrm{C}^{2} \mathrm{~J}^{-1} \mathrm{~m}^{-1}\right)$

Um valor de potencial zeta mais alto numa mesma fase contínua indica que a partícula carregada apresenta uma espessura de camada de Stern maior e com maior densidade de cargas. Como essa camada é fixa à partícula, quanto mais espessa, maior a proteção de cada partícula contra a floculação, o mesmo acontece para as emulsões.

O resultado da aproximação entre as partículas dependerá de um balanço entre a energia de atração proporcionada pelas forças de Van der Waals e a energia de repulsão proporcionada pela dupla camada elétrica. Se há um predomínio das forças de atração, as partículas apresentarão tendência á floculação. Se as forças repulsivas forem predominantes, as partículas permanecerão cineticamente independentes e a suspensão será estável (DALTIN, 2011). 


\subsubsection{Ponto isoelétrico (PIE)}

A determinação do potencial zeta para diferentes valores de $\mathrm{pH}$ permite a obtenção de curvas de potencial zeta vs $\mathrm{pH}$ e, consequentemente, a determinação do ponto isoelétrico. $O$ ponto isoelétrico (PIE) pode-se definir como o pH correspondente ao potencial zeta nulo ou seja, o pH em que as cargas da superfície das partículas são neutralizadas (PASHLEY; KARAMAN, 2004; REED, 1995).

As partículas normalmente adquirem carga superficial quando suspensas em meio liquido. Utilizando o meio liquido mais comum, a água, temos que essas cargas superficiais podem ser neutralizadas pela presença de íons de carga oposta em solução. Portanto, a variação de $\mathrm{pH}$, gerando a variação de concentração de íons $\mathrm{H}^{+}$e $\mathrm{OH}^{-}$, pode neutralizar essas cargas (DALTIN, 2011).

\subsubsection{Fatores que afetam o potencial zeta}

Os principais fatores que afetam o potencial zeta são mencionados a seguir (ZETA, [...], 2004).

\subsubsection{1 $\mathrm{pH}$}

Em meio aquoso o pH de uma amostra é um dos fatores mais importantes que afeta o valor do potencial zeta. O próprio valor de potencial zeta sem definir as condições da solução é um número praticamente insignificante. Por exemplo, uma partícula em suspensão com um potencial zeta negativo, se mais álcali é adicionado à suspensão, as partículas tendem a adquirir uma carga mais negativa. Se ácido é adicionado para a suspensão, um ponto será atingido onde a carga será neutralizada. Uma posterior adição de ácido irá causar um acúmulo de carga positiva. Portanto, um potencial zeta em relação à curva de $\mathrm{pH}$ será positivo em $\mathrm{pH}$ baixo e menor ou negativa em pH alto (VENKATARAMAN, 2002; SOARES, 2009). 


\subsubsection{Condutividade}

A espessura da dupla camada depende da concentração dos íons em solução e esta pode ser calculada a partir da resistência iônica do meio. Quanto maior é a resistência iônica, mais comprimida se torna a dupla camada elétrica. A valência dos íons também influencia na espessura da dupla camada elétrica, por exemplo, um íon trivalente como $\mathrm{Al}^{3+}$ (que tem raio iônico menor) comprimirá mais a dupla camada elétrica em comparação com um íon monovalente como $\mathrm{Na}^{+}$ (LEROY, 2011; ZAYID, 2014).

\subsubsection{Concentração de um componente}

O efeito da concentração de um componente sobre o potencial zeta pode nos fornecer informação para auxiliar na formulação de um produto e dar uma máxima estabilidade. Por exemplo, a influência de contaminantes conhecidos sobre o potencial zeta de uma amostra pode ser uma ferramenta poderosa na formulação de um produto para resistir à floculação.

\subsection{Teoria sobre polieletrólitos, formação, caracterização e aplicação}

Nos últimos anos o estudo de polieletrólitos tem sido renovado por causa do uso recente de técnicas experimentais disponíveis e a introdução de novos conceitos teóricos, alguns dos quais têm sido transferidos de outras áreas do conhecimento. Embora novos conhecimentos tenham sido ganhos até agora, existe ainda muita coisa por pesquisar nesta área dos polieletrólitos (HARA, 1993).

\subsubsection{Polieletrólitos}

Polieletrólito é um polímero no qual os monômeros são sais de grupos iônicos e não metálicos provenientes do encadeamento de moléculas menores. 
Quando dissolvidos num solvente polar (geralmente água), esses grupos são parcialmente ionizados, e dessa forma pode-se obter diversas densidade de carga na cadeia (HARA, 1993; DAUTZENBERG et al., 1994). Dessa forma, os polieletrólitos são preparados em solução aquosa e em seguida usados para a montagem de filmes finos pelo método de Layer-by-Layer (camada por camada).

\subsubsection{Classificação dos polieletrólitos}

Os polieletrólitos são classificados em vários tipos. Segundo a origem, eles podem ser classificados como polieletrólitos naturais, polieletrólitos sintéticos e biopolímeros modificados quimicamente. Segundo a composição podem ser homopolímeros e copolímeros. Segundo a arquitetura molecular podem ser lineares, ramificados e reticulados (SELVAN et al., 1998).

Pode-se ter uma diferente classificação baseada na natureza eletroquímica dos grupos ionizáveis. Os poliácidos com grupos carboxila $(-\mathrm{COOH})$ e o grupo sulfônico $\left(-\mathrm{SO}_{3} \mathrm{H}\right)$ podem dissociar em poliânions e prótons $\mathrm{H}^{+}$. As polibases com grupos amina $\left(-\mathrm{NH}_{2}\right)$ podem se ligar a um próton gerando policátions. Polieletrólitos que contêm grupos ácidos e básicos são chamados de polianfóteros, possuindo carga negativa ou positiva para $\mathrm{pH}$ alto ou baixo, respectivamente (LANKALAPALLI; KOLAPALLI, 2009).

Outro tipo de classificação é dado em função do pKa (cologaritmo da constante de equilíbrio do grupo ácido, ou seja, $(\mathrm{pKa}=-\operatorname{logKa})$. No caso de um ácido fraco HA, sua dissociação em água fica sujeita ao equilíbrio representado pela Equação 2.2:

$$
\mathrm{HA} \leftrightarrow \mathrm{H}^{+}+\mathrm{A}^{-}
$$


Onde a constante de equilíbrio de dissociação Ka é definida segundo a Equação 2.3 como:

$$
\mathrm{Ka}=\underline{\left[\mathrm{H}^{+}\right]\left[\mathrm{A}^{-}\right]}
$$$$
\text { Equação } 2.3
$$

Desta equação é possível observar que a constante Ka é proporcional à concentração de íons formados. Ou seja, um maior valor de Ka significa uma maior ionização deste ácido e consequentemente uma maior força de ionização. $\mathrm{A}$ fim de entender os parâmetros que controlam as interações entre dois polieletrólitos opostamente carregados, tem-se que considerar a distinção entre polieletrólitos fortes e fracos. O conceito de força iônica é usado para controlar a morfologia e espessura das multicamadas, a qual é restrita a baixas concentrações de ambos os componentes, já que um aumento da forca iônica pode causar problemas de solubilidade e decomposição da multicamada.

Por exemplo, a polietilenoimina (PEI) é um polieletrólito fraco positivamente carregado quando em solução aquosa, devido ao equilíbrio ácido-base dos grupos amina $\left(-\mathrm{R}_{3} \mathrm{NH}^{+}\right)$(SILVA, 2006). O poli (estirenosulfonado) é um polieletrólito forte, pois quando dissociado em solução aquosa os grupos sulfônicos se ionizam (LANKALAPALLI; KOLAPALLI, 2009).

A densidade de carga distribuída dentro da cadeia dos polieletrólitos é um parâmetro importante para a adsorção e morfologia das multicamadas. Ou seja, dentre os polímeros sintéticos têm alguns cuja densidade de carga é sempre alta e outros cuja densidade de carga depende das condições do meio ( $\mathrm{pH}$ da solução, forca iônica, temperatura, etc). Os primeiros são chamados de polieletrólitos fortes, como o poli(estirenosulfonado) e o poli(dialidimetil cloreto de amônia). No caso do segundo grupo, são chamados de polieletrólitos fracos, como as poliaminas e os poliácidos (PATERNO; MATOSSO; OLIVEIRA, 2001). 


\subsubsection{Parâmetros que afetam a ligação entre polieletrólitos}

Existe um número de parâmetros os quais têm influência na formação de sistemas de polieletrólitos (DAUTZENBERG et al., 1994). Estes são a localização do íon, densidade de carga, concentração do polieletrólito, pH, força iônica, tipo de solvente e temperatura. Vários pesquisadores têm avaliado os fatores que permitem a formação de camadas de polieletrólitos usando diferentes misturas poliméricas (HARA, 1993; DAUTZENBERG et al., 1994). A formação é causada por atrações eficazes devido a flutuações de carga e de atrações de curto alcance entre os monômeros. Empregando políions com uma densidade de carga reduzida ao longo da cadeia, isto é, formados por co-monômeros carregados e não carregados, observou-se que uma densidade de carga mínima (LANKALAPALLI; KOLAPALLI, 2009) é necessária para adsorção do polieletrólito. Alterando a força iônica por adição de sais pode-se modular as interações eletrostáticas em uma solução de polieletrólito. As interações eletrostáticas podem ser enfraquecidas pela adição de sais inorgânicos nas soluções.

Portanto, o aumento da força iônica da solução evita a complexação entre os poliíons, devido a que as cargas opostas das macromoléculas são ocultadas por íons de baixo peso molecular. O grau de ionização dos polieletrólitos fracos durante a formação das camadas pode ser controlado mediante a variação do $\mathrm{pH}$ do meio (SILVA, 2006; PATERNO; MATOSSO; OLIVEIRA, 2001), onde este parâmetro $\mathrm{pH}$ afeta as propriedades de formação de camadas múltiplas, tais como espessura da camada, o grau de interpenetração entre as camadas, molhabilidade da superfície e o número de grupos funcionais não ligados. Em resumo, escolhendo as condições de $\mathrm{pH}$ adequadas, uma variedade de propriedades podem ser encontradas, as quais são vantajosas para o carregamento de pequenas moléculas depositadas dentro das paredes dos polieletrólitos através de interações eletrostáticas (MINATTI et al., 2007).

Como foi dito acima, o pH da solução do polieletrólito é um fator importante que influi na densidade de carga da cadeia dos polieletrólitos alterando dessa 
forma a morfologia das camadas do filme L-b-L (camadas mais espessas ou mais finas). Em polieletrólitos com alta densidade de carga, a repulsão eletrostática entre as unidades repetitivas favorece o estiramento da cadeia, formando assim camadas mais finas. No entanto, se há uma diminuição de carga na cadeia, esta se pode enroscar, formando camadas mais espessas (DE SOUZA, 2010).

\subsubsection{Formação de camadas de polieletrólitos}

O procedimento para a formação de camadas de polieletrólitos envolve principalmente três passos como mostrado na Figura 2.1. O primeiro passo consiste na formação de um complexo primário, onde as forças de Coulomb são predominantes nesta etapa. O segundo passo envolve a formação de novas ligações e/ou a correção das distorções das cadeias do polímero. No terceiro passo é realizado o processo de ligação entre os complexos, o qual envolve a agregação de complexos secundários, principalmente por meio de interações hidrofóbicas.

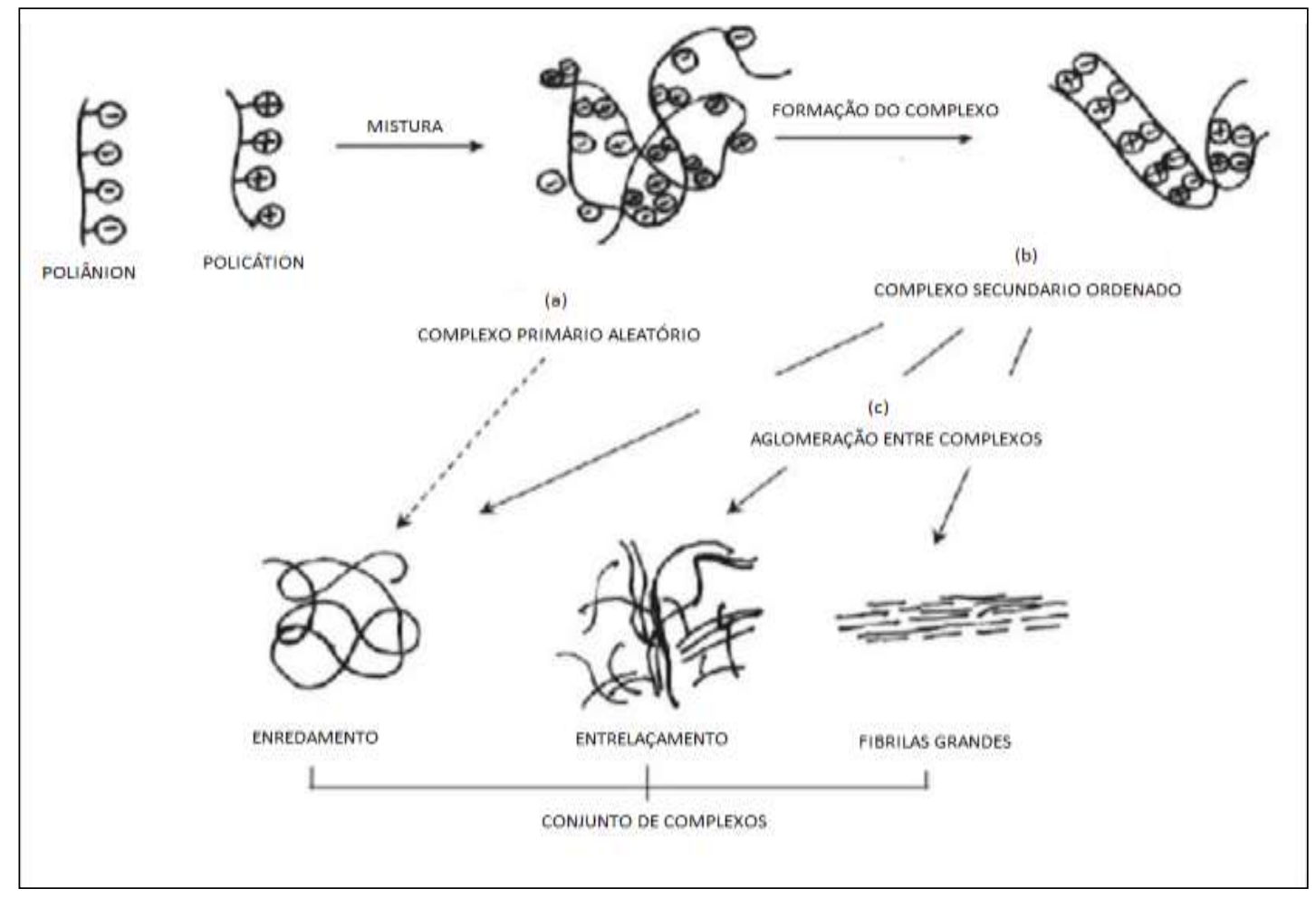

Figura 2.1 - Representação esquemática da formação e agregação de camadas de polieletrólitos (a) formação de um complexo primário (b) processo de formação dentro dos complexos internos (c) processo de ligação entre os complexos (VERMA; VERMA, 2013). 


\subsubsection{Mecanismos de adsorção para a formação de camadas}

O mecanismo de adsorção entre as bicamadas para a formação dos filmes Layer-by-Layer podem ser classificados em quatro tipos: filmes formados via interações a partir de polieletrólitos altamente carregados; filmes formados via interações a partir de polieletrólitos parcialmente carregados; filmes formados via interações secundárias como pontes de hidrogênio, interações hidrofóbicas ou em conjunto com interações eletrostáticas e filmes formados via interações muito especificas (ZUCOLOTTO, 2003).

a) Filmes formados via interações a partir de polieletrólitos altamente carregados

Neste caso, as interações que predominam no mecanismo de adsorção são do tipo iônico (eletrostática), obtendo-se camadas muito estáveis. O mecanismo de adsorção é limitado, já que termina quando há um equilíbrio entre as forças. Devido ao forte grau de atração entre as cargas opostas há formação de camadas muito finas e homogêneas de quase $1 \mathrm{~nm}$ de espessura.

b) Filmes formados via interações a partir de polieletrólitos parcialmente carregados

Onde as interações são também do tipo eletrostática, mas o uso de polieletrólitos fracamente carregados altera a espessura das camadas, tornando-a maior, variando até uma ordem de grandeza em comparação com aquelas obtidas com polieletrólitos altamente carregados. Neste caso é importante controlar o pH da solução e dos polieletrólitos utilizados, já que para este tipo de filme a espessura de cada camada depositada pode ser controlada variando parâmetros que influenciam a adsorção, como por exemplo, o pH e a forca iônica da solução (concentração de eletrólitos), que alteram a ionização dos polieletrólitos gerando modificações na espessura e rugosidade do filme conforme este vai crescendo. 
c) Filmes formados via interações secundárias

Neste caso as interações entre as camadas são de vários tipos, além de serem eletrostáticas, ocorrem também por pontes de hidrogênio, forças de van der Waals e interações hidrofóbicas ou associação entre elas.

d) Filmes formados via interações especificas

Estes tipos de interações não são muito comuns, já que seguem um mecanismo de adsorção muito diferente, onde o filme pode ser formado por polieletrólitos de mesma carga. Por exemplo, a interação entre a avidina e a biotina (ANZAl et al., 1999) onde a adsorção entre camadas da avidina e camadas de polímeros catiônicos só ocorre devido à forte ligação entre a avidina-biotina. Outro trabalho foi reportado por Shimazaki et al. (1997), o qual usou dois tipos de polímeros (poli[2-(9-carbazol)etilmetacrilato] e poli[2-[(3,5-dinitrobenzoil)oxil] etilmetacrilato] para a formação de filmes. Esses polímeros foram alternadamente adsorvidos sobre um substrato de ouro e a adsorção deu-se através da transferência de cargas, já que estes polímeros apresentam cadeias laterais com caráter doador e receptor de elétrons, respectivamente.

\subsubsection{Influência do $\mathrm{pH}$ nas propriedades de liberação dos polieletrólitos}

As multicamadas de polieletrólitos com inibidor encapsulado podem armazenar e liberar o inibidor sob demanda tão logo o pH da solução local sofra uma mudança devido ao início do processo de corrosão (LAMAKA et al., 2008). O polieletrólito complexo estudado neste trabalho consiste de um poliânion forte (poliestirenosulfonado) e um policátion fraco (polietilenoimina). Este sistema de multicamadas de polieletrólitos (PEI + PSS) são mais sensíveis às mudanças do pH no meio em comparação por exemplo com sistemas conformados por pares de polieletrólitos forte-forte e fraco-fraco. Esta diferença entre pares de polieletrólitos fortes e fracos é refletida no grau relativo de associação entre os segmentos do 
polieletrólito carregados opostamente. Pares de polímero que formam complexos mais fortes são esperados ter uma melhor associação em contato com soluções aquosas e, portanto, seriam menos sensíveis às mudanças de pH (ANDREEVA et al., 2008).

As paredes dos polieletrólitos formados são semipermeáveis e sensíveis à uma variedade de condições físicas e químicas no meio ao redor, as quais podem influenciar drasticamente na estrutura dos polieletrólitos complexos. Usualmente, estas paredes são permeáveis a macromoléculas e nanopartículas em $\mathrm{pH}<3$ ou em alta resistência iônica e se fecham para um $\mathrm{pH}$ neutro. Uma possível explicação sobre as propriedades de permeabilidade das paredes tem a ver com as interações dos polieletrólitos nas paredes das camadas. Sob as condições de formação da cápsula ( $\mathrm{pH}$ 7), as densidades de carga em ambos os polieletrólitos determina sua relação estequiométrica durante a adsorção, já que os polímeros são adsorvidos irreversivelmente sobre as paredes das camadas, um abaixamento do pH não provocará uma dessorção do polímero. No entanto, pode ocorrer o carregamento de uns dos polieletrólitos, o qual induz uma carga positiva ou negativa na parede da camada e dessa forma criar defeitos sobre as paredes por causa do aumento da repulsão.

A possibilidade de manobrar as paredes das cápsulas entre o estado aberto e fechado fornece uma ferramenta eficiente para o carregamento e liberação de materiais ativos. Por exemplo, o carregamento de um inibidor dentro das cápsulas pode ser realizado em baixo $\mathrm{pH}$ e em seguida ser capturado por causa de um incremento do $\mathrm{pH}$. Assim é possível ter um controle de carga e liberação de macromoléculas dentro e fora das cápsulas dos polieletrólitos e dessa forma encontrar uma vasta aplicação em revestimentos de autorreparação (SHCHUKIN; MÖHWALD, 2007). 


\subsection{Técnicas de encapsulamento}

Atualmente existe uma variedade de técnicas de encapsulamento que são utilizadas na indústria de revestimentos, onde a escolha de uma determinada técnica para uma aplicação específica vai depender de uma série de fatores, tais como: tamanho de partícula requerido, propriedades físicas e químicas do núcleo e da parede, aplicação do produto final, mecanismos desejados de liberação, escala de produção e custo. Os processos utilizados para encapsular uma substância podem ser classificados em: processos químicos, processos físicoquímicos ou processos mecânicos. A Tabela 2.2 apresenta os processos mais importantes usados na indústria.

Tabela 2.2 - Diferentes técnicas usadas na indústria de microencapsulamento (GHOSH, 2006).

\begin{tabular}{|c|c|c|}
\hline Processos químicos & $\begin{array}{c}\text { Processos } \\
\text { Físico- químicos }\end{array}$ & Processos mecânicos \\
\hline $\begin{array}{c}\text { Polimerização por } \\
\text { suspensão, dispersão e } \\
\text { emulsão }\end{array}$ & Coacervação & Spray-Drying \\
\hline Policondensação & $\begin{array}{c}\text { Técnica Layer-by-Layer } \\
\text { (L-b-L) } \\
\text { Encapsulamento pelo } \\
\text { processo sol-gel }\end{array}$ & $\begin{array}{c}\text { Técnicas de } \\
\text { centrifugaçãa } \\
\text { Pulverização de múltiplos } \\
\text { bicos } \\
\text { Encapsulamento à vácuo } \\
\text { Encapsulamento } \\
\text { eletrostático }\end{array}$ \\
\hline
\end{tabular}

2.5.1 Encapsulamento em microcápsulas de paredes poliméricas

Processos de polimerização in situ tais como por dispersão, suspensão ou emulsão e policondensações interfaciais são as técnicas químicas mais importantes para a preparação de microcápsulas com paredes poliméricas (GHOSH, 2006). 


\subsubsection{Polimerização em emulsão}

A polimerização em emulsão é um processo heterogêneo de grande importância industrial, o qual permite a obtenção de partículas poliméricas em dispersões aquosas estáveis como é mostrado na Figura 2.2. A técnica consiste em misturar, sob vigorosa agitação, água, monômero e um tensoativo. A polimerização começa pela adição de um iniciador, o qual é solúvel em água e conduz à formação de partículas com diâmetros finais na faixa de 0,05 $\mu \mathrm{m}-1 \mu \mathrm{m}$ muito menor que aquelas obtidas no processo de polimerização por suspensão. Uma característica importante desta técnica é a habilidade para controlar a morfologia das partículas, assim como obter polímeros de alto peso molecular em velocidades rápidas, enquanto que a desvantagem desta técnica é a obtenção de altas concentrações de monômero que não reagem durante o processo (METHODS [...], 2010).

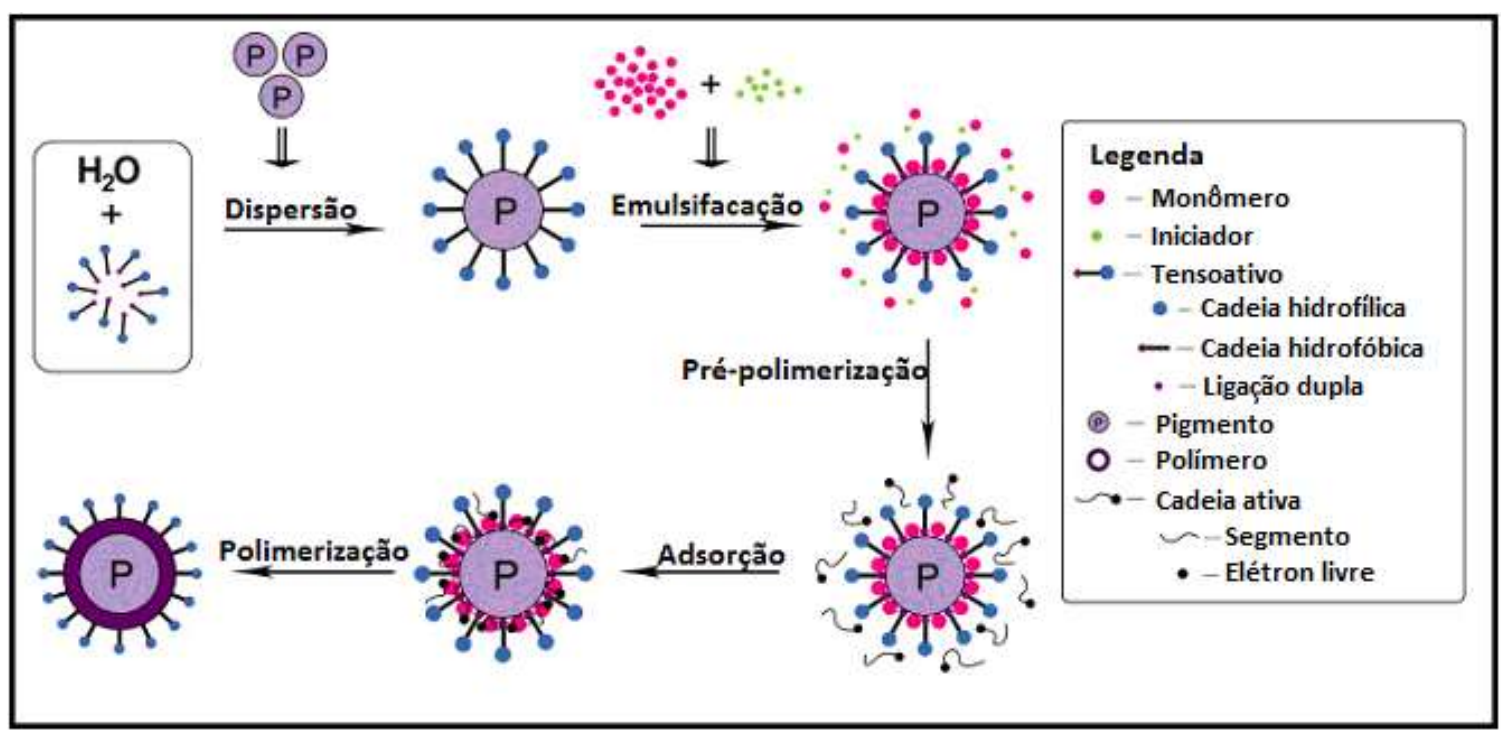

Figura 2.2 - Etapas do processo de encapsulação de partículas pela técnica de polimerização em emulsão (FU et al.,2011).

\subsubsection{Polimerização em suspensão}

A polimerização em suspensão mostrada na Figura 2.3 é também conhecida como polimerização em esferas, a qual envolve o aquecimento de um monômero 
insolúvel em água, onde esta fase aquosa pode conter estabilizadores, tampões, eletrólitos, etc. Gotas dessa fase orgânica são formadas e mantidas em suspensão na água pelo uso de: (i) agitação vigorosa através da reação e (ii) estabilizadores hidrofílicos (tensoativos) dissolvidos em água e catalisadores da polimerização. O material ativo a ser encapsulado pode ser o óleo ou monômero. O esquema da figura não mostra claramente como será formada a parede polimérica. Partículas esféricas uniformes e com propriedades de liberação de material ativo são produzidas com diâmetros na faixa de $0,01 \mathrm{~mm}-2 \mathrm{~mm}$.

A desvantagem desta técnica é a dificuldade de separar o produto final de aditivos não desejados e problemas de coalescência (METHODS [...], 2010).

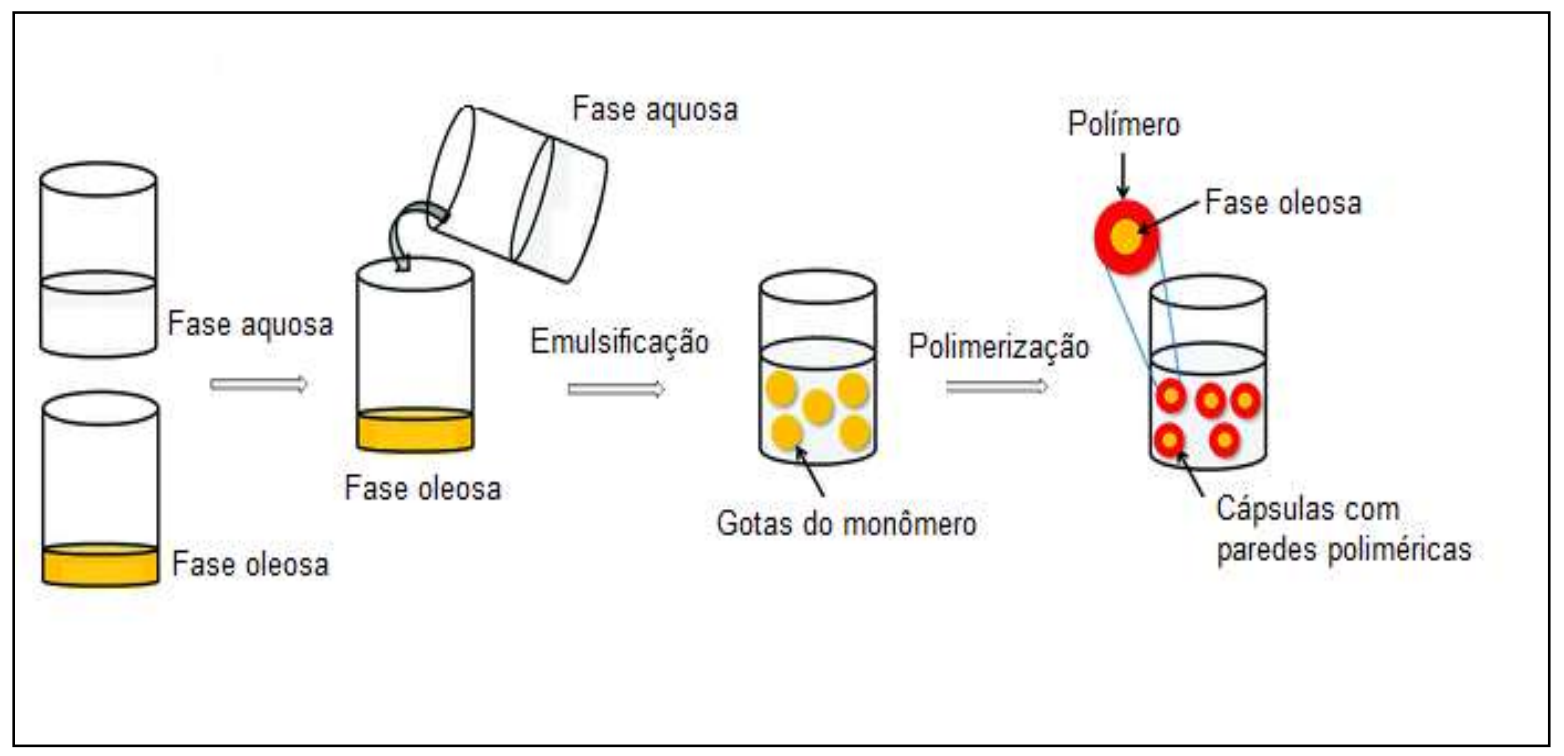

Figura 2.3 - Etapas do processo de encapsulação de uma fase oleosa pela técnica de polimerização em suspensão (CHAIYASAT; ISLAM; CHAIYASAT, 2013).

2.5.1.3 Polimerização em emulsão e evaporação de solvente

Esta técnica é baseada na evaporação da fase interna de uma emulsão por agitação, e é aplicável para uma ampla variedade de cápsulas com núcleo sólido ou liquido. Existem dois tipos de evaporações por solvente: (i) evaporação de emulsão simples e (ii) evaporação de emulsão múltipla. Nesta técnica o agente ativo (inibidor) é dissolvido numa fase contendo o polímero hidrofóbico (tensoativo) e um solvente orgânico. A emulsão formada inicialmente é emulsificada numa 
solução aquosa de colóide hidrofílico, a qual contém um tensoativo que evita a agregação e coalescência das partículas. Em seguida, por um aumento de temperatura, o solvente é evaporado ficando o polímero em forma de cápsulas e contendo o agente ativo (inibidor). A Figura 2.4 mostra as diferentes etapas para a formação de microcápsulas poliméricas contendo o agente ativo encapsulado (METHODS [...], 2010).

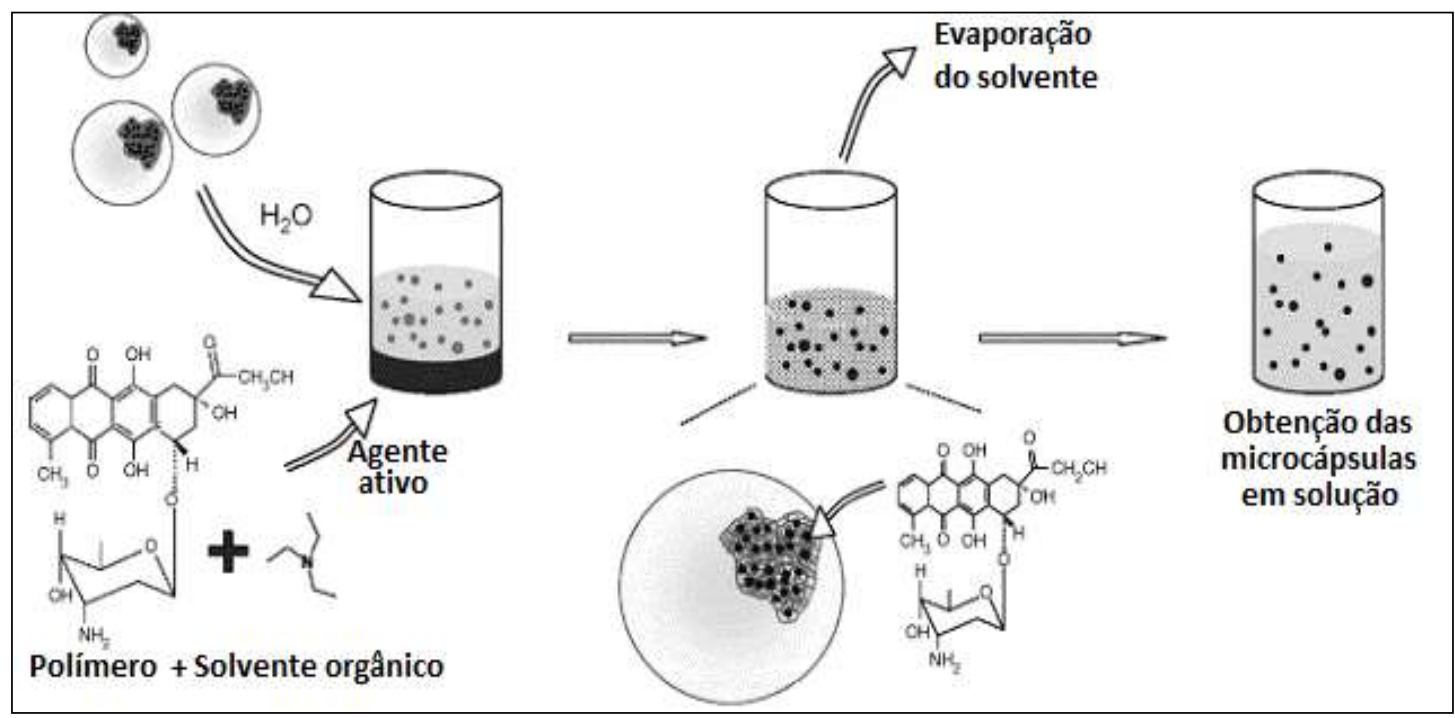

Figura 2.4 - Etapas do processo de encapsulação pela técnica de evaporação por solvente (MISSIRLIS et al., 2006).

\subsection{Técnica de encapsulamento por Layer-by-Layer (L-b-L)}

A técnica de deposição eletrostática Layer-by-Layer (L-b-L) de partículas carregadas eletricamente tem atraído muita atenção devido ser uma técnica extremamente versátil, onde filmes finos e uniformes com uma ampla faixa de propriedades podem ser preparados sobre vários substratos $(\mathrm{GHOSH}, 2006$; LEE et al., 2007) ou superfícies de partículas coloidais na ordem de micro ou nanômetros (SHCHUKIN, 2008). Dessa forma, a possibilidade para um preciso controle das propriedades das paredes abre perspectivas para aplicações adicionais destes nanocontainers, como por exemplo, nos campos da indústria química, de petróleo, medicina, e indústria farmacêutica (GRIGORIEV, 2008). 
Esta técnica L-b-L permite a montagem de camadas de polieletrólitos carregados em forma alternada sobre nanopartículas permitindo assim a formação de filmes com espessuras que variam desde $5 \mathrm{~nm}$ a $500 \mathrm{~nm}$ sobre uma partícula inerte. As forças entre nanopartículas e de atração entre as camadas formadas mediante esta técnica são primariamente eletrostáticas (ligação de van der Waals) e de natureza não covalente, mas estas também podem envolver ligações de hidrogênio ou outros tipos de interações (LVOV, 2000). As "paredes" feitas dos polieletrólitos que formam as diferentes camadas possuem semipermeabilidade e sensibilidade a uma variedade de condições químicas e físicas do meio em que as nanopartículas estão inseridas, usualmente estas paredes são permeáveis a macromoléculas em $\mathrm{pH}<3$ de forma que, para $\mathrm{pH}$ neutro, elas ficam fechadas. Uma possível explicação para estas propriedades de permeabilidade tem a ver com as interações entre as moléculas dos polieletrólitos dentro da camada (parede).

A possibilidade de manobrar as paredes das cápsulas entre um estado aberto e fechado fornece-nos uma eficiente ferramenta para carregar e liberar materiais ativos de forma controlada (SKORB; ANDREEVA, 2013). Por exemplo, as cápsulas podem ser carregadas em $\mathrm{pH}$ baixo e depois incrementar o $\mathrm{pH}$ para capturar o material dentro da cápsula (SHCHUKIN, 2008). A Figura 2.5 ilustra a técnica Layer-by-Layer para o encapsulamento do inibidor dentro das camadas de dois diferentes polieletrólitos (polietilenoimina e poliestirenosulfonado) depositados sobre nanopartículas de sílica $\left(\mathrm{SiO}_{2}\right)$. 


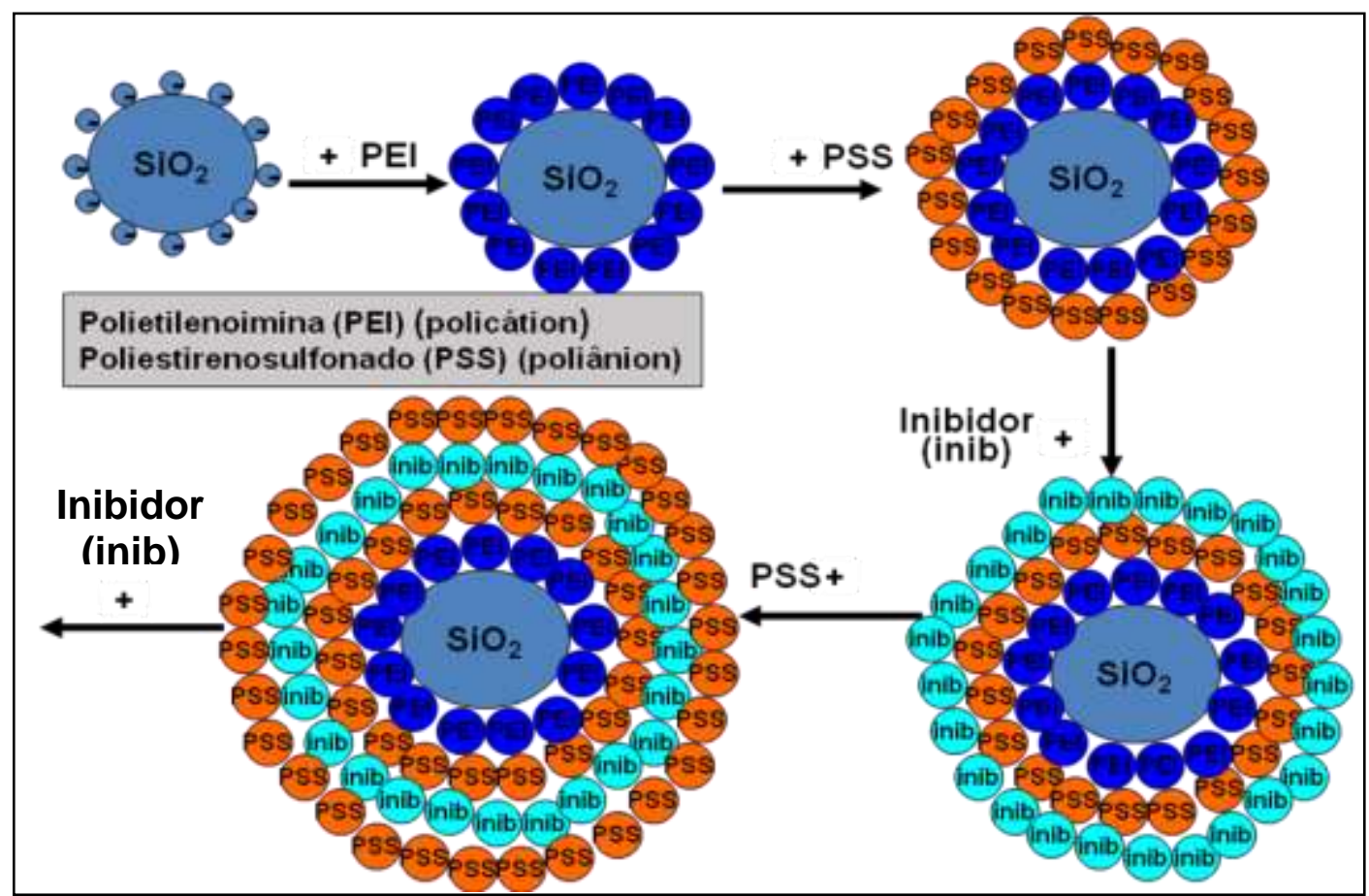

Figura 2.5 - Esquema mostrando as diferentes etapas para o encapsulamento de um agente ativo (inibidor de corrosão) pela técnica Layer-by-Layer.

Sukhorukov et al. (2000) usaram a técnica de deposição Layer-by-Layer (Lb-L) para a fabricação de micro e nanocápsulas a base de polieletrólitos com diferentes tipos de tamanhos, espessuras e composições das paredes e conclusões importantes foram obtidas pelos autores. Eles conseguiram assim obter cápsulas com importantes características como: i) estabilidade, espessura e permeabilidade das paredes da cápsula podendo ser controladas, ou seja, uma adequada composição da parede permitia mudar as propriedades da cápsula, ii) propriedades de portabilidade das cápsulas em função das propriedades de afinidade entre elas, iii) as paredes das cápsulas são altamente permeáveis a pequenas moléculas solúveis em água.

Shchukin e Möhwald (2007) estudaram as propriedades de liberação do inibidor benzotriazol em diferentes tipos de nanocontainers quando submetidos a um tratamento com diferentes camadas de polieletrólitos depositados pela técnica de Layer-by-Layer (L-b-L). Estes três tipos de nanocontainers foram: nanopartículas de sílica, nanotubos de haloisita e nanocontainers de paredes 
poliméricas. Segundo os resultados obtidos pelos autores, eles puderam concluir que para os diferentes nanocontainers estudados houve um incremento na liberação do inibidor benzotriazol em pH ácido, e que essa velocidade de liberação dependia da natureza dos polieletrólitos depositados e da estrutura geométrica do nanocontainer. Eles também determinaram que a maior eficiência de carga de inibidor foi obtida para os nanotubos de haloisita.

Zheludkevich et al. (2007) desenvolveram sistemas de proteção ativa contra a corrosão a partir de nanocontainers feitos a base nanopartículas de sílica carregadas com inibidor benzotriazol e por diferentes camadas de polieletrólitos usando a técnica Layer-by-Layer (L-b-L). Através desta técnica os autores conseguiram encapsular o benzotriazol dentro das camadas dos polieletrólitos fornecendo ao sistema uma liberação inteligente do inibidor de corrosão mediante uma regulação da permeabilidade das paredes dos polieletrólitos em função de estímulos externos como $\mathrm{pH}$, umidade, radiação, etc. Os autores conseguiram incrementar a resistência à corrosão da liga de alumínio AA2024 introduzindo os nanocontainers carregados com inibidor dentro dos filmes híbridos a base de solgel e demonstraram que a introdução direta do inibidor sobre a matriz sol-gel originava uma desativação direta do inibidor devido à interação do benzotriazol com os componentes da matriz.

Lamaka et al. (2008) produziram nanocontainers carregados com inibidor 8hidroxiquinolina mediante a montagem de filmes de polieletrólitos usando a técnica de Layer-by-Layer (L-b-L) e mediante aplicação por spray-coating. Medidas de impedância eletroquímica e uso da técnica de varredura do eletrodo vibratório (SVET) permitiram demonstrar o caráter self-healing ou de autorreparação dos revestimentos aditivados com estes nanocontainers, onde as multicamadas de polieletrólitos abrem-se para liberar o inibidor encapsulado quando existem mudanças de $\mathrm{pH}$ devido à iniciação do processo de corrosão (o pH é baixo em áreas anódicas) em defeitos. As multicamadas também mostraram boa 
compatibilidade com a matriz híbrida, alta capacidade de carregamento do inibidor e bom grau de cobertura da partícula base.

\subsection{Técnicas para avaliar a liberação dos inibidores de corrosão}

\subsubsection{Espectroscopia na região do infravermelho}

A espectroscopia no infravermelho tem-se tornado uma ferramenta indispensável para a determinação e informação estrutural de substâncias orgânicas, onde as análises quali e quantitativa têm sido uma das maiores aplicações desta versátil ferramenta analítica. Em geral, muitos químicos orgânicos usam este método para examinar materiais não conhecidos, determinando a presença ou ausência de grupos funcionais específicos numa mistura de compostos. Em alguns casos esta técnica pode detectar grupos funcionais cuja presença é impossível detectar por testes químicos convencionais. O espectro na região do infravermelho de uma substância orgânica é característico da substância, onde notáveis mudanças podem ser rapidamente percebidas quando a substância é contaminada com apreciáveis quantidades de impurezas de outras espécies ou componentes isoméricos (CONLEY, 1972).

Para que exista absorção da radiação infravermelha tem que haver uma variação do momento dipolo elétrico da molécula como consequência de seu movimento vibracional ou rotacional resultando em absorção da energia radiante (SILVERSTEIN; BASSIER; MORRIL, 1979). As posições relativas dos átomos em uma molécula não são fixas, mas oscilam continuamente como consequência de vibrações e rotações de diferentes tipos que ocorrem nas ligações da molécula (SKOOG; HOLLER; NIEMAN, 2002). Os tipos de vibrações podem ser divididos em duas categorias chamadas de estiramentos (deformações axiais) e deformações angulares que podem ser simétricas e assimétricas. Os diferentes tipos de vibrações são mostrados na Figura 2.6. 


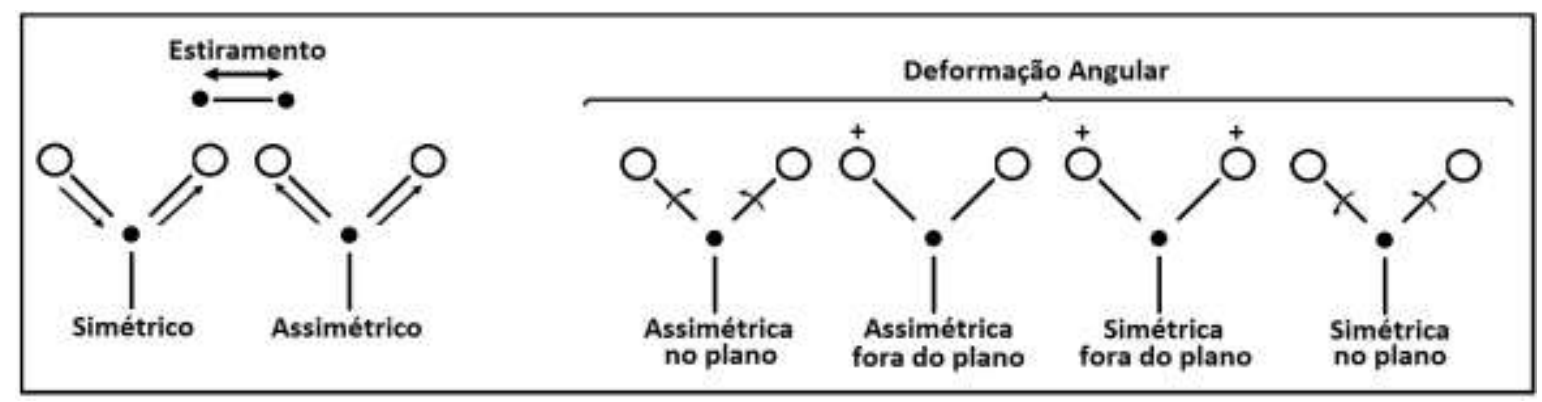

Figura 2.6 - Esquema mostrando os diferentes tipos de vibrações moleculares (SKOOG; HOLLER; NIEMAN, 2002).

Uma vibração de estiramento se relaciona a uma variação continua na distância interatômica ao longo do eixo da ligação entre dois átomos, enquanto que as vibrações de deformação são caracterizadas por uma variação no ângulo formado entre duas ligações (SILVERSTEIN; BASSIER; MORRIL, 1979).

O uso da técnica de infravermelho tem algumas vantagens tais como ser uma análise não destrutiva, precisar de pequenas quantidades de amostra e ser um método rápido de análise. Além disso, com a aparição de novos equipamentos de infravermelho com transformada de Fourier (FTIR) foi possível acoplar técnicas analíticas, como por exemplo, a cromatografia gasosa (CG), espectrometria de massa (MS) e a análise termogravimétrica. Estas técnicas de acoplamento são muito úteis para misturas de substâncias, pois melhoram sua separação e aumentam a sensibilidade para a caracterização dos mesmos (ESPECTROSCOPIA [...], 2009).

Kartsonakis, Daniilidis e Kordas (2008) usaram a técnica de espectroscopia no infravermelho para avaliar a presença do inibidor 8-hidroxiquinolina encapsulado dentro de nanocontainers feitos a base de nanopartículas de óxido de cério. O equipamento utilizado foi um espectrômetro Bruker Equinox 55-S, cujo espectro apresentou picos bem definidos nos números de onda $491 \mathrm{~cm}^{-1}, 785 \mathrm{~cm}$ $1,823 \mathrm{~cm}^{-1}, 1059 \mathrm{~cm}^{-1}, 1154 \mathrm{~cm}^{-1}, 1512 \mathrm{~cm}^{-1}, 1581 \mathrm{~cm}^{-1}$ e $1626 \mathrm{~cm}^{-1}$ que revelaram a presença dos anéis característicos da molécula do inibidor de corrosão 8-hidroxiquinolina. 
Danilidis et al. (2010) confirmaram a presença dos inibidores de corrosão 8hidroxiquinolina e ácido p-toluenosulfônico encapsulados dentro de nanocontainers feitos a base de nanopartículas de dióxido de titânio. Dos espectros obtidos apareceram picos nos comprimentos de onda $491 \mathrm{~cm}^{-1}, 785 \mathrm{~cm}$ 1, $823 \mathrm{~cm}^{-1}, 1059 \mathrm{~cm}^{-1}, 1154 \mathrm{~cm}^{-1}, 1512 \mathrm{~cm}^{-1}, 1581 \mathrm{~cm}^{-1}$ e $1626 \mathrm{~cm}^{-1}$ característicos da 8-hidroxiquinolina e picos entre $1150 \mathrm{~cm}^{-1}$ e $1160 \mathrm{~cm}^{-1}$ e entre $1325 \mathrm{~cm}^{-1}$ e $1335 \mathrm{~cm}^{-1}$ correspondentes ao p-toluenosulfonico.

Sonawane et al. (2012) usaram a técnica de espectroscopia no infravermelho para demonstrar a presença do inibidor de corrosão benzotriazol encapsulado sobre nanocontainers formados por nanopartículas de óxido de zinco revestidas com camadas de polianilina e ácido poliacrílico. Os ensaios foram realizados num espectrômetro Shimadzu 8400 S na região de $4000 \mathrm{~cm}^{-1}$ a $500 \mathrm{~cm}$ ${ }^{1}$, onde os espectros característicos do inibidor benzotriazol apresentaram picos nos comprimentos de onda $1400 \mathrm{~cm}^{-1}, 1278 \mathrm{~cm}^{-1}, 1203 \mathrm{~cm}^{-1}, 1120 \mathrm{~cm}^{-1}$ e $768 \mathrm{~cm}^{-1}$.

2.7.2 Medida indireta da liberação de inibidores encapsulados pela técnica de espectroscopia de impedância eletroquímica, EIE

A espectroscopia de impedância eletroquímica (EIE) é uma técnica poderosa e amplamente usada para a investigação e predição da proteção contra corrosão. Através dos diagramas de impedância é possível estimar mudanças em metais imersos em meios agressivos bem como em sistemas revestidos para longos períodos de tempo antes que mudanças visuais possam ser observadas usando os métodos tradicionais de exposição (LAMAKA, 2007). Durante os experimentos de impedância eletroquímica, uma pequena amplitude de potencial é aplicada no sistema a ser estudado e este responde com um sinal alternado de corrente. Portanto, este não é um método destrutivo e serve para avaliar uma ampla faixa de materiais, incluindo revestimentos, filmes anodizados e inibidores de corrosão. Esta técnica pode fornecer informação detalhada dos sistemas sob estudo: parâmetros como velocidade de corrosão, mecanismo de reação, cinética 
do processo eletroquímico e detecção de corrosão localizada (HAMDY; SHENAWY; BITAR, 2006).

O método de impedância eletroquímica apresenta também diversas vantagens com relação às técnicas de corrente contínua, a saber (WOLYNEC, 2003):

1. Utilização de sinais bem pequenos que não perturbam as propriedades do eletrodo.

2. Possibilidade de estudar a corrosão e determinar taxas de corrosão em meios de baixa condutividade.

3. A resistência de polarização e a capacitância da dupla camada elétrica podem ser determinadas numa mesma medida.

A impedância é semelhante a uma resistência, ou seja, implica numa obstrução ao fluxo de elétrons ou corrente elétrica. No entanto, ela envolve o uso de capacitores e indutores que respondem ao fluxo de corrente alternada.

As medidas envolvem a aplicação de uma perturbação com frequência de alternância de potencial, $\Delta E(w)$, ou de corrente, $\Delta \mathrm{l}(\mathrm{w})$, superposta ao potencial existente entre o eletrodo de trabalho e o eletrodo de referência ou superposta à corrente existente entre o eletrodo de trabalho e o contra-eletrodo. A medida é realizada em uma ampla faixa de frequência e o eletrodo irá responder a perturbação com sinal de potencial, $\Delta \mathrm{E}(\mathrm{w})$, ou corrente, $\Delta \mathrm{l}(\mathrm{w})$, também alternados e na mesma frequência de perturbação, porém com possível defasagem e com diferença na amplitude (AOKI; DE MELO, 2009).

Normalmente a perturbação é um sinal senoidal $\Delta E(\omega)=E_{o} \operatorname{sen}(\omega t)$ e a resposta também é um sinal senoidal $\Delta \mathrm{l}(\omega)=\mathrm{I}_{\mathrm{osen}}(\omega \mathrm{t}+\theta)$. A impedância é calculada pela relação $Z(\omega)=\Delta \mathrm{E} / \Delta \mathrm{I}$, onde $\omega=2 \pi f$ ou também pela expressão $Z(\omega)=\left(\Delta E_{0} / \Delta \mathrm{l}_{0}\right) e^{j \theta}$, onde $\mathrm{j}$ é o operador de números complexos e $\mathrm{j}=\sqrt{ }-1=$ 
$\mathrm{e}^{\mathrm{j} \theta}$ indica uma rotação de $\theta$ no sentido anti-horário em relação ao eixo X. Como $\mathrm{e}^{\mathrm{j} \theta}$ $=\cos \theta+j \operatorname{sen} \theta$, logo o valor de $\mathrm{Z}(\omega)=\left(\Delta \mathrm{E}_{0} / \Delta \mathrm{l}_{\mathrm{o}}\right)(\cos \theta+\mathrm{j} \operatorname{sen} \theta)$, onde $\Delta \mathrm{E}_{\mathrm{o}}$ e $\Delta \mathrm{l}_{\mathrm{o}}$ correspondem à amplitude dos sinais de perturbação e de resposta, enquanto $\theta$ corresponde a defasagem entre $o$ sinal de corrente e o de potencial, sendo este 0 chamado ângulo de fase.

$\mathrm{Na}$ apresentação dos dados dos ensaios de impedância, quando a impedância é medida num certo número de frequências e é obtido num gráfico de eixos cartesianos, este gráfico é chamado de Nyquist ou diagrama no plano complexo (Figura 2.7a). Quando os três parâmetros que caracterizam a impedância são colocados num gráfico ou diagrama, este é chamado de Bode (Figura 2.7b).

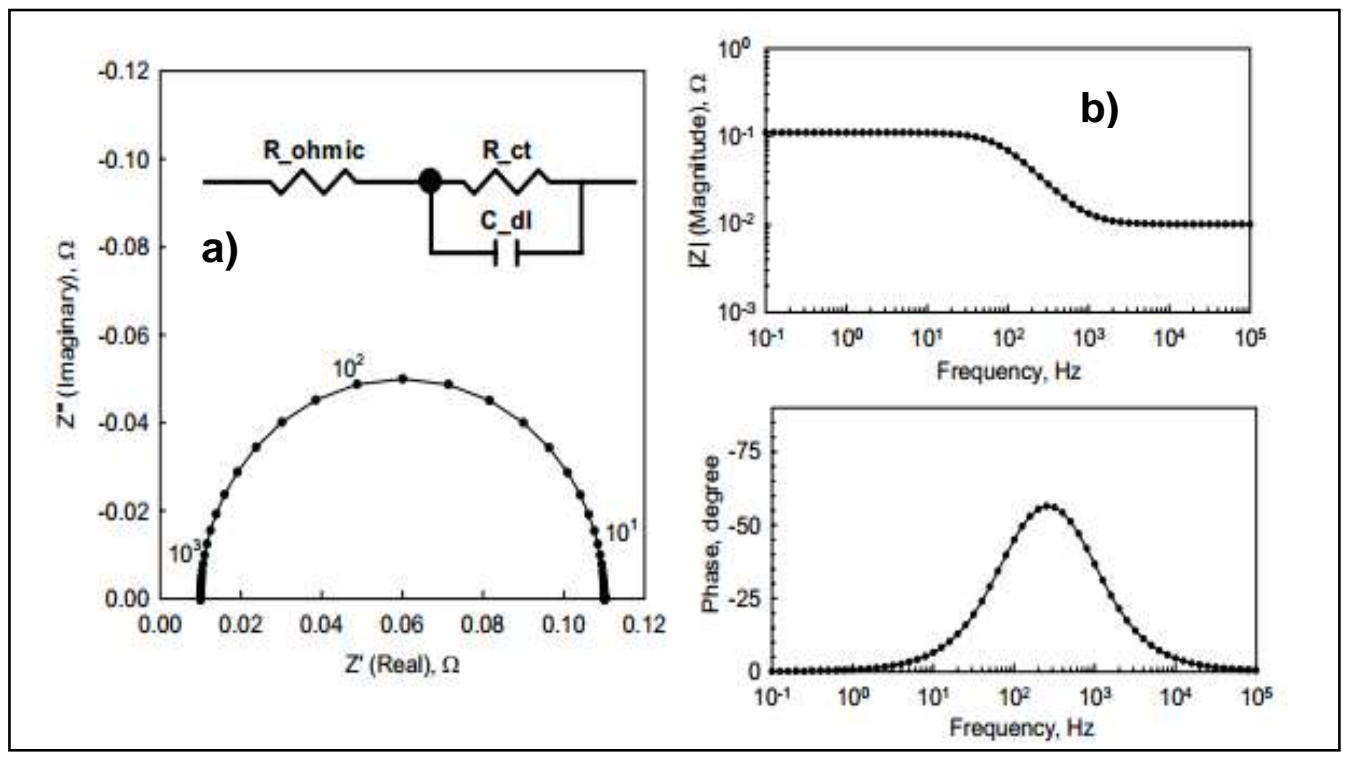

Figura 2.7 - Representação esquemática do (a) Diagrama de Nyquist e (b) Diagramas de Bode (ELECTROCHEMICAL [...], 2007).

Mekeridis et al. (2011) estudaram a liberação dos inibidores 2mercaptobenzotiazol (2-MB) e 8-hidroxiquinolina (8-HQ) encapsulados dentro de nanocontainers feitos à base de óxido de titânio e cério usando a técnica de espectroscopia de impedância eletroquímica. Os nanocontainers foram produzidos através de duas etapas: na primeira, nanoesferas de poliestireno (PS) foram 
obtidas usando polimerização em suspensão, logo após estas esferas foram revestidas via o método sol-gel para formar camadas de óxido de titânio e cério. Os estudos foram divididos em três partes onde a primeira foi usando os inibidores puros em solução de $\mathrm{NaCl} 0,05 \mathrm{~mol} / \mathrm{L}$ a uma concentração de $0,1 \% \mathrm{v} / \mathrm{v}$ para conhecer o efeito contra a corrosão atribuído a cada inibidor; a segunda foi usando os nanocontainers carregados com os inibidores de corrosão (8-HQ ou 2$\mathrm{MB}$ ) a fim de observar o efeito da proteção devido à liberação do inibidor de dentro dos nanocontainers; e a terceira etapa foi usando diferentes quantidades dos inibidores em solução $\mathrm{NaCl} 0,05 \mathrm{~mol} / \mathrm{L}(0,01 \% \mathrm{v} / \mathrm{v}, 0,05 \% \mathrm{v} / \mathrm{v}$ e $0,1 \% \mathrm{v} / \mathrm{v})$. Os melhores resultados foram obtidos para a concentração de $0,1 \% \mathrm{v}$, o que mostra que quando a concentração do inibidor é incrementada dentro dos nanocontainers, uma efetiva camada protetora é formada sobre a superfície da liga de alumínio, provocada pela liberação do inibidor a partir dos nanocontainers.

Tedim et al. (2010) estudaram a cinética da corrosão e os processos de inibição na presença de nanocontainers feitos à base de hidróxidos duplos lamelares (LDH) e carregados com diferentes inibidores de corrosão como vanadatos, fosfatos e 2-mercaptobenzotiazol através da técnica de impedância eletroquímica. Os ensaios foram feitos usando como substrato metálico o alumínio AA2024, o qual foi imerso numa solução de $\mathrm{NaCl} 0,05 \mathrm{~mol} / \mathrm{L}$ contendo os nanocontainers $(\mathrm{LDH})$ carregados em forma intercalada com os anions $\mathrm{VO}_{\mathrm{x}}$, $\mathrm{H}_{\times} \mathrm{PO}_{4}$ e MBT. Entre os sistemas de LDH simples os autores encontraram que 0 módulo da impedância a baixas frequências decresce na seguinte ordem: IZI $($ LDH-VO $))>$ IZI $($ LDH-MBT $)>$ IZI $\left(\mathrm{LDH}-\mathrm{H}_{\mathrm{x}} \mathrm{PO}_{4}\right)$, confirmando dessa forma o vanadato como o melhor inibidor de corrosão para o alumínio no meio neutro. Por outro lado, a combinação obtida para os nanocontainers LDH carregados com os ânions vanadato e fosfato $\left(\mathrm{LDH}-\mathrm{VO}_{x}\right.$ e $\left.\mathrm{LDH}-\mathrm{H}_{\mathrm{x}} \mathrm{PO}_{4}\right)$ e vanadato e MBT $\left(\mathrm{LDH}-\mathrm{VO} \mathrm{O}_{x}\right.$ e LDH-MBT) mostraram um maior sinergismo na proteção contra a corrosão do alumínio AA2024. Os autores explicaram que este maior efeito de inibição da mistura dos LDHs em comparação aos sistemas individuais é atribuído à estabilização de uma camada de óxido sobre a superfície da liga de alumínio. 
Poznyak et al. (2009) estudaram os mecanismos associados com a liberação de inibidores de corrosão (ácido quinaldico e 2-mercaptobenzotiazol) encapsulados dentro de nanocontainers inorgânicos feitos a base de hidróxidos duplos lamelares LDHs ( $\mathrm{Zn}-\mathrm{Al}$ e $\mathrm{Mg}-\mathrm{Al}$ ) usando a técnica de impedância eletroquímica. Os autores concluíram que para tempos longos de imersão, a solução $\mathrm{NaCl}$ 0,05 mol/L contendo os nanocontainers carregados com o inibidor MBT apresentou um melhor efeito de inibição em comparação com os nanocontainers carregados com ácido quinaldico, onde esta proteção é atribuída à formação de um filme protetor que se adsorve sobre a superfície do alumínio. Zheludkevich et al. (2010) usaram também a técnica de impedância eletroquímica para estudar o mecanismo de liberação de inibidores de corrosão (íons vanadatos) contidos dentro deste tipo de nanocontainers de dupla camada de hidróxidos LDHs (Zn-Al e Mg-Al), onde foi demonstrado que os nanocontainers do tipo $\mathrm{Zn} / \mathrm{Al}$ LDH apresentaram uma melhor eficiência de inibição da corrosão sobre o alumínio AA2024 em comparação com as do tipo Zn/Mg LDH.

Kuang et al. (2009) estudaram a liberação do inibidor de corrosão tiouréia encapsulado dentro de três tipos de microcápsulas mediante a técnica de impedância eletroquímica. Os ensaios foram realizados usando como substrato o aço carbono Q235 imerso numa solução de $\mathrm{H}_{2} \mathrm{SO}_{4}$ 0,1 mol/L contendo diferentes quantidades das microcápsulas. Estas microcápsulas foram produzidas usando glúten ou álcool polivinilico (PVA) e através da técnica de separação térmica de fase. Os autores concluíram que a velocidade de corrosão do aço decrescia à medida que o inibidor era liberado a partir das microcápsulas e este valor permanecia estável depois que a tiouréia havia sido liberada por completo. Os tempos para a liberação do inibidor obtidos dos diagramas de Nyquist para os três tipos de microcápsulas em estudo foram 12 h, 18 h e 48 h, onde os maiores tempos (18 h e 48 h) corresponderam às microcápsulas feitas usando álcool polivinilico (PVA) e, portanto, elas possuem uma velocidade de liberação do inibidor bastante lenta em comparação com as cápsulas feitas usando glúten. 


\subsection{Materiais mesoporosos ordenados}

Os materiais porosos ordenados são classificados segundo a IUPAC de acordo ao tamanho de poro do material (SING, 2002).

- Microporosos (<2 nm);

- Mesoporosos (<2-50 nm);

- Macroporosas (>50 nm).

Em 1998, uma nova família de sílicas mesoporosas foi desenvolvida usando um copolímero orgânico como material de template e TEOS (tetraortosilicate) como precursor de silício (VAN DER MEER et al., 2010). Ela foi chamada de SBA (o acrônimo de Santa Barbara Amorphous) (MEYNEN; COOL; VANSANT, 2009). A sílica denominada SBA-15 é um material meso e microporoso porque ele apresenta poros nas duas dimensões. O sufixo "-15" indica que ele é produzido com o uso do copolímero de três blocos chamado $\mathrm{PE}_{20} \mathrm{PO}_{70} \mathrm{PE}_{20}$ como surfactante.

Este material sintetizado tem uma estrutura mesoporosa com um diâmetro de poro entre 4,6 nm e $30 \mathrm{~nm}$, com área superficial alta, paredes com espessuras entre $3,1 \mathrm{~nm}$ e $6,4 \mathrm{~nm}$ e uma estabilidade térmica maior que outros materiais mesoporosos descobertos. Da maioria dos materiais mesoestruturados este tipo de sílica tem sido o de maior interesse devido a suas propriedades como catalisador (TAGUCHI; SCHÜTH, 2005), adsorvente, suporte catalítico e como nanoreservatório para o armazenamento e liberação controlada de fármacos (VALLET-REGí et al., 2001; VALLET-REGí et al., 2004; RÁMILA et al., 2003; BORISOVA; MÖHWALD; SHCHUKIN, 2011; FU et al., 2013; ZHAO et al., 1998a) ou inibidores de corrosão (JIANG et al., 2011; SKORB et al., 2009; BORISOVA; MÖHWALD; SHCHUKIN, 2011; CHEN; FU, 2012; YEGANEH; SAREMI; REZAEYAN, 2014). 
A estrutura dos poros desta sílica mesoporosa pode ser facilmente controlável durante o processo de síntese, tornando-o um material versátil de baixo custo e com uma ampla gama de aplicações. Esta sílica mesoporosa pode ser obtida entre $35^{\circ} \mathrm{C}$ e $80^{\circ} \mathrm{C}$ resultando em uma variedade de tamanhos dos poros e espessura das paredes. Os microporos tem função de conectar os mesoporos, por isso não são vistos em técnicas de microscopia, mas podem ser detectados em ensaios de volume de poro (adsorção de gás inerte).

Cada pluronic tem seu nome especifico, onde cada um possui informações sobre a quantidade relativa dos diferentes blocos, quanto o peso molecular. Por exemplo, o Pluronic P123 é um copolímero em forma de bastão com $30 \%$ de PEO (do número 3 em 123), enquanto o número 12 refere-se o que chamamos de "grade plurônico" (PASCUALI; CHIAPPETTA; BREGNI, 2005). A estrutura do P123 é apresentada na Figura 2.8.

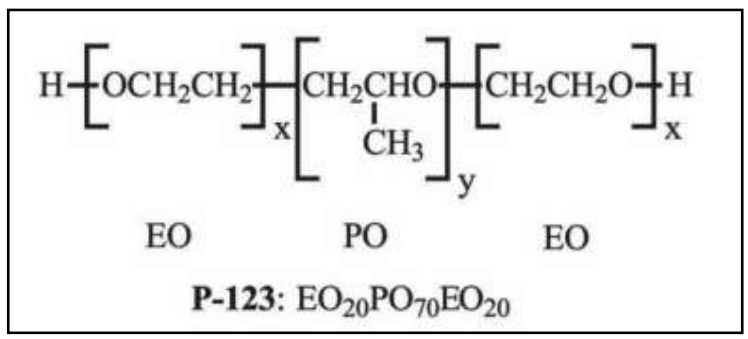

Figura 2.8 - Formula estrutural do P123 (KAVANOV et al., 2002).

Esta sílica, por apresentar paredes mais grossas em comparação com outros tipos de sílica, pode ser utilizada para condições mais severas, como temperatura e pressões mais elevadas. Os microporos são formados devido ao caráter hidrofílico das cadeias de grupo de óxido de etileno que são capturados nas paredes de silício durante o processo de condensação de espécies de silício gerando uma microporosidade adicional após o processo de calcinação. Enquanto que, os blocos de PPO (poli-(oxido de propileno)) formam a estrutura dos mesoporos (hidrofóbicos) (MEYNEN; COOL; VANSANT, 2009). 
Esta microporosidade faz que esta sílica tenha bastantes aplicações na difusão de reagentes e produtos em processos catalíticos. A Figura 2.9 mostra a dualidade porosa desta sílica mesoporosa calcinada.

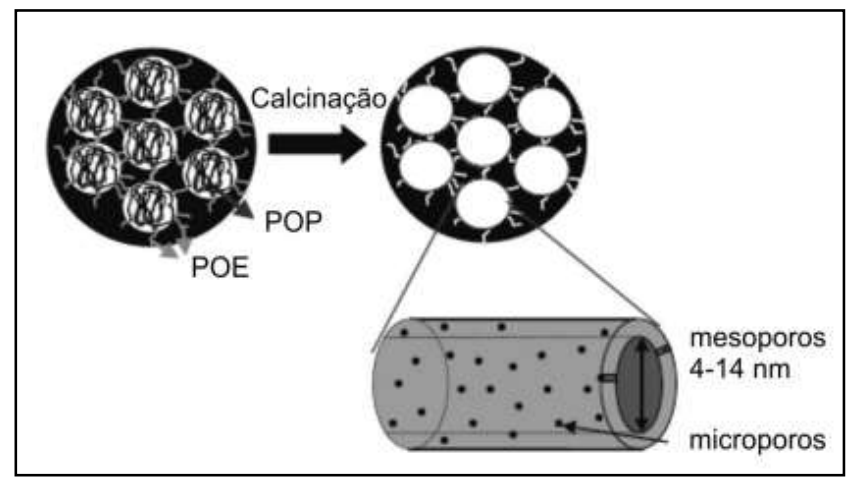

Figura 2.9 - Dualidade porosa do SBA-15 (GALARNEAU et al., 2001).

As etapas de sínteses da sílica mesoporosa têm inicialmente uma organização das moléculas de surfactantes para formar micelas. Posteriormente, as micelas se agrupam formando tubos cilíndricos (Figura 2.10).

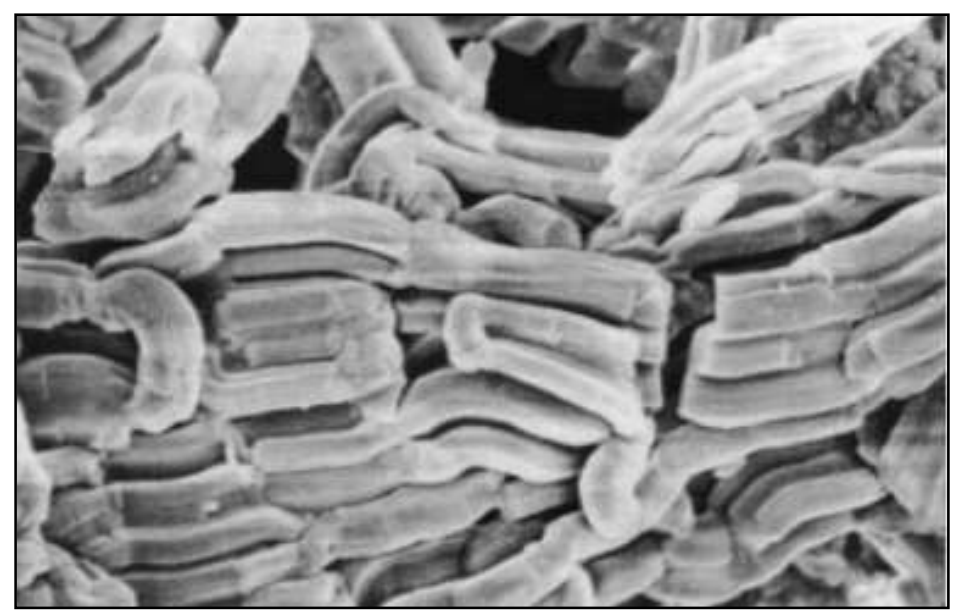

Figura 2.10 - Microscopia eletrônica de varredura da sílica mesoporosa calcinada (ZHAO et al., 1998b). 


\subsubsection{Mecanismo de formação da sílica mesoporosa}

$\mathrm{Na}$ preparação da sílica mesoporosa, são necessários pelo menos, três reagentes em quantidades apropriadas: uma fonte de sílica (TEOS), um surfactante (Pluronic P123) e um solvente (usualmente água). Outros reagentes, tais como: ácidos, bases, sais e co-solventes, também podem ser utilizados. O mecanismo de formação de sílicas mesoporosas ordenadas é basicamente um processo de auto-agregação de moléculas de surfactante, que funcionam como direcionadores estruturais, seguido da precipitação de um precursor inorgânico sobre esses moldes. Neste processo, um surfactante e um solvente são misturados ocasionando a formação de micelas, cuja morfologia pode variar dependendo do tipo de surfactante (DE SOUZA, 2012).

Em seguida, a fonte de sílica é adicionada à solução e um ácido ou uma base desencadeia a hidrólise do precursor de sílica transformando-o em um sol de oligômeros de silício. As interações entre os oligômeros e as micelas de surfactante resultam em uma reação de precipitação de um gel que gera a mesoestrutura. Durante essa etapa, ocorre a condensação dos oligômeros de silício. Dependendo das condições de síntese, as fases supramicelares podem evoluir de hexagonais para cúbicas ou lamelares. Quando o molde é removido por calcinação a $550{ }^{\circ} \mathrm{C}$ sob fluxo de ar, obtém-se a sílica mesoporosa com um conjunto de cavidades que constituem, em certo modo, uma réplica da morfologia das micelas formadas durante o processo de síntese (HATTON et al., 2005). A Figura 2.11 representa a sequência de síntese para a formação da sílica mesoporosa. 


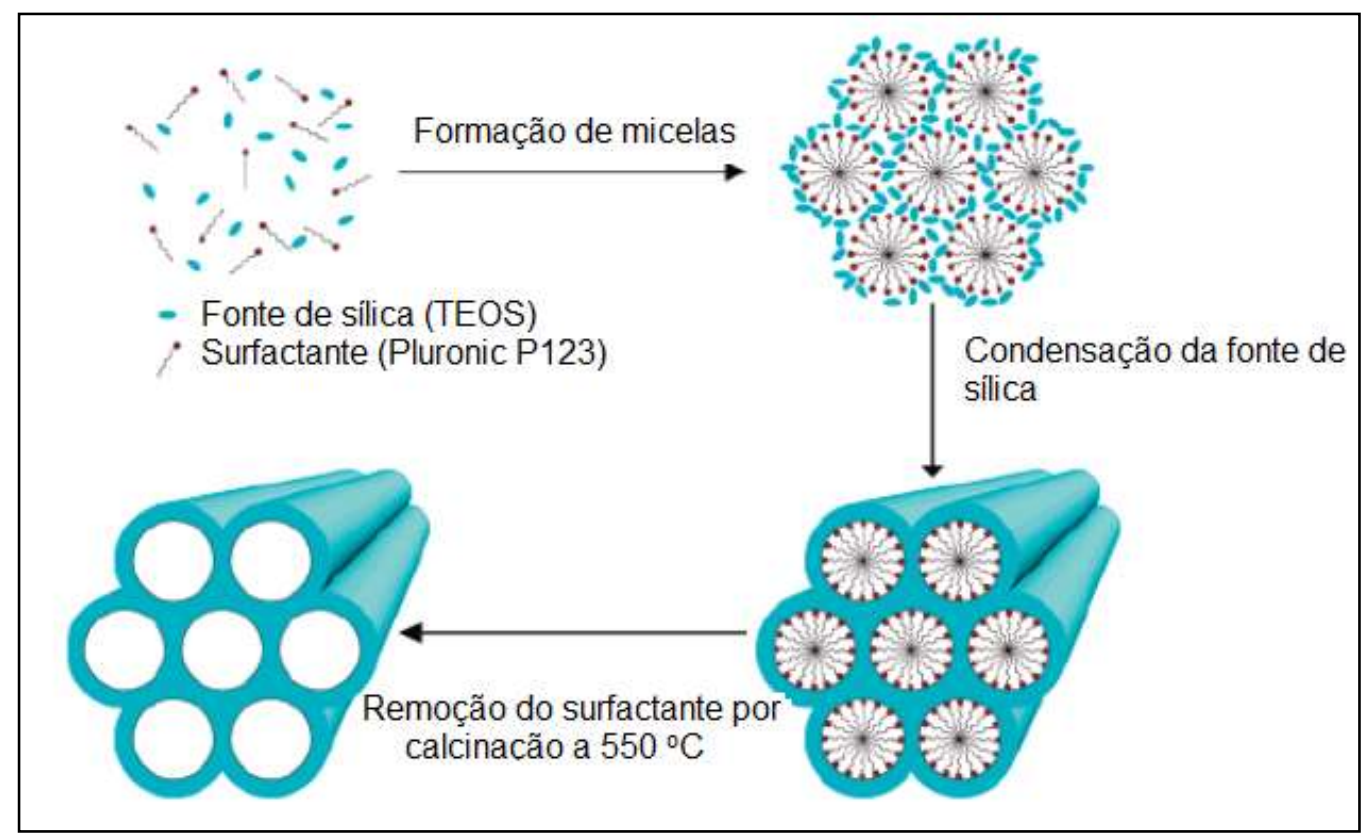

Figura 2.11 - Representação esquemática da síntese da sílica mesoporosa. (Adaptado do HATTON et al. (2005)).

\subsubsection{Técnicas de caraterização de materiais mesoporosos}

As técnicas de caraterização podem ser realizadas por diferentes técnicas, dentre as quais destacam-se: microscopia eletrônica de transmissão (MET), difração de raios-X (DRX), adsorção e dessorção de nitrogênio, termogravimetria (TGA) e calorimetria exploratória diferencial (DSC).

\subsubsection{Análise termogravimétrica (TGA/DTG)}

O método da termogravimétria consiste na medida da mudança da massa de uma substância com a variação da temperatura, enquanto esta é submetida a uma programação controlada. Para melhorar a análise e comparação de curvas, a ordenada é geralmente apresentada na forma de massa percentual ao invés de massa total (MOTHÉ; AZEVEDO, 2009). Já a termogravimetria derivada (DTG), nada mais é do que um arranjo matemático, no qual a derivada da variação da 
massa em relação ao tempo $(\mathrm{dm} / \mathrm{dt})$ é registrada em função da temperatura ou tempo. Ou seja, a DTG é a derivada primeira da TGA (DENARI, 2012).

Mediante a obtenção das curvas TGA e DTG, é possível obter informações sobre a cinética das reações, taxas de evaporação e sublimação, e até de propriedades magnéticas (MOTHÉ; AZEVEDO, 2009). O equipamento da análise termogravimétrica é composto basicamente pela termobalança. $O$ equipamento pode mudar de configuração de um fabricante para outro, mas os fundamentos de todos eles são os mesmos. A termobalança é um instrumento que permite a pesagem continua de uma amostra em função da temperatura, ou seja, à medida que ela é aquecida ou resfriada (DENARI, 2012).

Os principais componentes de uma termobalança são: balança registradora, forno, suporte de amostra e sensor de temperatura, programador de temperatura do forno, sistema registrador e controle da atmosfera do forno. A Figura 2.12 ilustra um diagrama de um equipamento de termogravimetria genérico.

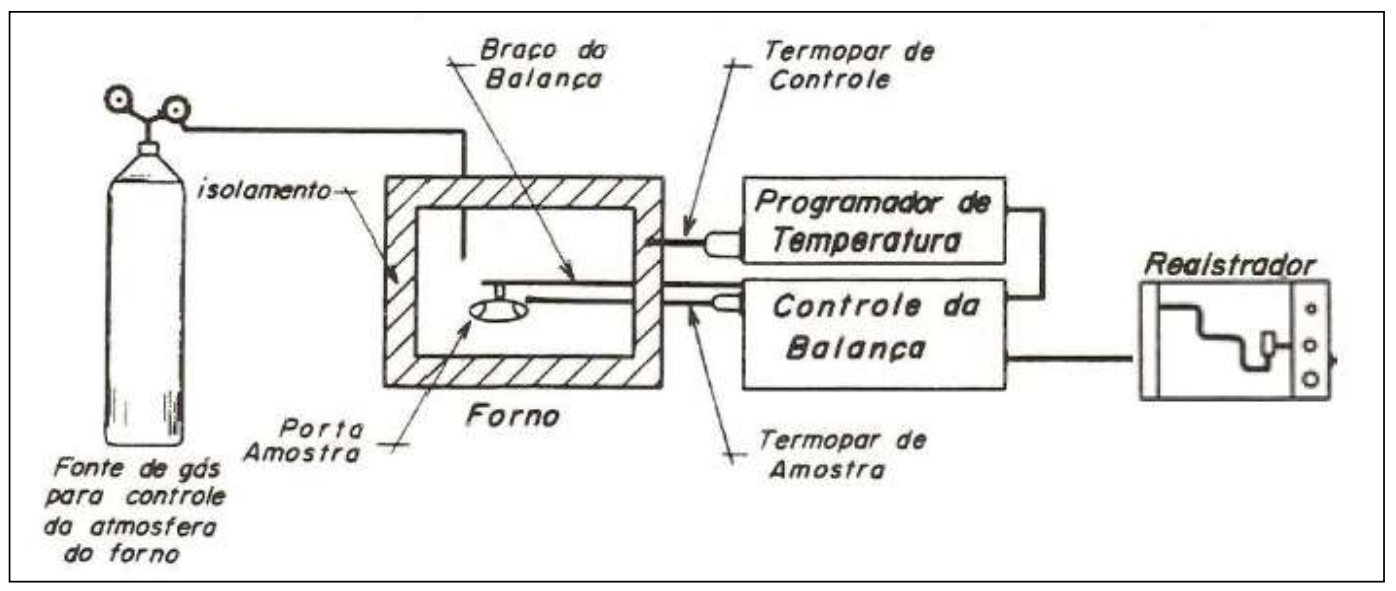

Figura 2.12 - Diagrama de um equipamento para análises termogravimétricas (DENARI, 2012).

As balanças mais utilizadas são as eletromagnéticas porque possuem pequena influência da vibração, alta sensibilidade e pequena flutuação térmica. 
Estas técnicas, apesar de antigas, ainda constituem as principais formas de análise das propriedades dos materiais. Além destas técnicas, há ainda a calorimetria diferencial de varredura (DSC), dilatometria (DIL) e a análise dínamomecânica (DMA), que podem dar importantes informações a respeito dos materiais (MOTHÉ; AZEVEDO, 2009). Os fatores mais comuns que podem afetar as medidas de TGA/DTG estão representados na Tabela 2.3.

Tabela 2.3 - Principais fatores que podem influenciar nas medidas de TGA/DTG (DENARI, 2012).

\begin{tabular}{|c|c|}
\hline Fatores instrumentais & Fatores de amostra \\
\hline Razão de aquecimento do forno & Quantidade de amostra \\
\hline Velocidade de registro & Solubilidade dos gases envolvidos \\
\hline Atmosfera do forno & Tamanho das partículas e calor de reação \\
\hline Geometria do suporte de amostra & Empacotamento da amostra \\
\hline Sensibilidade da balança & Natureza da amostra \\
\hline Composição do suporte de amostra & Condutividade térmica \\
\hline
\end{tabular}

Dentre as várias aplicações existentes da termogravimetria destacam-se:

- Corrosão de materiais em várias atmosferas (SEGOVIA; DUTRA, 2009);

- Curvas de adsorção e desadsorção;

- Desenvolvimentos de processos gravimétricos analíticos (peso constante);

- Decomposição térmica ou pirólise de matérias orgânicos, inorgânicos e biológicos;

- Estudo da cinética das reações envolvendo espécies voláteis;

- Reações no estado sólido que liberam produtos voláteis;

\subsubsection{Adsorção e dessorção de nitrogênio}

A adsorção física é um fenômeno reversível onde normalmente ocorre a deposição de mais de uma camada de adsorbato (espécie química retida pelo adsorvente) sobre a superfície do adsorvente (sólido sobre o qual a adsorção é 
feita). Esta adsorção física constitui o princípio da maioria dos processos de purificação e separação (QUINTELLA, 2009).

As isotermas são classificadas pela IUPAC em 6 tipos, de acordo com seu formato e as áreas de histerese. Para cada uma é usado um modelo numérico para estimativa das propriedades do material: tamanho, distribuição e volume de poro; área superficial e tamanho de partícula. A Figura 2.13 apresenta os diferentes tipos de isotermas de adsorção segundo a IUPAC.

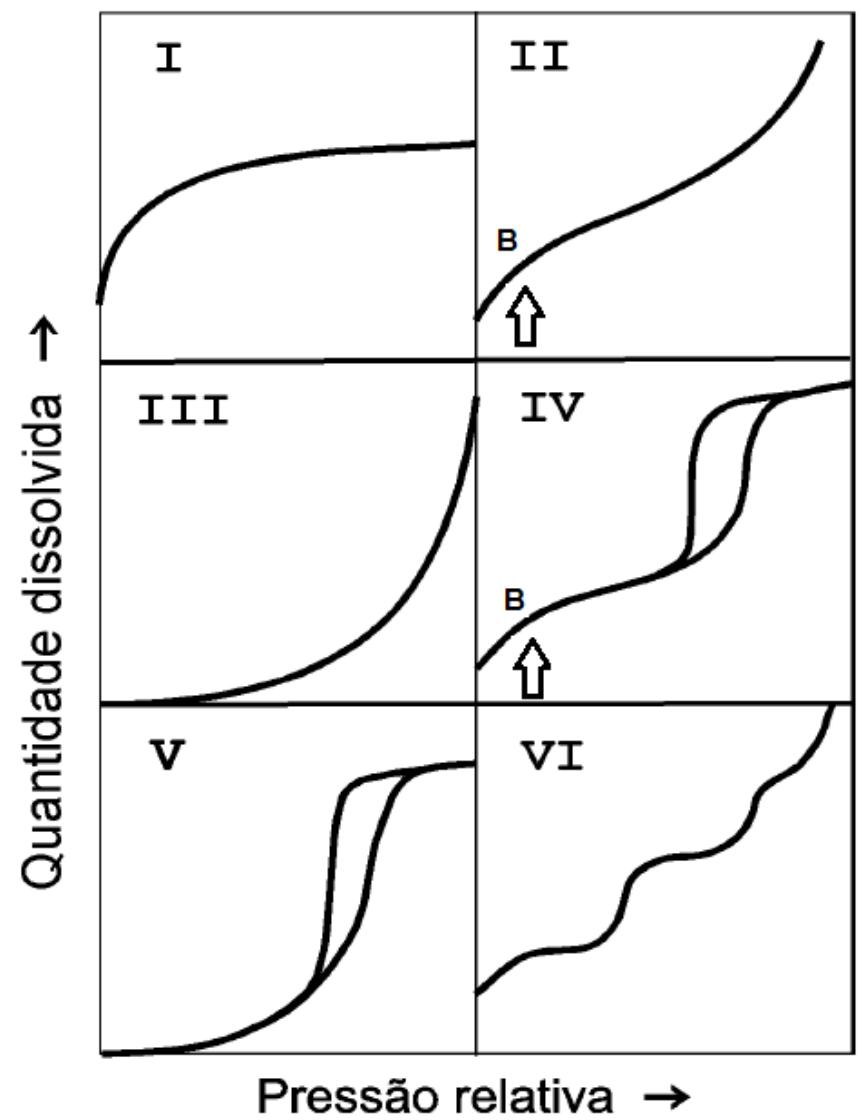

Figura 2.13 - Classificação das isotermas de adsorção e dessorção segundo IUPAC (NEIMARK; SING, 2008).

Nas isotermas do tipo I observa-se um rápido aumento de gás adsorvido à medida que a pressão também aumenta, até um patamar. Essa isoterma é para sólidos microporosos tendo superfície externa relativamente pequena e é também obtida quando no processo de adsorção se forma apenas uma monocamada 
(OSCIK, 1982). Esta isoterma é considerada reversível, já que o processo de adsorção coincide com o processo de dessorção.

As isotermas do tipo II são típicas de adsorbentes não porosos ou macroporosos. Se o ponto de inflexão da isoterma é bem nítido, é possível obter no início da parte quase linear o valor do ponto $B$, o qual representa a capacidade da monocamada (pela extrapolação deste valor na ordenada), ou seja, a quantidade de adsorbato necessária para cobrir a superfície com uma monocamada completa. Aqui onde começa a formação da multicamada

As isotermas do tipo III não são muito comuns, mas formam-se sob condições onde as moléculas de gás apresentam maior afinidade umas pelas outras do que pela superfície do adsorbente. Para essas condições analisar a área superficial e a porosidade não têm qualquer sentido.

As isotermas do tipo IV são conseguidas através de adsorbentes mesoporosos. Este tipo de isoterma, na maioria dos casos, mostra uma relevante região na qual a pressão relativa varia pouco e o volume adsorvido aumenta repentinamente. Junto com o processo secundário de condensação capilar está o loop de histerese, que traz como consequência o preenchimento completo dos mesoporos em pressão relativa menor que 1 (P/P0 <1). Nas situações mais simples, a parte inicial da curva segue o mesmo perfil que aquele do tipo II. Quando o ponto B está bem definido possivelmente obtém-se a capacidade da monocamada. Esta isoterma é como uma impressão digital da geometria específica da estrutura dos poros, na qual esses fenômenos ocorrem. Sua localização indica o tamanho do poro característico do material e dá indícios do volume de poro. Enquanto menor seja sua inclinação, mais homogênea é a distribuição de tamanho de poros.

As isotermas do tipo $\mathrm{V}$ são poucos raras e podem aparecer com alguns tipos de adsorbentes porosos. Elas estão relacionadas às isotermas do tipo III em 
que a interação adsorvente-adsorbato é muito fraca, mas o preenchimento dos poros também acontece, levando o valor limite de adsorção para altos valores de P/PO.

Finalmente as isotermas do tipo VI indicam uma adsorção gradual da multicamada e estão relacionadas à adsorção sobre superfície não porosas uniformes. Estas isotermas são uma variação das do tipo II. O tamanho do degrau releva a formação de uma monocamada completa e para casos mais simples, continua constante para duas ou três camadas adsorvidas (ALVES, 1999; SING et al., 1985).

2.8.2.3 Método BET de adsorção de $\mathrm{N}_{2}$ para determinação da área superficial de sólidos

Este método desenvolvido por Brunaeur-Emment-Teller é o mais usado para estimar propriedades quantitativas de sólidos porosos. Ele é uma adaptação da isoterma de Langmuir, para a adsorção de monocamadas, com ajustes para poder ser usada quando mais de uma camada é adsorvida (NEIMARK; SING, 2008). As moléculas da primeira camada atuam como novos centros de adsorção para poder se juntar com as moléculas da camada seguinte. $O$ equilíbrio é atingido quando a velocidade de adsorção é igual à velocidade de dessorção. A Equação 2.4 representa essa situação de equilíbrio:

$\left(P / P^{\circ}\right) /\left[n\left(1-P / P_{0}\right)\right]=1 / C \cdot n_{m}+\left[(C-1) / C . n_{m}\right]\left(P / P_{o}\right)$

Onde, $\mathrm{P}=$ Pressão; $\mathrm{P}_{\mathrm{o}}=$ Pressão de saturação do gás;

$\mathrm{n}=$ Quantidade de gás adsorvido;

$\mathrm{C}$ = constante empírica relacionada com o tamanho de poro;

$\mathrm{n}_{\mathrm{m}}=$ capacidade de adsorção de cada camada 
Ambas as variáveis que devem ser definidas no modelo podem ser empiricamente calculadas. Com a linearização da Equação 2.4, ou seja, um gráfico de $p /\left[n\left(p^{\circ}-p\right] v s p / p^{\circ}, C\right.$ e $n_{m}$ são os pontos de intersecção como o eixo e a inclinação, respectivamente. No entanto, a linearização é válida apenas para uma pequena extensão de $\mathrm{p} / \mathrm{p}^{\circ}(0,05$ a 0,3$)$ em que se caracteriza a região mesoporosa.

Encontrado um valor de $\mathrm{n}_{\mathrm{m}}$ que tenha validade física como a isoterma, pode-se fazer o cálculo da área superficial através da Equação 2.5.

$$
a_{B E T}=n_{m} \cdot \text { L. } \theta
$$

Equação 2.5

$\mathrm{L}=$ número de Avogadro

$\Theta=$ área de cada molécula de gás (para $\mathrm{N}_{2}$ é $0,162 \mathrm{~nm}^{2}$ )

Como o método de BET é uma aproximação empírica do processo de adsorção, é necessário verificar as condições em que ele pode ser aplicado. No software é feito um refinamento estatístico do método aplicado a cada situação, e os valores são recalculados de acordo com o gás utilizado.

\subsection{3.1 Interpretação da isoterma de tipo IV}

Para as isotermas do tipo IV (aplicável ao material mesoporoso designado por SBA-15), é importante notar que a primeira parte, antes do loop da histerese, é semelhante a uma isoterma do tipo II (de um sólido não poroso). Isso indica que a monocamada de gás no começo da adsorção (para baixas pressões) ocorre dentro dos poros da mesma maneira que uma superfície totalmente aberta (DISTRIBUTION; INTER, 2002).

No entanto, a partir de uma determinada pressão, começa a ocorrer condensação capilar dentro dos poros, provocando aumento da quantidade 
adsorvida. Esse fenômeno é descrito de acordo com a Equação 2.6 (simplificada para o $\mathrm{N}_{2}$ e poros cilíndricos).

$$
r_{k}=-\underline{2 \cdot v \cdot v 1} \ln \left(p / p_{0}\right)
$$

Equação 2.6

R.T

$r_{k}=$ raio de Kelvin

$Y=$ tensão superficial

$\mathrm{v} 1=$ volume molar

Para múltiplas camadas, pode-se definir o tamanho de poro como:

$$
r_{p}=r_{k}+t
$$

Equação 2.7

Onde t é a espessura das demais camadas

Esse equacionamento é utilizado no método estatístico BJH (Barrett Joyner - Halenda) para o cálculo e distribuição de tamanho de poro (SING et al., 1985).

O fenômeno da histerese de adsorção é explicado claramente pela teoria da condensação capilar que está associado com a condensação capilar em mesoporos e aparece na faixa de adsorção em multicamadas. A histerese significa que a curva de dessorção não coincide com a curva de adsorção. A adsorção em monocamada sobre a parede do poro em baixas pressões ocorre no ramo de adsorção da isoterma. A adsorção em multicamadas, e, ocasionalmente a condensação do adsorbato acontecem com o aumento da pressão. A geometria da interface é considerada a ser diferente daquela da adsorção, durante a dessorção, já que a pressão $\mathrm{p}$ durante a evaporação do menisco, fornecida pela equação de Kelvin, é diferente da pressão de saturação de vapor, po. Segundo a IUPAC as isotermas de adsorção compreendem quatro tipos de histerese, designados como H1, H2, H3 e H4. Estes tipos são representados na Figura 2.14. 


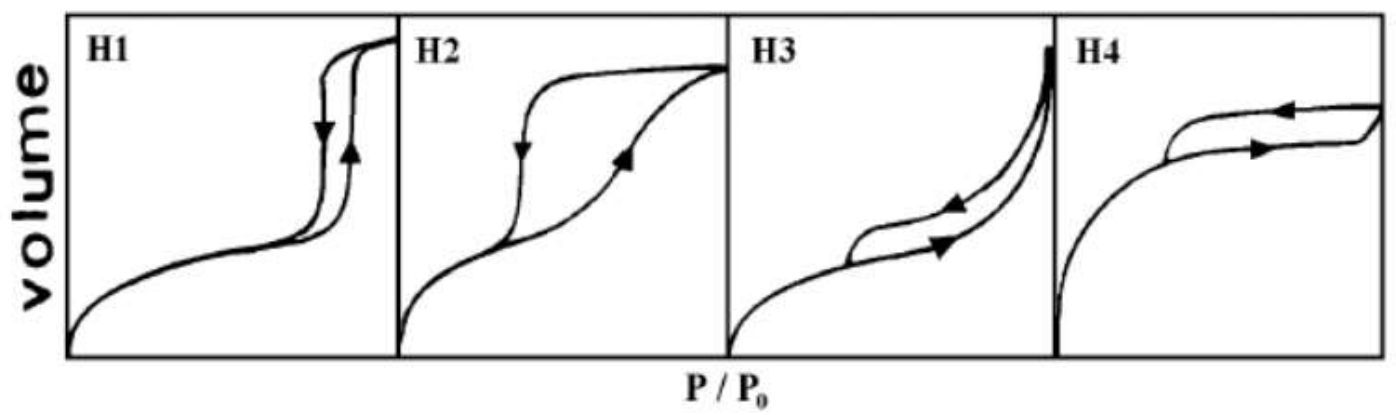

Figura 2.14 - Tipos de histerese (SING et al., 1985).

Dois tipos diferentes de estrutura mesoporosa são característicos dos tipos $\mathrm{H} 1$ e H2. Enquanto o tipo $\mathrm{H} 1$ é representativo de um adsorvente com uma estreita distribuição de poros relativamente uniforme, o tipo $\mathrm{H} 2$ está relacionado com uma estrutura mais complexa, onde a distribuição do tamanho de poro e a forma não estão bem definidas. Os tipos H3 e H4 não exibem qualquer adsorção limitante em altas pressões relativas.

Yamada et al. (2010) usaram isoterma BTE para determinar a área especifica e o diâmetro do poro de esferas de sílica mesoporosas dispersas sintetizadas a partir de cápsulas de poliestireno amino-modificadas para o encapsulamento de óxidos inorgânicos $\left(\mathrm{TiO}_{2}\right.$ e $\left.\mathrm{Fe}_{2} \mathrm{O}_{3}\right)$. As áreas específicas foram deduzidas a partir da isoterma pelo método BTE considerando uma faixa de P/Po $=0,05$ até $P / P_{0}=0,15$. Os autores encontraram que as áreas específicas para esta sílica ficavam entorno de 988 e $893 \mathrm{~m}^{2} / \mathrm{g}$ com um diâmetro de poro de quase $20 \AA$ ( $2 \mathrm{~nm}$ ) conseguindo-se encapsular aproximadamente $40,2 \% \mathrm{~m} / \mathrm{m}$ de $\mathrm{TiO}_{2} \mathrm{e}$ $36,4 \% \mathrm{~m} / \mathrm{m}$ de $\mathrm{Fe}_{2} \mathrm{O}_{3}$.

Dhar et al. (2005) determinaram a área de superfície e a distribuição do tamanho de poro de uma sílica mesoporosa impregnada com diferentes concentrações de íons molibdato usando isotermas BET. A área de superfície do material mesoporoso SBA-15 que foi usado como suporte foi determinado como sendo $696 \mathrm{~m}^{2} / \mathrm{g}$ com um tamanho de diâmetro de poro de $72 \AA(7,2 \mathrm{~nm})$. Os 
autores determinaram que a área de superfície está em função do carregamento dos íons molibdato e que esta área fica quase constante até um valor de $8 \% \mathrm{~m} / \mathrm{m}$ para esta sílica mesoporosa, entanto que, para uma sílica amorfa o carregamento vai até $4 \% \mathrm{~m} / \mathrm{m}$. Eles concluíram que esta sílica mesoporosa acomoda maior quantidade de íons molibdato dispersado que a amorfa e, portanto suas propriedades de superfície são diferentes.

Zhao et al. (1998b) usando isotermas de adsorção BTE encontraram tamanhos de poro de aproximadamente $300 \AA$ ( $30 \mathrm{~nm}$ ) quando sintetizaram uma sílica mesoporosa hexagonalmente ordenada. Eles utilizaram diferentes copolímeros triblocos obtendo áreas superficiais entre $630 \mathrm{~m}^{2} / \mathrm{g}$ a $1040 \mathrm{~m}^{2} / \mathrm{g} \mathrm{e}$ tamanhos de poros de $46 \AA$ (4,6 nm) a $100 \AA$ (10 nm).

\subsubsection{Difração de raios-X (DRX)}

A difração de raios-X (DRX) é utilizada para obter determinadas informações sobre as propriedades dos materiais, tais como: estrutura cristalina e o grau de cristalinidade; identificação quantitativa das fases existentes no material; os parâmetros da cela unitária; textura e tamanho dos cristalitos. As amostras podem estar na forma de pó, monocristais, folhas e fibras. Embora esta seja uma técnica bastante empregada em catálise, principalmente para determinação da estrutura cristalina de materiais sintetizados, a técnica apresenta algumas limitações, a saber (QUINTELLA, 2009):

- Esta técnica é usada em materiais estruturados, cristalinos ou não. Os materiais amorfos não fornecem uma boa difração não apresentando picos bem definidos, mas bandas;

- A sobreposição de picos pode interferir na análise quantitativa para identificação;

- Materiais com difração forte podem encobrir os fracamente difratados, o que é chamado efeito de matriz; 
- Amostras fluorescentes podem elevar a linha base de difração ou pode causar saturação em certos tipos de detectores;

Nesta técnica, um feixe de raios $X$ com comprimento de onda conhecido incide na superfície da amostra, e é difratado somente quando condições geométricas definidas pela lei de Bragg, que relaciona o ângulo formado entre os raios $X$ incidentes e a superfície da amostra, o comprimento de onda e 0 espaçamento interplanar da amostra, são satisfeitas. A Figura 2.15 representa um plano cristalino para a formulação da Lei de Bragg, representada pela Equação 2.8 (NEIVA, 2004).

$$
\mathrm{n} \lambda=2 \cdot \mathrm{d} \cdot \operatorname{sen} \theta
$$

\section{Equação 2.8}

Onde $n$ é a ordem de reflexão $(n=1,2,3, \ldots .$.$) , \lambda$ é o comprimento de onda, d é a distância interplanar e $\theta$ é o ângulo de incidência entre os planos reticulados.

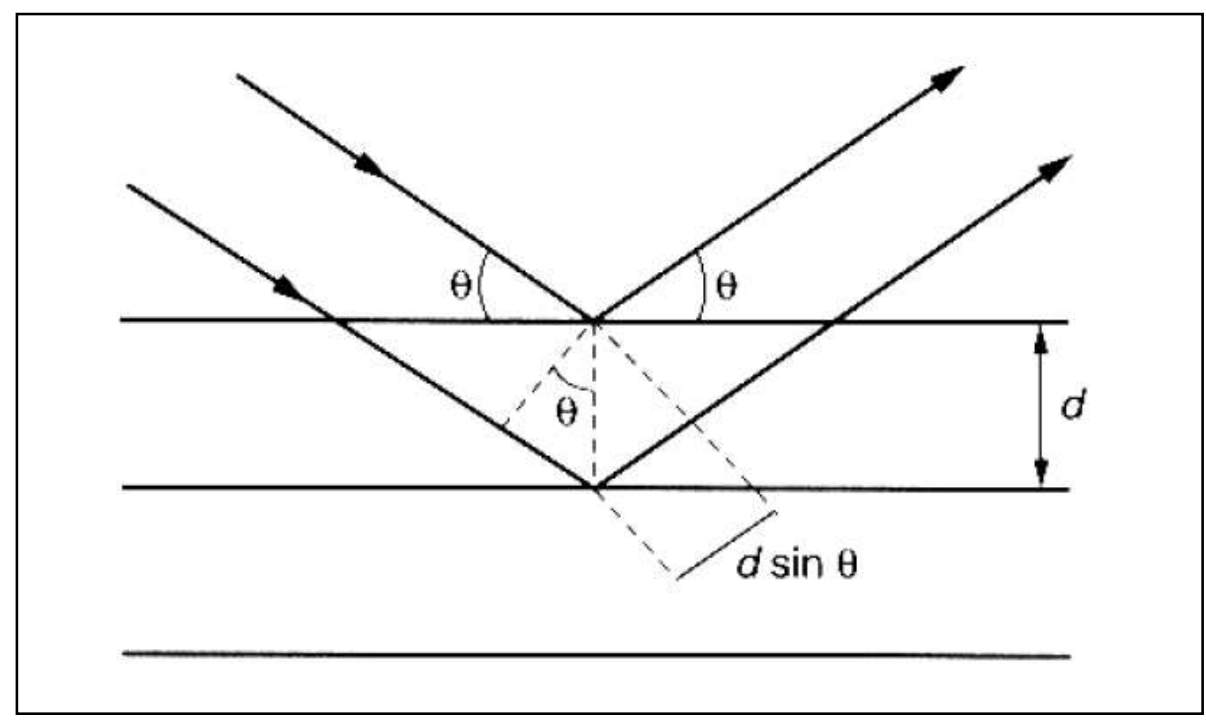

Figura 2.15 - Esquema representativo para a formulação da lei de Bragg (SKOOG; HOLLER; NIEMAM, 2002).

As condições necessárias para a difração de raios $X$ são: (a) 0 espaçamento entre as camadas deve ser de aproximadamente o mesmo valor que o comprimento de onda da radiação e (b) os centros espalhadores devem estar 
espacialmente distribuídos em um arranjo altamente regular. Desta forma, um difratograma de uma substância cristalina apresenta um conjunto de picos em diferentes valores de $2 \theta$ e com diferentes intensidades que são características do composto que está sendo analisado, permitindo a identificação da composição química da amostra (SKOOG; HOLLER; NIEMAM, 2002).

Para o caso de materiais mesoporosos altamente ordenados é utilizado o método proposto por Settle (SETTLE, 1997). Este método consiste basicamente em uniformizar a amostra e torná-la um pó fino e homogêneo. Desta forma quando é colocado no porta amostra do equipamento um grande número de pequenos cristalitos é orientado em todas as direções possíveis. Assim, quando o feixe de elétrons do raios- $X$ atravessa o material, um grande número de partículas estarão orientadas de tal forma que a lei de Bragg seja obedecida (Eq. 8). A identificação das fases ocorre quando é observada a aparição de três a cinco picos referentes aos planos (100), (110), (200), (210) e (300), na faixa de $0,5^{\circ}$ a $3,0^{\circ}$. Estes planos são característicos de estruturas hexagonais para este tipo de materiais mesoporosos segundo a literatura (ZHAO et al., 1998b; YAMADA et al., 2010; HAN; KIM; STUCKY, 2000; TUEL; HUBERT-PFALZGRAF, 2003; BECK et al., 1992; KO; RYOO, 2000; THIELEMANN, et al., 2011).

O parâmetro mesoporoso da rede $\left(\mathrm{a}_{0}\right)$ que representa a soma do diâmetro dos poros $\left(d_{p}\right)$ do material e a espessura média da parede de sílica $\left(W_{t}\right)$ pode ser obtido a partir do valor da distância interplanar no plano (100). A Equação 2.9 correlaciona as distâncias interplanares no plano (100) com o valor do parâmetro mesoporoso ao (BECK et al., 1992).

$$
a_{0}=\underline{2 d(100)}
$$

Equação 2.9

$\sqrt{ } 3$

A Figura 2.16 representa um difratograma obtido para a sílica mesoporosa calcinada obtida de trabalhos da literatura (BECK et al., 1992; KUMARAN et al., 2006). 


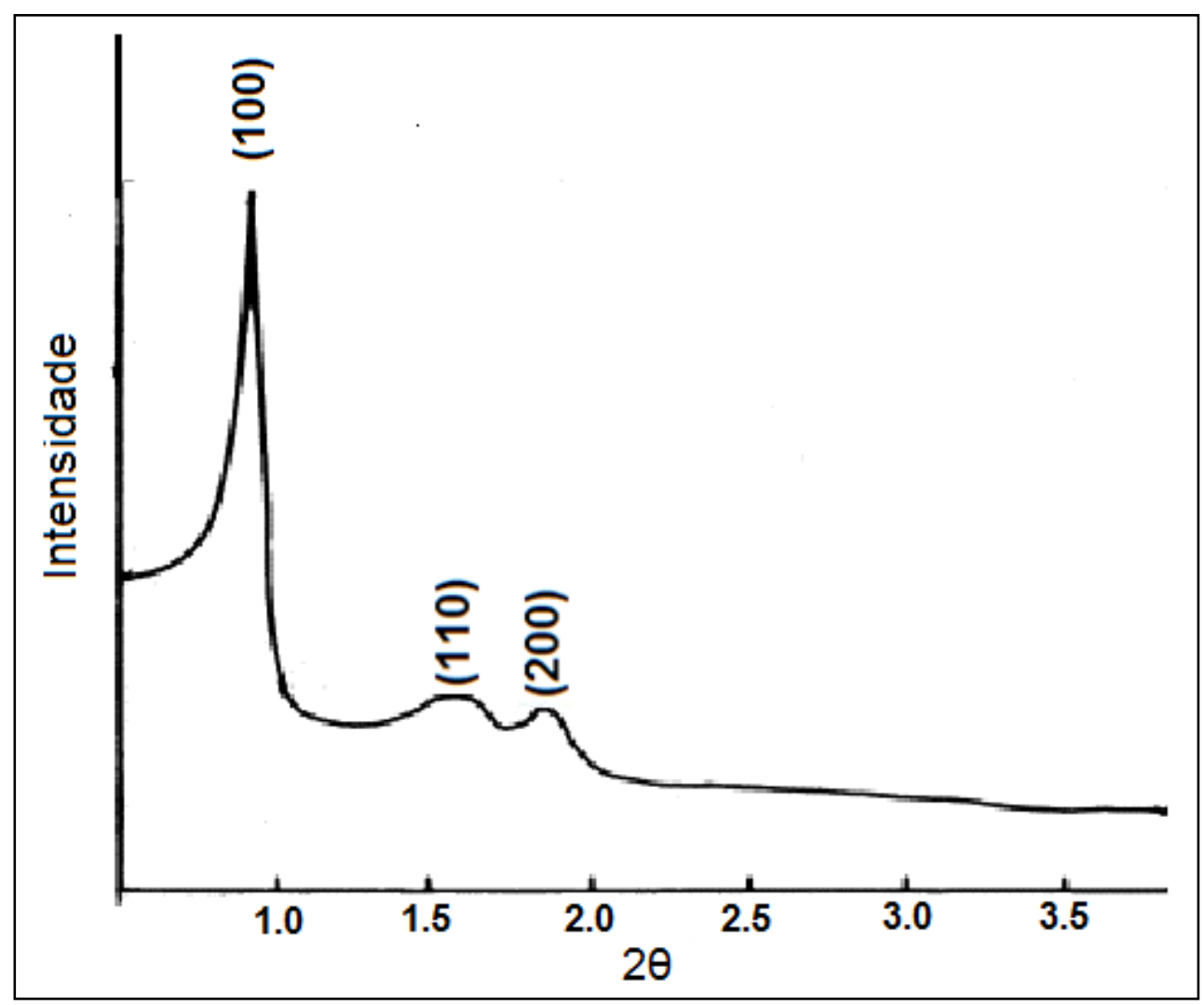

Figura 2.16 - Difratograma de raios-X para a sílica mesoporosa calcinada DHAR et al., 2005).

\subsubsection{Microscopia eletrônica de transmissão (MET)}

A técnica de microscopia eletrônica de transmissão possibilita a aquisição de imagens com resolução muito superior às obtidas em qualquer microscópio ótico tradicional, em consequência da utilização de elétrons para a formação das imagens (MICROSCOPIA [...], 2002). Na microscopia eletrônica de transmissão um feixe de elétrons é irradiado em direção a uma fina camada de amostra que dispersa os raios. Eles são recombinados com uma lente objetiva eletromagnética e formam a imagem da amostra estudada.

Devido ao pequeno comprimento de onda dos elétrons, essa técnica permite uma ampliação significativamente maior e de boa resolução. Ela permite analisar características nanométricas da amostra como composição química, 
orientação molecular, estrutura eletrônica e tamanho de partículas. Em geral, os microscópios utilizados operam na faixa de $200 \mathrm{kV}$. O aumento da energia utilizada aumenta a resolução, mas em contra partida aumenta a deterioração da amostra (KOOT et al., 2007).

Os elementos básicos que constituem um microscópio eletrônico de transmissão são: 1) Canhão de elétrons; 2) Lentes Eletromagnéticas: lentes condensadoras, lente objetiva, lentes intermediárias e lentes projetoras; e 3) Conjunto de aberturas: aberturas das lentes condensadoras, aberturas do plano focal e aberturas de Difração de Elétrons de Área Selecionada (Selected Area Diffraction - SAD).

O canhão de elétrons gera e acelera o feixe de elétrons. Imediatamente após serem gerados, os elétrons são convergidos e direcionados pelo cilindro Wehnelt no caso de canhões termiônicos e por anodos no caso de canhões por efeito de campo (Field Emission Gun - FEG). O ponto do primeiro cruzamento de feixes é chamado de crossover e é importante que seja uma região a menor possível, pois esta é efetivamente a fonte de iluminação do microscópio e, portanto, limita a resolução do mesmo. Abaixo do canhão se tem o conjunto de lentes condensadoras. Geralmente há de duas a três lentes condensadoras em um microscópio de transmissão e sua função é fazer com que os feixes atinjam a amostra o mais paraxiais ou com um determinado ângulo quando é usado em técnicas que envolvam feixe convergente sobre a amostra como, por exemplo, Convergent Beam Electron Diffraction (ROA, 2008).

Junto ao conjunto de lentes condensadoras há um conjunto de aberturas formado por uma série de orifícios de tamanhos variados onde se pode selecionar a corrente de elétrons do feixe e o ângulo máximo de convergência sobre a amostra. É fundamental um bom alinhamento desta abertura em relação ao eixo óptico. A Figura 2.17 esquematiza o funcionamento de um microscópio eletrônico de transmissão. 


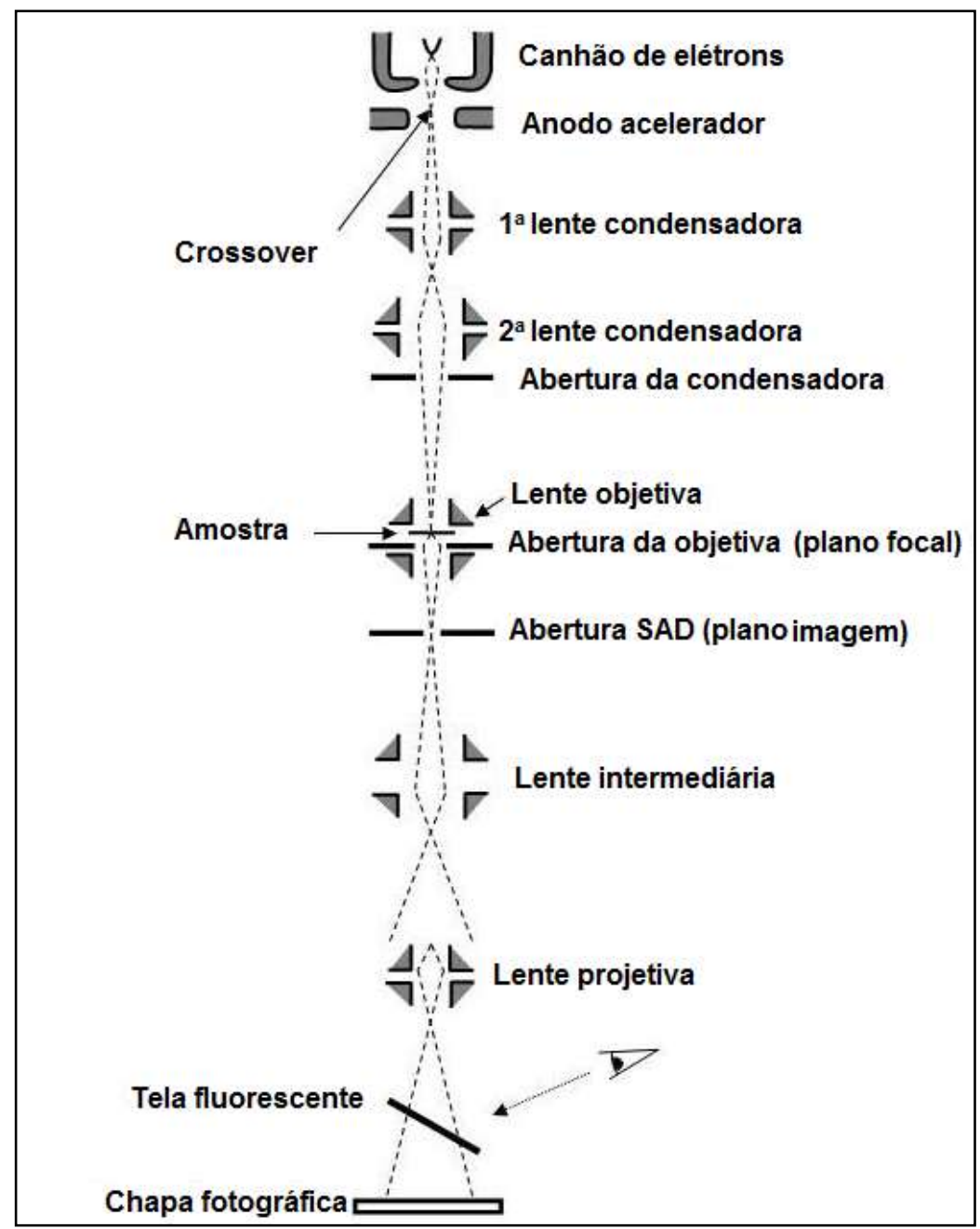

Figura 2.17 - Esquema de funcionamento de um microscópio eletrônico de transmissão (ROA, 2008).

A lente objetiva é a principal lente do microscópio de transmissão e a que possui menor distância focal. Microscópios atuais possuem um conjunto de lentes objetivas na qual a amostra fica inserida no interior quando é analisada. A peça superior desse tipo garante o ângulo de convergência desejado sobre a amostra e a peça inferior converge o feixe muitas vezes em conjunto com minilentes auxiliares. Abaixo da lente objetiva, temos o plano onde o feixe é convergido (plano focal) e mais abaixo temos o plano no qual é formada a imagem (plano imagem). A posição na qual a amostra é inserida é chamada plano objeto (ROA, 2008). 
As amostras utilizadas em MET devem ter as seguintes características: espessura de $500 \AA$ a $5000 \AA$ e a superfície polida e limpa de cada lado. Durante a preparação, a amostra não deve ser alterada por causa de deformações plásticas, difusão de hidrogênio, polimento eletrolítico ou transformações martensíticas.

Os corpos de prova podem ser de dois tipos: lâminas finas do próprio material ou réplicas de sua superfície. A preparação de lâminas finas de metais e ligas segue normalmente a seguinte sequência de preparação: corte de lâminas de $0,8 \mathrm{~mm}$ a $1,0 \mathrm{~mm}$ de espessura, afinamento por polimento mecânico até $0,1 \mathrm{~mm}-0,2 \mathrm{~mm}$ de espessura e polimento eletrolítico final. As lâminas finas de materiais poliméricos e de outros materiais orgânicos são obtidas por microtomia, onde uma navalha corta películas finas e com espessura controlada. Em geral, o material orgânico é resfriado em nitrogênio líquido (ultramicrotomia) para minimizar a deformação durante 0 corte. $O$ afinamento final das lâminas de materiais cerâmicos é geralmente feito por desbaste iônico (PADILHA, 2004).

\subsection{Avaliação do efeito self-healing ou autorreparação em camadas de tinta aditivadas com cápsulas contendo inibidores}

O grande impacto da corrosão em estruturas metálicas é atualmente um assunto estratégico para todas as sociedades modernas. Estima-se que o custo pela degradação de materiais causada pela corrosão é de aproximadamente $€ 200$ bilhões por ano na Europa e de US\$200 bilhões por ano nos EUA. Os materiais avançados que estão sendo desenvolvidos e usados em indústrias modernas requerem constantemente revestimentos sofisticados para melhorar seu desempenho e durabilidade. Dessa forma, surgiram os chamados revestimentos inteligentes "smart coatings", os quais não são apenas barreiras passivas entre o substrato e o meio agressivo, mas eles possuem muitas funcionalidades que de fato resultam em capacidade de apresentar o efeito self-healing ou de 
autorreparação (ZWAAG, 2007; WU; MEURE; SOLOMON, 2008; WOOL, 2008; SYRETT; BECER; HADDLETON, 2010). O conceito global destes materiais inteligentes que agem a um estímulo externo $(\mathrm{pH}$, umidade, temperatura, dano físico) e se autorreparam tem experimentado uma ajuda valiosa vinda da nanotecnologia.

O termo self-healing é definido por Skorb et al. (2009) como a autorrecuperação das propriedades iniciais de um material depois da ação destrutiva de um agente externo, e cujo esquema é representado na Figura 2.18. No entanto, uma recuperação parcial da principal funcionalidade do material pode ser também considerada como habilidade self-healing (YABUKI; OKUMURA, 2012; WANG et al., 2014; STANKIEWICZ; SZCZYGIEL; SZCZYGIEL, 2013). As estruturas de multicamada de um revestimento, onde os componentes são integrados, são o foco de uma proteção contra a corrosão prolongada e sofisticada (WANG et al., 2014; STANKIEWICZ; SZCZYGIEL; SZCZYGIEL, 2013; LI et al., 2013; SKORB et al., 2009).

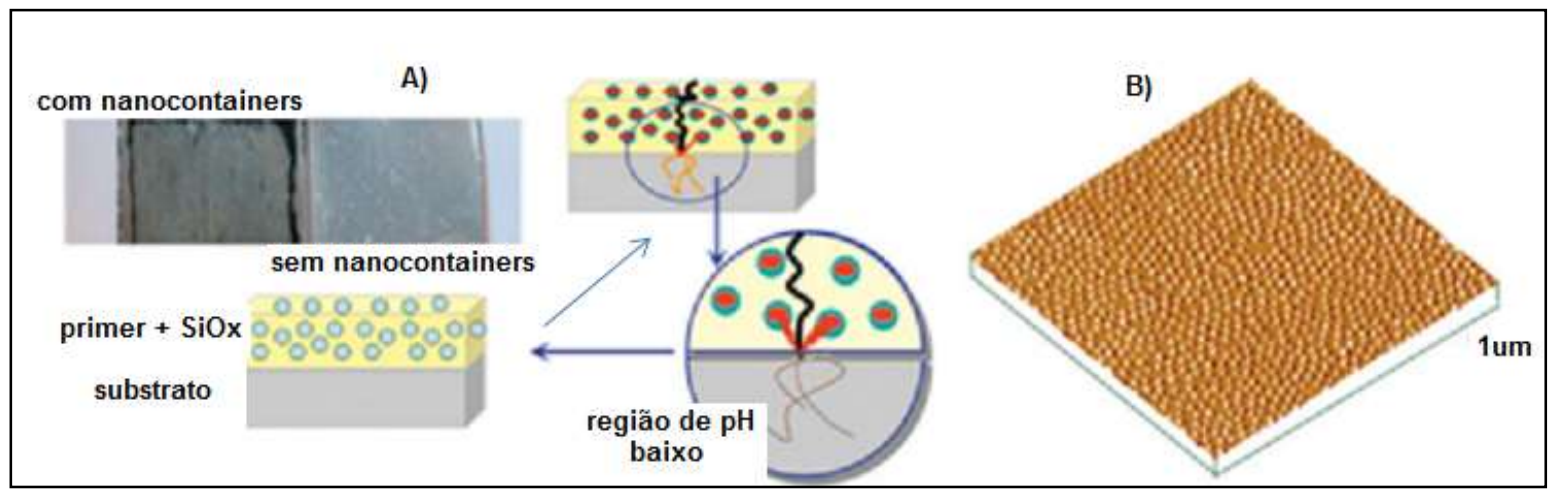

Figura 2.18 - (A) Esquema do efeito self-healing de um revestimento aditivado ou não e (B) imagem por AFM de um primer contendo as nanopartículas de sílica dopadas com inibidor (SKORB et al., 2009). 
2.9.1 Medidas de espectroscopia de impedância eletroquímica, EIE, em corpos de prova pintados e com defeito provocado

Sem dúvida a avaliação do comportamento frente à corrosão de revestimentos poliméricos tem sido uma das importantes aplicações da técnica de impedância eletroquímica, a qual é comumente usada pelos pesquisadores em tintas para a avaliação do desempenho de sistemas de pintura sobre o aço carbono ou aço galvanizado. Um resultado típico que normalmente se obtêm na avaliação destes tipos de revestimentos é mostrado na Figura 2.19.

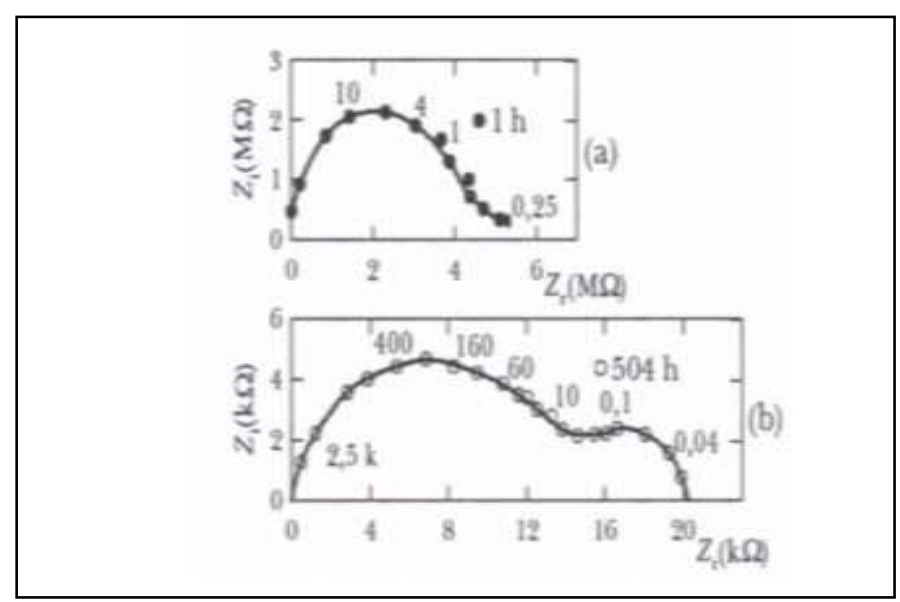

Figura 2.19 - Representação de Nyquist dos valores de impedância de um aço pintado com tinta epóxi-óxido de ferro após diferentes tempos de imersão em solução $1 \mathrm{~mol} / \mathrm{L}$ de $\mathrm{NaCl}$ (a) após $1 \mathrm{~h}$ de imersão e (b) após 504 h de imersão (WOLYNEC, 2003).

A técnica de impedância eletroquímica é útil para caracterizar um substrato pintado porque se podem medir simultaneamente dois fenômenos: (1) a deterioração do revestimento orgânico por exposição na solução agressiva e (2) o incremento da velocidade de corrosão do substrato devido à deterioração do revestimento e o subsequente ataque pela solução agressiva. Dessa forma, a impedância eletroquímica pode quantificar valores de resistências e capacitâncias dentro de uma cela eletroquímica, onde a resistência corresponde às reações de transferência de carga tais como a corrosão e a capacitância é um termo elétrico, que contém informação tanto da composição química, como as propriedades 
químicas e de barreira do material do revestimento, e que é de grande importância para qualquer sistema eletroquímico, cujo valor depende de $\epsilon / d$, onde $\epsilon$ é a constante dielétrica e d é a espessura do revestimento (WOLYNEC, 2003; CABRERA; MARIN; GONZÁLEZ, 2007). Quando um revestimento orgânico é submetido a uma solução agressiva, ele se degrada com o tempo, isto origina mudanças no valor da capacitância do revestimento que podem ser medidas pela técnica da espectroscopia de impedância eletroquímica. Estas mudanças são causadas especificamente pela penetração do eletrólito dentro do revestimento, que muda o valor da constante dielétrica $€$ (LOVEDAY; PETERSON; RODGERS, 2004).

Montemor et al. (2012) estudaram o efeito self-healing sobre o aço galvanizado de revestimentos protetores a base de epóxi modificados com hidróxidos duplos lamelares e nanocontainers de molibdato de cério carregados com o inibidor de corrosão 2-mercaptobenzotiazol usando a técnica de espectroscopia de impedância eletroquímica. Os autores fizeram defeitos artificiais de 0,2 $\mathrm{mm}$ executado com o auxílio de um equipamento perfurador nestes revestimentos antes de colocá-los numa solução de $\mathrm{NaCl} 0,05 \mathrm{~mol} / \mathrm{L}$, onde se atingiu só a camada de zinco, mas não a camada do ferro. Segundo os resultados obtidos dos diagramas de impedância, os autores observaram que os revestimentos dopados com hidróxidos duplos lamelares carregados com 2mercaptobenzotiazol (LDH/MBT) não tinham um efeito negativo com relação às propriedades de barreira destes revestimentos protetores. No entanto, a adição de nancontainers de molibdato de cério carregados com 2-mercaptobenzotiazol (CeMo/MBT) induziram uma menor perda das propriedades de barreira com o tempo. Os autores também testaram a mistura destes aditivos (LDH/MBT e $\mathrm{CeMo} / \mathrm{MBT}$ ) resultando num efeito sinérgico de inibição que combina um sistema de proteção ativa da corrosão por um tempo mais longo, para o revestimento.

Koumoulos et al. (2012) estudaram o uso de nanocontainers de cério contendo 2-mercaptobenzotiazol (MBT) como inibidor de corrosão, aditivados num 
revestimento polimérico condutor (CP) feito a base de copolímeros de polipirrol e polianilina coberto com uma camada híbrida de sol-gel na proteção da liga de alumínio AA2024-T3. Os autores utilizaram técnicas como a espectroscopia de impedância eletroquímica e curvas de polarização potenciodinâmicas para avaliar as propriedades de proteção contra a corrosão destes revestimentos, usando para este propósito uma solução agressiva de $\mathrm{NaCl}$ 0,05 mol/L onde os corpos de prova foram imersos por um tempo de 72 horas para os estudos de EIE. Segundo os resultados obtidos nos diagramas de impedância, os autores demonstraram que a incorporação de nanocontainers de cério carregados com 2mercaptobenzotiazol na camada polimérica do filme condutor conduziu a um aumento das propriedades anticorrosivas do sistema devido ao incremento do valor da impedância total.

Kartsonakis et al. (2012) estudaram o comportamento frente à corrosão de um revestimento epóxi tratado com e sem nanocontainers de molibdato de cério carregados com o inibidor de corrosão 2-mercaptobenzotiazol depositados sobre o aço galvanizado usando a técnica de espectroscopia de impedância eletroquímica. Para um melhor estudo do comportamento da corrosão, os autores fizeram defeitos artificiais de $1,0 \mathrm{~mm}$ sobre estes revestimentos, expondo-os a seguir numa solução de $\mathrm{NaCl} 0,05 \mathrm{~mol} / \mathrm{L}$. Segundo os diagramas de impedância obtidos os autores concluíram que para aqueles revestimentos dopados diretamente com inibidor e revestimentos contendo uma determinada porcentagem em massa de nanocontainers sem inibidor (coat- $4 \%$ nc e coat10\%nc) não exibiram propriedades de recuperação depois da formação dos defeitos artificiais e exposição ao meio corrosivo. No entanto, para os revestimentos sem inibidor e contendo $10 \% \mathrm{~m} / \mathrm{m}$ de nanocontainers carregados com inibidor apresentaram uma recuperação parcial da área danificada depois da imersão em solução de $\mathrm{NaCl}$ 0,05 mol/L.

Balaskas et al. (2012) estudaram a influência de revestimentos epoxi dopados com nanocontainers a base de $\mathrm{TiO}_{2}$ contendo o inbidor 8-hidroxiquinolina 
e depositados sobre a liga de alumino AA2024. A avaliação destes revestimentos foi feita usando a técnica de espectroscopia de impedância eletroquímica, onde os valores da impedância totais foram medidos em função do tempo de exposição numa solução agressiva de $\mathrm{NaCl} 0,05 \mathrm{~mol} / \mathrm{L}$. Os revestimentos testados neste estudo foram um revestimento epóxi (sem nanocontainers ou inibidor), outro revestimento epóxi contendo o inibidor e finalmente um revestimento contendo os nanocontainers carregados com o inibidor. Os ensaios eletroquímicos revelaram que a adição de nanocontainers contendo inibidor fornece um impacto benéfico sobre a resistência do revestimento epóxi, já que os valores de impedância em baixas freqüências aumentam $e$ as propriedades de barreira são comparativamente superiores às do revestimento de epóxi sem inibidor.

Zheludkevich et al. (2010) fizeram um estudo sobre o efeito na proteção da corrosão de primers contendo nanocontainers feitos a base de hidróxidos duplos lamelares (Zn-Al e Mg-Al) carregados com inibidores de corrosão. As medidas de impedância eletroquímica de corpos de prova de alumínio AA2024 revestidos foram realizadas numa solução agressiva de $\mathrm{NaCl} 0,05 \mathrm{~mol} / \mathrm{L}$ durante um tempo de imersão de duas semanas. Baseando-se nos resultados obtidos dos testes eletroquímicos de espectroscopia de impedância eletroquímica, os autores concluíram que a adição destes nanocontainers sobre um primer comercial usado para aplicações aeronáuticas conduz a uma significativa melhora na proteção contra a corrosão, fornecendo um efeito de proteção ativa adicional.

Dias et al. (2012) usaram a técnica de impedância eletroquímica para avaliar o desempenho da proteção contra a corrosão de um novo sistema que consistia de um revestimento híbrido sol-gel aditivado com nanocontainers feitos a base de zeólita e carregados com íons de cério (III). Para a realização dos ensaios de impedância foram executados defeitos sobre as chapas de alumínio AA2024 revestidas com: 1) camada de sol-gel; 2) camada de sol-gel modificada com nitrato de cério e 3) camada de sol-gel contendo nanocontainers de zeólita carregados com íons de cério (III), onde para as três condições as amostras foram 
imersas numa solução de $0,3 \%$ de $\mathrm{NaCl}$ por um período de duas semanas. Os autores demonstraram que o revestimento sol-gel contendo nanocontainers de zeólita carregados com íons de cério apresentou uma melhora no desempenho de proteção contra a corrosão em comparação com os outros revestimentos. Os autores explicaram que este comportamento é devido à liberação dos íons $\mathrm{Ce}^{3+}$ desde a estrutura da zeólita em $\mathrm{pH}$ ácido. Onde este abaixamento do $\mathrm{pH}$ em áreas locais poderia ser originado devido a hidrólises dos cátions do metal produzidos pela corrosão do substrato.

Tavandashti e Sanjabi (2010) investigaram o efeito da presença de nanopartículas de boemita carregadas com nitrato de cério como inibidor de corrosão sobre um revestimento híbrido a base de epóxi e sílica. O desempenho na proteção contra a corrosão e processo de liberação dos inibidores contidos dentro dos nanocontaners foi acompanhado por períodos de longos de imersão numa solução de $3 \%$ de $\mathrm{NaCl}$ e usando a técnica de impedância eletroquímica. Os autores concluíram que a introdução de nanopartículas de boemita carregadas com inibidor de corrosão melhorou significativamente as propriedades de proteção contra a corrosão, já que eles observaram o aparecimento de uma camada de óxido produzida pela deposição de óxido e hidróxidos de cério (III) os quais bloqueiam as áreas afetadas e reduzem a velocidade de corrosão.

\subsubsection{Técnica de varredura com eletrodo vibratório - SVET}

Atualmente técnicas modernas utilizam procedimentos rápidos no processamento de dados com o objetivo de fazer medições em tempo real e em diferentes tipos de superfícies. Técnicas eletroquímicas de varredura com alta resolução espacial permitem fazer medidas in situ fornecendo informação valiosa sobre o comportamento de um processo de corrosão em nível microscópico. Uma delas é a técnica de varredura com eletrodo vibratório (SVET), a qual permite00000 obter mapas de densidades de corrente iônica sobre amostras de metal corroendo livremente ou sob polarização. Com esta técnica de SVET, as 
variações com o tempo durante uma corrosão localizada podem ser avaliadas sem alterar o andamento da corrosão. Portanto, SVET e outras técnicas de varredura fornecem medidas úteis para estudar inibidores de corrosão (SIMOES et al., 2007), corrosão localizada, revestimentos, interfaces e contornos de grãos, partículas de fase secundária, corrosão sob fadiga e corrosão microbiológica (DA SILVA, 2009).

\subsubsection{Principio de operação - SVET}

Durante a corrosão localizada de um metal é gerada uma separação espacial das áreas anódicas e catódicas, a qual conduz a pequenas variações no potencial e geração de um fluxo iônico dentro do eletrólito. Este fluxo iônico gera uma corrente iônica e um campo de potencial é distribuído acima dos sítios ativos de corrosão (Fig. 2.20), onde h é a distância desde o ponto de origem até o ponto médio das duas linhas equipotenciais. Desta forma, a técnica de varredura com eletrodo vibratório usa um microeletrodo fino acima da amostra, o qual é capaz de medir estes gradientes de potencial entre os pontos de vibração, permitindo assim fazer um estudo in situ da corrosão. A resolução das medidas é determinada pelo diâmetro do eletrodo usado, o qual varia tipicamente entre $20 \mu \mathrm{m}$ e $200 \mu \mathrm{m}$. Na Figura 2.21 mostram-se os diferentes resultados obtidos de acordo com as intensidades de corrente na região anódica (AKID; GARMA, 2004).

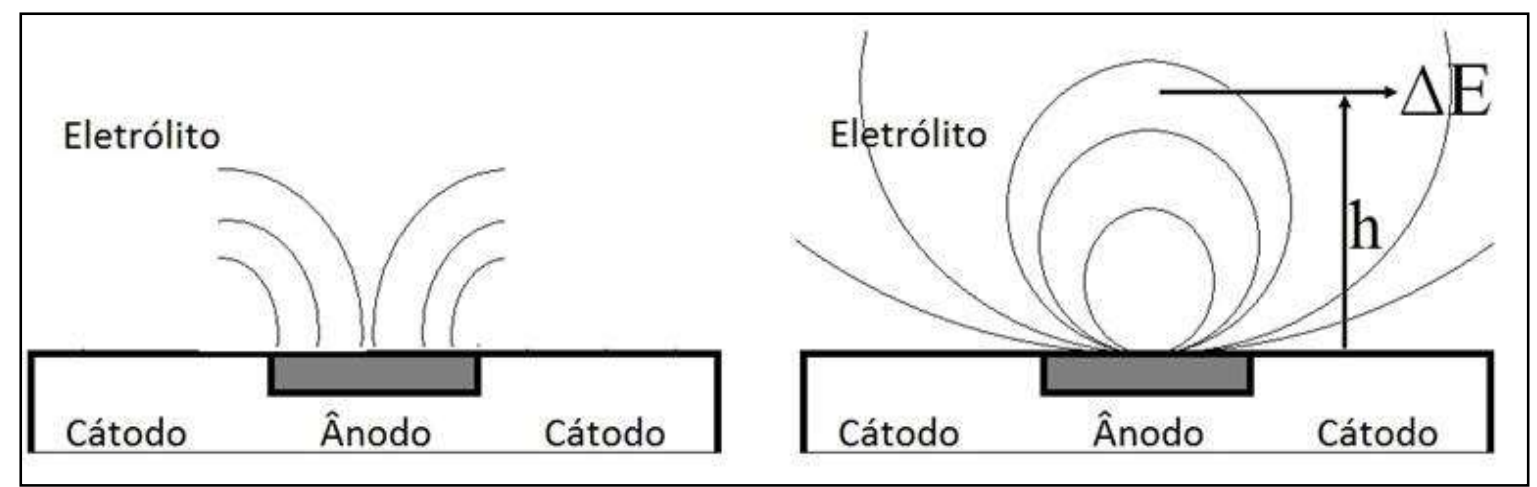

Figura 2.20 - Diagrama esquemático do (a) fluxo iônico gerado pelas regiões anódicas e (b) as respectivas correntes em diferença de potencial geradas (AKID; GARMA, 2004). 

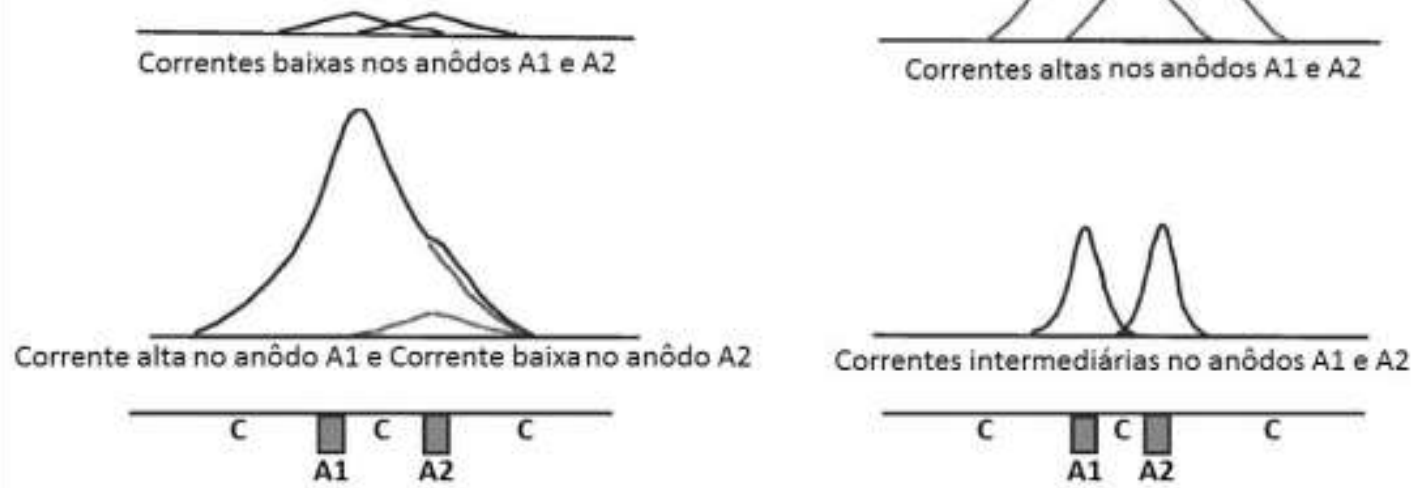

Figura 2.21 - Diferentes tipos de resposta em função das intensidades de correntes detectadas pela SVET (AKID; GARMA, 2004).

Na Figura 2.22 é mostrado um diagrama esquemático do SVET. Este modelo incorpora um amplificador lock-in que retifica o sinal AC usando filtros de frequência eletrônica que convertem a corrente contínua em corrente alternada, com uma frequência igual à da vibração do eletrodo, a qual é analisada num amplificador que aceita só o sinal proveniente da frequência de vibração do microeletrodo. Conseguindo-se assim eliminar o ruído não desejado e aumentar a sensibilidade da técnica, possibilitando assim detectar variações de intensidade de corrente da ordem de nanoampere (VIEIRA, 2010).

No SVET, a sonda pode ser movimentada verticalmente ou horizontalmente, em relação à superfície de uma amostra para medir os componentes do campo ou em ambas as direções, simultaneamente, para medir o vetor bi-dimensional (DA SILVA, 2010). 


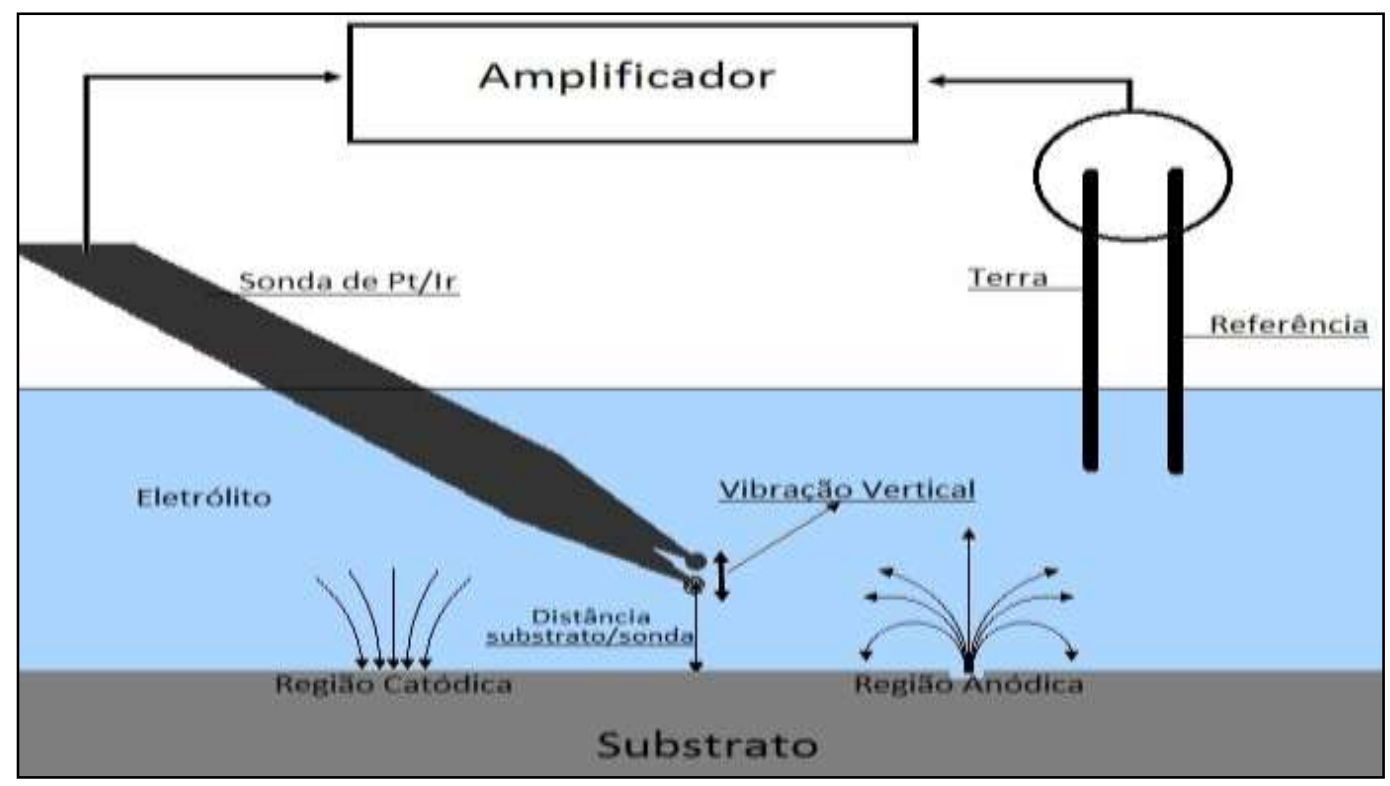

Figura 2.22 - Esquema de funcionamento da SVET.

Abdullayev et al. (2009) usaram a técnica de varredura do eletrodo vibratório para medir as intensidades de corrente locais ao longo da superfície da liga de alumínio AA2024 revestido com uma camada fina de sol-gel com e sem nanocontainers a base de haloisita e submerso numa solução de $\mathrm{NaCl} 0,05 \mathrm{~mol} / \mathrm{L}$ para diferentes tempos de imersão. Antes de acompanhar as medidas por SVET com o tempo, fizeram-se defeitos artificiais sobre a superfície de ambos os tipos de revestimentos depois de $24 \mathrm{~h}$ de imersão na solução de $\mathrm{NaCl}$ 0,05 mol/L, onde os autores observaram que para $24 \mathrm{~h}$ de imersão o defeito no revestimento de solgel dopado com nanocontainers começou a se passivar e ficou intacto até depois de $48 \mathrm{~h}$ em comparação com aquele revestimento sem nanocontainers que ficou atacado no local do defeito. Dessa forma, os autores confirmaram o efeito selfhealing deste tipo de revestimento, onde o mecanismo de liberação foi provocado por uma mudança de $\mathrm{pH}$, a qual originou a liberação do inibidor de dentro dos nanocontainers.

Fix et al. (2009) obtiveram mapas de densidade de corrente via SVET de uma liga de alumínio AA2024 revestida nas seguintes condições: a) com uma 
camada pura de sol-gel, b) com uma camada sol-gel contendo nanotubos de haloisita sem inibidor, c) com uma camada de sol-gel contendo nanotubos de haloisita carregados com o inibidor de corrosão benzotriazol e d) com uma camada de sol-gel contendo nanotubos de haloisita carregados com o inibidor de corrosão 8-hidroxiquinolina. Os tempos de imersão em solução de $\mathrm{NaCl}$ $0,05 \mathrm{~mol} / \mathrm{L}$ foram de $4,5 \mathrm{~h}$ e $10 \mathrm{~h}$, onde as amostras foram danificadas com uma ferramenta pontiaguda a fim de acelerar o processo de corrosão. Os autores conseguiram comprovar o efeito de inibição do benzotriazol e da 8-hidroxiquinolina na proteção contra a corrosão da liga de alumínio, onde para ambos os casos obtiveram-se densidades de corrente anódicas bem baixas em comparação com aquelas obtidas para as chapas de alumínio revestidas com apenas sol-gel. Para o caso do benzotriazol, seu efeito inibidor é baseado na formação de complexos insolúveis de cobre, os quais formam uma camada espessa estável sobre a superfície do alumínio (principalmente sobre os intermetálicos $\mathrm{Al}_{2} \mathrm{Cu}$ ) e forma uma barreira física adicional contra o meio agressivo. A 8-hidroxiquinolina fornece também uma barreira física contra o meio agressivo, mas ela não é tão estável em comparação com aquela formada pelo benzotriazol. Os autores explicaram que esta menor eficiência da 8-hidroxiquinolina é causada pela sua alta carga dentro dos nanotubos de haloisita $(17 \% \mathrm{~m} / \mathrm{m})$, o que possivelmente provocou uma desestabilização da matriz sol-gel, fazendo que as correntes anódicas não ficassem constantes durante o tempo de imersão na solução de $\mathrm{NaCl}$ 0,05 mol/L.

Andreeva, Skorb e Shchukin (2010) investigaram a proteção contra a corrosão de uma liga de alumínio quando esta foi revestida por três diferentes sistemas de multicamadas de polieletrólitos usando a técnica de varredura com eletrodo vibratório, o primeiro sistema foi formado por dois polieletrólitos fortes (polidialildimetilamonia (PDADMAC) e poliestireno sulfonado (PSS)), o segundo por um polieletrólito forte e outro fraco (poliestireno sulfonado (PSS) e polietilenoimina $(\mathrm{PEI})$ ), e o último formado por dois polieletrólitos de caráter fraco (polietilenoimina (PEI) e + ácido poliacrilico (PAA)). Os autores determinaram que para o segundo caso, onde as multicamadas foram formadas por um polieletrólito 
forte e outro fraco, as correntes anódicas e catódicas registradas no SVET foram bem menores em comparação com aquelas obtidas para os outros dois sistemas. Eles explicaram que estas multicamadas formadas por um polieletrólito forte e outro débil, as quais são comumente usadas na formação de filmes finos, apresentam propriedades que são mais fáceis de controlar através de ajustes no $\mathrm{pH}$. No entanto, para o caso das camadas formadas por polieletrólitos fortes, elas apresentam densidade de carga muito alta, produzindo assim uma interação muito forte entre eles e sendo difícil a influência do $\mathrm{pH}$ no sistema, o qual resulta mais complicada a saída do inibidor de corrosão do nanocontainer. Para o caso das multicamadas formadas por polieletrólitos de caráter fraco, elas apresentam um grau de expansão muito grande incrementando a permeabilidade do revestimento.

Borisova, Möhwald e Shchukin (2011a) estudaram a resistência à corrosão de uma liga de alumínio revestida com uma camada híbrida de sol-gel contendo nanopartículas de sílica mesoporosa carregadas com os inibidores de corrosão benzotriazol através de um processo de corrosão monitorado via SVET, onde amostras foram imersas numa solução corrosiva de $\mathrm{NaCl} 0,05 \mathrm{~mol} / \mathrm{L}$ por um tempo de $10 \mathrm{~h}$. Para um melhor estudo da corrosão, defeitos artificiais foram feitos nas camadas de sol-gel a fim de induzir e acelerar o processo de corrosão. Os revestimentos estudados foram os seguintes: a) camada de sol-gel pura, b) camada sol-gel contendo o inibidor benzotriazol e c) camada de sol-gel contendo nanopartículas de sílica mesoporosa carregadas com benzotriazol. Segundo os mapas de densidades de corrente obtidos os autores concluíram que para o caso dos revestimentos contendo as nanopartículas de sílica carregadas com inibidor, as correntes anódicas e catódicas foram bastante baixas em comparação com os outros revestimentos. Os autores explicaram que este efeito é baseado na formação de um filme denso adsorvido sobre a superfície do metal que atua como barreira física ao meio agressivo.

Mas tarde, Borisova, Möhwald e Shchukin (2012b) usaram também nanopartículas de sílica carregadas o inibidor de corrosão 2-mercaptobenzotiazol 
para avaliar o efeito da concentração destas (NPs-inib) na camada de sol-gel, onde os autores encontraram que a incorporação destes NPs-inib nem sempre é favorável no desempenho do revestimento contra a corrosão. Ou seja, em baixas concentrações $(0,04 \% \mathrm{~m} / \mathrm{m})$ se tem boas propriedades de barreira, mas não há uma inibição ativa da corrosão devido a uma baixa quantidade de inibidor disponível, já para concentrações maiores $(0,8 \% \mathrm{~m} / \mathrm{m}-1,7 \% \mathrm{~m} / \mathrm{m})$ há uma deterioração do revestimento pela formação de defeitos que servem como caminhos de difusão para a entrada de espécies agressivas. Para uma concentração de $0,7 \% \mathrm{~m} / \mathrm{m}$ de NPs-inib foi encontrado uma maior resistência à corrosão o qual foi mostrado por técnicas de EIS e SVET.

\section{MATERIAIS E MÉTODOS}

\subsection{Materiais}

Para os ensaios realizados neste estudo foram utilizadas chapas de aço carbono ABNT 1020.

Soluções de ácido clorídrico $(\mathrm{HCl})$ 0,1 mol/L e hidróxido de sódio $(\mathrm{NaOH})$ $1 \mathrm{~mol} / \mathrm{L}$ foram preparadas para ajustar os $\mathrm{pHs}$ dos eletrólitos.

Para a preparação dos nanocontainers a base de nanopartículas de sílica $\left(\mathrm{SiO}_{2}\right)$ foi usado uma sílica coloidal LUDOX TM-40 (suspensão $40 \% \mathrm{~m} / \mathrm{m} \mathrm{SiO}$ em $\mathrm{H}_{2} \mathrm{O}$ ) fornecida pela Sigma-Aldrich, cujo diâmetro de partícula médio é 8,6 \pm $1,3 \mathrm{~nm}$.

Foi necessário também o uso de centrifuga da marca JOUAN modelo MR 18.12 do Laboratório de Bioquímica e Processos do Departamento de Engenharia Química, a qual serviu para separar o excesso de polieletrólito e inibidor usados nas diferentes etapas da preparação dos nanocontainers.

Para a preparação dos nanocontainers a base de nanotubos de haloisita foi usado uma argilomineral haloisita fornecida pela Sigma Aldrich de diâmetro $30 \mathrm{~nm}$ e área superficial de $64 \mathrm{~m}^{2} / \mathrm{g}$. 
Os polieletrólitos polietilenoimina, PEI (peso molecular 2000) e poliestirenosulfonado, PSS (peso molecular 70000) foram também adquiridos da Sigma-Aldrich. Estes polieletrólitos foram escolhidos tendo como base os diferentes trabalhos descritos na literatura [38, 39, 53, 119, 133].

Para a preparação da sílica mesoporosa do tipo SBA-15 foram necessários os seguintes reagentes: Surfactante BASF® Pluronic P123 (PE $\left.{ }_{20} \mathrm{PO}_{70} \mathrm{PE}_{20}\right)$, TEOS (tetraetoxisilano) como fonte de silício e ácido clorídrico $37 \%$ ( $\mathrm{HCl})$.

$\mathrm{O}$ inibidor de corrosão usado foi a dodecilamina $\mathrm{CH}_{3}\left(\mathrm{CH}_{2}\right){ }_{11} \mathrm{NH}_{2}$ com grau de pureza $\geq 99 \%$ da Sigma-Aldrich.

Para a preparação da solução do inibidor de corrosão $(10 \mathrm{mg} / \mathrm{mL})$ foi dissolvido $1 \mathrm{~g}$ de dodecilamina utilizando $0,2 \mathrm{~mL}$ de ácido acético concentrado e completando um volume de $100 \mathrm{~mL}$ com uma solução de cloreto de sódio $(\mathrm{NaCl})$ $0,1 \mathrm{~mol} / \mathrm{L}$.

Os eletrólitos usados para os ensaios de impedância eletroquímica foram uma solução de cloreto de sódio $(\mathrm{NaCl}) 0,1 \mathrm{~mol} / \mathrm{L}$ com diferentes valores de $\mathrm{pH}(6,2,2$ e 9), onde foram adicionadas diversas concentrações do inibidor dodecilamina.

Foi preparada também uma solução de cloreto de sódio $(\mathrm{NaCl})$ 0,01 mol/L e 0,05 mol/L para os ensaios de varredura com eletrodo vibratório (SVET), uma solução de $(\mathrm{NaCl})$ 0,5 mol/L utilizada para a deposição das camadas de PSS e uma solução de PVA (álcool polivinilico) $1 \% \mathrm{~m} / \mathrm{m}$ como dispersante dos nanocontainers.

As tintas alquídicas utilizadas para pintar os corpos de prova foram: Admiral Primer 581, Tinta grafite coral e Metalatex, todas elas da Sherwin-Willians.

\subsection{Preparo dos corpos de prova}

Os corpos de prova utilizados para os ensaios eletroquímicos foram chapas de aço carbono ABNT 1020, com geometria de face quadrangular e dimensões de $3 \mathrm{~cm} \times 3 \mathrm{~cm} \times 0,8 \mathrm{~cm}$. Para a limpeza dos corpos de prova foi feito um lixamento usando lixas de granas 320, 400 e 600 para a remoção de produtos de corrosão, 
seguido de uma lavagem com água destilada, álcool e acetona, para logo serem secos com um jato de ar quente.

Para os ensaios acelerados de corrosão em câmara de névoa salina foram usadas chapas de aço carbono lixadas com dimensões de $15 \mathrm{~cm}$ x $10 \mathrm{~cm} \times$ $0,1 \mathrm{~cm}$ e chapas de aço carbono jateadas com grau de acabamento AS 3 (metal branco) e perfil de rugosidade entre $60 \mu \mathrm{m}-80 \mu \mathrm{m}$ com dimensões de $15 \mathrm{~cm} \times$ $10 \mathrm{~cm} \times 0,4 \mathrm{~cm}$. Para os ensaios de SVET ou técnica de varredura do eletrodo vibratório foram usadas chapas lixadas, as quais foram cortadas em forma quadrangular nas dimensões de $1,0 \mathrm{~cm} \times 1,0 \mathrm{~cm}$.

\subsection{Preparo do inibidor de corrosão para encapsulamento}

Para ter a dodecilamina em solução aquosa de cloreto de sódio na concentração de $10 \mathrm{mg} / \mathrm{mL}$ ela foi previamente dissolvida $(1 \mathrm{~g})$ em $0,2 \mathrm{~mL}$ de ácido acético concentrado, o qual foi ligeiramente aquecido para agilizar a dissolução da amina; em seguida esta solução foi adicionada com agitação constante a uma solução de cloreto de sódio ( $\mathrm{NaCl})$ 0,1 mol/L com pH 6,2.

\subsection{Preparo dos nanorreservatórios ou nanocontainers}

3.4.1 Nanorreservatórios feitos à base de nanoparticulas de sílica $\left(\mathrm{SiO}_{2}\right)$

Para a preparação dos nanocontainers foram misturados $20 \mathrm{~mL}$ de uma suspensão coloidal de nanopartículas de $\mathrm{SiO}_{2}$ com $12 \mathrm{~mL}$ de uma solução de $0,5 \mathrm{mg} / \mathrm{mL}$ de PEI por um tempo de $15 \mathrm{~min}$. Em seguida a amostra de $\mathrm{SiO}_{2} / \mathrm{PEI}$ foi lavada três vezes com água destilada e centrifugada. Para a deposição da camada negativa de PSS (poli-estireno-sulfonado) foram necessários $20 \mathrm{~mL}$ de uma solução de $0,3 \mathrm{mg} / \mathrm{mL}$ de PSS. Esta adição foi feita sobre a amostra de $\mathrm{SiO}_{2} / \mathrm{PEI}$ previamente dispersa em solução de $0,5 \mathrm{~mol} / \mathrm{L}$ de $\mathrm{NaCl}$ usando um banho de ultrassom por um tempo de $30 \mathrm{~min}$. Para a deposição da terceira 
camada de inibidor, a amostra já formada de $\mathrm{SiO}_{2} / \mathrm{PEI} / \mathrm{PSS}$ foi também dispersa em solução de $0,5 \mathrm{~mol} / \mathrm{L}$ de $\mathrm{NaCl}$ com o auxílio do ultrassom por 30 min para diminuir o diâmetro de partícula e aumentar a área de contato com as moléculas do inibidor. Para isto foram usados $30 \mathrm{~mL}$ de uma solução acida $(\mathrm{pH}=3)$ de inibidor com concentração de $10 \mathrm{mg} / \mathrm{mL}$ para que ela pudesse se juntar à camada negativa do PSS. Estas duas últimas etapas de deposição (PSS e o inibidor) foram repetidas mais uma vez para garantir uma alta carga do inibidor na estrutura final do nanocontainer, onde o sistema resultante teve uma estrutura do tipo $\mathrm{SiO}_{2} / \mathrm{PE} / / \mathrm{PSS} / \mathrm{inib} / \mathrm{PSS} / \mathrm{inib}$.

\subsubsection{Nanorreservatórios feitos à base de nanoparticulas de haloisita}

Antes do carregamento do inibidor, os nanotubos de haloisita foram submetidos a um pré-tratamento com ácido sulfúrico $2 \mathrm{~mol} / \mathrm{L}$ durante um tempo de $6 \mathrm{~h}$ a uma temperatura $55^{\circ} \mathrm{C}$, com o objetivo de incrementar a capacidade do lúmen da haloisita e aumentar a eficiência de carregamento do inibidor, segundo o procedimento encontrado na literatura (ABDULLAYEV et al., 2012).

Para o carregamento dos nanotubos de haloisita com 0 inibidor (dodecilamina) foi usada a técnica descrita na literatura (PRICE; GABER; LVOV, 2001), onde $50 \mathrm{mg}$ de nanotubos de haloisita foram misturados com $6 \mathrm{~mL}$ de uma solução de etanol contendo o inibidor a uma concentração de $10 \mathrm{mg} / \mathrm{mL}$ por um tempo de 15 min sob agitação, logo esta solução foi transferida para um kitassato conectado a uma bomba de vácuo, a qual remove o ar dentro do lúmen (parte interna dos tubos) da haloisita. A solução foi mantida fechada sob vácuo (-500 $\mathrm{mmHg}$ ) por $30 \mathrm{~min}$ até que a distribuição do inibidor atingisse o equilíbrio (cessar o desprendimento de bolhas de ar), o que aumentava a eficiência de carregamento do inibidor nos tubos ocos da haloisita.

Em seguida, os nanotubos de haloisita foram separados da solução mediante centrifugação, lavados três vezes com água deionizada e secos na 
estufa a uma temperatura de $60{ }^{\circ} \mathrm{C}$. Após secagem dos nanotubos de haloisita foi repetido o mesmo procedimento quatro vezes para garantir uma alta carga do inibidor dentro da haloisita.

\subsubsection{Nanorreservatórios feitos à base de partículas de sílica mesoporosa}

Para a preparação das nanopartículas de sílica mesoporosa com arranjo hexagonal foi seguido o procedimento reportado na literatura (MEYNEN; COOL; VANSANT, 2009), onde $4 \mathrm{~g}$ de surfactante Pluronic $\mathrm{P} 123\left(\mathrm{PE}_{20} \mathrm{PO}_{70} \mathrm{PE}_{20}\right)$ foi misturado com $130 \mathrm{ml}$ de $\mathrm{H}_{2} \mathrm{O}$ e $20 \mathrm{ml}$ de $\mathrm{HCl}$ concentrado à temperatura ambiente; agitar até dissolução completa e se for necessário aumentar levemente a temperatura para $30{ }^{\circ} \mathrm{C}$. Em seguida, foi adicionado $9,14 \mathrm{ml}$ de TEOS (tetraetoxisilano) e se agitou mecanicamente a $900 \mathrm{rpm}$ por $7,5 \mathrm{~h}$ a $45^{\circ} \mathrm{C}$. Desligar o agitador e repousar durante $15,5 \mathrm{~h}$ a $80{ }^{\circ} \mathrm{C}$. O produto resultante foi filtrado, lavado com água destilada três vezes e secado em estufa sob vácuo à $60^{\circ} \mathrm{C}$. Em seguida o material foi calcinado a $550^{\circ} \mathrm{C}$ por $6 \mathrm{~h}$ com um aumento de temperatura de $1^{\circ} \mathrm{C} / \mathrm{min}$ sob fluxo de ar para a remoção por queima do surfactante.

Para o carregamento da sílica mesoporosa com o inibidor (dodecilamina) o procedimento foi similar ao utilizado nos nanotubos de haloisita, onde $50 \mathrm{mg}$ de sílica mesoporosa foram misturados com $6 \mathrm{~mL}$ de solução de etanol contendo o inibidor a uma concentração de $10 \mathrm{mg} / \mathrm{mL}$ por um tempo de 15 min sob agitação, logo esta solução foi transferida para um kitassato conectado a uma bomba de vácuo, a qual remove o ar dentro dos poros internos da sílica. A solução foi mantida fechada sob vácuo $(-500 \mathrm{mmHg})$ por $30 \mathrm{~min}$ até que a distribuição do inibidor atingisse o equilíbrio.

A Figura 3.1 mostra um fluxograma para preparação dos diferentes tipos de nanocontainers 


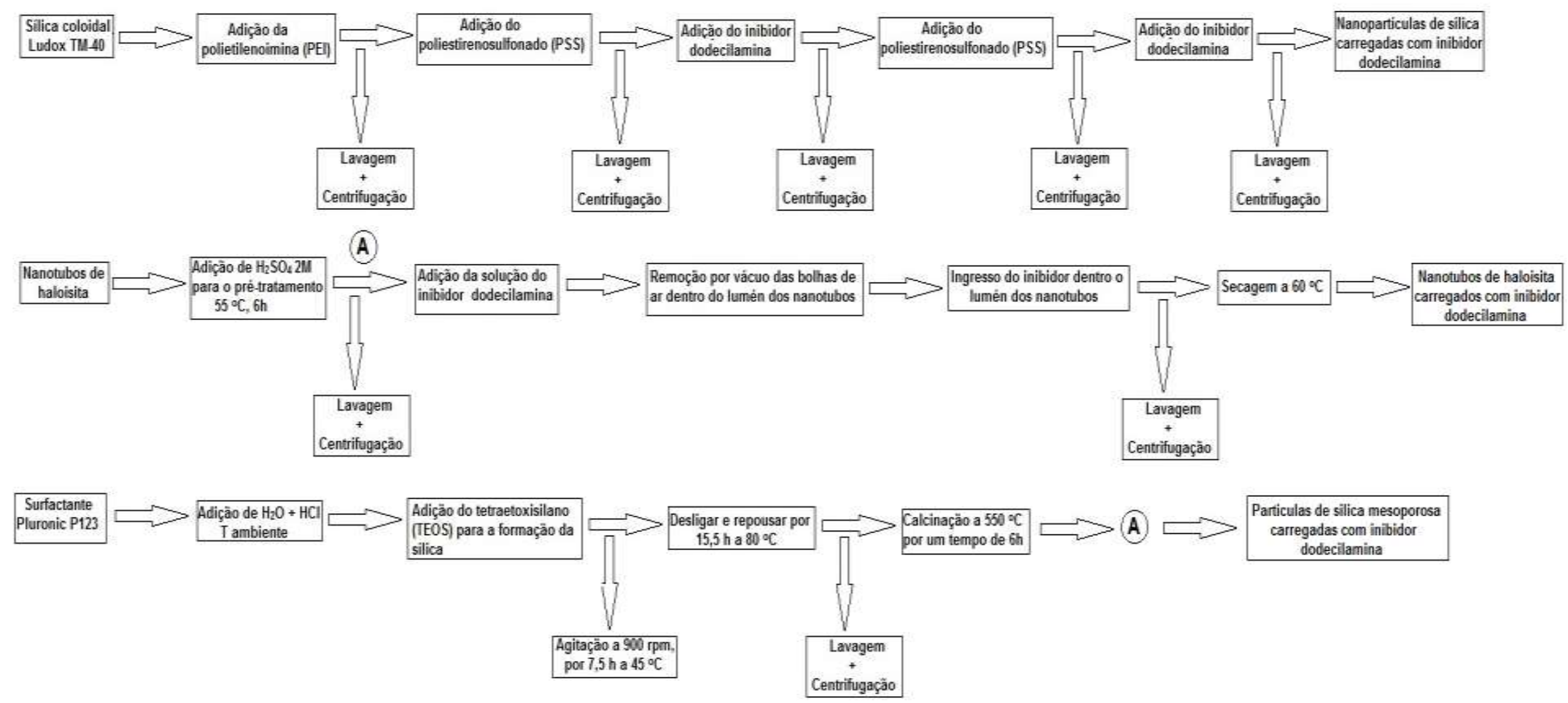

Figura 3.1 - Fluxograma para a obtenção dos diferentes tipos de nanocontainers estudados. 


\subsection{Método de obtenção dos nanocontainers obtidos pelo método Layer-by- Layer com dispersante PVA e método sem dispersante}

Com o objetivo de conseguir nanocontainers bem dispersos foram feitos dois tipos de tratamentos sobre as nanopartículas de sílica na preparação dos nanocontainers. O primeiro procedimento foi realizado dispersando as nanopartículas de sílica em água e sem tratamento em banho ultrassônico entre as diferentes etapas após centrifugação, sendo a secagem final das nanopartículas numa estufa a $60{ }^{\circ} \mathrm{C}$. O segundo procedimento foi realizado dispersando os nanocontainers (nanopartículas de sílica) em $1 \%$ de PVA (álcool polivinilico) e com tratamento em banho ultrassônico por 30 min usando uma freqüência de $25 \mathrm{KHz}$ entre as etapas, sendo a secagem final das nanopartículas feita ao ar.

\subsection{Medidas de potencial zeta e tamanho de partícula}

Para as medidas de potencial zeta e tamanho de partícula foi utilizado o equipamento Zetasizer Nano-ZS90/Malvern Instruments, que baseia-se na técnica LDV (Laser Doppler Velocimetry) para medidas de potencial zeta e DLS (Dynamic Light Scattering) para medidas de tamanho de partícula. Para cada etapa de deposição do polieletrólito, 0,1 gramas da suspensão formada era dispersa em 10 gramas de água deionizada e agitada com uma sonda de ultrassom de alta potência $(750 \mathrm{~W})$ durante 30 segundos a $40 \%$ de amplitude. Para essas suspensões foi utilizado um valor baixo de amplitude e um tempo curto no ultrassom para evitar o aquecimento, já que a quantidade de amostra era pequena. $O$ potencial zeta, $\zeta$, foi calculado a partir das medidas de mobilidade eletroforética, $\mu_{\mathrm{E}}$, pelo emprego da Equação 3.1 de Smoluchowski, a saber:

$$
\zeta=\frac{\mu E \eta}{\varepsilon_{0} \varepsilon_{\mathrm{r}}}
$$


Onde $\varepsilon_{0}$ é a permissividade do vácuo, $\varepsilon_{r}$ é a permissividade dielétrica relativa do meio (constante dielétrica) e $\eta$ é a viscosidade da fase dispersora.

\subsection{Análise termogravimétrica (TGA)}

As curvas termogravimétricas foram obtidas em um equipamento da marca Mettler Toledo, modelo TGA/DSC1. Nas análises foram utilizados aproximadamente $5 \mathrm{mg}$ de material colocado em um cadinho de alumina, sendo as amostras submetidas a aquecimento de uma temperatura de $30{ }^{\circ} \mathrm{C}$ até $600{ }^{\circ} \mathrm{C}$, com uma razão de aquecimento de $10 \mathrm{~K} / \mathrm{min}$, numa atmosfera de $\mathrm{N}_{2}$ dinâmica e controlada com fluxo de $50 \mathrm{~mL} \cdot \mathrm{min}^{-1}$.

\subsection{Caracterização por difração de raios-X}

Para determinar a estrutura cristalina de materiais mesoporosos foi usado um método analítico baseado no uso de raios- $\mathrm{X}$. O método do pó tem sido o mais utilizado para a obtenção dos difratogramas para estruturas mesoporosas com arranjo hexagonal e poder verificar se houve aparecimento de estrutura hexagonal mesoporosa ordenada. Os ensaios de difração de raios- $X$ foram realizados usando uma radiação de $\mathrm{Ka}$ de $\mathrm{Cu}$, com tensão acelerada de $40 \mathrm{kV}$ e corrente de $40 \mathrm{~mA}$, com varredura de $0,96^{\circ}$ a $80^{\circ}$ para $2 \theta$ e tamanho de passo de $0,02^{\circ}$. As medidas foram feitas no difratômetro de marca Panalytical modelo X'Pert com detector X'Celerator do Laboratório de Caracterização Tecnológica do Departamento de Engenharia de Minas da Escola Politécnica da USP.

\subsection{Adsorção e dessorção de $\mathrm{N}_{2}$}

O cálculo da área superficial da sílica mesoporosa foi feito através da adsorção de $\mathrm{N}_{2}$ a $77 \mathrm{~K}$ usando o método BET em um equipamento da Quantachrome modelo NOVA-2000. Antes de cada análise cerca de $500 \mathrm{mg}$ de 
amostra, previamente calcinada, foi pré-tratada a $200{ }^{\circ} \mathrm{C}$ sob vácuo por 3 horas. Este tratamento tem por finalidade remover a umidade da superfície do sólido. As isotermas de adsorção para as amostras foram obtidas na faixa de $P / P_{\circ} 0,1$ a 0,9 onde é possível obter algumas informações como área superficial e volume poroso. As isotermas de adsorção e dessorção foram obtidas numa faixa de P/Po 0,05 a 0,98 . Os dados com relação ao volume de gás adsorvido em função da pressão parcial foram correlacionados por modelos matemáticos para o cálculo da área superficial (BRUNAUER; EMMETT; TELLER, 1938), volume e distribuição de poros (BARRETT; JOIYNER; HALENDA, 1953).

\subsection{Microscopia eletrônica de transmissão (MET)}

As imagens foram obtidas no Instituto de Pesquisas Energéticas e Nucleares (IPEN) da Universidade de São Paulo. A microscopia eletrônica da sílica mesoporosa sintetizada foi feita usando um equipamento da marca JEOL-2011, modelo JEM2100 operando a uma voltagem de aceleração de $200 \mathrm{kV}$. As amostras foram preparadas dispersando uma pequena porção do pó em isopropanol. Após a dispersão, um filme fino desta solução foi depositado sobre uma grade de $\mathrm{Cu}$ recoberta com collodium.

\subsection{Caracterização morfológica dos nanocontainers por microscopia ótica}

A caracterização da morfologia dos nanocontainers foi realizada por um microscópio ótico da marca Olympus modelo BX60M e com o auxílio do software Motic Images Plus 2.0ML.

As imagens foram obtidas no Laboratório de Eletroquímica e Corrosão (LEC) do Departamento de Engenharia Química da USP. 
3.12 Caracterização morfológica dos nanocontainers por microscopia eletrônica de varredura (MEV)

A obtenção das imagens por MEV ocorreu no Laboratório do Grupo de Pesquisa em Eletroquímica da Universidade Estadual do Centro-Oeste em Guarapuava - São Paulo usando um equipamento da marca TESCAN modelo VEGA 3 LMU comercializado pela Shimadzu.

\subsection{Caracterização morfológica dos nanocontainers por microscopia eletrônica de varredura por emissão de campo (MEV-FEG)}

As imagens por MEV-FEG foram obtidas na Central Analítica do Instituto de Química da Universidade de São Paulo. Esta caracterização foi realizada no Laboratório de Microscopia Eletrônica da Central Analítica do IQUSP usando um equipamento da marca JEOL, modelo JSM-7401 F.

\subsection{Preparo dos revestimentos aditivados com nanocontainers de sílica contendo dodecilamina obtidos pelo método Layer-by-Layer}

O revestimento aplicado sobre as chapas de aço carbono foi primeiramente feito misturando a tinta alquídica pura (Admilral primer 581 ) $(35 \% \mathrm{~m} / \mathrm{m}$ de solvente na tinta) com $15 \% \mathrm{~m} / \mathrm{m}$ do diluente águarrás. Após ter a tinta diluída foram adicionados os nanocontainers a base de nanopartículas de sílica $\left(\mathrm{SiO}_{2}\right)$ carregados com inibidor dodecilamina nas proporções de $10 \% \mathrm{~m} / \mathrm{m}$ e $15 \% \mathrm{~m} / \mathrm{m}$ em relação à tinta diluída ou em base úmida. Isso significa que após a secagem da tinta, a percentagem de partículas é muito maior tomando por base a tinta seca e nesse caso as percentagens foram de $16,7 \% \mathrm{~m} / \mathrm{m}$ e $24,2 \% \mathrm{~m} / \mathrm{m}$, respectivamente. 


\subsection{Preparo dos revestimentos aditivados com nanocontainers de haloisita contendo dodecilamina}

Para este caso, o revestimento foi preparado misturando a tinta alquídica pura (Admilral primer 581) ( $35 \% \mathrm{~m} / \mathrm{m}$ de solvente na tinta) com $15 \% \mathrm{~m} / \mathrm{m}$ do diluente águarrás. Na tinta já diluída foram adicionados os nanocontainers a base de haloisita carregados com inibidor dodecilamina nas proporções de $10 \% \mathrm{~m} / \mathrm{m}$ em relação à tinta diluída ou base úmida o que resulta em $16,7 \% \mathrm{~m} / \mathrm{m}$ em base seca.

\subsection{Preparo dos revestimentos aditivados com nanocontainers de sílica mesoporosa}

Neste caso a preparação do revestimento seguiu o mesmo procedimento usado para os revestimentos anteriores, onde a tinta alquídica foi misturada só com $15 \% \mathrm{~m} / \mathrm{m}$ do diluente águarrás. Em seguida foram adicionados os nanocontainers a base de sílica mesoporosa carregados com inibidor dodecilamina nas proporções de $15 \% \mathrm{~m} / \mathrm{m}$ em base úmida o que resulta em $24,2 \% \mathrm{~m} / \mathrm{m}$ em base seca.

Foi escolhido a tinta alquídica porque ela é menos resistente em comparação com outras tintas como a epóxi, além disso, foi possível avaliar o efeito de inibição da dodecilamina em um intervalo de tempo bastante curto. Durante todos ensaios foram usados vários lotes de tinta alquídica com cores diferentes (cinza clara, cinza escura e branca) já que a tinta envelhecia e originava problemas de aderência.

\subsection{Preparo dos corpos de prova para a aplicação dos revestimentos contendo nanocontainers}

No caso das chapas de aço carbono jateadas, este jateamento foi realizado no Laboratório de Corrosão do Instituto de Pesquisas Tecnológicas do Estado de 
São Paulo, usando microesferas de vidro até conseguir o grau de acabamento SA 3 (metal branco) com perfil de rugosidade de $60 \mu \mathrm{m}-80 \mu \mathrm{m}$. No caso das chapas não jateadas foi feito um lixamento com lixas de SiC de granas 320, 400 e 600, e posterior lavagem com água destilada, álcool e acetona. Essas chapas serão referidas como chapas lixadas.

\subsection{Ensaios eletroquímicos}

Os ensaios eletroquímicos foram divididos em duas partes, a primeira onde se faz uso da técnica de impedância eletroquímica (EIE) para estudar a cinética de liberação do inibidor dodecilamina encapsulado dentro dos nanocontainers e também avaliar o desempenho destes nanocontainers quando forem aditivados em tintas aplicadas sobre os corpos de prova. Na segunda parte, o uso de técnica de varredura com eletrodo vibratório (SVET) foi para investigar a degradação de corpos de prova pintados quando eles são expostos a uma solução de $\mathrm{NaCl}$ e na presença de um defeito provocado. Para caso dos corpos de prova aditivados com nanopartículas de sílica e haloisita a concentração de $\mathrm{NaCl}$ usada foi de $0,01 \mathrm{~mol} / \mathrm{L}$. Já para os corpos de prova aditivados com partículas de sílica mesoporosa a concentração de $\mathrm{NaCl}$ foi de $0,05 \mathrm{~mol} / \mathrm{L}$. Para os ensaios eletroquímicos foi utilizada uma célula típica de três eletrodos, onde os eletrodos de referência e contra-eletrodo foram de $\mathrm{Ag} / \mathrm{AgCl} / \mathrm{KCl}$ sat e uma chapa de platina de grande área, respectivamente. O equipamento utilizado na avaliação de corpos de prova revestidos foi um potenciostato/galvanostato/ZRA Gamry Reference 600 controlado pelo software Gamry Framework. Para avaliação do inibidor foi utilizado um potenciostato PAR 273 A acoplado a um analisador de frequências Solartron 1255B.

3.18.1 Medidas de espectroscopia de impedância eletroquímica, EIE

As medidas de espectroscopia de impedância eletroquímica (EIE) foram realizadas em potencial de circuito aberto, após estabilização do mesmo na 
solução de $\mathrm{NaCl}$ 0,1 mol/L com ou sem cápsulas após tempos crescentes de contato dos nanocontainers com a solução agressiva. $O$ equipamento utilizado foi um potenciostato/galvanostato/ZRA Gamry Reference 600 controlado pelo software Gamry Framework e usando uma perturbação senoidal de potencial de amplitude $10 \mathrm{mV}$ rms e uma faixa de frequências de $50 \mathrm{kHz}$ a $5 \mathrm{mHz}$ com 10 medidas por década de frequência.

3.18.2 Medidas com o eletrodo vibratório, SVET

Para realizar as medidas de SVET, as chapas de aço carbono (jateadas e lixadas) revestidas com a tinta alquídica e aditivadas com nanocontainers (10\% $\mathrm{m} / \mathrm{m}$ e $15 \% \mathrm{~m} / \mathrm{m}$ em base úmida) carregadas com inibidor dodecilamina foram cortadas nas dimensões $1 \mathrm{~cm} \times 1 \mathrm{~cm}$. Estas medidas foram feitas utilizando o equipamento da Applicable Electronics controlado pelo software ASET (Sciencewares). O eletrodo vibratório era de platina-iridio coberto com polímero, ficando apenas uma ponta descoberta com diâmetro de $40 \mu \mathrm{m}$ - $50 \mu \mathrm{m}$. A distância da ponta à superfície foi mantida em $100 \mu \mathrm{m}$ e a área de varredura foi de $3 \mathrm{~mm} \times 4 \mathrm{~mm}$.

Para avaliar a resistência à corrosão do aço carbono revestido com as tintas aditivadas, foi executado um defeito artificial sobre a superfície da amostra pintada utilizando uma ferramenta pontiaguda segunda mostrado na Figura 3.2.

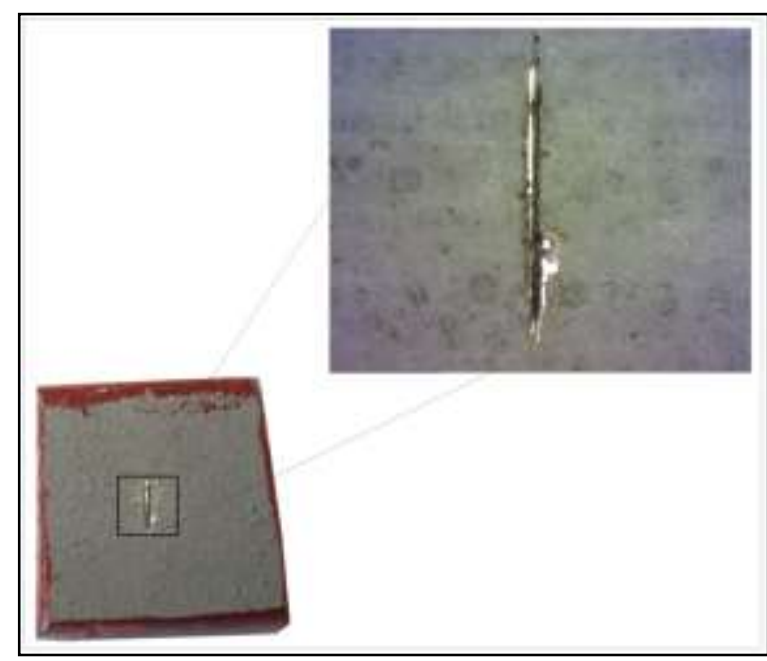

Figura 3.2 - Imagem ilustrativa do defeito artificial feito sobre a amostra pintada para a realização dos ensaios de SVET. 
A solução de imersão utilizada para o caso dos corpos prova pintados e aditivados com nanoparticulas de sílica $\left(\mathrm{SiO}_{2}\right)$ ou nanotubos de haloisita foi de $\mathrm{NaCl}$ 0,01 mol/L. No caso dos corpos de prova pintados e aditivados com sílica mesoporosa a solução usada foi de $\mathrm{NaCl} 0,05 \mathrm{~mol} / \mathrm{L}$.

\subsection{Uso de uma sonda para análise na região do infravermelho para detectar a saída do inibidor dodecilamina dos nanocontainers obtidos pelo método Layer-by-Layer}

Para detectar a saída do inibidor de corrosão a partir dos nanocontainers foi feito um estudo em tempo real usando uma sonda para detecção e análise da dodecilamina na região do infravermelho médio. Estas medidas foram feitas usando o equipamento Easymax da Mettler Toledo mostrado na Figura 3.3, o qual possui uma sonda ReactIR 15 que permite monitorar reações químicas em tempo real, utilizando interação entre a radiação na região do infravermelho e as moléculas participantes das reações. A sonda do ReactIR foi inserida diretamente numa solução de $\mathrm{NaCl}$ 0,1 mol/L com pH 2 contendo os nanocontainers (nanopartículas de sílica) carregadas com inibidor de corrosão. O monitoramento e análise foi realizado durante aproximadamente $6 \mathrm{~h}$ a $25{ }^{\circ} \mathrm{C}$ sob agitação magnética de 100 rpm utilizando uma barra magnética.

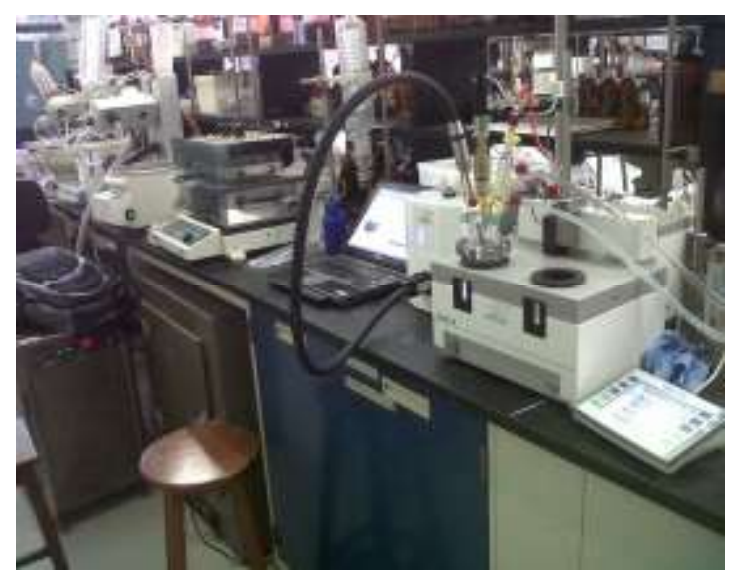

Figura 3.3 - Foto ilustrativa do reator Easymax integrado com a sonda de infravermelho. 


\subsection{Obtenção de corpos de prova pintados com tinta aditivada contendo os diferentes tipos de nanocontainers estudados carregados com inibidor de corrosão dodecilamina}

Para os três tipos de nanocontainers estudados a tinta foi aplicada com a ajuda de um pincel sobre os corpos de prova lixados (com lixas de $\mathrm{SiC}$ de granas

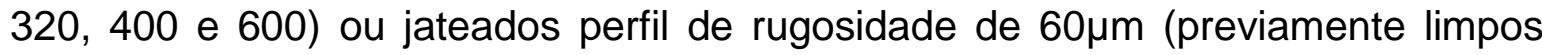
com álcool e acetona) até obter uma espessura úmida (controlada com um pente calibrado) de aproximadamente $127 \mu \mathrm{m}$ em cada demão. Foram preparados aproximadamente 50 gramas de tinta alquídica contendo nanocontainers para pintar 8 corpos de prova com primeira demão e 50 gramas mais de tinta sem nancontainers para a aplicação de uma segunda demão. As medidas de espessuras úmidas e secas para as diferentes demãos aplicadas sobre os corpos de prova usando os diferentes tipos de nanocontainers são apresentadas nas Tabelas 3.1, 3.2 e 3.3. Essas medidas de espessura seca foram feitas com o medidor de espessura marca FISHER, modelo DualScope ${ }^{\circledR}$ MP40. As medidas de espessura úmida foram feitas com um pente calibrado.

Tabela 3.1- Medidas das espessuras das camadas em base seca e úmida para os corpos de prova revestidos usando nanocontainers a base de sílica $\left(\mathrm{SiO}_{2}\right) \mathrm{L}-\mathrm{b}-\mathrm{L}$.

\begin{tabular}{|c|c|c|c|}
\hline & \multicolumn{2}{|c|}{$\begin{array}{c}\text { Espessura da camada em base úmida } \\
\text { (Medição feita com um pente calibrado) }\end{array}$} & $\begin{array}{c}\text { Espessura final da } \\
\text { camada em base } \\
\text { seca }\end{array}$ \\
\hline$\% \mathrm{~m} / \mathrm{m}$ de NC & $\begin{array}{c}1^{\text {a }} \text {. demão com } \\
\text { nanocontainers }\end{array}$ & $\begin{array}{c}2^{\mathrm{a}} \text {. demão sem } \\
\text { nanocontainers }\end{array}$ & \\
\hline $0 \%$ & $127 \mu \mathrm{m}$ & $127 \mu \mathrm{m}$ & $99 \mu \mathrm{m} \pm 4,6 \mu \mathrm{m}$ \\
\hline $10 \%$ & $127 \mu \mathrm{m}$ & $127 \mu \mathrm{m}$ & $102 \mu \mathrm{m} \pm 5,7 \mu \mathrm{m}$ \\
\hline $15 \%$ & $127 \mu \mathrm{m}$ & $127 \mu \mathrm{m}$ & $105 \mu \mathrm{m} \pm 6,2 \mu \mathrm{m}$ \\
\hline
\end{tabular}


Tabela 3.2 - Medidas das espessuras das camadas em base seca e úmida para os corpos de prova revestidos usando nanocontainers a base de nanotubos de haloisita.

\begin{tabular}{|c|c|c|c|}
\hline & \multicolumn{2}{|c|}{$\begin{array}{c}\text { Espessura da camada em base úmida } \\
\text { (Medição feita com um pente calibrado) }\end{array}$} & $\begin{array}{c}\text { Espessura final da } \\
\text { camada em base } \\
\text { seca }\end{array}$ \\
\hline$\% \mathrm{~m} / \mathrm{m}$ de NC & $\begin{array}{c}1^{\text {a }} \text {. demão com } \\
\text { nanocontainers }\end{array}$ & $\begin{array}{c}2^{\text {a }} \text {. demão sem } \\
\text { nanocontainers }\end{array}$ & \\
\hline $0 \%$ & $127 \mu \mathrm{m}$ & $127 \mu \mathrm{m}$ & $93,7 \mu \mathrm{m} \pm 3,8 \mu \mathrm{m}$ \\
\hline $10 \%$ & $127 \mu \mathrm{m}$ & $127 \mu \mathrm{m}$ & $98,8 \mu \mathrm{m} \pm 3,4 \mu \mathrm{m}$ \\
\hline
\end{tabular}

Tabela 3.3 - Medidas das espessuras das camadas em base seca e úmida para os corpos de prova revestidos usando nanocontainers a base de sílica mesoporosa.

\begin{tabular}{|c|c|c|c|}
\hline & \multicolumn{2}{|c|}{$\begin{array}{c}\text { Espessura da camada em base úmida } \\
\text { (Medição feita com um pente calibrado) }\end{array}$} & $\begin{array}{c}\text { Espessura final da } \\
\text { camada em base } \\
\text { seca }\end{array}$ \\
\hline$\% \mathrm{~m} / \mathrm{m}$ de NC & $\begin{array}{c}1^{\text {a }} \text {. demão com } \\
\text { nanocontainers }\end{array}$ & $\begin{array}{c}2^{\mathrm{a}} \text {. demão sem } \\
\text { nanocontainers }\end{array}$ & \\
\hline $0 \%$ & $127 \mu \mathrm{m}$ & $127 \mu \mathrm{m}$ & $135 \mu \mathrm{m} \pm 4,2 \mu \mathrm{m}$ \\
\hline $15 \%$ & $127 \mu \mathrm{m}$ & $127 \mu \mathrm{m}$ & $143 \mu \mathrm{m} \pm 5,3 \mu \mathrm{m}$ \\
\hline
\end{tabular}

Do total de corpos de prova pintados uns foram colocados na câmara de névoa salina (3 para cada condição) e outros serviram para os ensaios de impedância eletroquímica e SVET. Os corpos de prova pintados foram secados ao ar durante 72 horas para a cura da tinta.

\subsection{Ensaios acelerados de corrosão em câmara de névoa salina}

A realização dos ensaios de névoa salina seguiu a norma ASTM B117 (50 g/L NaCl, $35^{\circ} \mathrm{C}, \mathrm{pH}$ da solução entre 6,5 e 7,2), e foram feitos defeitos artificiais sobre os corpos de prova pintados com duas demãos de tinta usando como ferramenta um estilete. $O$ equipamento para exposição em névoa salina utilizado foi da marca BASS, modelo USC-ISSO-(PLUS) do Laboratório de 
Química Tecnológica Geral do Departamento de Engenharia Química da USP. A Figura 3.4 ilustra a disposição dos corpos de prova dentro da câmara de névoa salina antes do início dos ensaios. Foram colocados três corpos de prova para cada condição ensaiada.

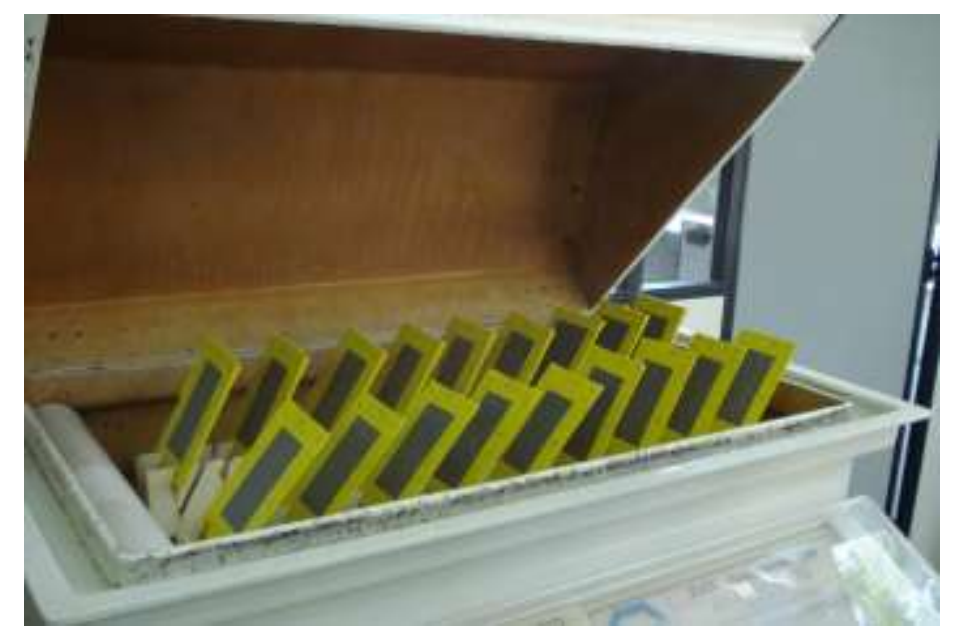

Figura 3.4 - Foto ilustrativa dos corpos de prova dentro da câmara de névoa salina e com as bordas protegidas com fita adesiva.

\section{RESULTADOS E DISCUSSÕES}

Neste capítulo serão apresentados os resultados obtidos do estudo de inibição de corrosão pela dodecilamina, da cinética de liberação do inibidor a partir dos nanocontainers, da análise e monitoramento da saída do inibidor por espectroscopia vibracional na região do infravermelho e por espectroscopia de impedância eletroquímica, e das técnicas de impedância eletroquímica (EIE) e varredura com eletrodo vibratório (SVET) para verificação do efeito de autorreparação das tintas aditivadas com os nanocontainers contendo a dodecilamina como inibidor de corrosão. Assim como também a caracterização superficial e morfológica dos nanocontainers por microscopia ótica, microscopia eletrônica de varredura e microscopia por transmissão. 


\subsection{Curvas de tafel do inibidor dodecilamina sobre aço carbono}

A Figura 4.1 apresenta as curvas de Tafel para o aço carbono imerso numa solução de $\mathrm{NaCl}$ 0,1 mol/L sem inibidor e contendo 400 ppm do inibidor dodecilamina. Nesta figura é possível observar que quando é adicionado o inibidor dodecilamina tanto a curva anódica e catódica são polarizadas em relação aquela obtida na ausência de inibidor, além disso, o potencial de corrosão do aço muda para valores mais positivos. Isto indica que a dodecilamina age como um inibidor tipo misto, já que atua reduzindo as reações anódicas e catódicas. Baseando-se nesses resultados nos podemos utilizar o inibidor dodecilamina para a diminuir a intensidade dos processos corrosivos nas áreas anódicas.

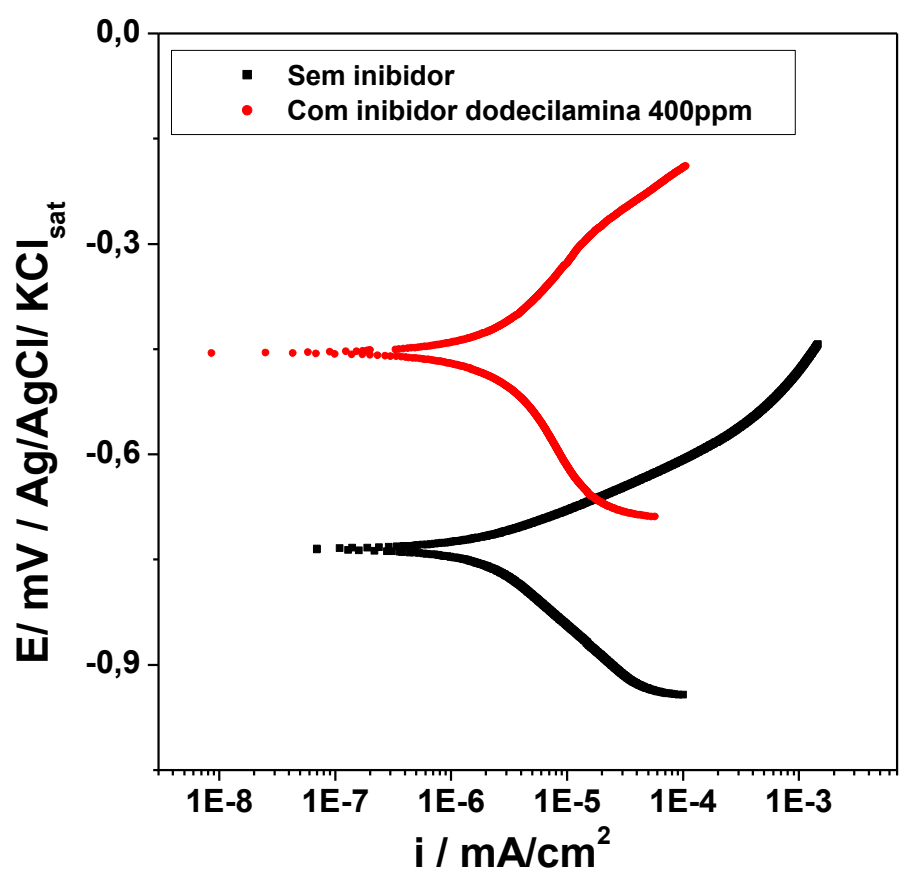

Figura 4.1 - Curvas de Tafel para o aço carbono imerso numa solução de $\mathrm{NaCl} 0,1 \mathrm{~mol} / \mathrm{L}$ a pH 6.2 sem inibidor e contendo $400 \mathrm{ppm}$ do inibidor dodecilamina. 


\subsection{Caracterização da dodecilamina como inibidor de corrosão para aço carbono em meio neutro e em meio ácido}

Nas Figuras 4.2 e 4.3 são apresentados os resultados de impedância obtidos para o aço carbono quando submetido a uma solução de $\mathrm{NaCl} 0,1 \mathrm{~mol} / \mathrm{L}$ sem inibidor e contendo diferentes concentrações do inibidor dodecilamina em diferentes condições de $\mathrm{pH}$. Nos diagramas de Nyquist e Bode pode-se observar que o diâmetro do arco capacitivo e ângulo de fase para ambas as condições de $\mathrm{pH}(6,2$ e 2,0) aumenta à medida que as concentrações do inibidor dodecilamina vai aumentando na solução, onde a concentração máxima estudada foi de 400 ppm. Este efeito de inibição desta amina pode ser explicado pela formação de um filme adsorvido protetor sobre a superfície do aço carbono ABNT 1020 originado pela adsorção de moléculas da dodecilamina sobre o aço (BRAUN; LOPEZ; VOLLMER, 1993; SZAUER; BRANDT, 1981; BASTIDAS; POLO; CANO, 2000; SRHIRI; ETMAN; DABOSI, 1996; BASTIDAS et al., 2000; BASTIDAS; DAMBORENEA; VÁZQUEZ, 1997; DAMBORENEA; BASTIDAS; VAZQUEZ, 1997), isolando dessa forma a superfície do substrato das espécies agressivas.
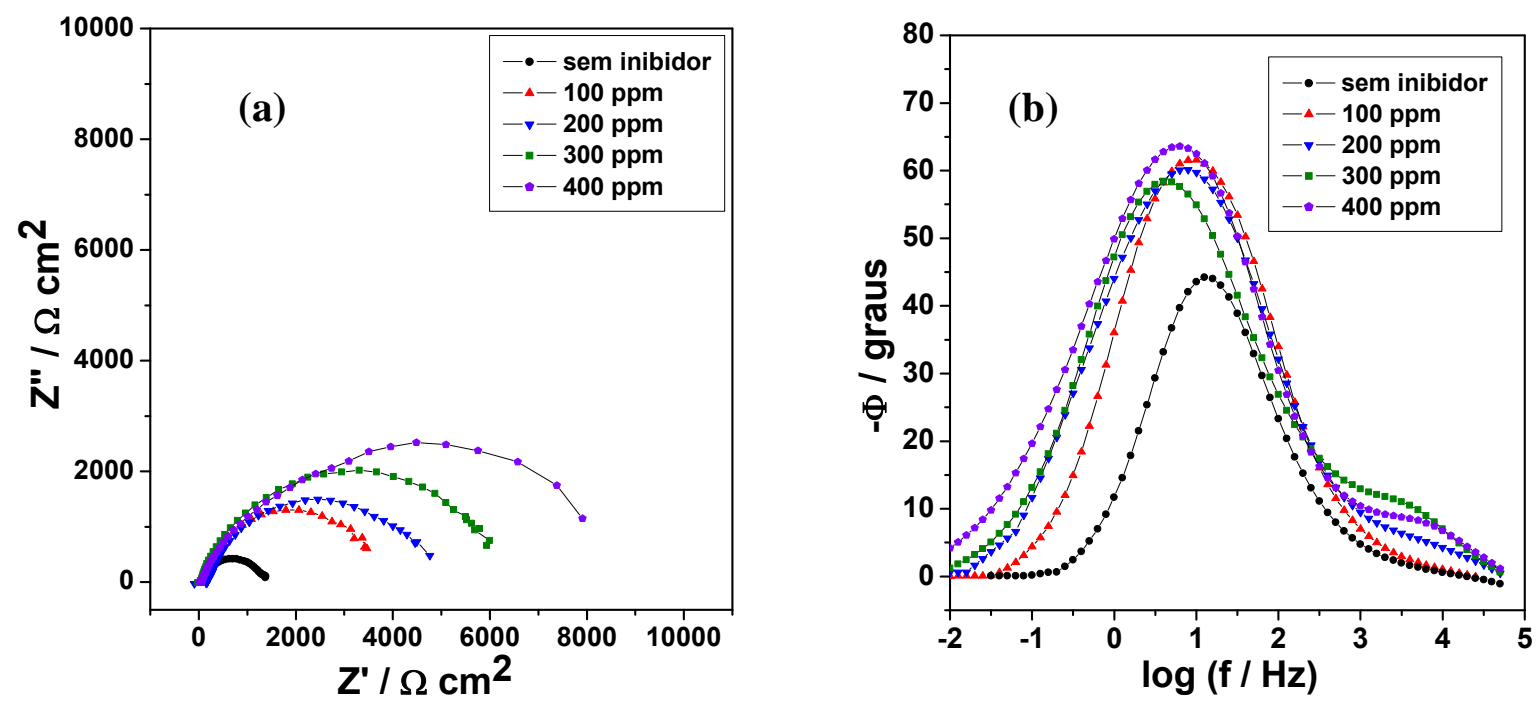

Figura 4.2 - Diagramas de Nyquist (a) e de Bode (b) obtidos para o aço carbono quando foi imerso durante $1 \mathrm{~h}$ numa solução de $\mathrm{NaCl} 0,1 \mathrm{~mol} / \mathrm{L}$ a $\mathrm{pH} 6.2$ sem inibidor e contendo diferentes concentrações do inibidor dodecilamina. 

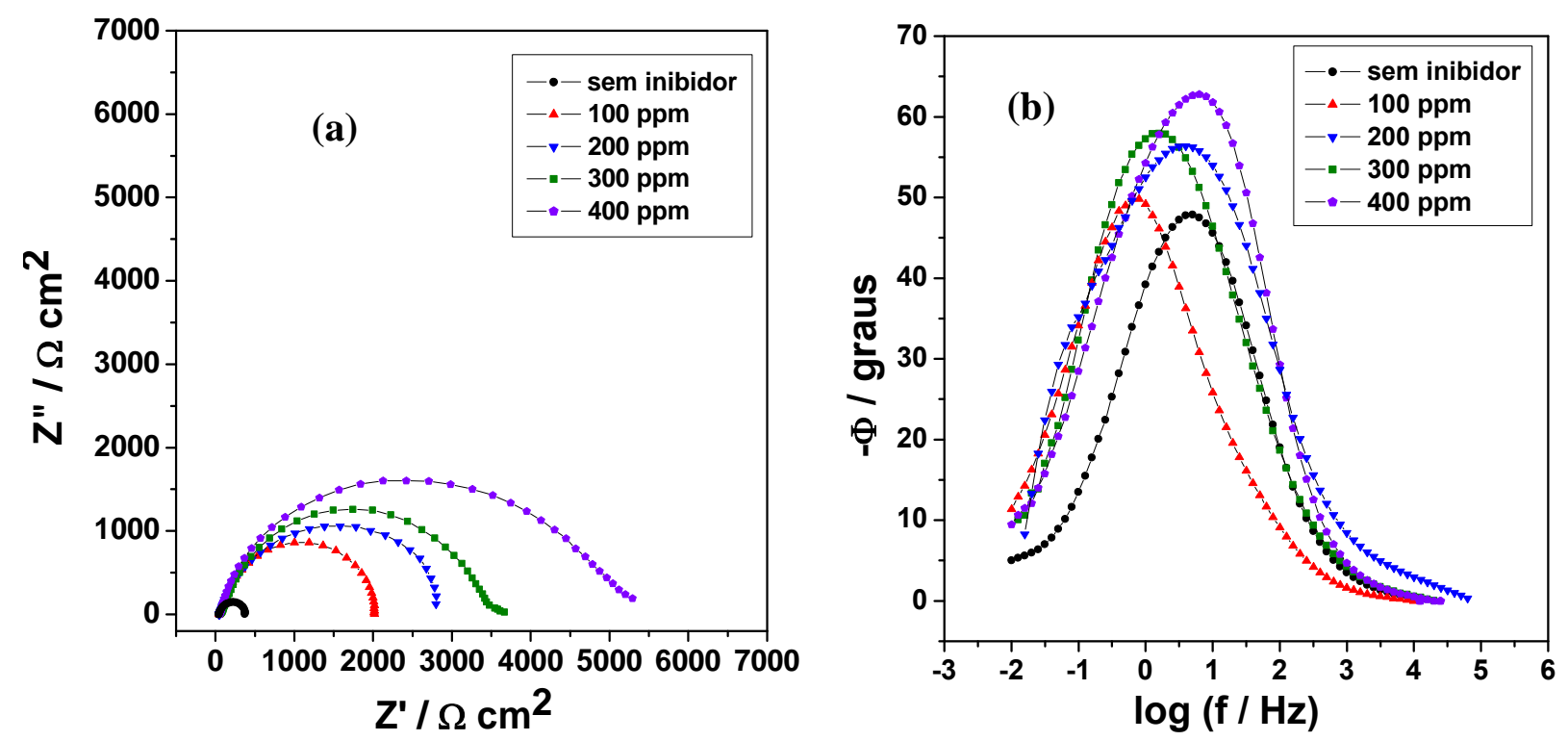

Figura 4.3 - Diagramas de Nyquist (a) e de Bode (b) obtidos para o aço carbono quando foi imerso durante $1 \mathrm{~h}$ numa solução de $\mathrm{NaCl} 0,1 \mathrm{~mol} / \mathrm{L}$ a pH 2 sem inibidor e contendo diferentes concentrações do inibidor dodecilamina.

Para determinar a eficiência de inibição do inibidor dodecilamina para a condições de pH 6,2 e 2,0 a partir dos resultados obtidos da impedância eletroquímica, foi utilizada a Equação 4.1:

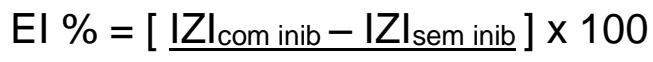

Equação 4.1

$\mid Z I_{\text {com inib }}$

Onde:

IZI com inib é o valor do módulo de impedância obtido a $31,5 \mathrm{mHz}$ para o aço carbono imerso na solução de $\mathrm{NaCl}$ contendo o inibidor dodecilamina.

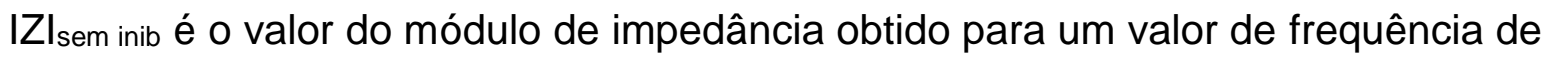
$31,5 \mathrm{mHz}$ do aço carbono imerso na solução $\mathrm{NaCl}$ sem inibidor.

El é a eficiência do inibidor. 
Considera-se um valor de frequência de $31,5 \mathrm{mHz}$, já que para valores em muitas baixas frequências tem-se normalmente valores de impedância muito dispersos e além disso, a frequência de $31,5 \mathrm{mHz}$ ainda é considerada baixa, permitindo que se detectem os fenômenos de troca de carga na interface metal/solução. Dessa forma não se pode comparar diretamente os valores de módulos de impedâncias nessa frequência com o parãmetro Rp, pois este, só seria comparável ao módulo de impedãncia obtido nas mais baixas frequências, como $5 \mathrm{mHz}$, por exemplo.

As Tabelas 4.1 e 4.2 apresentam os resultados de eficiência de inibição obtidos para as duas condições de pH estudadas (2 e 6,2). Os resultados de $\mathrm{EI}$ indicam claramente que a condição de pH 2,0 aumenta a eficiência do inibidor dodecilamina, o qual demonstra a efetividade de inibição contra a corrosão das aminas em meio ácido. A eficiência aqui calculada para $\mathrm{pH} 2$ é próxima daquela calculada por outros autores na literatura (ELACHOURI et al., 1995; MERNARI et al., 1998; BASTIDAS et al., 2000; BASTIDAS; POLO; CANO, 2000).

Tabela 4.1 - Valores de eficiência de inibição da dodecilamina para aço carbono em $\mathrm{NaCl} 0,1 \mathrm{~mol} / \mathrm{L}$ em pH 6,2 calculada a partir dos diagramas de impedância.

\begin{tabular}{|c|c|c|c|}
\hline $\begin{array}{c}\text { Concentração do } \\
\text { inibidor dodecilamina } \\
(\mathrm{ppm})\end{array}$ & $\begin{array}{c}\text { IZIcom inib } \\
(31,5 \mathrm{mHz})\end{array}$ & EI (\%) & $\begin{array}{c}\text { Desvio padrão } \\
(\mathrm{EI})\end{array}$ \\
\hline 0 & 1288 & - & - \\
\hline 100 & 3311 & 61,1 & 0,21 \\
\hline 200 & 3630 & 64,5 & 0,28 \\
\hline 300 & 5248 & 75,4 & 0,14 \\
\hline 400 & 6166 & 79,1 & 0,14 \\
\hline
\end{tabular}


Tabela 4.2 - Valores de eficiência de inibição da dodecilamina para aço carbono em $\mathrm{NaCl}$ 0,1 $\mathrm{mol} / \mathrm{L}$ em $\mathrm{pH} 2,0$ calculada a partir dos diagramas de impedância.

\begin{tabular}{|c|c|c|c|}
\hline $\begin{array}{c}\text { Concentração do } \\
\text { inibidor dodecilamina } \\
(\mathrm{ppm})\end{array}$ & $\begin{array}{c}\mathrm{IZ} \text { (com inib } \\
(31,5 \mathrm{mHz})\end{array}$ & El (\%) & $\begin{array}{c}\text { Desvio padrão } \\
(\mathrm{EI})\end{array}$ \\
\hline 0 & 380 & - & - \\
\hline 100 & 2042 & 81,4 & 0,24 \\
\hline 200 & 2818 & 86,5 & 0,27 \\
\hline 300 & 3388 & 88,8 & 0,16 \\
\hline 400 & 4677 & 91,8 & 0,15 \\
\hline
\end{tabular}

Aminas primárias são ambientalmente amigáveis como inibidores de corrosão e estão atraindo a atenção como alternativas para a substituição dos cromatos (ANDREEVA et al., 2008). A atividade inibidora das aminas tem sido já estudada sobre o aço carbono por outros autores (SAEED; ALI; RAHMAN, 2003; ASHASSI - SORKHABI; NABAVI - AMRI, 2002; BADIEA; KIKKERI, 2009; SRHIRI; ETMAN; DABOSI, 1996; AYERS; HACKERMAN, 1962).

\subsection{Caraterização morfológica e estrutural dos diferentes tipos de nanocontainers estudados}

Os diferentes tipos de nanocontainers estudados foram caracterizados pelas técnicas de microscopia ótica, microscopia eletrônica de varredura e microscopia eletrônica de transmissão. Potencial zeta e tamanho de partícula foi feito especificamente para as nanoparticulas de sílica ( $L-b-L)$, já para o caso dos nanocontainers a base de sílica mesoporosa foram usadas análises por difração de raios- $\mathrm{X}$, termogravimétria (TGA), calorimetria de varredura diferencial (DSC) e adsorção e dessorção de nitrogênio $\left(\mathrm{N}_{2}\right)$. 
4.3.1 Nanocontainers feitos à base de nanopartículas de sílica

\subsubsection{Microscopia ótica (MO)}

A Figura 4.4 ilustra a imagem por microscopia ótica das nanopartículas de sílica coloidal Ludox TM-40 revestidas com as diferentes camadas de polieletrólitos (PEI e PSS) e inibidor (dodecilamina) usando o método de deposição Layer-by-Layer ( $L-b-L)$, onde é possível observar uma geometria não muito bem definida e uma distribuição de tamanho bem variada das partículas devido à aglomeração ocorrida durante a etapa de secagem. O diâmetro médio destas partículas de sílica ficou em torno de $1 \mu \mathrm{m}-2 \mu \mathrm{m}$.

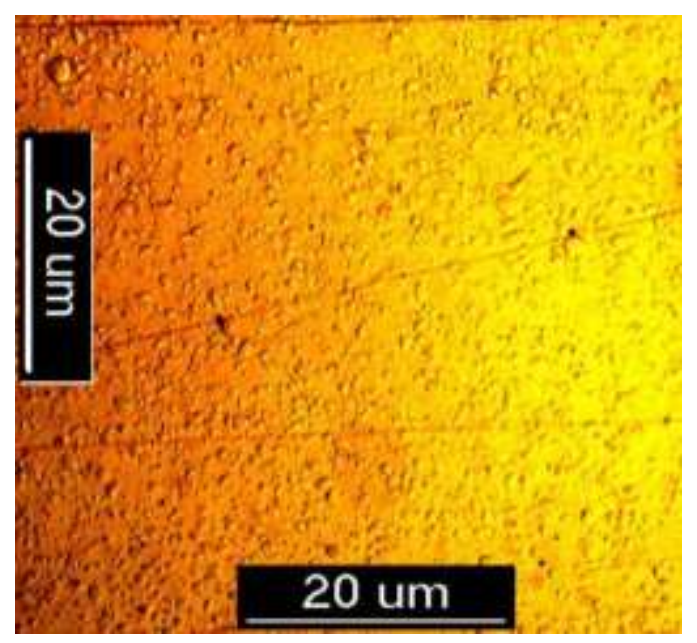

Figura 4.4 - Imagens por MO das nanopartículas de sílica (L-b-L) contendo o inibidor dodecilamina.

\subsubsection{Potencial zeta e tamanho de partícula}

A Figura 4.4 representa as medidas de potencial zeta obtido para as diferentes camadas de polieletrólitos (PEI e PSS) e inibidor depositadas sobre as nanopartículas de sílica. 

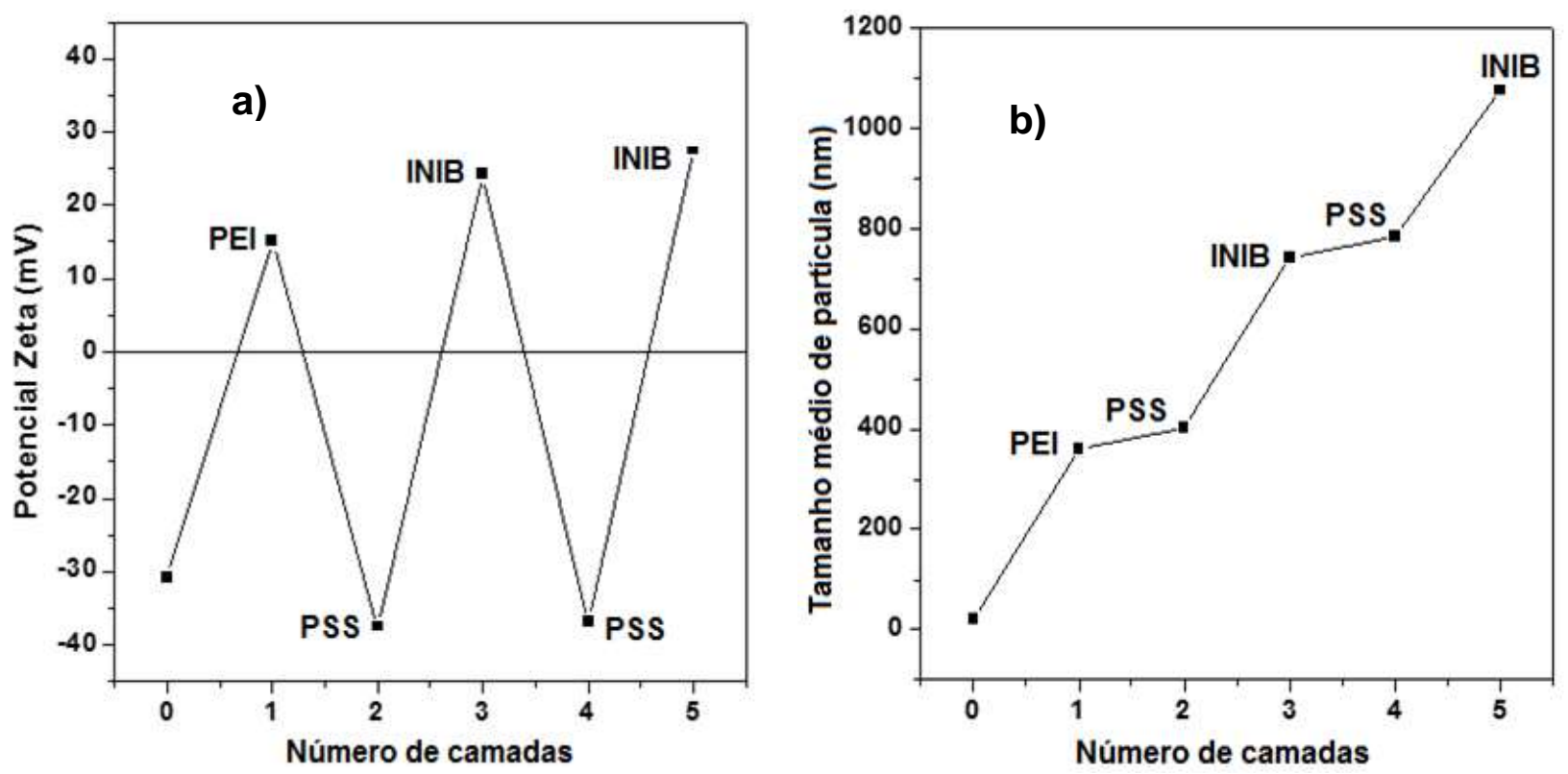

Figura 4.5 - (a) Medidas de potencial zeta dos nanocontainers: número de camadas de 0 , nanopartículas de $\mathrm{SiO}_{2}$ iniciais; 1, $\mathrm{SiO}_{2} / \mathrm{PEI} ; 2, \quad \mathrm{SiO}_{2} / \mathrm{PEI} / \mathrm{PSS} ; \quad 3$, $\mathrm{SiO}_{2} / \mathrm{PEI} / \mathrm{PSS} /$ dodecilamina; 4, $\mathrm{SiO}_{2} / \mathrm{PEI} / \mathrm{PSS} /$ dodecilamina/PSS; 5, $\mathrm{SiO}_{2} / \mathrm{PEI} / \mathrm{PSS} /$ dodecilamina/P SS/dodecilamina. (b) Diâmetro dos nanocontainers vs número de etapas de deposição.

$\mathrm{Na}$ Figura 4.5a é possível observar que as partículas originais de sílica apresentam potencial zeta negativo (em torno de $-30 \mathrm{mV}$ ) e que há um incremento na carga positiva da superfície depois da deposição da primeira camada de PEI $(45 \mathrm{mV})$ seguido de um decréscimo $(50 \mathrm{mV})$ atingindo valor de $-40 \mathrm{mV}$ revelando a presença de carga líquida negativa na superfície das partículas depois da adsorção da camada de PSS. A deposição da camada do inibidor dodecilamina conduz a um aumento mais pronunciado do valor de potencial zeta $(60 \mathrm{mV})$ para valores positivos devido a uma completa recarga das moléculas do inibidor sobre a superfície do PSS, o que leva à presença de carga líquida positiva sobre as partículas. Isso é possível porque a amina foi dissolvida em meio ácido e se encontra na forma catiônica. Na formação da quarta camada se tem novamente uma diminuição do valor de potencial zeta em aproximadamente $63 \mathrm{mV}$ indo para valor negativo de $40 \mathrm{mV}$, já que as grandes cadeias destes polieletrólitos possuem carga negativa com forças eletroestáticas bastante fortes as quais permitem uma adsorção rápida. Com relação às moléculas do inibidor, embora elas sejam menores, elas são facilmente adsorvidas devido a sua linearidade na cadeia e 
baixo impedimento estérico. Na Figura $4.5 \mathrm{~b}$ pode ser facilmente observado um aumento do tamanho dos nanocontainers em função do número de camadas depositadas. Para as camadas depositadas de PSS se pode observar um aumento do tamanho de partícula em aproximadamente $40 \mathrm{~nm}$, enquanto que para as camadas de inibidor o aumento foi de aproximadamente $300 \mathrm{~nm}$. Provavelmente a molécula do PSS (maior peso molecular) e com vários grupos de interação, se orienta horizontalmente em relação ao substrato, o que justifica o menor aumento da partícula quando a camada é de PSS. Para a camada de PEI (uma amina) há um aumento da camada também da ordem de $300 \mathrm{~nm}$. Isso indica uma possível orientação vertical das moléculas de dodecilamina e PEI em relação à superfície do substrato e/ou a presença de mais de uma camada adsorvida.

\subsubsection{Nanocontainers feitos à base de nanopartículas de haloisita}

Na Figura 4.6 são mostradas as imagens por microscopia eletrônica de varredura com emissão de campo (MEV-FEG) da haloisita antes e depois do tratamento com ácido sulfúrico 2,0 mol/L, onde se pode ver claramente que depois do ataque com ácido sulfúrico por 12 horas, a superfície externa da haloisita foi alterada. A ideia do tratamento com ácido sulfúrico é incrementar o diâmetro do lúmen da haloisita (sem alterar a sua morfologia externa) por ataque seletivo da alumina $\left(\mathrm{Al}_{2} \mathrm{O}_{3}\right)$, o qual incrementa eficiência de carga em 2 a 3 vezes devido ao aumento do espaço interno disponível dentro dos tubos da haloisita (ABDULLAYEV et al., 2012). 


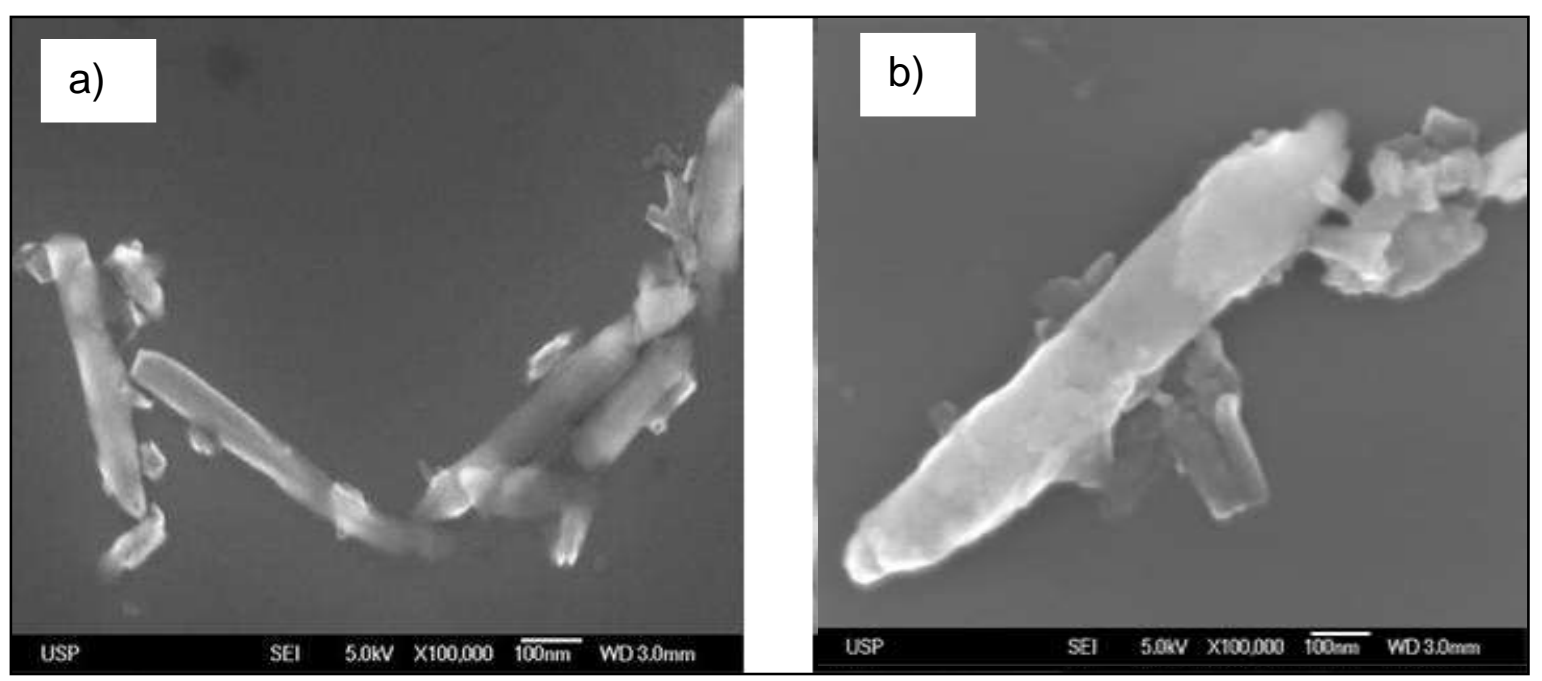

Figura 4.6 - Imagens do MEV-FEG da haloisita sem inibidor antes (a) e depois do tratamento com ácido sulfúrico $2 \mathrm{~mol} / \mathrm{L}$ durante um tempo de 12 horas (b).

Em vista de, para um tempo de 12 horas, o ataque do ácido ter sido muito severo, foi usado um tempo menor de permanência ( 6 horas) da haloisita dentro do ácido sulfúrico só para conseguir a remoção das paredes internas da haloisita sem alterar ou atacar a superfície externa. Com este tipo de tratamento é possível obter uma remoção seletiva de $60 \%$ do óxido de alumínio (alumina), o qual incrementa a eficiência de carregamento do inibidor de corrosão até 4 vezes. Durante o pré-tratamento alguns nanotubos preservam sua geometria enquanto que, para níveis mais altos de ataque algumas regiões de ataque localizado podem aparecer sobre as paredes da haloisita. A haloisita perde gradualmente sua morfologia tubular e termina se transformando em nanovaras durante a remoção total da alumina nas seguintes etapas: primeiramente a espessura das paredes uniformes é perdida, depois quando acima de 30-40 \% de remoção de alumina, aparecem tubos com espessura variável, e finalmente, quando acima de $50-60 \%$ da alumina é removida, começam a aparecer poros nas paredes, os quais crescem como um ataque adicional. Quando há uma completa remoção da alumina do interior do lúmen, a morfologia tubular é perdida e o lúmen desaparece (ABDULLAYEV et al., 2012; ZHANG et al., 2012). 


\subsubsection{Análise termogravimétrica (TGA)}

As Figuras 4.7 e 4.8 representam as curvas TGA para a haloisita sem inibidor e com inibidor respectivamente, onde a linha vermelha indica as principais etapas de perdas de massa durante todo o ensaio. Para a haloisita sem inibidor mostrada na Figura 4.7 é possível notar três regiões principais de perda de massa, as duas primeiras perdas de massa de aproximadamente 3,1\% que ocorre entre as faixas de temperaturas $30^{\circ} \mathrm{C}$ e $250^{\circ} \mathrm{C}$ atribuída à água adsorvida na superfície e a água estrutural, respectivamente e a terceira perda de massa em aproximadamente $500{ }^{\circ} \mathrm{C}$ referente ao processo de desidroxilação dos grupos estruturais $\mathrm{AIOH}$, como já reportado em outros trabalhos na literatura (YUAN et al., 2008; BORDEEPONG et al., 2011; LIU et al., 2013; LUO et al., 2014). Com relação à Figura 4.8 observam-se 5 regiões principais de perda de massa, as duas primeiras $(3,0 \%)$ até $120^{\circ} \mathrm{C}$ relacionadas à água adsorvida sobre a superfície e a água estrutural e as outras 2 regiões na faixa de temperatura de $250^{\circ} \mathrm{C}$ a $450^{\circ} \mathrm{C}$ atribuídas à degradação do inibidor dodecilamina encapsulada dentro da haloisita (11\%). Estas diferentes inclinações podem estar relacionadas às diferentes etapas da saída do inibidor desde a haloisita, onde a primeira saída se refere às moléculas adsorvidas nas paredes externas da haloisita e a outra saída relacionada às moléculas contidas dentro do lúmen da haloisita. Finalmente uma última região em aproximadamente $483^{\circ} \mathrm{C}$ correspondente à degradação da haloisita. 


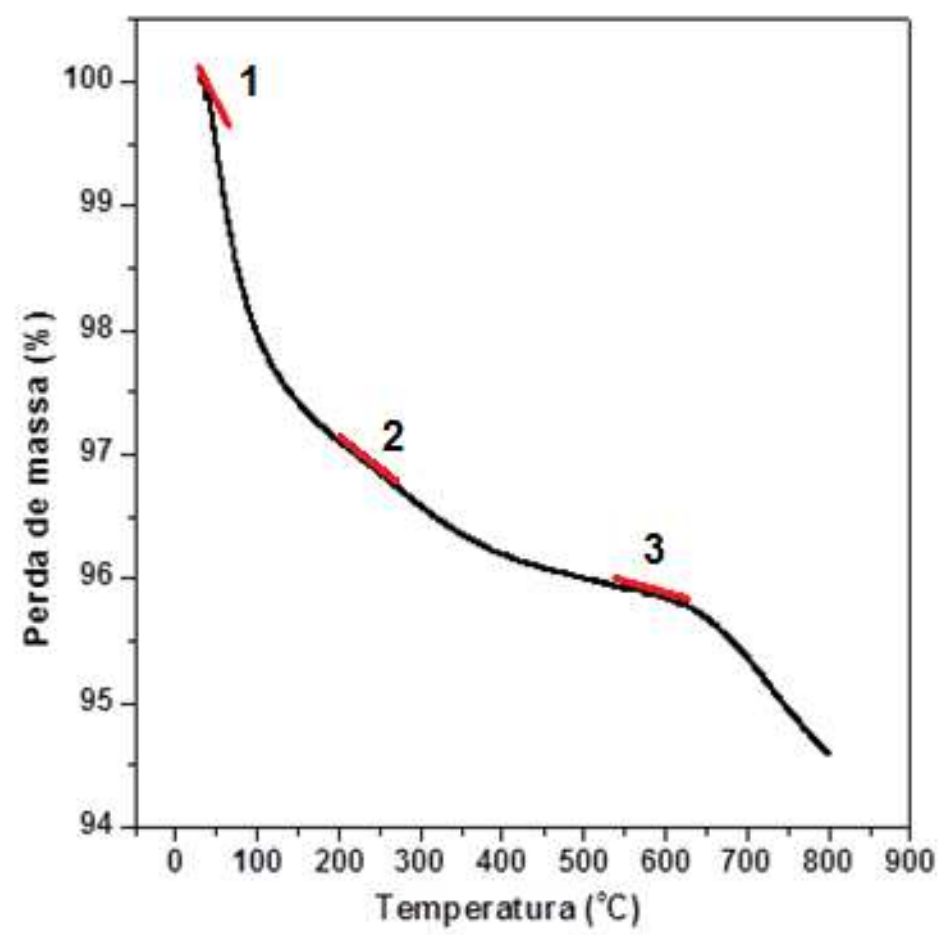

Figura 4.7 - Curva termogravimétrica (TGA) para a haloisita sem inibidor dodecilamina.

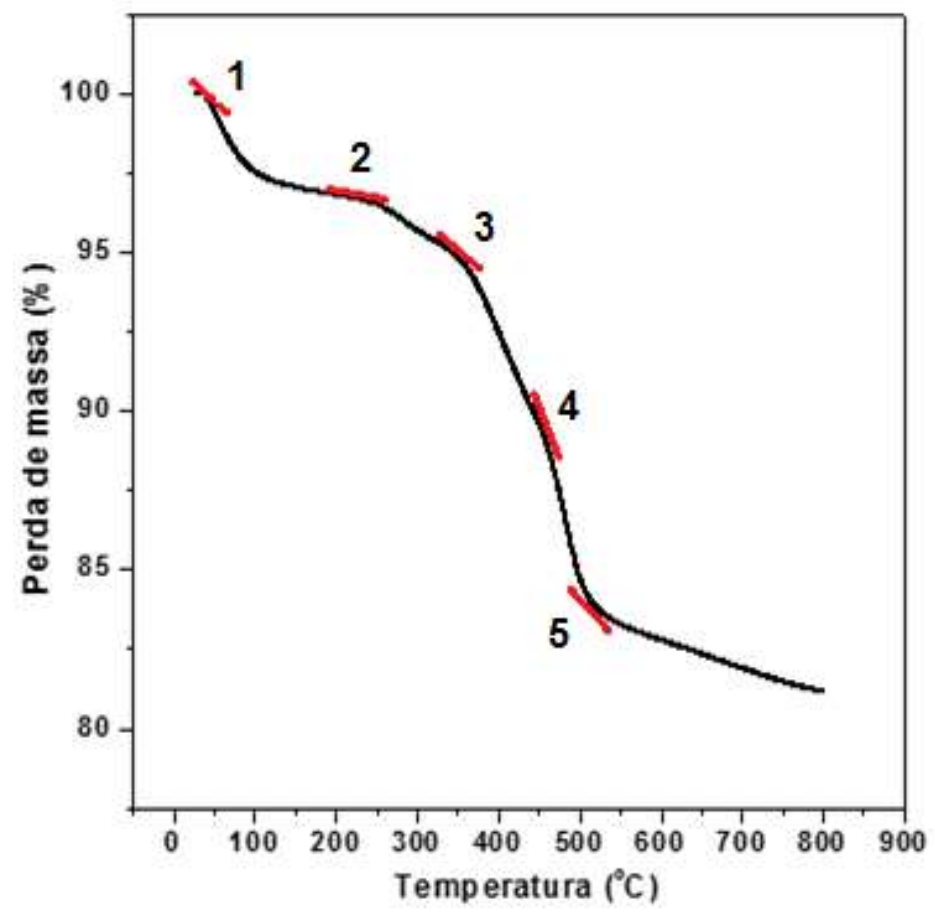

Figura 4.8 - Curva termogravimétrica (TGA) para a haloisita com inibidor dodecilamina. 
Nas Tabelas 4.3 e 4.4 são apresentadas as diferentes etapas de perdas de massa com seus respectivos percentuais perdidos para a haloisita sem inibidor e com inibidor respectivamente.

Tabela 4.3 - Etapas das perdas de massa com suas perdas porcentuais para a haloisita sem inibidor dodecilamina.

\begin{tabular}{|c|c|c|}
\hline Etapa & $\begin{array}{c}\text { Faixa de temperatura } \\
\left({ }^{\circ} \mathbf{C}\right)\end{array}$ & Massa perdida (\%) \\
\hline 1 & $25-100$ & 2,5 \\
\hline 2 & $200-250$ & 0,6 \\
\hline 3 & $500-550$ & 2,4 \\
\hline \multirow{2}{*}{} & Perda total em \% massa & 5,5 \\
\cline { 2 - 3 }
\end{tabular}

Tabela 4.4 - Etapas das perdas de massa com suas perdas porcentuais para a haloisita com inibidor dodecilamina.

\begin{tabular}{|c|c|c|}
\hline Etapa & $\begin{array}{c}\text { Faixa de temperatura } \\
\left({ }^{\circ} \mathbf{C}\right)\end{array}$ & Massa perdida (\%) \\
\hline 1 & $25-100$ & 2,5 \\
\hline 2 & $200-250$ & 0,5 \\
\hline 3 e 4 & $250-450$ & 11 \\
\hline 5 & $500-800$ & 2,5 \\
\hline \multirow{2}{*}{} & Perda total em \% massa & 16,5 \\
\hline
\end{tabular}

4.3.3 Nanocontainers feitos à base de partículas de sílica mesoporosa

\subsubsection{Análise termogravimétrica (TGA)}

As Figuras 4.9 e 4.10 representam as curvas TGA para a sílica mesoporosa sem inibidor e com inibidor respectivamente, onde a linha vermelha indica o início das perdas de massa durante todo o ensaio. Na curva termogravimétrica para sílica mesoporosa sem inibidor mostrada na Figura 4.9 é possível observar duas perdas de massa, a primeira de aproximadamente $28,6 \%$ que ocorre entre $25{ }^{\circ} \mathrm{C}$ e $100{ }^{\circ} \mathrm{C}$ relacionada a água fisissorvida nas cavidades porosas da sílica mesoporosa, a qual foi adquirida antes da análise (ARAUJO; JEROINEC, 2000) e 
a outra em aproximadamente $300^{\circ} \mathrm{C}$ relacionada a água estrutural. Com relação à Figura 4.10 é possível também notar uma perda inicial de massa correspondente à saída de água fisissorvida, mas em uma porcentagem bem menor (3,6 \%) em comparação com a obtida na Figura 4.9, já que as cavidades porosas foram ocupadas pelo inibidor e por isso as moléculas de água tem maior dificuldade de se adsorverem e uma segunda perda de massa relacionada à água estrutural em aproximadamente $250{ }^{\circ} \mathrm{C}$. Outras três de temperatura com perdas de massa $\left(15,8 \%\right.$ de perda total) na faixa de temperatura de $350^{\circ} \mathrm{C}$ a $550{ }^{\circ} \mathrm{C}$ são atribuídas à degradação do inibidor dodecilamina encapsulado dentro da sílica mesoporosa. Essa ampla faixa de perda de massa que ocorre, pode estar associada à dificuldade desta amina em sair da estrutura porosa desde fora para dentro da sílica. As três diferentes inclinações da curva mostram estágios diferentes de saída da dodecilamina a partir da sílica mesoporosa. Cada estágio revela o local de saída das moléculas de inibidor. A primeira saída se refere às moléculas adsorvidas nas paredes externas das partículas de sílica mesoporosa e as demais saídas são relativas aos poros mais profundos (canais típicos presentes nesse material).

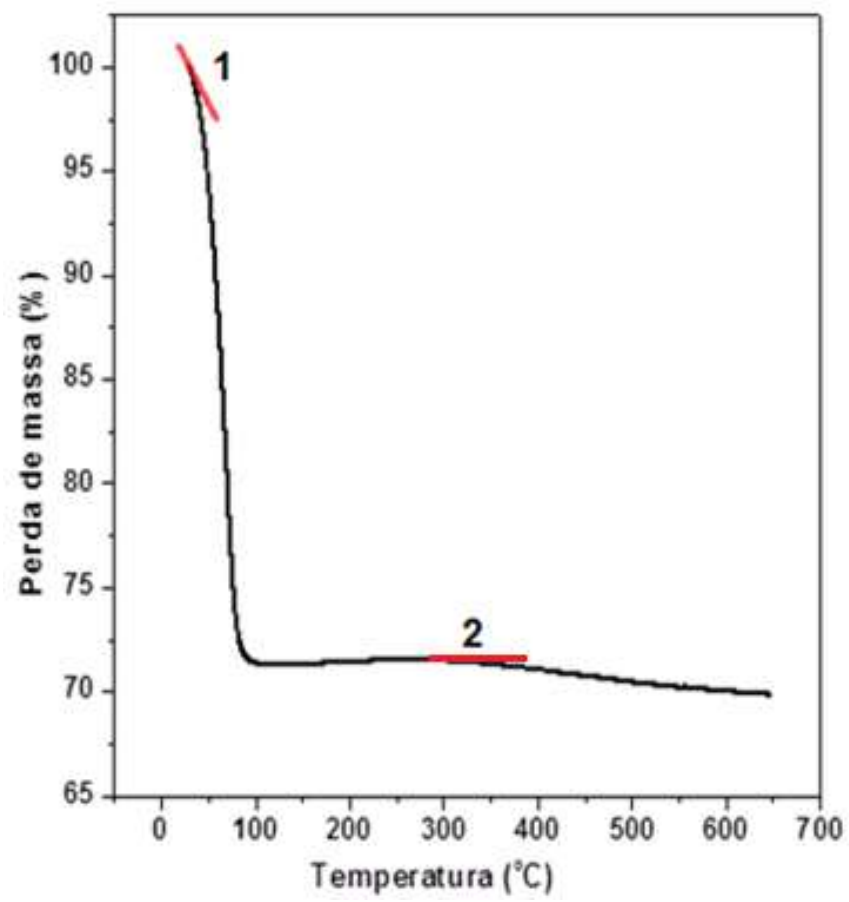

Figura 4.9 - Curva termogravimétrica (TGA) para a sílica mesoporosa sem inibidor dodecilamina. 


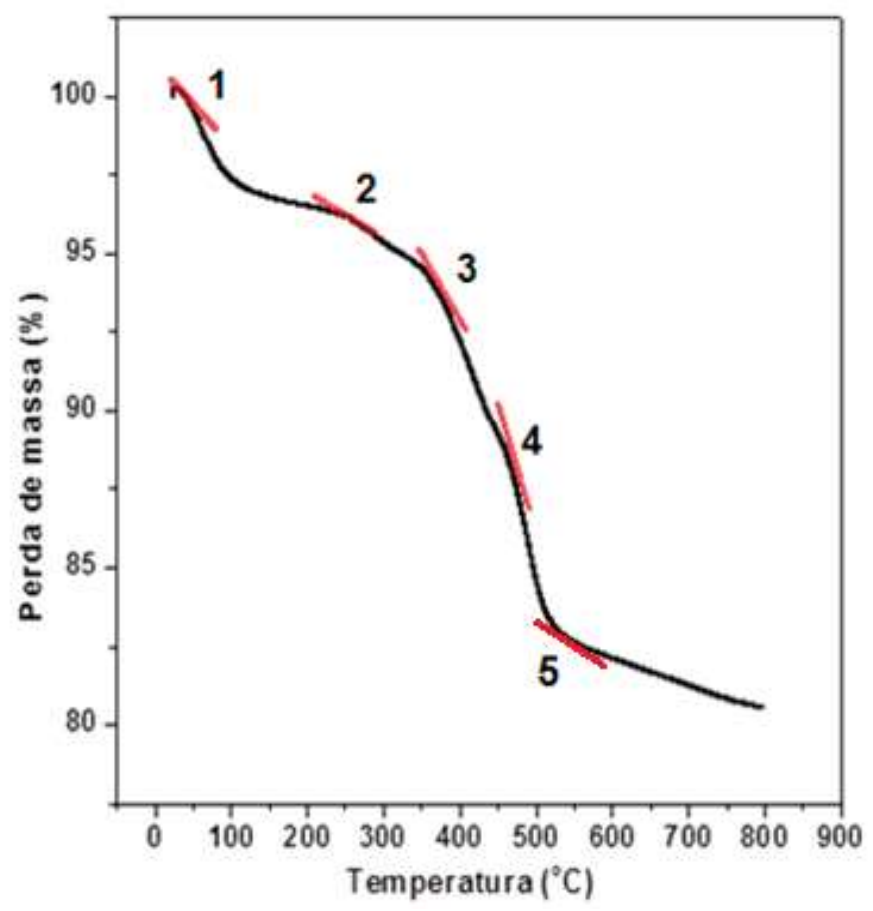

Figura 4.10 - Curva termogravimétrica (TGA) para a sílica mesoporosa com inibidor dodecilamina.

Nas Tabelas 4.5 e 4.6 são apresentadas as diferentes etapas de perdas de massa com seus respectivos percentuais perdidos para a sílica mesoporosa sem inibidor e com inibidor respectivamente.

Tabela 4.5 - Etapas das perdas de massa com suas perdas porcentuais para a sílica mesoporosa sem inibidor dodecilamina.

\begin{tabular}{|c|c|c|}
\hline Etapa & $\begin{array}{c}\text { Faixa de temperatura } \\
\left({ }^{\circ} \mathbf{C}\right)\end{array}$ & Massa perdida (\%) \\
\hline 1 & $25-100$ & 28,6 \\
\hline 2 & $300-650$ & 0,6 \\
\hline \multirow{2}{*}{} & Perda total em \% massa & 29,2 \\
\hline
\end{tabular}


Tabela 4.6 - Etapas das perdas de massa com suas perdas porcentuais para a sílica mesoporosa com inibidor dodecilamina.

\begin{tabular}{|c|c|c|}
\hline Etapa & $\begin{array}{c}\text { Faixa de temperatura } \\
\left({ }^{\circ} \mathbf{C}\right)\end{array}$ & Massa perdida (\%) \\
\hline 1 & $25-100$ & 3,6 \\
\hline 2 & $200-250$ & 0,5 \\
\hline 3,4 e 5 & $350-800$ & 13 \\
\hline \multirow{2}{*}{} & Perda total em \% massa & 17,1 \\
\hline
\end{tabular}

\subsubsection{Adsorção e dessorção de nitrogênio $\left(\mathrm{N}_{2}\right)$}

A Figura 4.11 representa a isoterma de adsorção e dessorção de $\mathrm{N}_{2}$ na sílica mesoporosa. Pode-se observar que o comportamento é bem parecido, em relação à sua forma, com a isoterma do tipo IV e com histerese do tipo $\mathrm{H} 1$, indicando processo de adsorção irreversível. Segundo a classificação encontrada na literatura (BRUNAUER; EMMETT; TELLER, 1938) esse comportamento é característico de materiais mesoporosos. Portanto, os materiais sintetizados neste trabalho são mesoporosos.

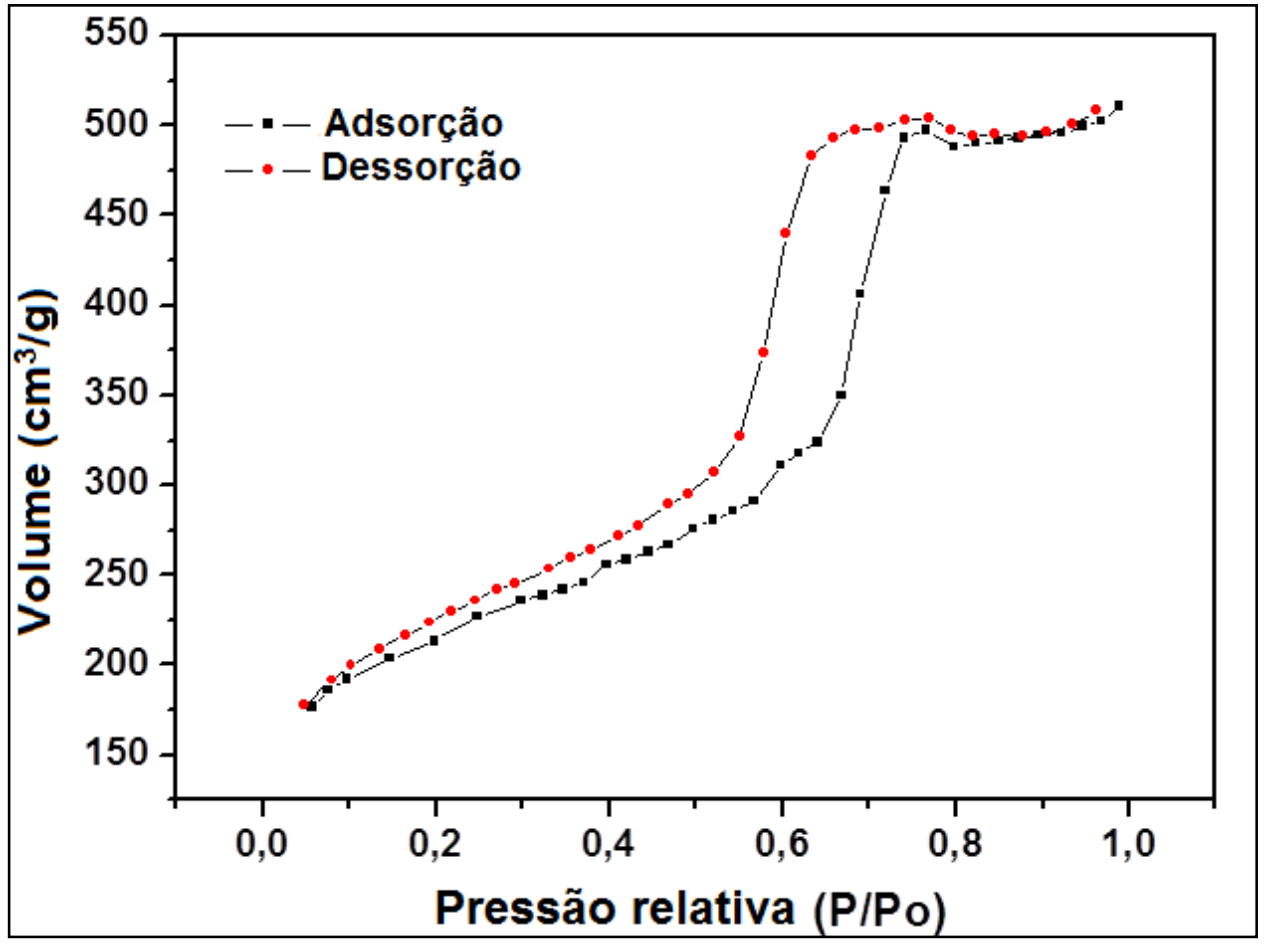

Figura 4.11 - Isotermas de adsorção e dessorção de $\mathrm{N}_{2}$ na sílica mesoporosa. 
A área superficial da sílica sintetizada foi determinada a partir das isotermas de adsorção de nitrogênio a $77 \mathrm{~K}$ utilizando o modelo de BET [Brunauer] e a faixa de P/Po usada nesta análise foi de 0,05 - 1.0.

O diâmetro de poro da sílica mesoporosa foi obtida pela pressão do $\mathrm{N}_{2}$ através do volume dessorvido do gás em função da pressão relativa $\left(P / P_{0}\right)$ proposto por BJH [Brunauer] utilizando uma faixa de poros de $1 \mathrm{~nm}-80 \mathrm{~nm}$ e cujo resultado é mostrado na Figura 4.12. Dessa curva se depreende que o raio médio de poros está entre $3 \mathrm{~nm}-4 \mathrm{~nm}$, o que comprova que se trata mesmo de material mesoporoso, pois se o raio é de cerca de $3,3 \mathrm{~nm}$, o diâmetro do poro é de cerca de $6,8 \mathrm{~nm}$ o que é próximo do valor de $6,61 \mathrm{~nm}$ calculado a partir da isoterma de adsorção (ver Tabela 4.3).

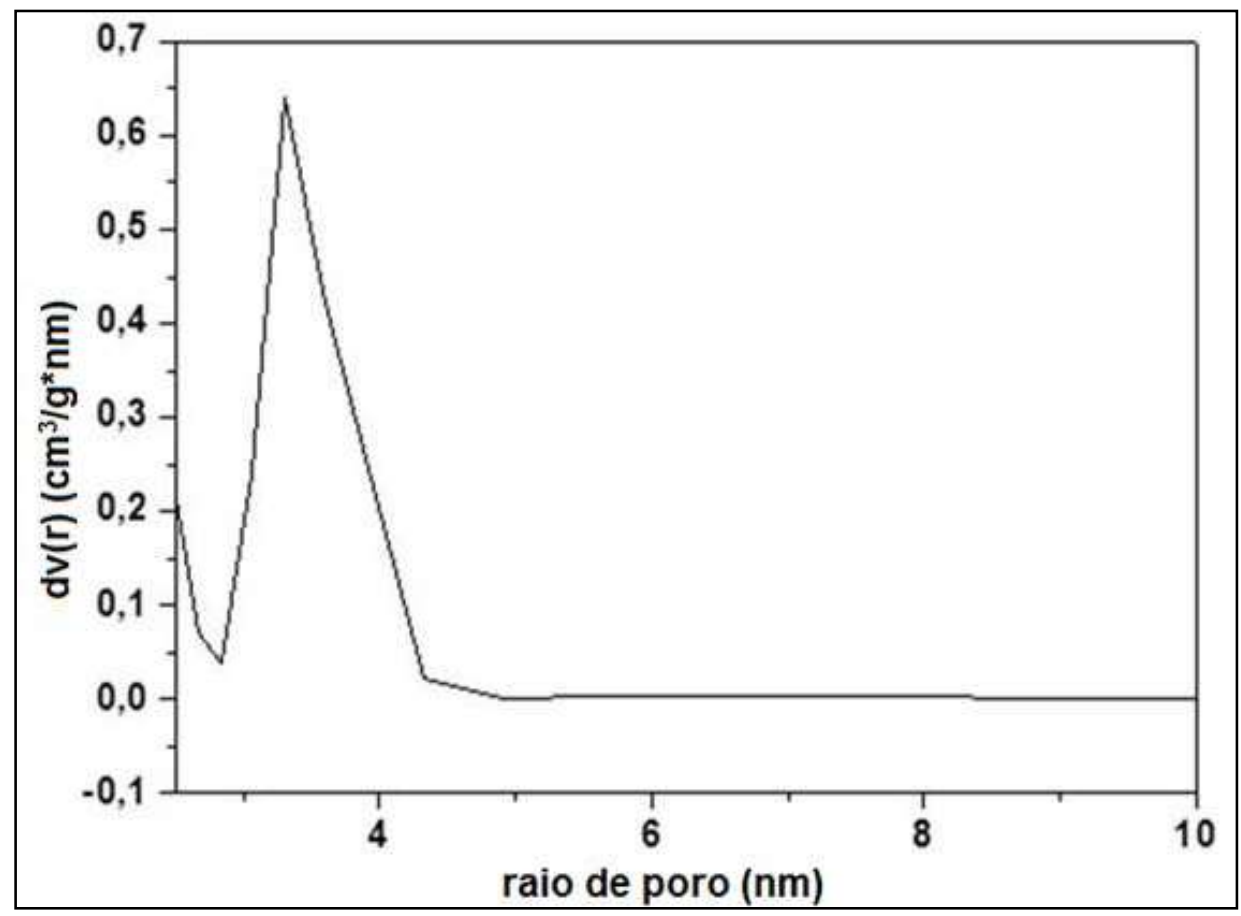

Figura 4.12 - Distribuição do raio de poro para a sílica mesoporosa.

$\mathrm{Na}$ Tabela 4.7 são apresentadas as características da sílica mesoporosa como diâmetro de poro, $D_{p}$, volume de poro, $V_{p}$ é a área superficial, $S_{B E T}$. 
Tabela 4.7 - Características estruturais da sílica mesoporosa obtidas a partir dos dados de adsorção e dessorção de $\mathrm{N}_{2}$.

\begin{tabular}{|c|c|c|c|}
\hline Amostra & $\mathbf{D}_{\mathbf{p}}(\mathbf{n m})$ & $\mathbf{V}_{\mathbf{p}}\left(\mathbf{c m}^{\mathbf{3}} \mathbf{~}^{-1}\right)$ & $\mathbf{S}_{\text {BET }}\left(\mathbf{m}^{\mathbf{2}} \mathbf{~ g}^{-1}\right)$ \\
\hline Sílica mesoporosa & 6,61 & 0,63 & 725,6 \\
\hline
\end{tabular}

Esses valores estão em concordância com o esperado para este tipo de sílica, que é na faixa de $650-950 \mathrm{~m}^{2} / \mathrm{g}$ e $0,65-1 \mathrm{~cm} / \mathrm{g}$ (MEYNEN; COOL; VANSANT, 2009), relativamente para a área superficial e volume de poro. Cabe ressaltar que o erro para esta técnica fica em torno de $20 \%$, o que faz com que os valores encontrados fiquem dentro das faixas consideradas.

\subsubsection{Difração de raios-X}

A difração de raios- $X$ foi realizada na amostra calcinada para identificar as estruturas ordenadas hexagonais que caracterizam esta sílica mesoporosa tipo SBA-15 (ZHAO, 1998b).

A Figura 4.13 mostra o difratograma da sílica mesoporosa, onde é possível observar dois picos que se apresentam como picos principais da difração referindo-se aos planos cristalinos com índices de Miller (110) e (200) (DHAR et al., 2005; KO; RYOO, 2000; THIELEMANN et al., 2011; KIWILSZA et al., 2013). Segundo a literatura (DHAR et al., 2005; KUMARAN et al., 2006) existe o aparecimento de um terceiro pico antes de 1 (aproximadamente em 0,85 ) mas que não aparece em nosso resultado, porque a faixa de varredura no equipamento utilizado não consegue fazer medidas para ângulos menores que 0,96 graus. 


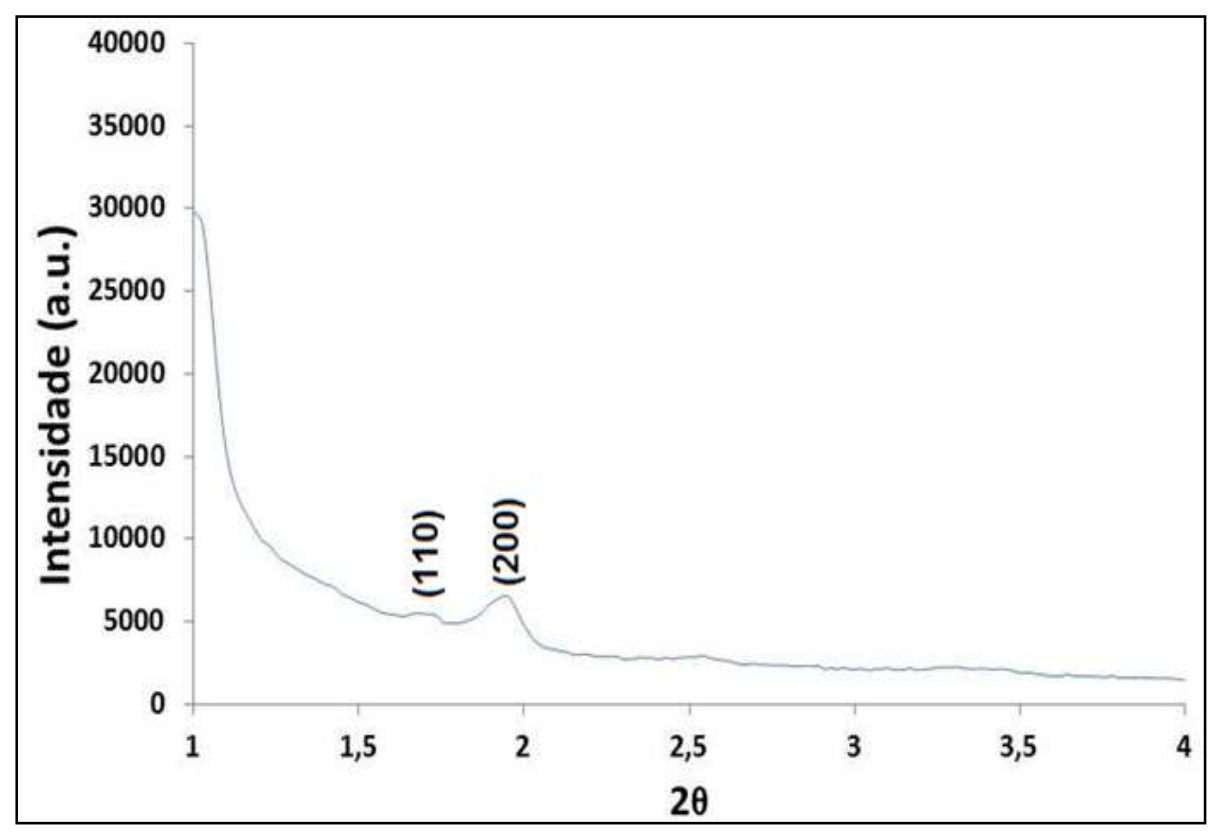

Figura 4.13 - Difração de raios-X para a sílica mesoporosa.

O parâmetro da rede característico do arranjo hexagonal mesoporoso da estrutura desta sílica foi calculado através das Equações 4.2, 4.3 e 4.4.

$\frac{1}{d(h k l)^{2}}=\frac{4\left(h^{2}+h k+l^{2}\right)}{3 a_{0}^{2}}+\frac{l^{2}}{c}$

Equação 4.2

Para o plano (110) teremos:

$\underline{1}=\underline{8}$

Equação 4.3

$\mathrm{d}_{(110)^{2}} \quad 3 \mathrm{a}_{0}{ }^{2}$

$a_{0}=\underline{2 \sqrt{ } 2 d_{(110)}}$

Equação 4.4

$\sqrt{3}$

Onde:

$\mathrm{d}_{(\mathrm{hkl})}=$ distância interplanar relativa ao plano (110); 
$a_{o}=$ parâmetro do arranjo hexagonal da estrutura mesoporosa;

A distância interplanar para o plano (110) pode ser obtida pela Equação 4.5;

$\lambda \lambda_{\text {cuKa }}=2 \mathrm{~d}_{(110)} \operatorname{sen} \theta$

Equação 4.5

Onde:

$\lambda$ CuK $\alpha=$ comprimento de onda para $\mathrm{CuK}_{\alpha}=1,5418 \AA$ (CULLITY, 1956);

Os valores dos ângulos $2 \theta$ com suas respectivas distâncias interplanares $\left(\mathrm{d}_{(\mathrm{hkl})}\right)$ no plano (hkl) e o parâmetro mesoporoso para os planos (110) e (200) correspondentes à sílica mesoporosa são apresentados na Tabela 4.8.

Tabela 4.8 - Valores de ângulo $2 \theta$ com os índices de Miller, suas respectivas distâncias interplanares e o parâmetro mesoporoso.

\begin{tabular}{|c|c|c|c|c|}
\hline Amostra & $\mathbf{2 \theta}$ & $\mathbf{h k l}$ & $\mathbf{d}_{(\mathbf{h k l})}$ & $\mathbf{a}_{\mathbf{o}}(\mathbf{n m})$ \\
\hline $\begin{array}{c}\text { Sílica mesoporosa } \\
\text { sem inibidor }\end{array}$ & 1,68 & 110 & 59,31 & 6,84 \\
\hline & 1,9 & 200 & 51,36 & 5,93 \\
\hline
\end{tabular}

O valor de årepresenta a soma da espessura da parede de sílica (Wt) e do diâmetro de poro $\left(d_{p}\right)$, ou seja;

$$
a_{o}=W t+d_{p}
$$

Equação 4.6

A espessura da parede da sílica pode também ser definida como:

$$
W t=a_{o}-d_{p}
$$

Equação 4.7

Para um valor de $d_{p}=6,61 \mathrm{~nm}$ (calculado a partir dos dados de adsorção de gases) e $a_{o}=6,84 \mathrm{~nm}$, o valor da espessura da parede da sílica seria: 


$$
\mathrm{Wt}=0,21 \mathrm{~nm}
$$

A Figura 4.14 apresenta a difração de raios- $X$ da sílica mesoporosa para valores maiores de ângulo $2 \theta$, onde se pode identificar entre os ângulos $20^{\circ}$ e $30^{\circ}$ um pico que caracteriza a presença de sílica amorfa no material sintetizado.

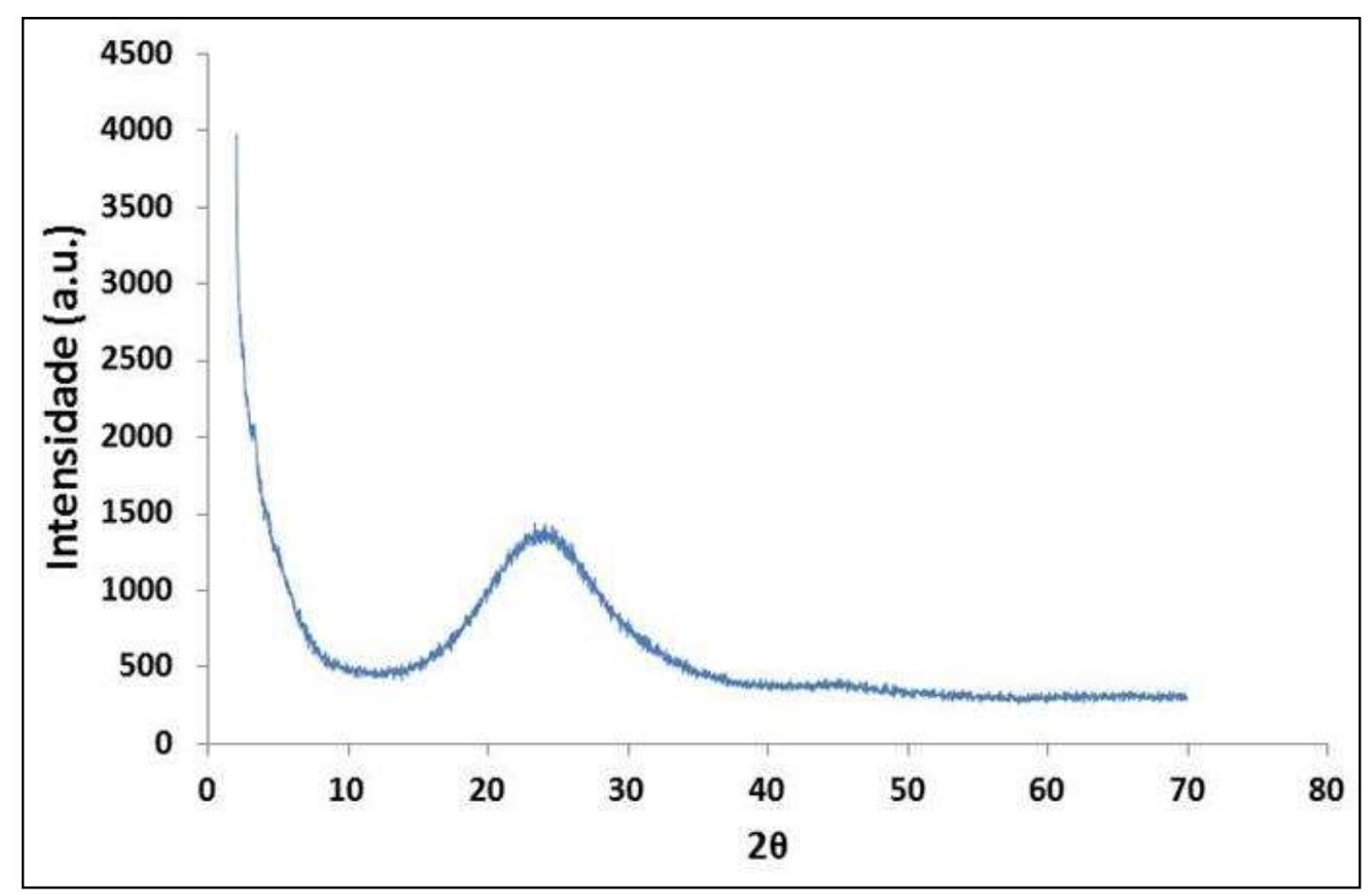

Figura 4.14 - Difração de raios-X para a sílica mesoporosa calcinada considerando uma faixa maior de valores de $2 \theta$.

\subsubsection{Microscopia eletrônica de varredura (MEV)}

A Figura 4.15 ( $a$ e b) apresenta as micrografias para a sílica mesoporosa em diferentes aumentos para uma melhor visualização de sua estrutura, onde pode ser observada uma morfologia tipo cordas entrelaçadas de tamanhos relativamente uniformes e de dimensões micrométricas (Figura 4.15 (b)), de forma semelhante ao que é encontrado na literatura (ZHAO et al., 1998b; CHAO et al., 2002; KATIJAR et al., 2006). Segundo a literatura (CHAO et al., 2002), os parâmetros fundamentais que afetam a morfologia destes materiais mesoporosos são o controle da nucleação (por meio da agitação), crescimento e a agregação das micelas no gel da solução. 

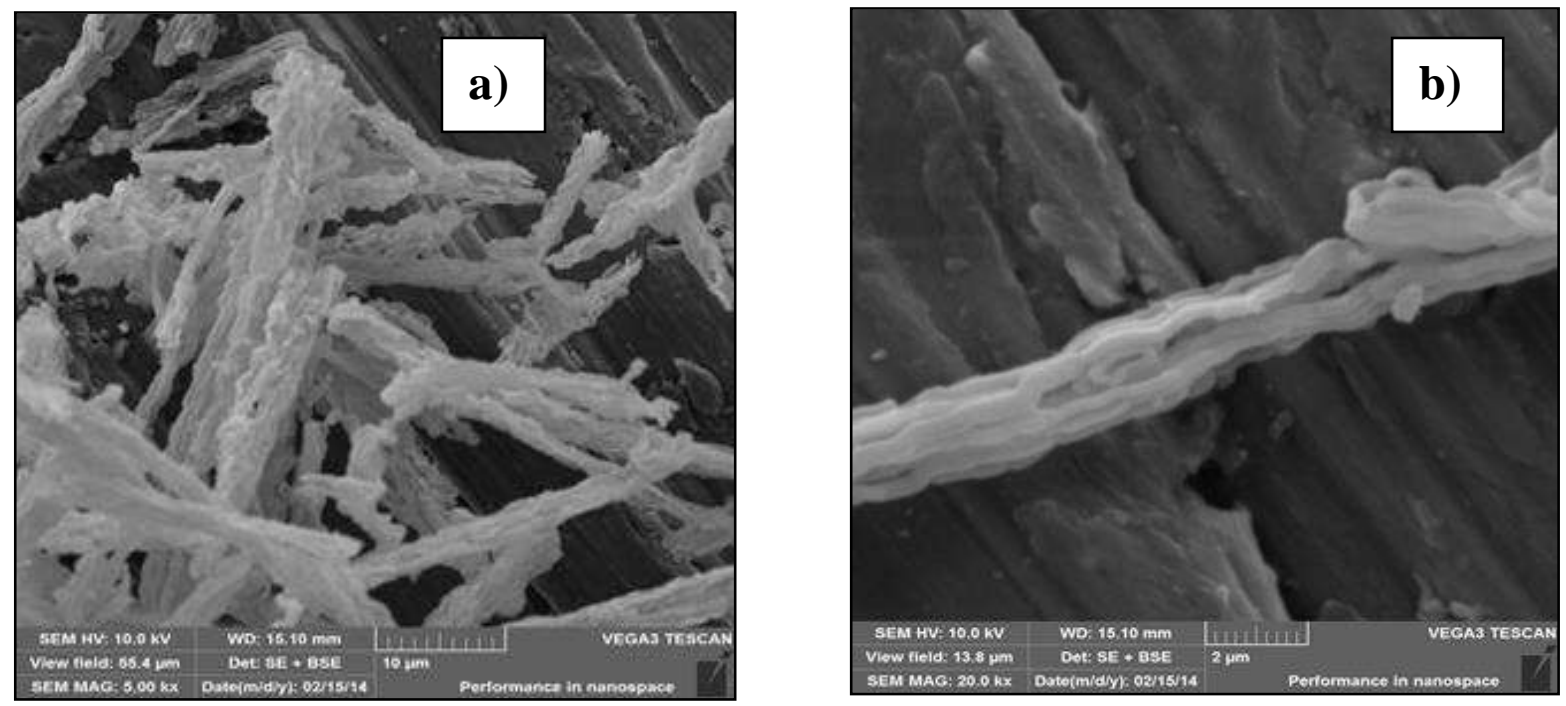

Figura 4.15 - Imagens de MEV das nanopartículas de sílica mesoporosa para diferentes aumentos (a) $5000 x$ e (b) 20000x.

\subsubsection{Microscopia eletrônica de transmissão (MET)}

Para confirmar os resultados das análises anteriores foram obtidas as imagens por microscopia eletrônica de transmissão, onde duas direções foram usadas para registrar as micrografias das amostras. Uma paralela ao eixo dos poros (Figura 4.16 (a)) e a outra perpendicular ao eixo dos poros (Figura 4.16 (b)). Estas imagens obtidas por TEM mostram claramente um arranjo hexagonal bem ordenado dos mesoporos de diâmetro interno da ordem de $6 \mathrm{~nm}$ a $7 \mathrm{~nm}$ formados nas paredes da sílica representado por uma estrutura 2-D e com um valor de a。 igual a 6,84 nm correspondente ao plano (110) determinado a partir da difração de raios- $X$, que representa a distância entre dois centros mais próximos dos mesoporos cilíndricos. Esses resultados estão em concordância com os obtidos por outros autores (ZHAO et al., 1998b; CHAO et al., 2002; KATIJAR et al., 2006), os quais obtiveram imagens com as mesmas características. Além disso, é possível observar a formação de canais homogêneos e paralelos bem definidos sobre a amostra sintetizada onde os mesoporos estão abertos e alinhados radial e uniformemente desde o centro até a superfície externa das partículas, o que 
significa que as condições usadas durante a síntese implicaram em sucesso na obtenção de sílica mesoporosa com arranjo hexagonal ordenado.
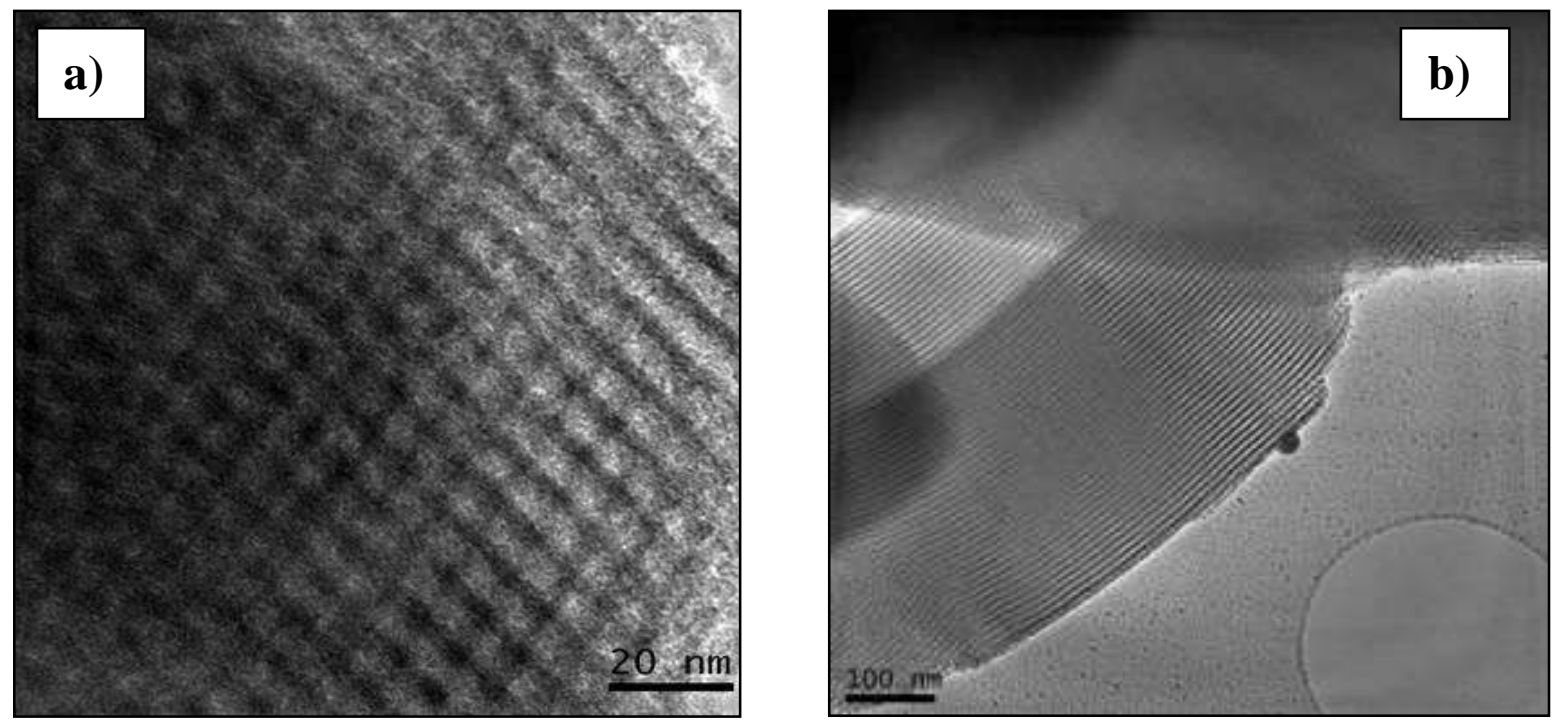

Figura 4.16 - Imagens obtidas por TEM da sílica mesoporosa (a) paralelo ao eixo dos poros e (b) perpendicular ao eixo dos poros.

\subsection{Avaliação por EIE da cinética de liberação do inibidor dodecilamina encapsulado sobre nanopartículas de sílica pela técnica L-b-L para diferentes valores de $\mathrm{pH}$ e diferentes formas de dispersar as partículas}

Nas Figuras 4.17, 4.18 e 4.19 são apresentados os diagramas de Nyquist e de Bode para o aço carbono obtidos em solução aquosa de $\mathrm{NaCl} 0,1 \mathrm{~mol} / \mathrm{L}$ sem nanocontainers e com os nanocontainers para valores de $\mathrm{pH} 2$, 6 e 9, em diferentes tempos de contato. Estes estudos foram feitos para testar a influência do valor de $\mathrm{pH}$ do meio agressivo na liberação do inibidor a partir dos nanocontainers, à medida que o substrato é imerso por longos períodos de tempo numa solução agressiva de $\mathrm{NaCl} 0,1 \mathrm{~mol} / \mathrm{L}$.

$\mathrm{Na}$ Figura 4.17 apresentam-se os diagramas de impedância para o aço carbono para diferentes tempos de imersão numa solução $\mathrm{NaCl} 0,1 \mathrm{~mol} / \mathrm{L}$ com $\mathrm{pH}=2$ e contendo $1 \% \mathrm{~m} / \mathrm{m}$ de nanocontainers a base de nanopartículas de sílica, 
onde pode-se observar que para tempos iniciais de imersão, há um pequeno aumento nos diâmetros dos arcos capacitivos mostrados no diagrama de Nyquist e cujos valores oscilam entre $500-750 \Omega . \mathrm{cm}^{2}$, mas para períodos longos de imersão (16 h) este diâmetro aumenta até um valor de $2500 \Omega . \mathrm{cm}^{2}$. Estes resultados demonstram que ocorre a liberação do inibidor com o tempo e as propriedades de permeabilidade das paredes dos polieletrólitos as quais se abrem para valores de $\mathrm{pH}<3$, como já foi corroborado por outros autores (LAMAKA et al., 2008; ANDREEVA et al., 2008; SHCHUKIN; MÖHWALD, 2007; ZHELUDKEVICH et al., 2007; SKORB et al., 2009; ANDREEVA et al., 2010).
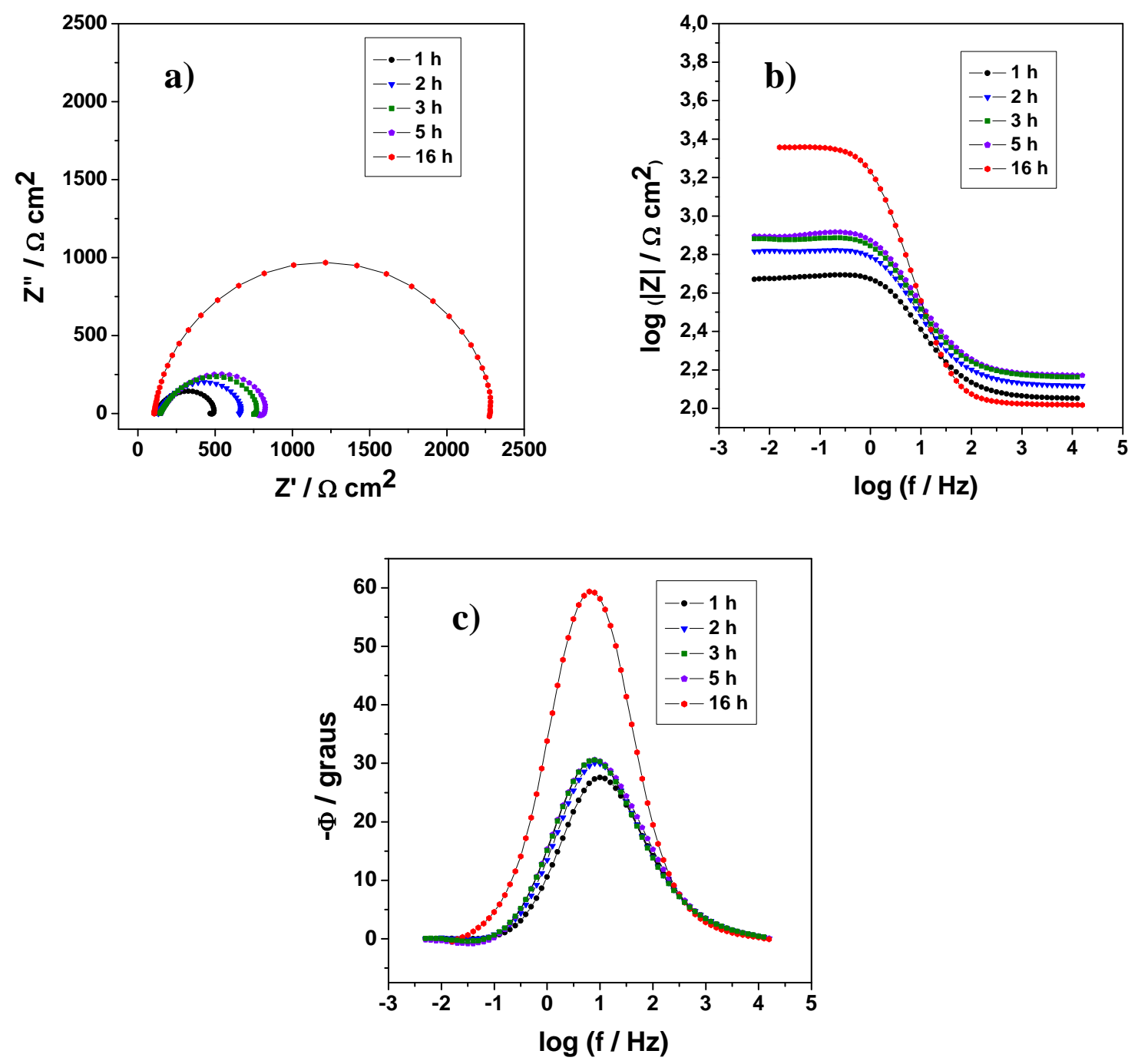

Figura 4.17 - Diagramas de Nyquist (a) e de Bode ((b) e (c)) para o aço carbono, para diferentes tempos de imersão numa solução de $\mathrm{NaCl} 0,1 \mathrm{~mol} / \mathrm{L} \mathrm{com} \mathrm{pH}=2$ contendo $1 \% \mathrm{em}$ massa de nanopartículas de sílica com dodecilamina encapsulada por L-b-L. 
Na Figura 4.18 são apresentados os diagramas de impedância para o aço carbono para diferentes tempos de imersão numa solução $\mathrm{NaCl} 0,1 \mathrm{~mol} / \mathrm{L}$ em $\mathrm{pH}=6,2$ e contendo $1 \%$ massa de nanocontainers. Neste caso pode-se observar que para um tempo de imersão de $5 \mathrm{~h}$ o valor do diâmetro do arco capacitivo ficou ao redor de $2000 \Omega . \mathrm{cm}^{2}$, em comparação com o valor obtido para tempos iniciais de imersão (1500 $\left.\Omega . \mathrm{cm}^{2}\right)$. Mas para longos períodos de imersão (16 h), pode-se observar apenas um pequeno acréscimo no diâmetro do arco capacitivo para $3000 \Omega . \mathrm{cm}^{2}$, o que permite concluir que para este pH neutro $(6,2)$ a liberação do inibidor é bastante lenta, e que as paredes dos polieletrólitos fecham-se para estas condições e armazenam o inibidor até que existam mudanças fortes de $\mathrm{pH}$ para valores menores, caracterizando o meio ácido.
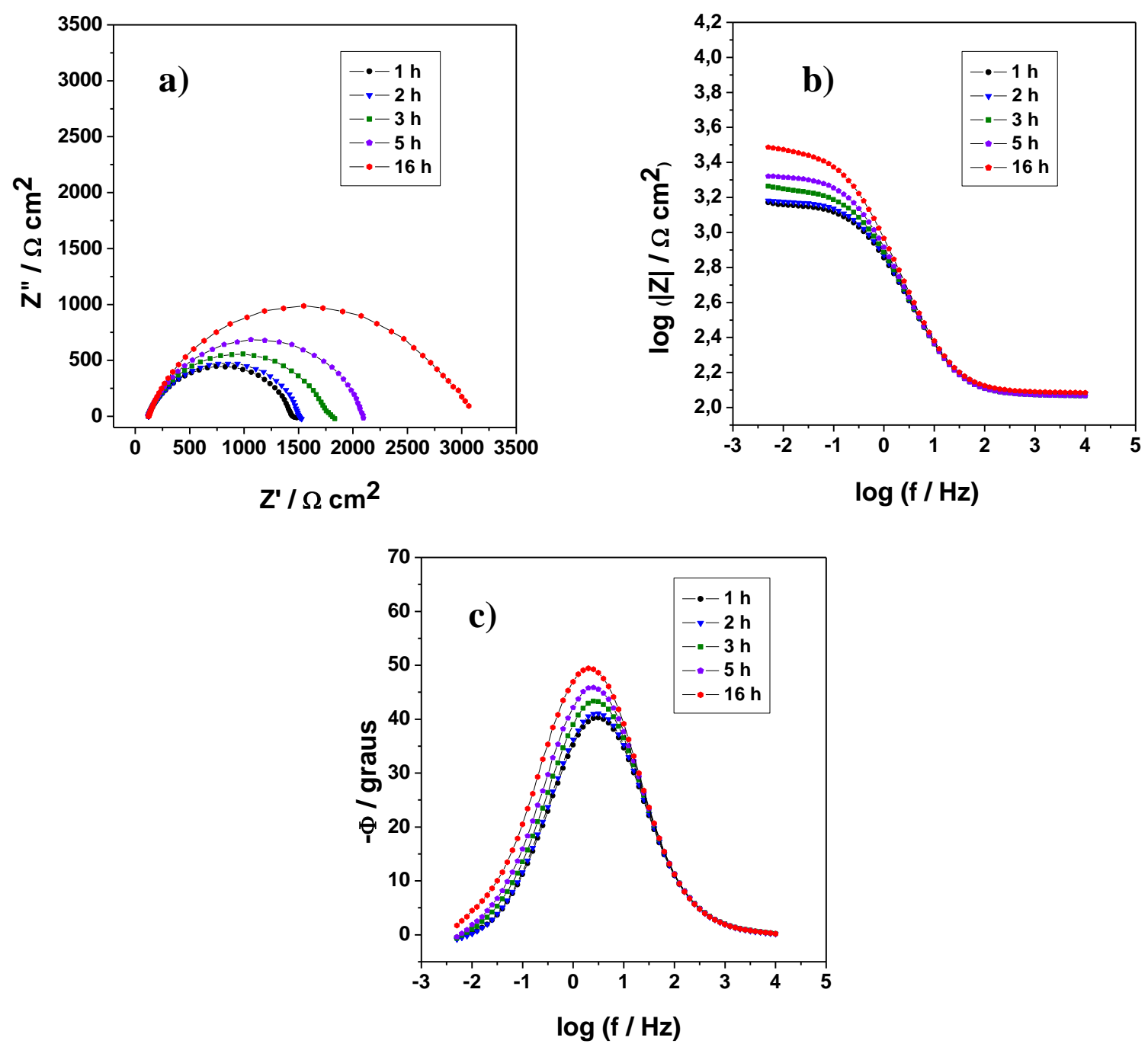

Figura 4.18 - Diagramas de Nyquist (a) e de Bode ((b) e (c)) para o aço carbono, para diferentes tempos de imersão numa solução de $\mathrm{NaCl} 0,1 \mathrm{~mol} / \mathrm{L}$ com $\mathrm{pH}=6,2$ contendo $1 \%$ em massa de nanopartículas de sílica com dodecilamina encapsulada por L-b-L. 
Na Figura 4.19 apresentam-se os diagramas de impedância para o aço carbono para diferentes tempos de imersão numa solução $\mathrm{NaCl} 0,1 \mathrm{~mol} / \mathrm{L} \mathrm{com} \mathrm{pH}$ = 9 e contendo $1 \%$ massa de nanocontainers. Neste caso pode-se observar quase a mesma resposta obtida para $\mathrm{pH}=6,2$, onde os valores do diâmetro do arco capacitivo não apresentam um incremento tão significativo para tempos de imersão longos (16 h), como aquele apresentado para $\mathrm{pH}=2$.
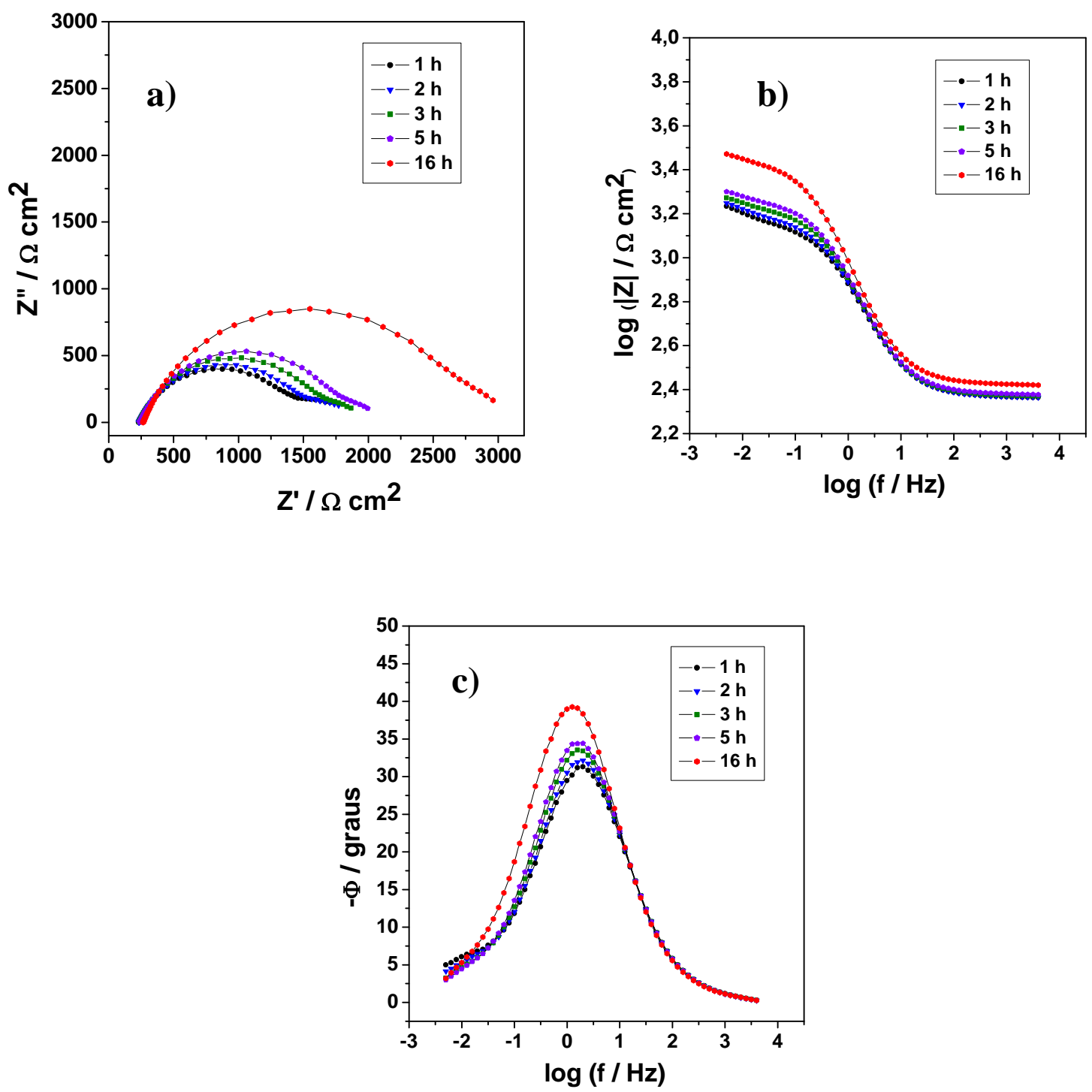

Figura 4.19 - Diagramas de Nyquist (a) e de Bode ((b) e (c)) para o aço carbono, para diferentes tempos de imersão numa solução de $\mathrm{NaCl} 0,1 \mathrm{~mol} / \mathrm{L} \mathrm{com} \mathrm{pH}=9$ contendo $1 \% \mathrm{em}$ massa de nanopartículas de sílica com dodecilamina encapsulada por L-b-L. 
De acordo com os resultados obtidos pode-se concluir que para a condição de $\mathrm{pH}=2$ existe um maior aumento progressivo no valor do diâmetro do arco capacitivo em comparação com as outras condições, ou seja, uma maior liberação do inibidor de corrosão a partir das camadas dos polieletrólitos devido a mudanças provocadas por um agente externo, que neste caso seria o $\mathrm{pH}$ em torno das paredes dos nanocontainers.

Outro detalhe observado nos diagramas de Nyquist para as três condições estudadas é o achatamento dos arcos frequentemente observados nos estudos de corrosão do aço carbono. Muitas explicações têm sido propostas para explicar esse tipo de comportamento, tais como o aumento da rugosidade da superfície (ZHANG; LYON, 1994; RAMMELT; REINHARD, 1987; RAMMELT; REINHARD, 1995), efeitos de transporte de massa através de poros nos filmes (MURRAY; MORAN; GILEADI, 1988; MULDER; SLUYTERS, 1988; SILVERMAN; CARRICO, 1988) e efeitos geométricos (ZHANG; LYON, 1994; MULDER; SLUYTERS, 1988) que levam a uma distribuição não uniforme da corrente na superfície do eletrodo.

4.4.1 Cinética de liberação do inibidor encapsulado de dentro dos nanocontainers de sílica $\left(\mathrm{SiO}_{2}\right)$

$\mathrm{Na}$ Figura 4.20 apresentam-se as retas que representam a cinética linear de liberação da dodecilamina encapsulada por L-b-L dentro dos nanocontainers de sílica para diferentes tempos de imersão em solução $\mathrm{NaCl} 0,1 \mathrm{~mol} / \mathrm{L}$ e para diferentes valores de $\mathrm{pH}$. Pode-se observar que para $\mathrm{pH} 2$ o valor da razão do módulo de impedância para a situação com e sem nanocontainers, aumenta consideravelmente para tempos maiores (inclinação da reta 0,0039) em comparação com os valores obtidos para tempos mais curtos. No entanto, para os pHs 6,2 e 9 o aumento dos valores de módulo de impedância são mais graduais (inclinação da reta 0,001 ), ou seja, a liberação do inibidor é bastante lenta devido à resistência à abertura das paredes dos nanocontainers para esses valores de pH. Segundo as inclinações das retas obtidas das linhas de tendência, também se 
pode afirmar que para $\mathrm{pH}=2$ a velocidade de liberação do inibidor é 3,9 vezes maior em comparação com os valores obtidos para $\mathrm{pH}=6,2$ e $\mathrm{pH}=9$.

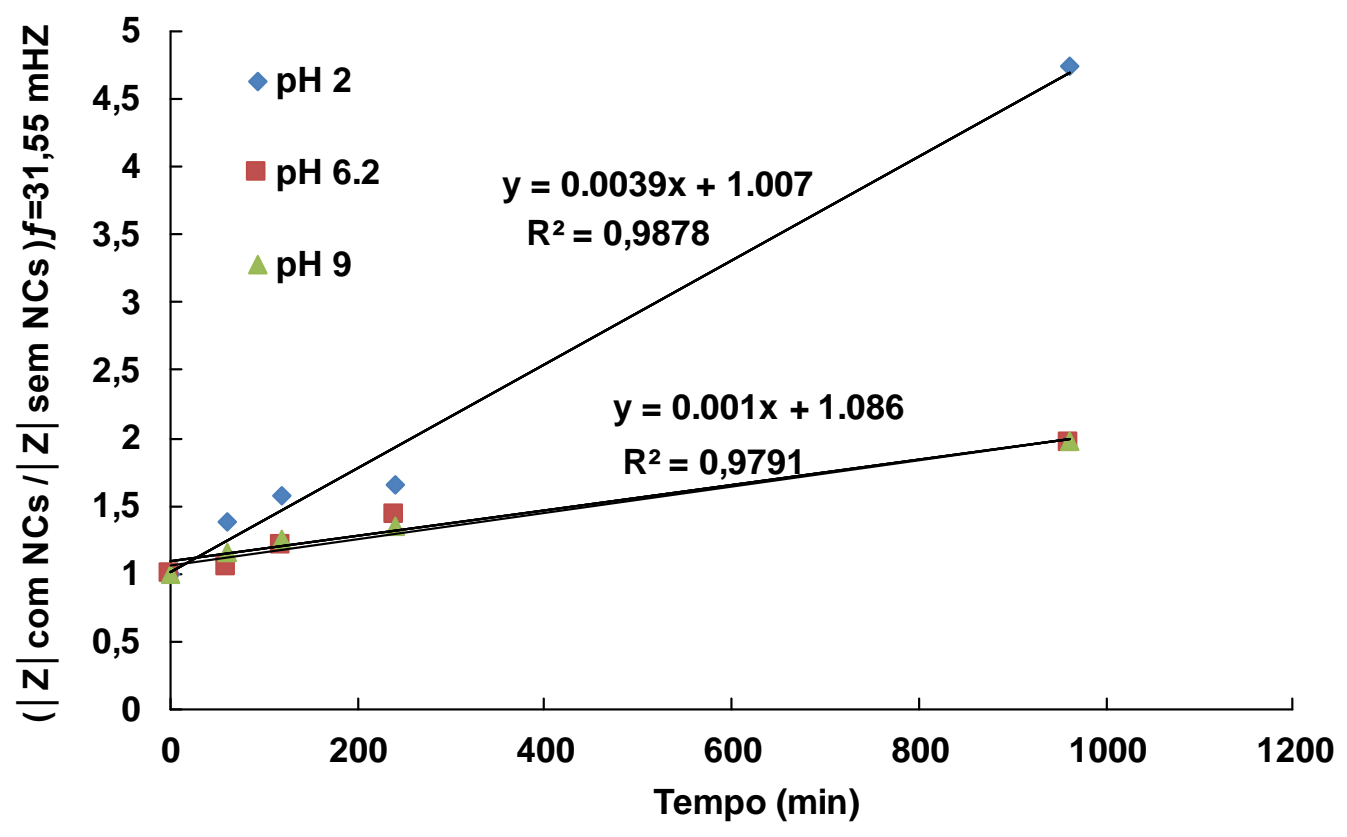

Figura 4.20 - Cinética da cinética de liberação do inibidor a partir das nanopartículas de sílica (Lb-L) para diferentes tempos de imersão numa solução de $\mathrm{NaCl} 0,1 \mathrm{~mol} / \mathrm{L}$ para valores de $\mathrm{pH}=2$, 6,2 e 9 usando como substrato uma chapa de aço carbono ABNT 1020.

Dos ensaios anteriores foi comprovado que para a condição de pH 2 existe uma maior quantidade de inibidor dodecilamina liberada a partir dos nanocontainers devido ao estímulo de variação de pH provocado nas paredes dos polieletrólitos, mas para corroborar esta hipótese foram feitos também ensaios em branco para saber se existe alguma influência dos polieletrólitos (PEI e PSS) que formam parte da estrutura das nanopartículas de sílica na inibição da corrosão do aço carbono. Antes disso, foram feitos ensaios de impedância para o aço carbono numa solução de $\mathrm{NaCl} 0,1 \mathrm{~mol} / \mathrm{L}$ com pH 2 e a diferentes tempos de imersão como é mostrado na Figura 4.21. Para esta condição de pH 2 pode-se observar que em ambos os diagramas de Nyquist e Bode, o valor do diâmetro de arco 
capacitivo e módulo de impedância não apresentaram uma variação significativa durante as $24 \mathrm{~h}$ de imersão. Isto significa que não há uma influência por parte do meio na proteção do aço carbono, já que não existem moléculas de inibidor que possam ser adsorvidas sobre o substrato.
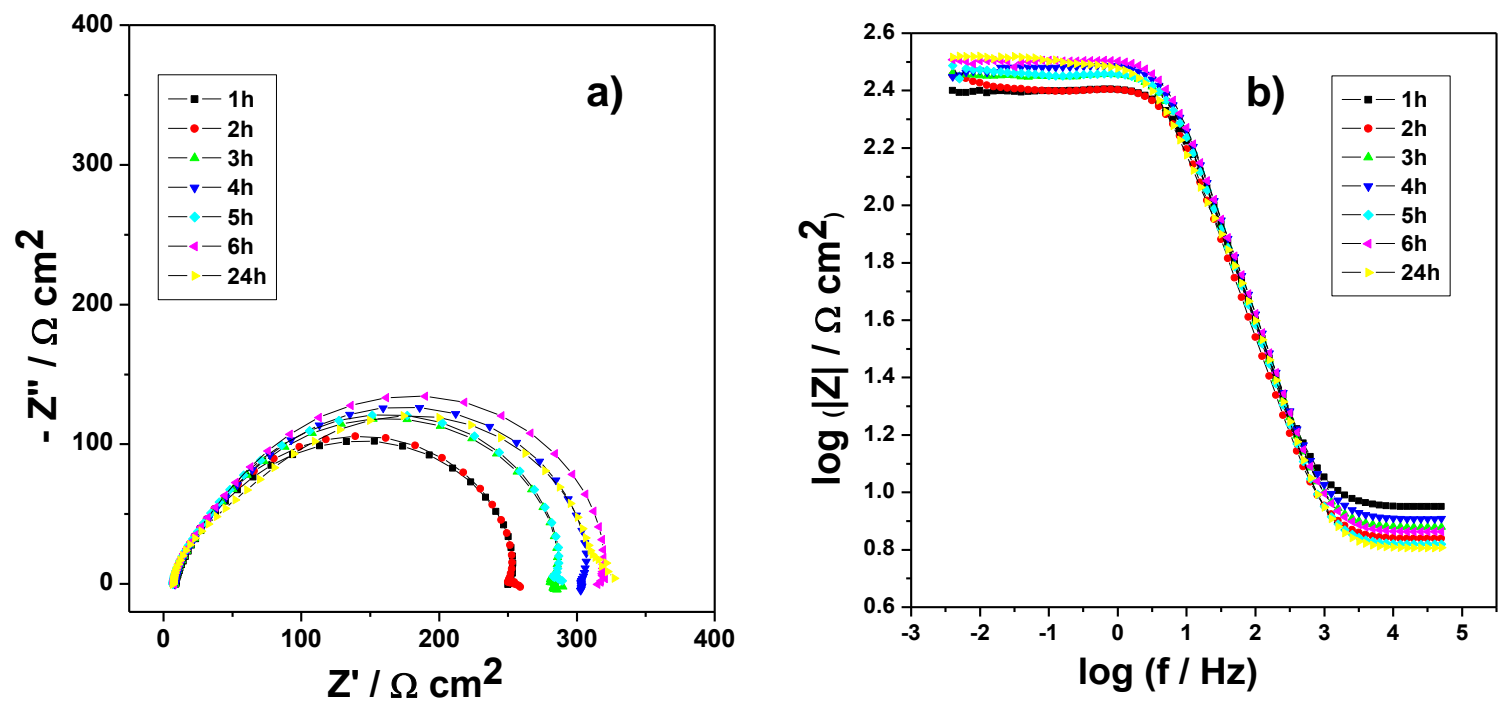

Figura 4.21 - Diagramas de Nyquist (a) e de Bode (b) para o aço carbono em diferentes tempos de imersão numa solução de $\mathrm{NaCl} 0,1 \mathrm{~mol} / \mathrm{L} \mathrm{com} \mathrm{pH}=2$ sem adição de nanocontainers com dodecilamina encapsulada por L-b-L.

Para observar alguma influência por parte dos polieletrólitos que conformam as paredes dos nanocontainers, foram feitos também ensaios de impedância para o aço carbono em diferentes tempos de imersão numa solução de $\mathrm{NaCl} 0,1 \mathrm{~mol} / \mathrm{L}$ com $\mathrm{pH} 2$ e contendo $1 \% \mathrm{~m} / \mathrm{m}$ de nanocontainers formados com camadas de PEI e PSS sem inibidor encapsulado. Estes resultados são mostrados na Figura 4.22 (a) onde é possível observar que existe um aumento nos valores de impedância com o decorrer do tempo devido à ação dos polieletrólitos (PEI e PSS) que retardam o ataque da solução agressiva sobre o substrato. Comparando os diagramas de Nyquist das Figuras 4.17 (a) e 4.22 (a) é possível observar que para um tempo de $16 \mathrm{~h}$ o valor do diâmetro do arco capacitivo do aço carbono imerso numa solução contendo $1 \% \mathrm{~m} / \mathrm{m}$ de nanocontainers com e sem inibidor encapsulado foi de $2250 \Omega . \mathrm{cm}^{2}$ e $750 \Omega . \mathrm{cm}^{2}$, respectivamente. Ou seja, na presença de nanocontainers com inibidor encapsulado o valor da impedância foi aproximadamente 3 vezes maior indicando uma maior ação por parte da 
dodecilamina na inibição da corrosão do aço carbono. Esta liberação do inibidor dodecilamina e dos polieletrólitos foi estudada mais detalhadamente através do uso de uma sonda de análise espectroscópica na região do infravermelho, a qual permitiu observar os aumentos das intensidades dos picos com o decorrer do tempo.
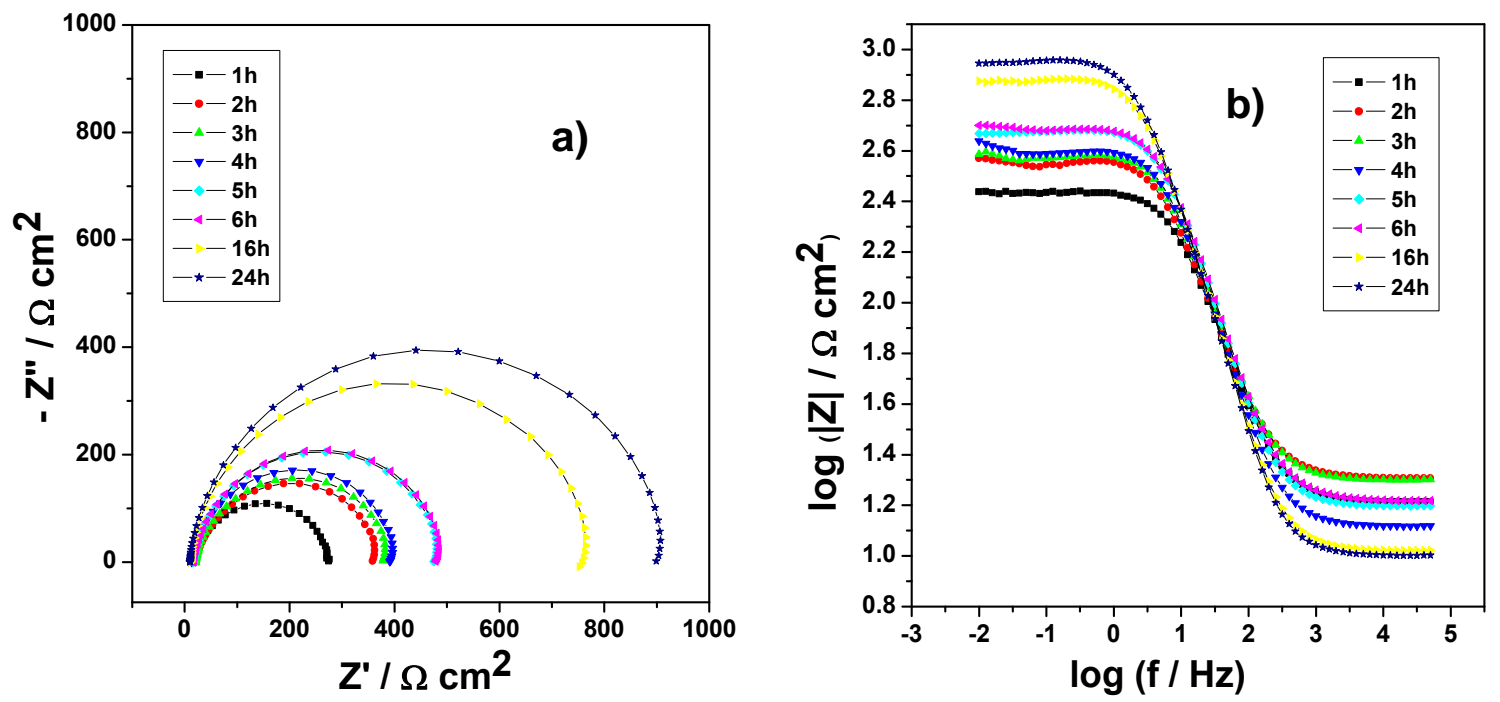

Figura 4.22 - Diagramas de Nyquist (a) e de Bode (b) para o aço carbono em diferentes tempos de imersão numa solução de $\mathrm{NaCl} 0,1 \mathrm{~mol} / \mathrm{L} \mathrm{com} \mathrm{pH}=2 \mathrm{com}$ adição de $1 \% \mathrm{~mm}$ de nanocontainers sem inibidor encapsulado.

4.4.2 Estudo da liberação do inibidor para diferentes procedimentos de dispersão das nanopartículas de sílica durante a obtenção dos nanocontainers

Nesta parte são apresentados os resultados obtidos para os dois tipos de tratamentos usados para a produção dos nanocontainers.

4.4.2.1 Nanocontainers obtidos pelo método sem uso de dispersante PVA e sem uso de ultrassom

A Figura 4.23 apresenta os diagramas de Nyquist para o aço carbono depois de diferentes tempos de imersão ( 1 h, 2 h, 3 h, 5 h e 17 h) numa solução de $\mathrm{NaCl}$ 0,1 mol/L a diferentes valores de $\mathrm{pH}(2$ e 6,2$)$ e contendo $1 \% \mathrm{~m} / \mathrm{m}$ de 
nanocontainers obtidos sem uso de dispersante PVA e ultrassom, e secos na estufa. Nestes diagramas pode-se observar que para a condição de pH 2 houve uma maior velocidade de liberação do inibidor em comparação com aquela obtida a $\mathrm{pH}$ 6,2, já que para longos tempos de imersão o diâmetro do arco capacitivo para a condição de pH 2 aumentou significativamente em comparação com os arcos capacitivos obtidos para tempos curtos de imersão, indicando assim uma maior permeabilidade das paredes dos polieletrólitos, os quais se abrem para valores de $\mathrm{pH}<3$ (LAMAKA et al., 2008; ANDREEVA et al., 2008; SHCHUKIN; MÖHWALD, 2007; ZHELUDKEVICH et al., 2007; SKORB et al., 2009; ANDREEVA et al., 2010). No entanto, para a condição de pH 6,2 as paredes dos polieletrólitos fecham-se e mantém o inibidor dentro de sua estrutura até que existam mudanças no $\mathrm{pH}$ (abaixamento) produzidas pelo processo de corrosão na áreas com defeito.
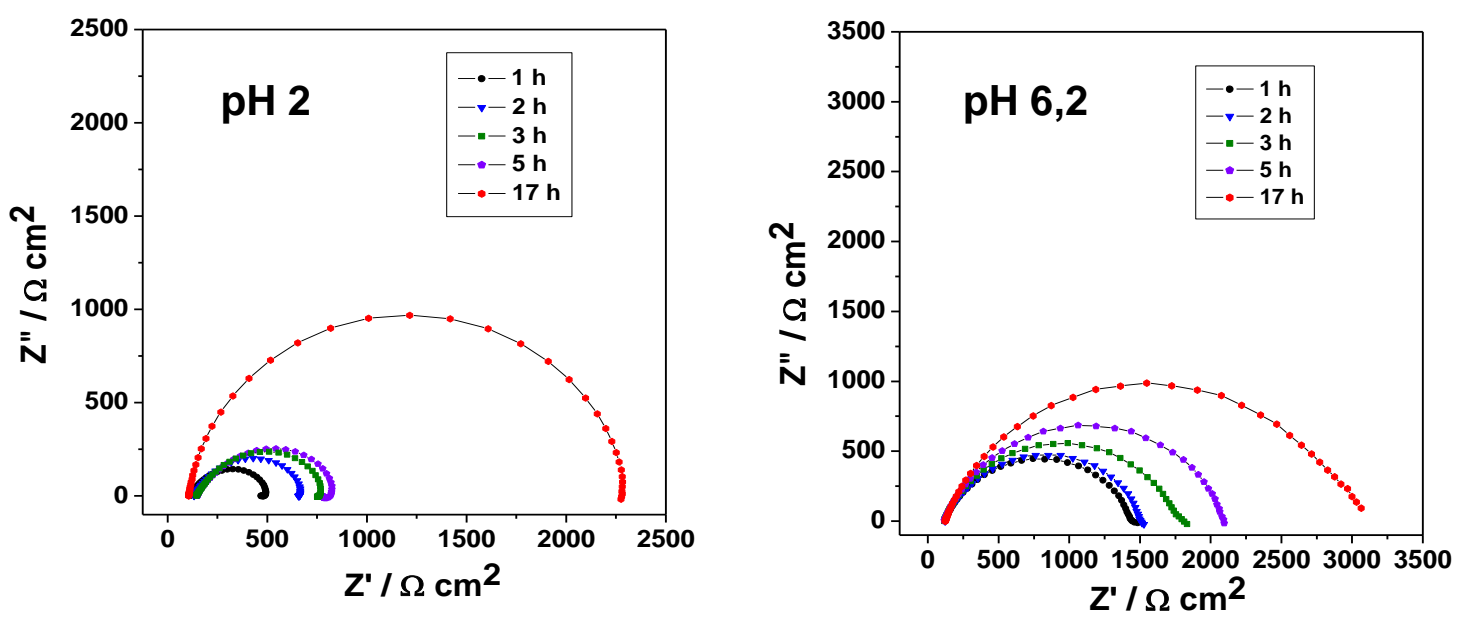

Figura 4.23 - Diagramas de Nyquist para o aço carbono seguindo o primeiro tratamento sem dispersante e sem ultrassom em diferentes tempos de imersão numa solução de $\mathrm{NaCl}$ $0,1 \mathrm{~mol} / \mathrm{L}$ para $\mathrm{pH}=2 \mathrm{e} \mathrm{pH}=6,2$ e contendo $1 \%$ em massa de nanocontainers.

4.4.2.2 Nanocontainers obtidos pelo método com uso de dispersante PVA e de ultrassom

A Figura 4.24 apresenta os diagramas de Nyquist para o aço carbono depois de diferentes tempos de imersão (1 h, 2 h, 3 h, 5 h e 17 h) numa solução agressiva de $\mathrm{NaCl}$ 0,1 mol/L a diferentes valores de $\mathrm{pH}(2$ e 6,2) e contendo $1 \% \mathrm{~m} / \mathrm{m}$ de nanocontainers obtidos com uso de dispersante PVA e tratados em 
banho ultrassônico e secos ao ar. Para este caso, na condição de pH 2 houve também uma maior velocidade de liberação do inibidor em comparação com a condição de pH 6,2, mas a quantidade do inibidor liberado para este caso foi muito menor que a obtida em $\mathrm{pH} \mathrm{2,} \mathrm{seguindo} \mathrm{o} \mathrm{primeiro} \mathrm{tratamento.} \mathrm{Uma} \mathrm{possível}$ explicação deste fato são os diferentes tempos de imersão dos nanocontainers em solução de PVA (1\%), o que pode ter originado uma fuga espontânea do inibidor dos nanocontainers.
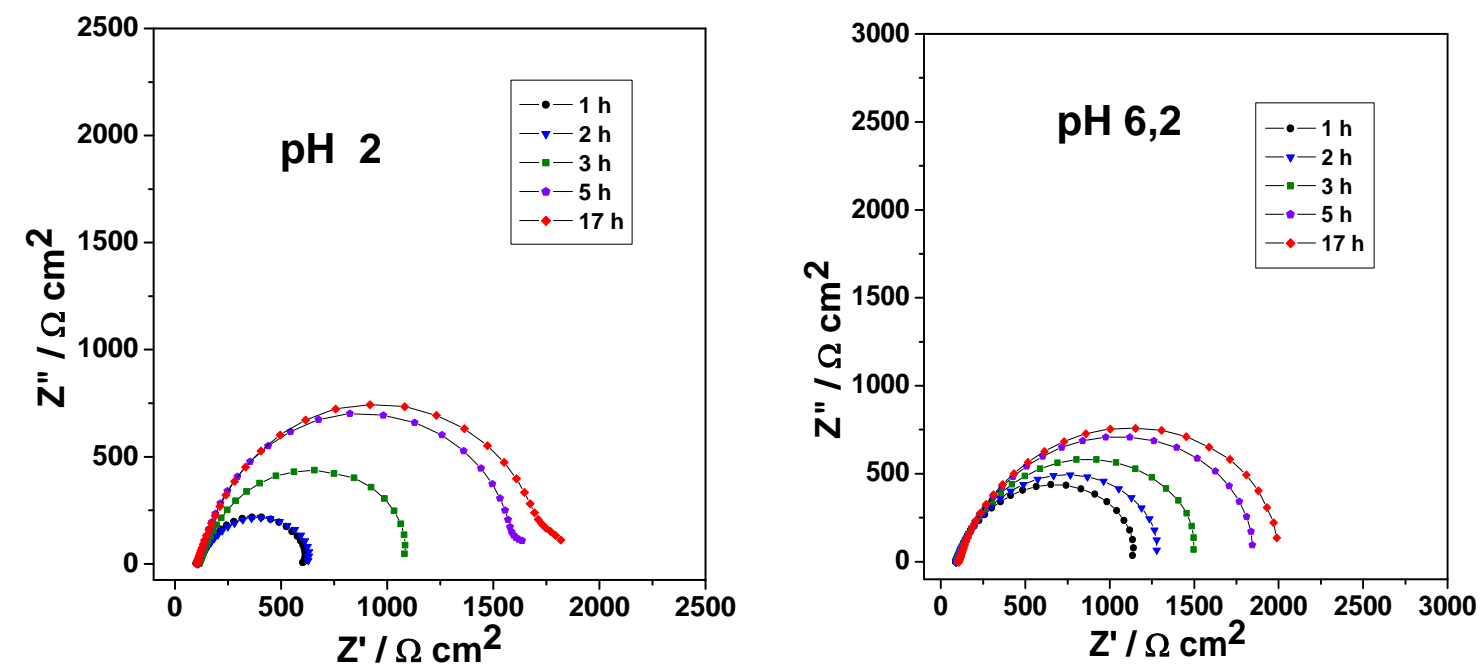

Figura 4.24 - Diagramas de Nyquist para o aço carbono seguindo o segundo tratamento em diferentes tempos de imersão numa solução de $\mathrm{NaCl} 0,1 \mathrm{~mol} / \mathrm{L}$ para $\mathrm{pH}=2 \mathrm{e} \mathrm{pH}=$ 6.2 e contendo $1 \%$ em massa de nanocontainers.

De acordo com os tratamentos feitos para a obtenção dos nanocontainers, o segundo procedimento foi melhor em termos do tamanho das partículas, já que pelo primeiro procedimento os nanocontainers eram muito grandes quando secos na estufa e sua dispersão na tinta para a aplicação, resultava mais difícil. No entanto, o uso do PVA como dispersante em todas as etapas de preparação provocou a liberação de uma parte do inibidor como foi mostrado nos gráficos de impedância.

Dessa forma o método escolhido para a produção dos nanocontainers foi usando como dispersante água destilada com um tempo $30 \mathrm{~min}$ no ultrassom e 
secados ao ar, no final. Na Figura 4.25 se mostram as micrografias obtidas no microscópio eletrônico de varredura dos nanocontainers produzidos.

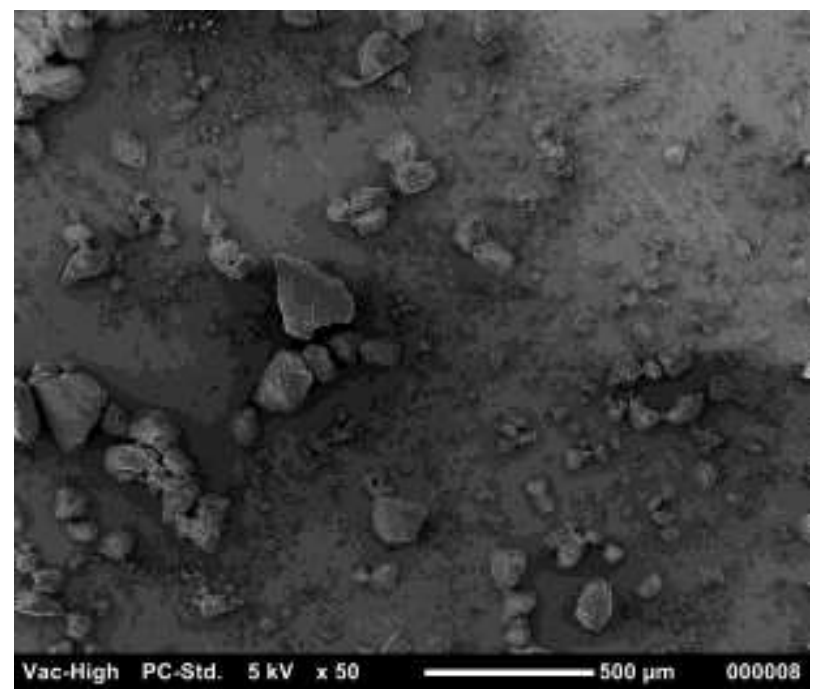

Figura 4.25 - Imagens dos nanocontainers de nanopartículas de sílica carregados de dodecilamina por L-b-L obtidas por MEV.

\subsection{Estudo da liberação do inibidor dodecilamina encapsulado sobre nanopartículas de sílica usando uma sonda de análise na região do infra- vermelho}

A Figura 4.26 mostra a superposição dos espectros da dodecilamina polietilenimina, poliestirenosulfonado, onde é possível observar um pico intenso em $1596 \mathrm{~cm}^{-1}$ correspondente a dodecilamina pura. Este pico foi monitorado durante todo o ensaio para confirmar a saída do inibidor dodecilamina a partir dos nanocontainers. 


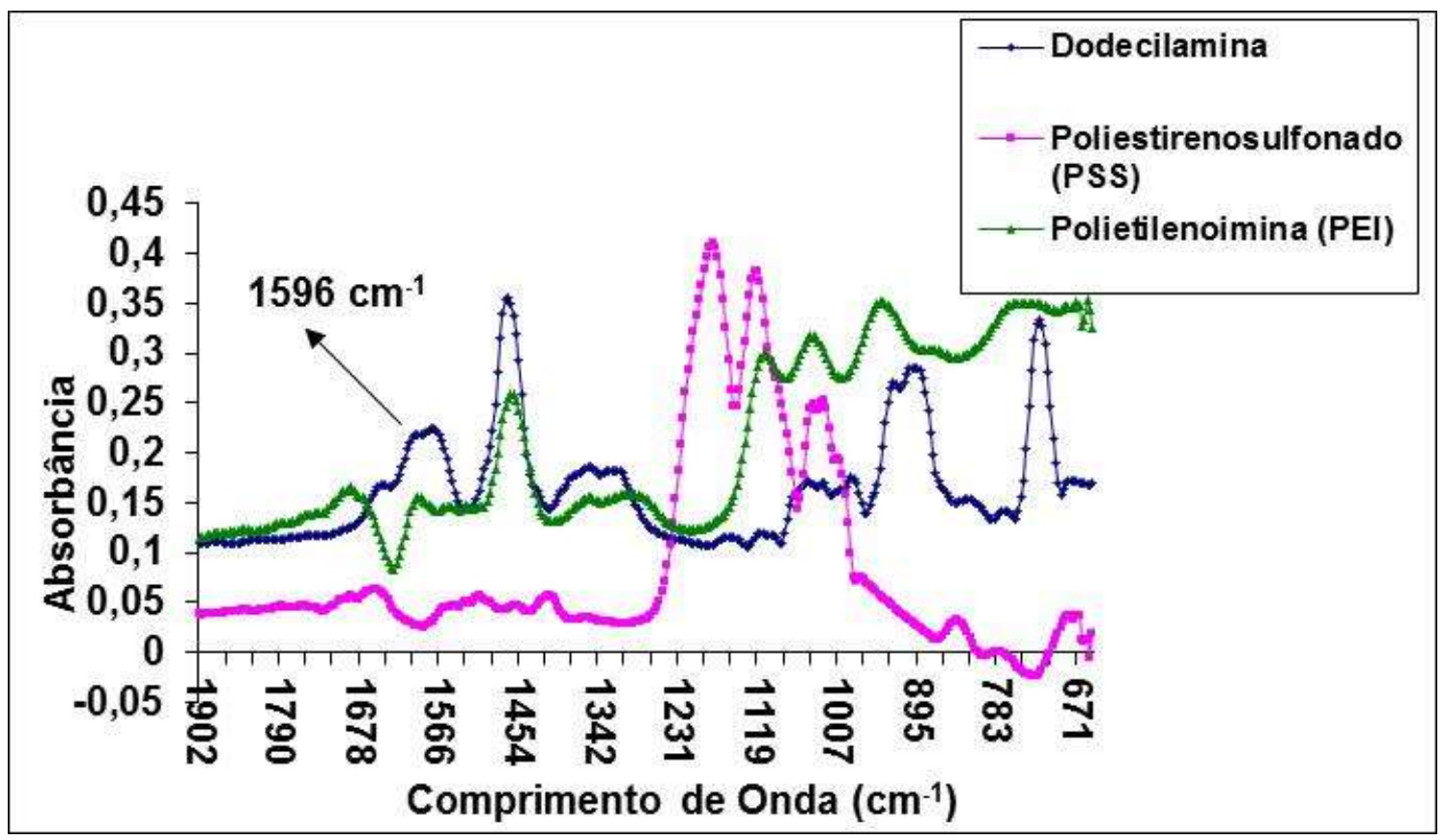

Figura 4.26 - Espectros de infravermelho para a dodecilamina, poliestirenosulfonado (PSS) e polietilenoimina (PEI) obtidos por subtração do espectro do solvente.

A Figura 4.27 ilustra um gráfico tridimensional dos espectros em função do tempo, onde é possível observar o aparecimento de três picos durante o experimento; um primeiro pico localizado em $1100 \mathrm{~cm}^{-1}$ e outro em $1640 \mathrm{~cm}^{-1}$, os quais são atribuídos às superposições dos picos do poliestirenosulfonado (PSS) e polietilenimina (PEI); o terceiro pico localizado em $1596 \mathrm{~cm}^{-1}$ é relacionado à liberação da dodecilamina. Portanto, pode ser concluído que além da liberação da dodecilamina, houve também liberação dos polieletrólitos que conformam as paredes dos nanocontainers. 


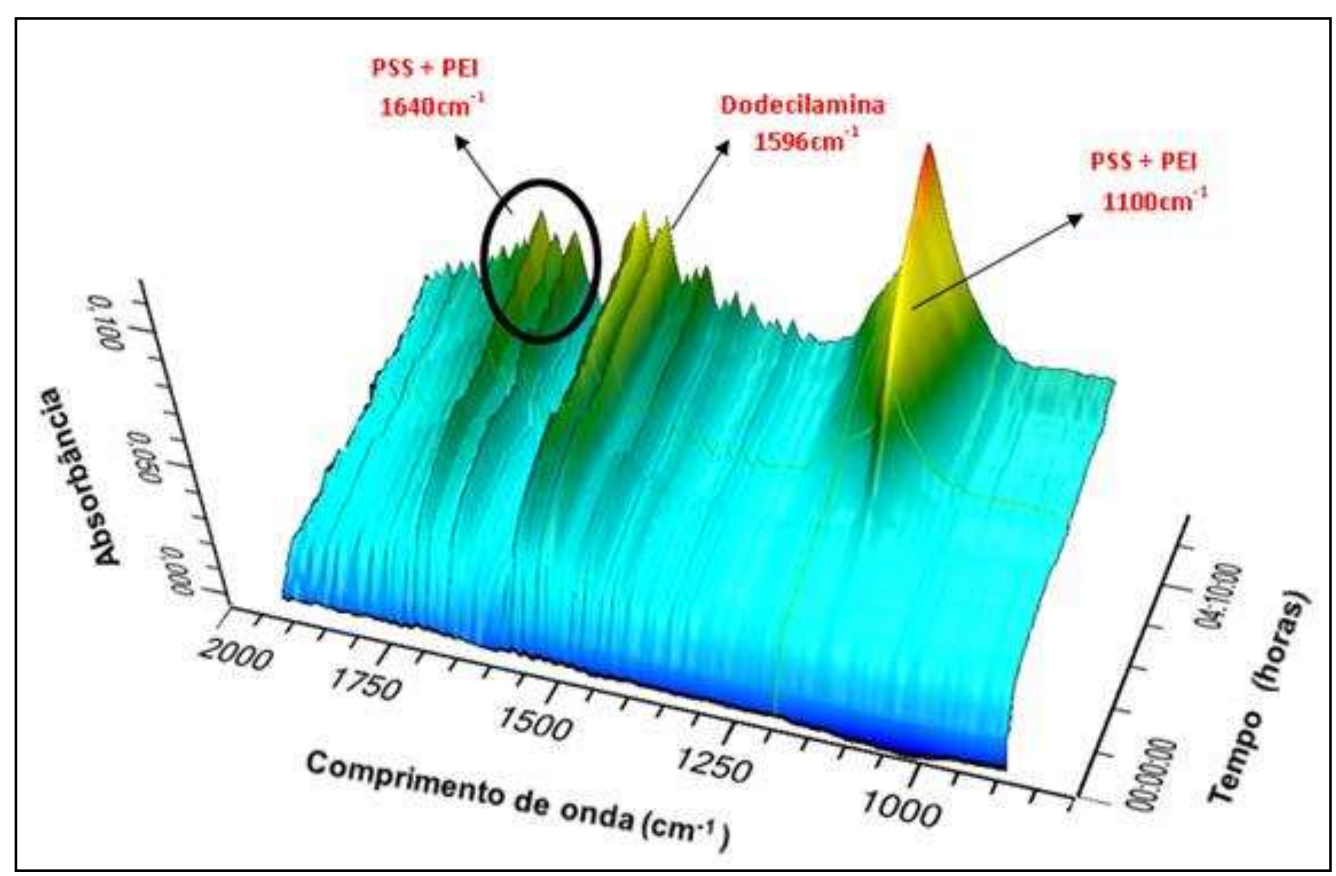

Figura 4.27 - Gráfico 3D dos espectros obtidos da liberação da dodecilamina e dos polieletrólitos (PEI e PSS) em função do tempo (subtraído o solvente inicial).

$\mathrm{Na}$ Figura 4.28 pode ser visto em forma mais clara a liberação do inibidor dodecilamina a partir dos nanocontainers em função do tempo para a condição de $\mathrm{pH} 2$, onde o pico de absorbância localizado em $1596 \mathrm{~cm}^{-1}$ incrementa com o tempo. Em resumo, este sistema é sensível à variação do $\mathrm{pH}$ na região ácida liberando o inibidor de corrosão sob demanda, quando o processo corrosivo começa. 


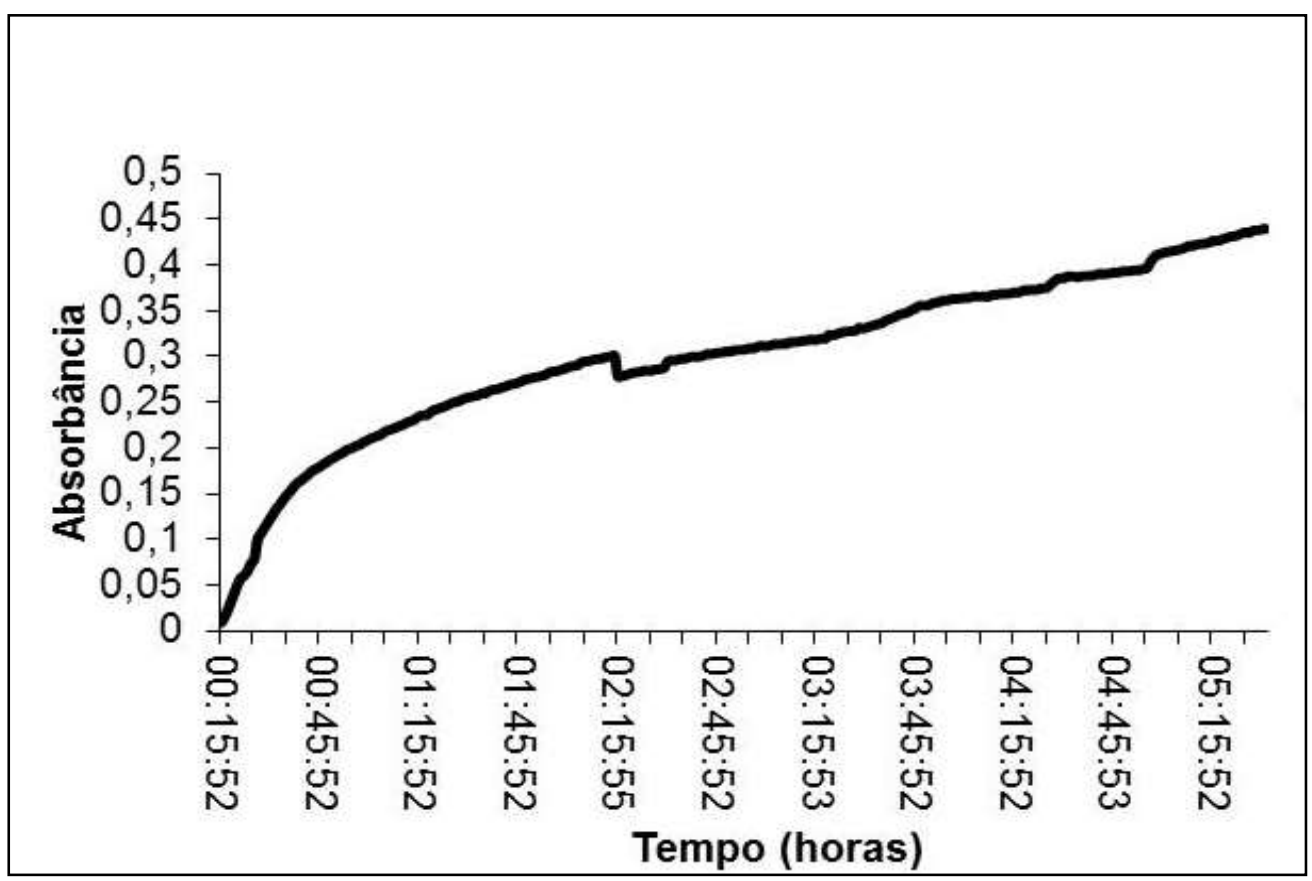

Figura 4.28 - Intensidade do pico de absorbância a $1596 \mathrm{~cm}^{-1}$ em função do tempo mostrando a liberação do inibidor de corrosão dodecilamina a partir dos nanocontainers a pH 2.

\subsection{Avaliação por EIE da cinética de liberação do inibidor dodecilamina encapsulado sobre nanopartículas de haloisita para diferentes valores de $\mathrm{pH}$}

Nas Figuras 4.29, 4.30 e 4.31 são apresentados os diagramas de Nyquist e de Bode para o aço carbono obtidos em solução aquosa de $\mathrm{NaCl}$ 0,1 mol/L contendo $1 \%$ de nanocontainers de haloisita contendo dodecilamina encapsulada para valores de pH 2, 6,2 e 9 e diferentes tempos de imersão. Estes estudos foram feitos para testar como o pH influi na liberação do inibidor à medida que o substrato é imerso por longos períodos de tempo, num meio corrosivo.

$\mathrm{Na}$ Figura 4.29 apresentam-se os diagramas de impedância para o aço carbono para diferentes tempos de imersão numa solução $\mathrm{NaCl} 0,1 \mathrm{~mol} / \mathrm{L}$ com $\mathrm{pH}=2$ e contendo $1 \%$ em massa de nanotubos de haloisita, onde se pode observar que para tempos iniciais de imersão ( 1 h, 2 h, 3 h e 5 h) há um pequeno aumento nos diâmetros dos arcos capacitivos mostrados nos diagramas de Nyquist e cujos valores oscilam em torno de $200 \Omega . \mathrm{cm}^{2}$, mas para períodos longos 
de imersão (18 h, 36 h e 48 h) este diâmetro aumenta significativamente até um valor de $1100 \Omega . \mathrm{cm}^{2}$, e que pode ser conferido no diagrama de Bode de ângulo de fase, $\theta$ vs log $f$ onde há um deslocamento a partir de frequências maiores para frequências menores para o máximo ângulo de fase que cresce com o tempo, indicando um caráter mais protetor do inibidor para o aço para maiores tempos de imersão. Estes resultados confirmam que a liberação do inibidor é significativamente acelerada em $\mathrm{pH}$ baixos, e já que uma atividade de corrosão está associada a mudanças no $\mathrm{pH}$ local para valores menores (ZHELUDKEVICH et al., 2007; TWITE; BIERWAGEN, 1998; ANDREEVA et al., 2008; PALANIVEL; HUANG; VAN OolJ, 2005; BECK et al., 1995) pode-se prever uma liberação garantida de inibidor em zonas onde haja corrosão.
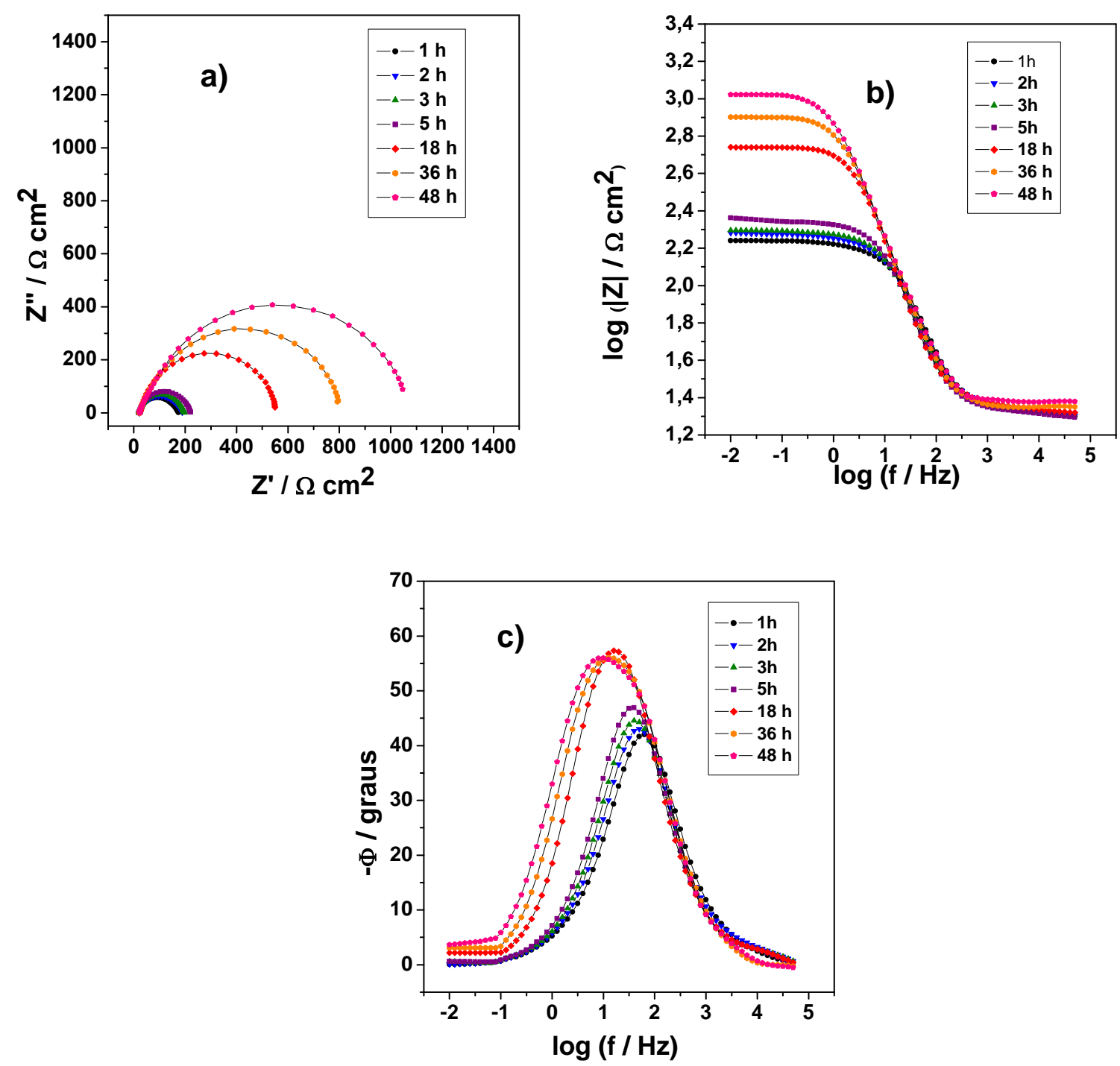

Figura 4.29 - Diagramas de Nyquist (a) e de Bode ((b) e (c)) para o aço carbono, para diferentes tempos de imersão numa solução de $\mathrm{NaCl} 0,1 \mathrm{~mol} / \mathrm{L} \mathrm{com} \mathrm{pH}=2$ e contendo $1 \%$ em massa de nanotubos de haloisita com dodecilamina encapsulada como inibidor de corrosão. 
Na Figura 4.30 são apresentados os diagramas de impedância para o aço carbono para diferentes tempos de imersão numa solução $\mathrm{NaCl} 0,1 \mathrm{~mol} / \mathrm{L} \mathrm{com} \mathrm{pH}$ = 6,2 e contendo $1 \%$ massa de nanotubos de haloisita contendo dodecilamina encapsulada. Neste caso pode-se observar que para períodos curtos de imersão ( 1 h, 2 h, 3 h e 5 h) o diâmetro do arco capacitivo ficou em torno de $1700 \Omega . \mathrm{cm}^{2}$. Já para longos períodos de imersão (18 h, 36 h, 48 h) pode-se observar só um ligeiro acréscimo do diâmetro capacitivo até $2000 \Omega . \mathrm{cm}^{2}$, o que pode levar a concluir que para esta condição de pH quase neutro, a liberação do inibidor de dentro do lúmen da haloisita é bastante difícil, ou seja, as paredes da haloisita estão fechadas até que existam mudanças fortes de pH levando-o para valores mais baixos, onde já se verificou que ocorre a saída do inibidor .

Outro detalhe observado no diagrama de Bode foi que para tempos maiores de imersão existe um pequeno deslocamento das constantes de tempo, onde os altos valores de ângulo de fase se estendem por uma faixa de frequências maior, indicando a presença de um filme adsorvido sobre o aço carbono, mas que não é tão efetivo para suprimir os fenômenos de troca de carga na interface do metal/eletrólito. 

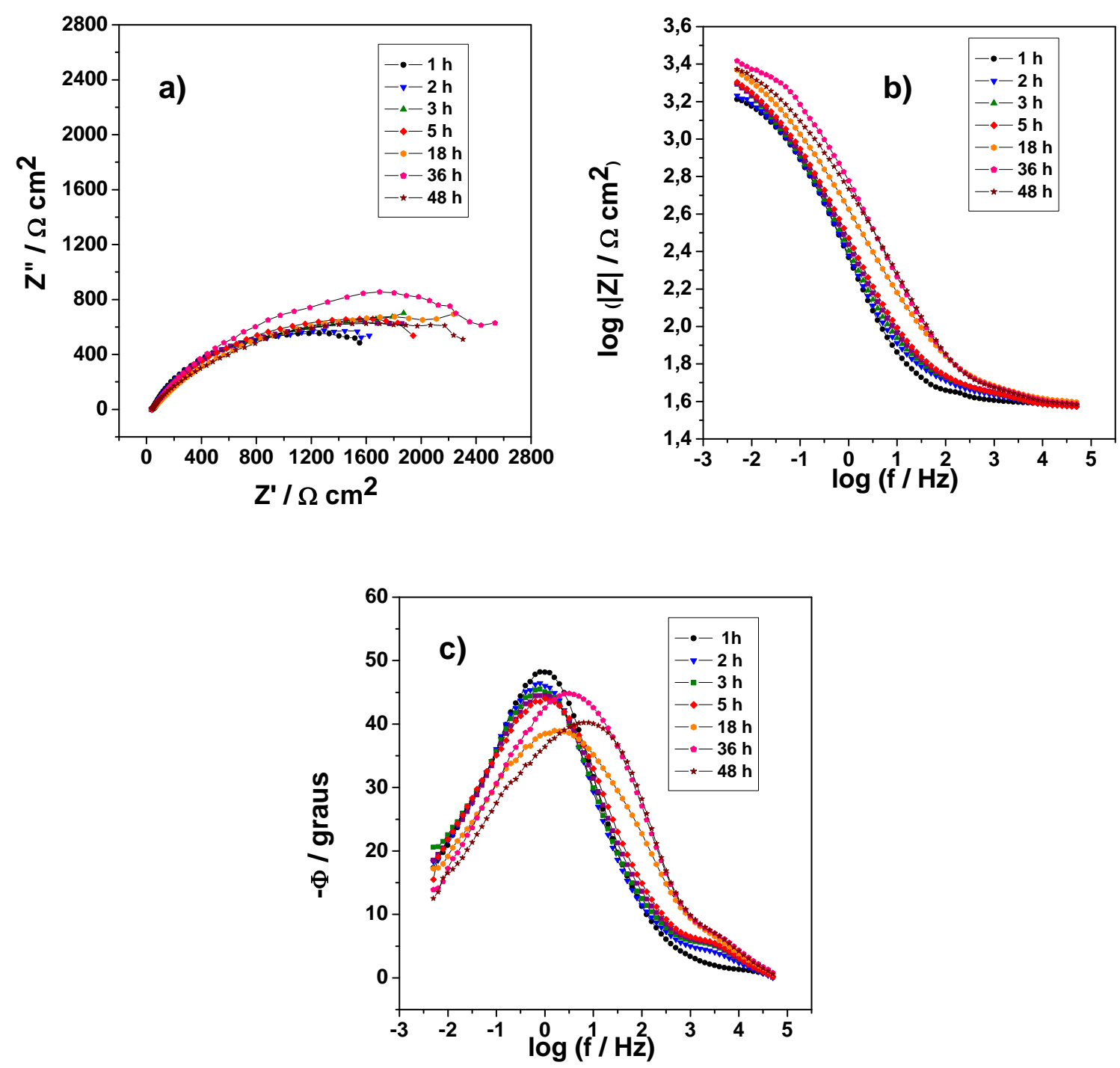

Figura 4.30 - Diagramas de Nyquist (a) e de Bode ((b) e (c)) para o aço carbono, para diferentes tempos de imersão numa solução de $\mathrm{NaCl} 0,1 \mathrm{~mol} / \mathrm{L} \mathrm{com} \mathrm{pH}=6,2$ e contendo $1 \%$ em massa de nanotubos de haloisita com dodecilamina encapsulada como inibidor de corrosão.

Para a condição de pH 9, a Figura 4.31 mostra os resultados de impedância para o aço carbono para diferentes tempos de imersão numa solução $\mathrm{NaCl}$ $0,1 \mathrm{~mol} / \mathrm{L}$ contendo $1 \%$ em massa de nanotubos de haloisita carregados com inibidor dodecilamina. Nesta condição é possível também observar um ligeiro aumento no valor do diâmetro de arco capacitivo para longos tempos de imersão (18 h, 36 h, 48 h) em comparação com os valores obtidos para tempos de curtos 
de imersão ( 1 h, 2 h, 3 h e 5 h) devido a que as paredes da haloisita impedem uma possível fuga do inibidor para essa condição de $\mathrm{pH}$.

Em comparação com a condição para pH 6,2 é também observado no diagrama de Bode (Figura $4.31 \mathrm{c}$ ) um deslocamento da constante de tempo para frequências maiores e em tempos grandes de imersão, indicando a presença de um filme adsorvido, mas que neste caso é efetivo, já que bloqueia a entrada de espécies agressivas para o metal.
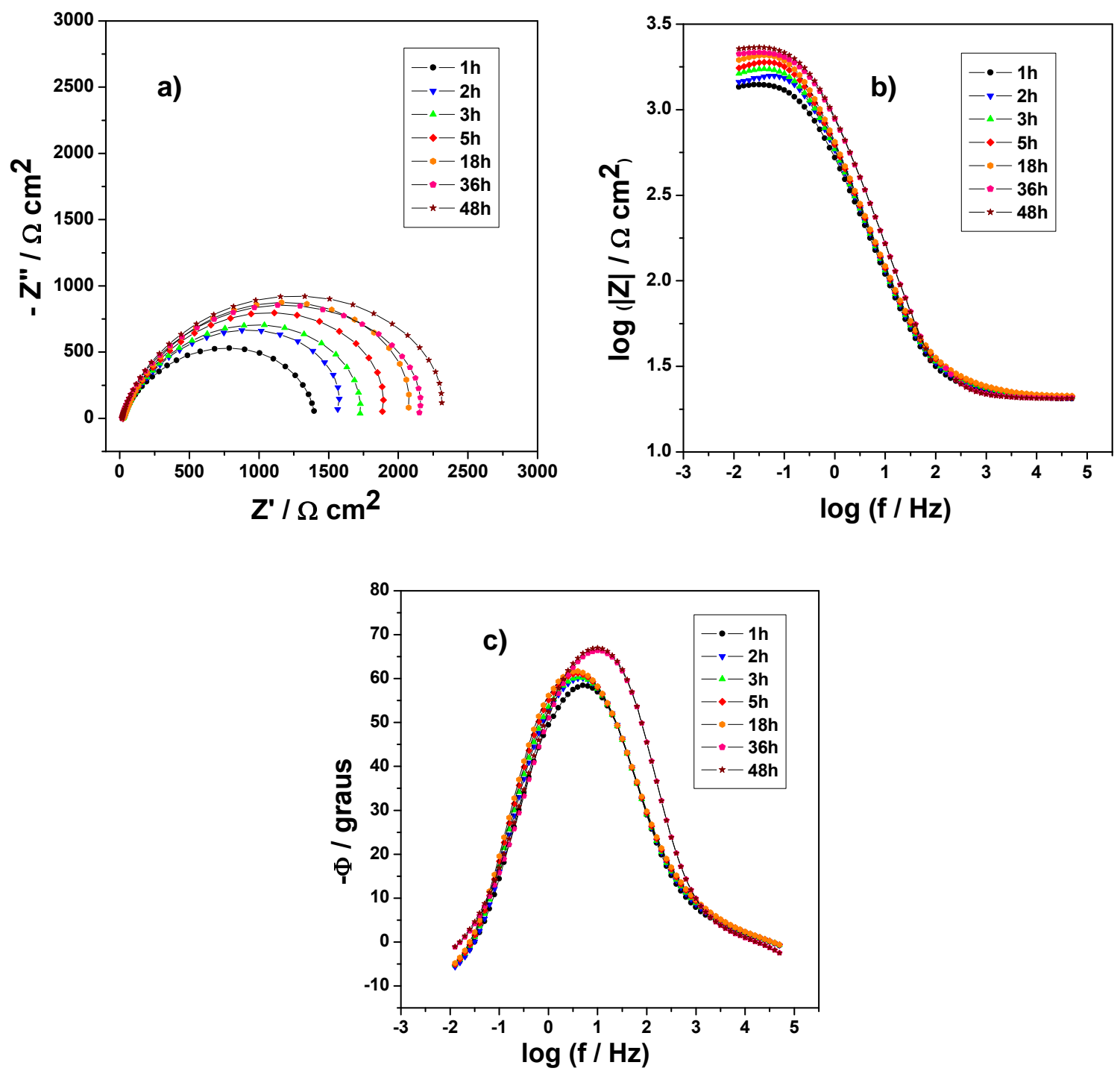

Figura 4.31 - Diagramas de Nyquist (a) e de Bode ((b) e (c)) para o aço carbono, para diferentes tempos de imersão numa solução de $\mathrm{NaCl} 0,1 \mathrm{~mol} / \mathrm{L} \mathrm{com} \mathrm{pH}=9$ e contendo $1 \%$ em massa de nanotubos de haloisita com dodecilamina encapsulada como inibidor de corrosão. 
De acordo aos valores obtidos nos diagramas de Nyquist e Bode pode-se concluir que para a condição de $\mathrm{pH}=2$, existe uma maior liberação do inibidor para tempos longos de imersão em comparação com a condição de $\mathrm{pH}=6,2$, e desta forma é possível conseguir um efeito self-healing em tintas anticorrosivas aditivadas com estes nanocontainers carregados com inibidor dodecilamina, já que 0 efeito self-healing de áreas danificadas pelo processo de corrosão pode ocorrer através de três tipos de mecanismos: neutralização do $\mathrm{pH}$, passivação da área danificada do metal por inibidores de corrosão encapsulados e reparação do revestimento (ANDREEVA et al., 2008).

4.6.1 Cinética de liberação do inibidor encapsulado de dentro dos nanotubos de haloisita para diferentes $\mathrm{pHs}$

$\mathrm{Na}$ Figura 4.32 apresentam-se as curvas de cinética de liberação da dodecilamina encapsulada dentro dos nanotubos de haloisita para diferentes tempos de imersão em solução $\mathrm{NaCl} 0,1 \mathrm{~mol} / \mathrm{L}$ e para diferentes valores de $\mathrm{pH}$. Pode-se observar que para pH 2 o valor da razão do módulo de impedância na presença e ausência da haloisita aumenta consideravelmente para tempos maiores em comparação com os valores obtidos para tempos mais curtos. No entanto, para pH 6,2 e 9 o aumento dos valores de módulo de impedância não foram muito significativos, sendo a liberação do inibidor mais lenta para esta condição de $\mathrm{pH}$. Outro fato que pode ser concluído segundo as inclinações das retas é que para condição de $\mathrm{pH}=2$ a velocidade de liberação do inibidor é 5,5 vezes maior em comparação com o valor obtido para $\mathrm{pH}=6,2$. 


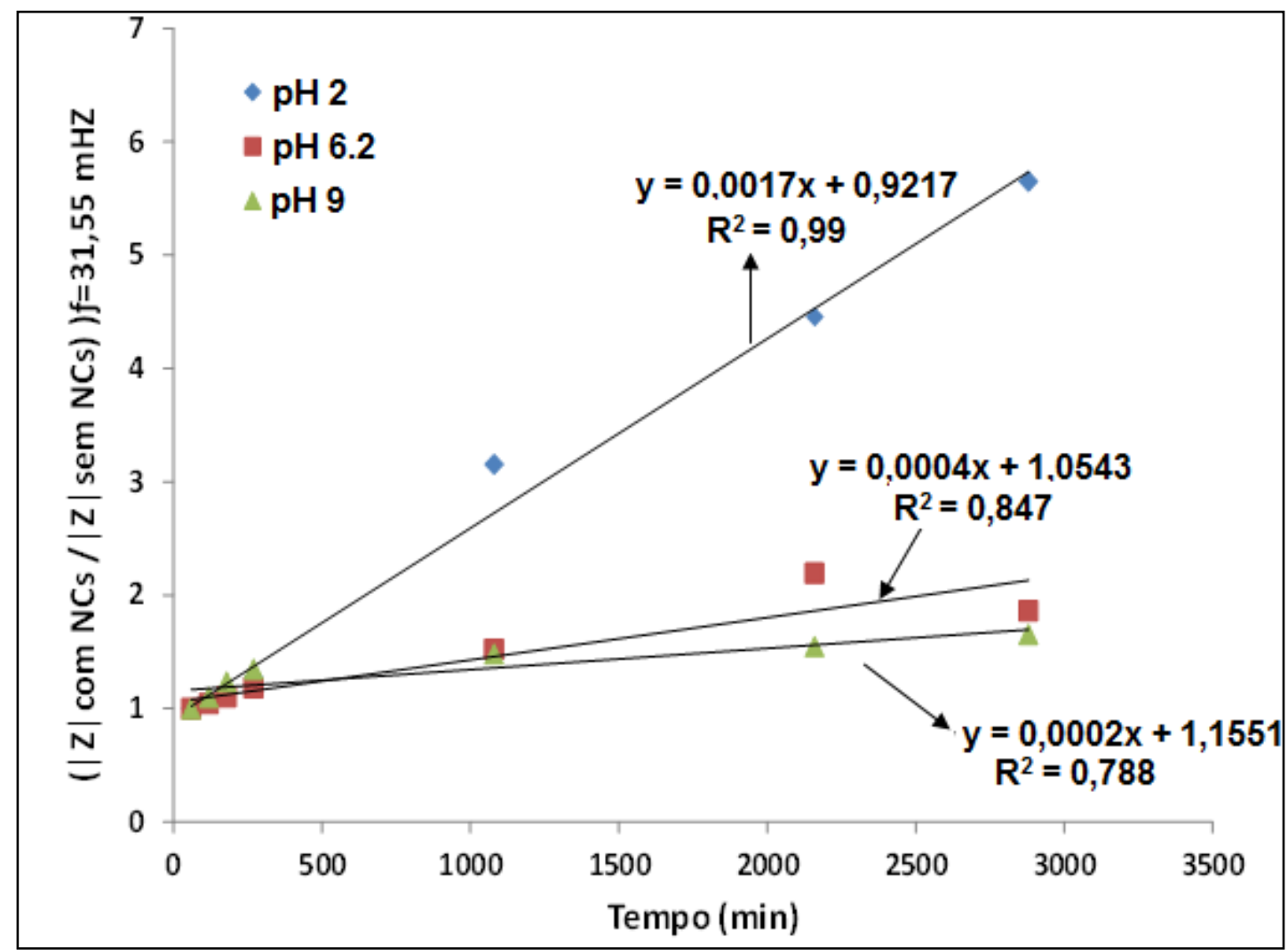

Figura 4.32 - Curvas da cinética de liberação do inibidor a partir da haloisita obtidas para diferentes tempos de imersão numa solução de $\mathrm{NaCl} 0,1 \mathrm{~mol} / \mathrm{L}$ para valores $\mathrm{de} \mathrm{pH}=2,6,2$ e 9 usando como substrato uma chapa de aço carbono ABNT 1020.

\subsection{Avaliação por EIE da cinética de liberação do inibidor dodecilamina encapsulado sobre partículas de sílica mesoporosa para diferentes valores de $\mathrm{pH}$}

Seguindo o mesmo procedimento feito para as partículas de sílica e haloisita foram também realizados ensaios de liberação do inibidor de corrosão a partir das nanopartículas de sílica mesoporosa em solução aquosa de $\mathrm{NaCl}$ $0,1 \mathrm{~mol} / \mathrm{L}$ para diferentes valores de $\mathrm{pH}(2,9$ e 6,2) e diferentes tempos de imersão.

No diagrama de Nyquist para a condição de pH 2 mostrado na Figura 4.33 (a) pode se observar aumentos pequenos nos valores dos diâmetros dos arcos capacitivos correspondentes a tempos iniciais de imersão $(1 \mathrm{~h}, 2 \mathrm{~h}, 3 \mathrm{~h}, 4 \mathrm{~h}, 5 \mathrm{~h}$ e 
6 h). Para períodos de imersão mais longos ( 24 h, 26 h e 28 h) o diâmetro do arco capacitivo aumentou até um valor de $1750 \Omega . \mathrm{cm}^{2}$, o qual pode ser confirmado no diagrama de Bode de ângulo de fase, $\theta$ contra log de fonde há um deslocamento de frequências maiores para frequências menores para o máximo ângulo de fase que cresce com o tempo. Este caráter mais protetor para o aço com o tempo é devido à ação do inibidor dodecilamina liberado a partir das partículas de sílica mesoporosa e que age formando um filme adsorvido sobre a superfície do aço carbono.
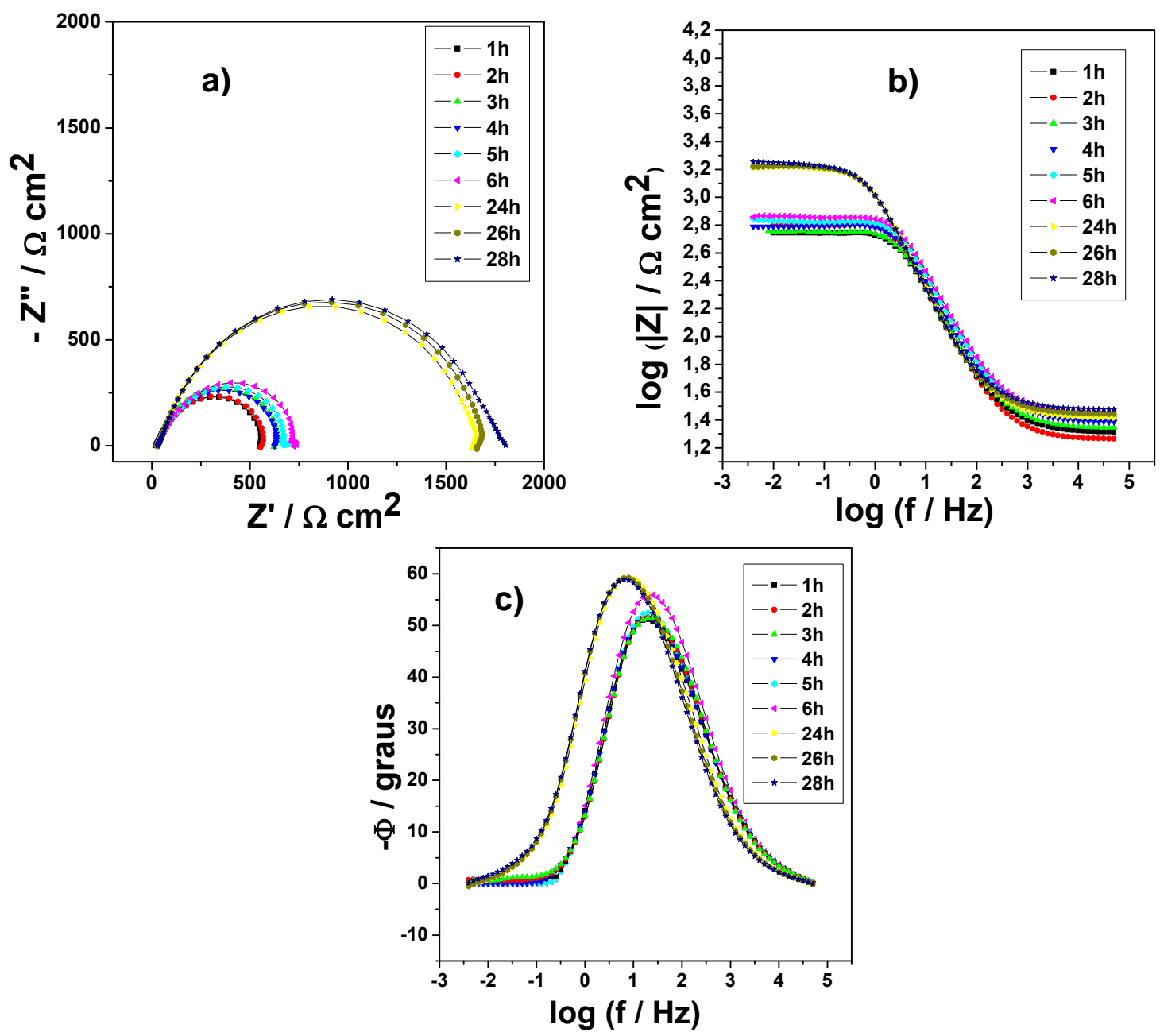

Figura 4.33 - Diagramas de Nyquist (a) e de Bode ((b) e (c)) para o aço carbono, para diferentes tempos de imersão numa solução de $\mathrm{NaCl} 0,1 \mathrm{~mol} / \mathrm{L} \mathrm{com} \mathrm{pH}=2$ e contendo $1 \% \mathrm{em}$ massa de sílica mesoporosa com dodecilamina encapsulada. 

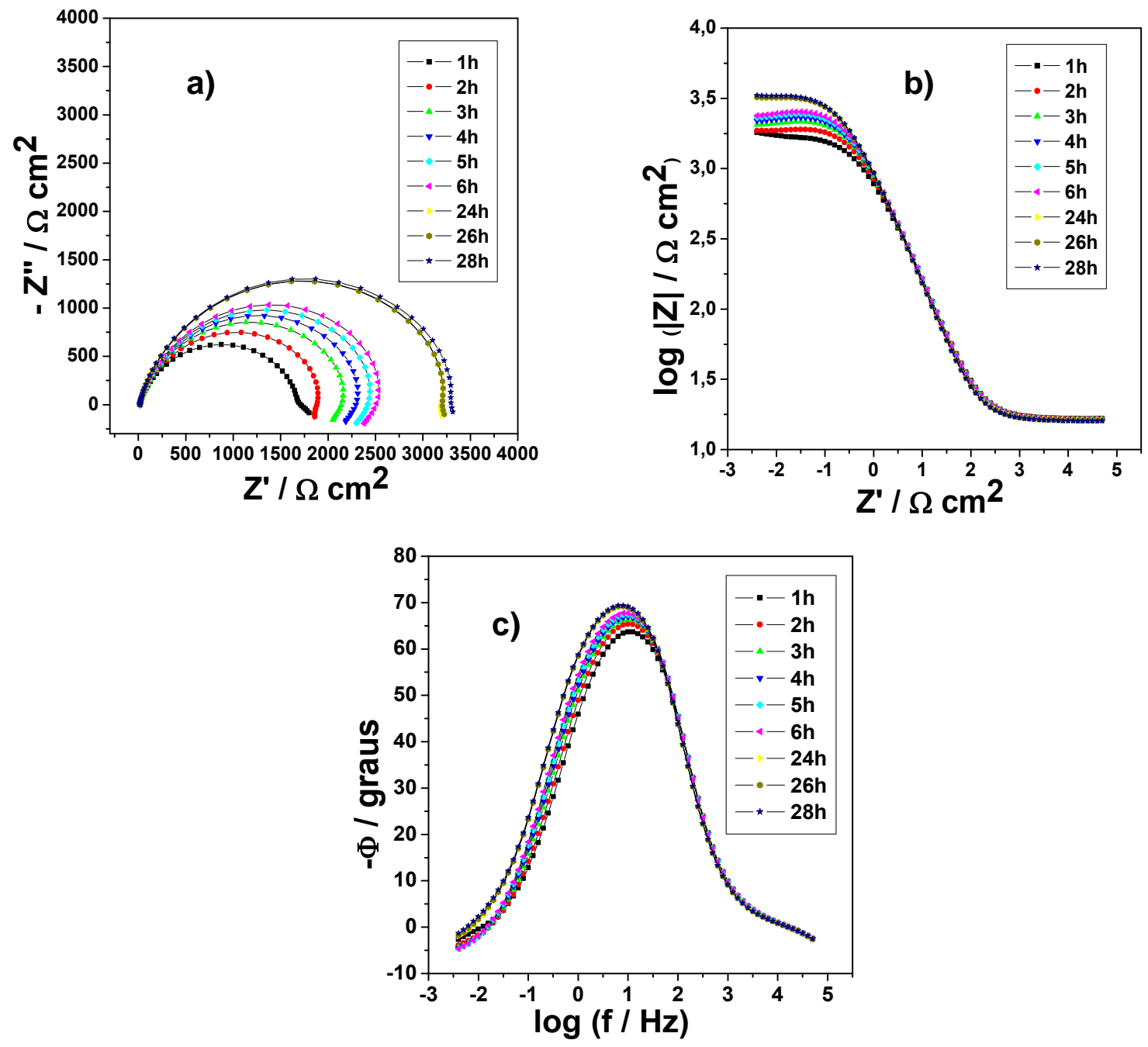

Figura 4.34 - Diagramas de Nyquist (a) e de Bode ((b) e (c)) para o aço carbono, para diferentes tempos de imersão numa solução de $\mathrm{NaCl} 0,1 \mathrm{~mol} / \mathrm{L} \mathrm{com} \mathrm{pH}=6,2$ e contendo $1 \%$ em massa de sílica mesoporosa com dodecilamina encapsulada.

A Figura 4.34 mostra os resultados de impedância para a condição de pH quase neutro $(6,2)$ em diferentes tempos de imersão, onde se pode observar um comportamento similar ao obtido para a condição de $\mathrm{pH} 2$, só que desta vez 0 aumento do valor do diâmetro de arco capacitivo para tempos longos de imersão

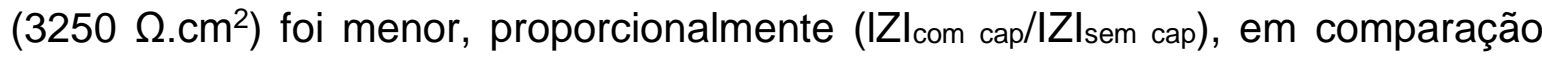
com os resultados obtidos para a condição de pH 2 . 

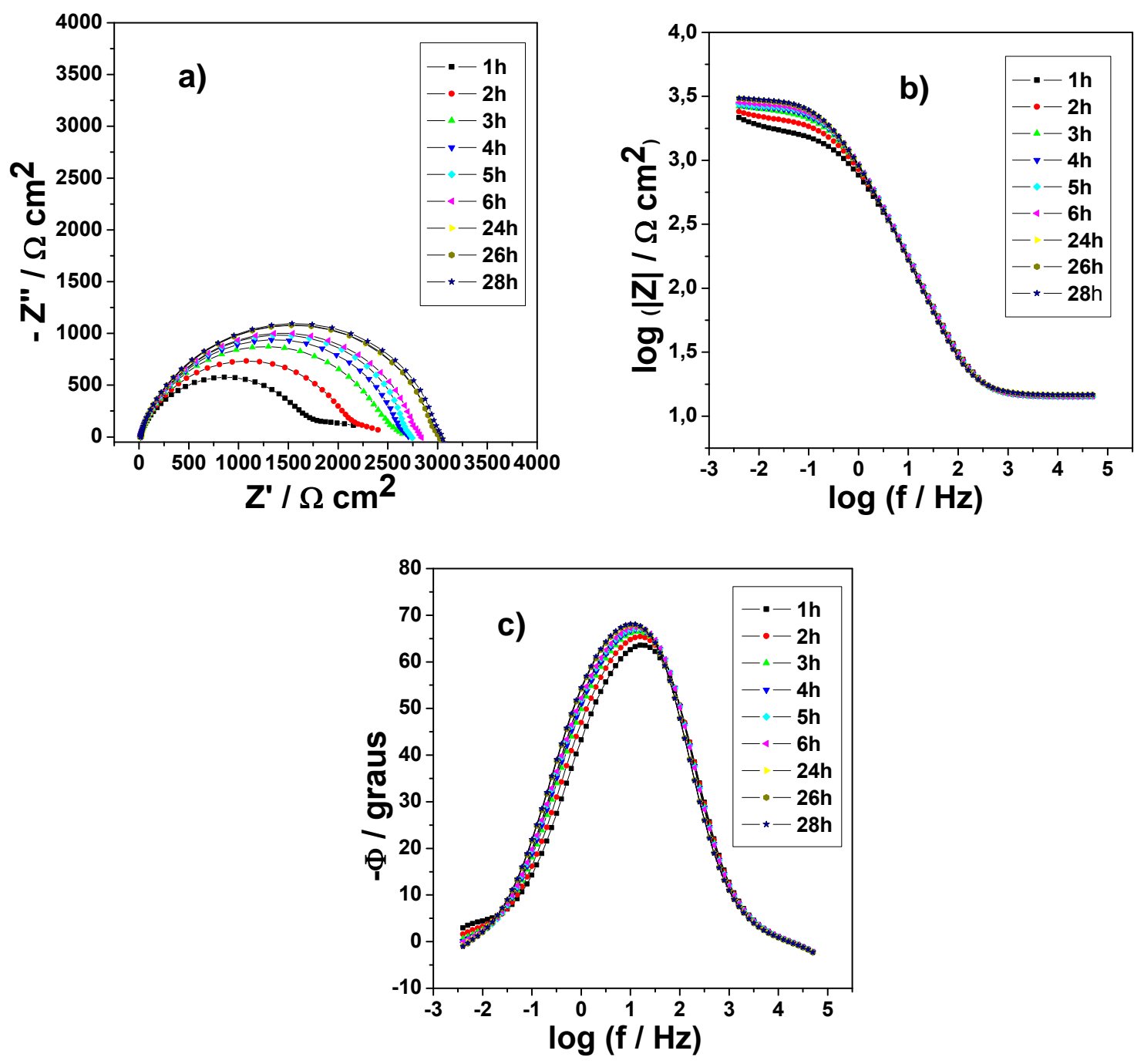

Figura 4.35 - Diagramas de Nyquist (a) e de Bode ((b) e (c)) para o aço carbono, para diferentes tempos de imersão numa solução de $\mathrm{NaCl} 0,1 \mathrm{~mol} / \mathrm{L} \mathrm{com} \mathrm{pH}=9$ e contendo $1 \%$ em massa de sílica mesoporosa com dodecilamina encapsulada.

No caso da condição de pH 9, os resultados reunidos na Figura 4.35 (a) mostram que o aumento no diâmetro do arco capacitivo para tempos longos de imersão (24 h, 26 h e 28 h) não foi tão significativo com relação à condição de pH 2, onde foi obtido um valor maior para a razão entre os módulos de impedância

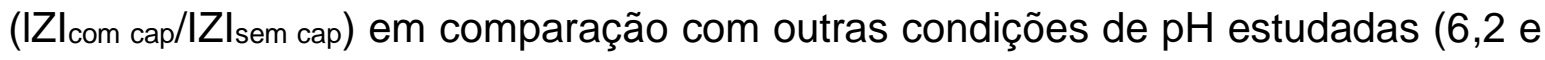
9). De acordo com os resultados obtidos de cinética de liberação da dodecilamina para as diferentes condições de $\mathrm{pH}$ pode-se concluir que para a condição de $\mathrm{pH} 2$ há uma maior quantidade de inibidor liberado a partir da sílica mesoporosa. $\mathrm{Na}$ 
situação de pH neutro as unidades de moléculas da dodecilamina estão em forma neutra $\left(\mathrm{pK}_{\mathrm{a}}=10,63\right)$ e podem formar complexos altamente estáveis com a sílica através de interações dipolo instantâneo-dipolo induzido. Isto indica uma compatibilidade e, portanto, uma liberação não muito significativa, já que as moléculas da dodecilamina estariam imobilizadas sobre a superfície da sílica mesoporosa. Quando há uma diminuição do pH as moléculas da dodecilamina são protonadas e as forças de ligação decrescem dramaticamente resultando na dissociação dos complexos formados. Isto é equivalente a abrir os canais que formam a estrutura da sílica mesoporosa para a difusão do inibidor (CHEN; FU, 2012).

Em valores de $\mathrm{pH}$ diferentes do neutro, ambas as partículas de sílica mesoporosa e as moléculas do inibidor têm a mesma carga (positiva a $\mathrm{pH}<6 \mathrm{e}$ negativa a $\mathrm{pH}>6$ ). Isto traz como consequência maiores forças de repulsão eletrostática e uma liberação mais rápida do inibidor. Estes resultados são favoráveis para uma aplicação destas partículas de sílica carregadas com inibidor em revestimentos ativos anticorrosivos, devido a que o processo de corrosão é normalmente seguido por mudanças do $\mathrm{pH}$ local para valor baixo ou ácido. Portanto, a liberação do inibidor como resposta a uma mudança de $\mathrm{pH}$ na área de defeito é prevista e será responsável pela proteção do substrato no local do defeito (BORISOVA; MÖHWALD; SHCHUKIN, 2011; CHEN; FU, 2012b).

4.7.1 Cinética de liberação do inibidor encapsulado de dentro das partículas de sílica mesoporosa.

Na Figura 4.36 apresentam-se as curvas de cinética de liberação do inibidor de corrosão dodecilamina encapsulada dentro das partículas de sílica mesoporosa para diferentes tempos de imersão em solução $\mathrm{NaCl} 0,1 \mathrm{mo} / \mathrm{L}$ e para valores de $\mathrm{pH}$ 2, 9 e 6,2. Para tempos iniciais de imersão é possível observar que as razões de módulo de impedância para as três condições estudadas apresentam inclinações similares, ou seja, velocidades de liberação do inibidor quase parecidas. Já para 
tempos mais longos de imersão a razão do módulo de impedância para a condição de $\mathrm{pH} 2$ aumenta consideravelmente devido a uma maior velocidade de liberação do inibidor a partir da estrutura da sílica mesoporosa. Baseando-se nos valores das inclinações das retas pode-se afirmar que para condição de $\mathrm{pH}=2 \mathrm{a}$ velocidade de liberação do inibidor é 4,7 e 2,8 vezes maior em comparação com o valor obtido para $\mathrm{pH}$ 6,2 e pH 9, respectivamente.

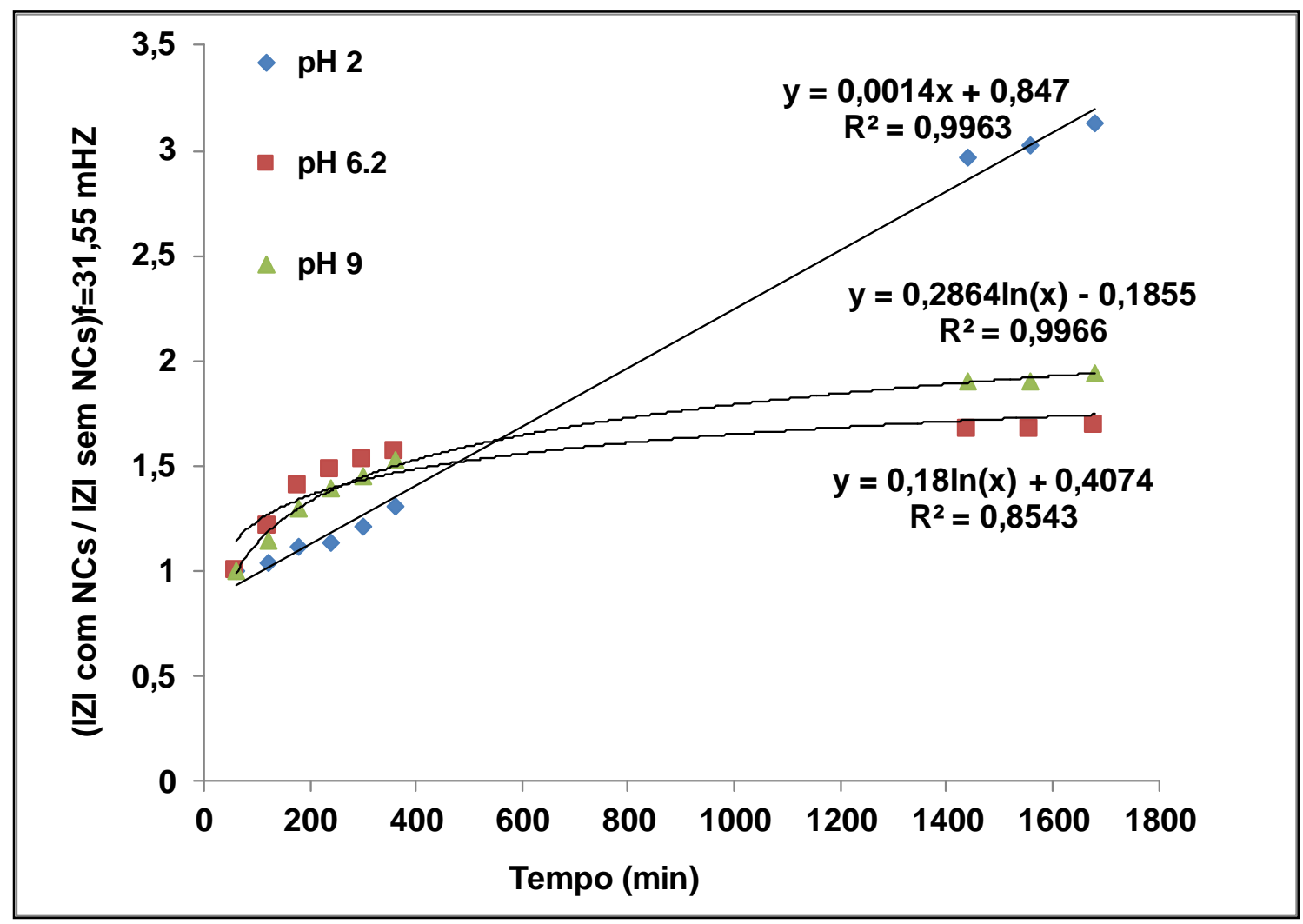

Figura 4.36 - Curvas da cinética de liberação do inibidor a partir da sílica mesoporosa para diferentes tempos de imersão numa solução de $\mathrm{NaCl} 0,1 \mathrm{~mol} / \mathrm{L}$ para valores de $\mathrm{pH}$ 2, 6,2 e 9, usando como substrato uma chapa de aço carbono ABNT 1020.

$\mathrm{Na}$ Figura 4.37 se faz uma comparação entre as curvas cinéticas de liberação do inibidor dodecilamina a partir dos três tipos de nanocontainers estudados (nanopartículas de sílica, nanotubos de haloisita e sílica mesoporosa) para um valor de $\mathrm{pH} 2$, onde se pode observar que a velocidade de liberação a partir das nanopartículas de sílica (L-b-L) foi 1,7 vezes maior em comparação com a haloisita e 3,3 vezes maior em comparação à sílica mesoporosa. Uma possível explicação a este fato é a localização do inibidor dentro do nanocontainer. No caso 
das nanopartículas de sílica (L-b-L) o inibidor está depositado entre as camadas dos polieletrólitos, mas esses polieletrólitos também vão saindo com o decorrer do tempo (como foi demonstrado na análise por infra-vermelho) não conseguindo reter as camadas de inibidor depositadas e provocando, assim, uma saída mais rápida do inibidor. No caso dos nanotubos de haloisita o inibidor apresenta maior dificuldade em sair por estar contido dentro do lúmen da haloisita, já para a sílica mesoporosa a dificuldade é ainda maior devido à estrutura porosa do material, onde o inibidor é contido dentro da superfície externa da sílica e nos mesoporos e microporos da sílica mais e mais profundos. Estes resultados permitem-nos escolher o tipo de nanocontainer adequado para uma necessidade especifica de uso, por exemplo, se é requerido uma saída rápida do inibidor sem deixar uma reserva dentro do nanocontainer, a melhor opção seria as nanopartículas de sílica (L-b-L), já se é requerido uma saída do inibidor em forma gradual mantendo uma reserva de inibidor dentro do nanocontainer, o mais idôneo seria usar as partículas de sílica mesoporosa.

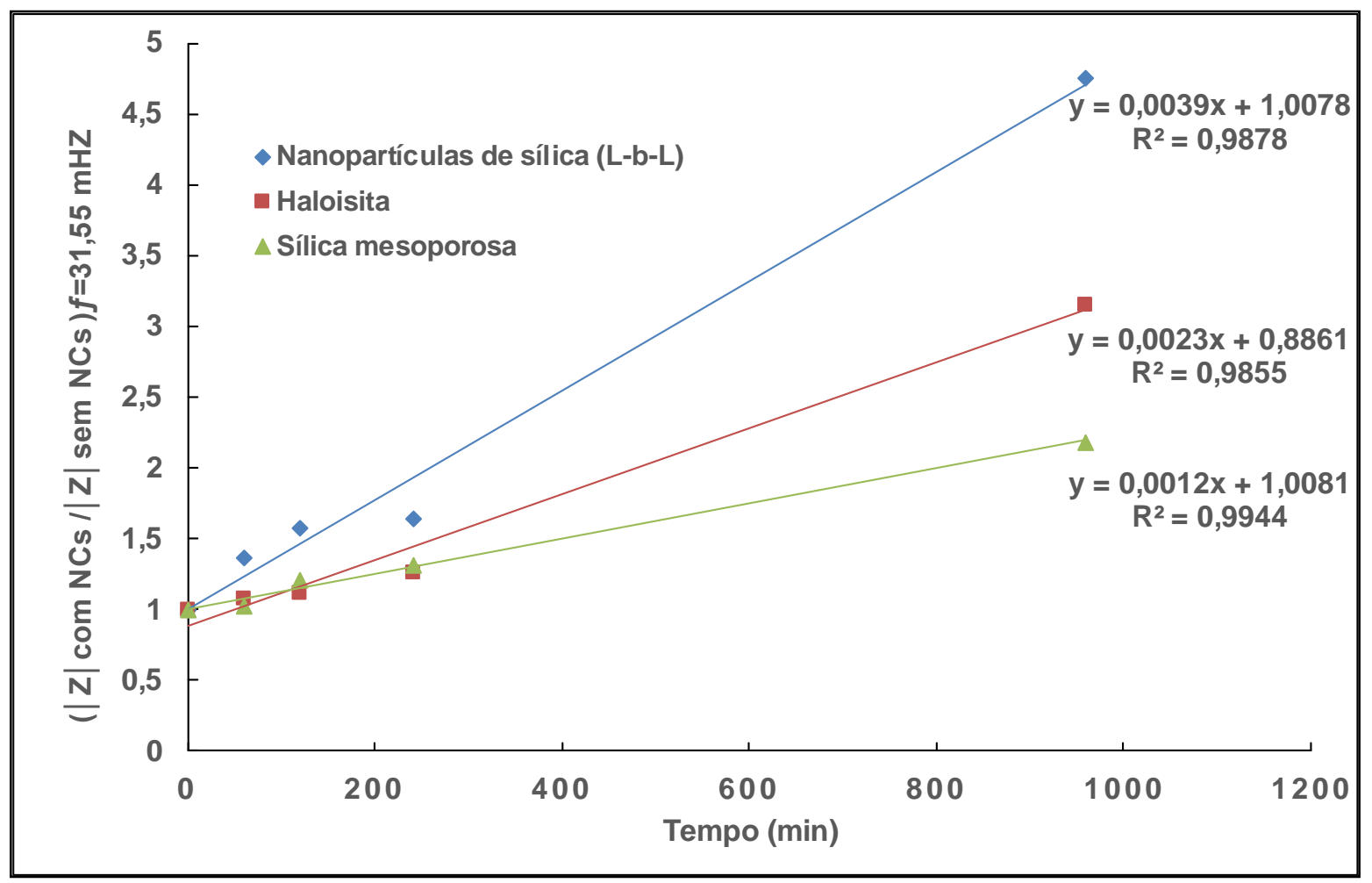

Figura 4.37 - Comparação entre as curvas de cinética de liberação do inibidor dodecilamina a partir dos três tipos de nanocontainers estudados obtidas para um tempo de imersão de até $16 \mathrm{~h}$ numa solução de $\mathrm{NaCl}$ 0,1 mol/L para $\mathrm{pH} 2$, usando como substrato uma chapa de aço carbono ABNT 1020. 
Baseando-se nos estudos de cinética de liberação dos três tipos de nanocontainers estudados em pHs 2, 9 e 6,2 é possível concluir que uma maior liberação do inibidor dodecilamina é atingida só em condições de pH ácidos. Para condições de pH alcalinos, a liberação não é muito significativa, já existem trabalhos reportados na literatura usando outros tipos de inibidores (benzotriazol, 8-hidroquinolina, 2-mercaptobenzotiazol) onde que para a condição de pH 9 a liberação foi também maior (SHCHUKIN; MÖHWALD, 2007; BORISOVA; MÖHWALD; SHCHUKIN, 2011; CHEN; FU, 2012a; CHEN; FU, 2012b).

\subsection{Avaliação por EIE e por SVET do efeito de autorreparação de um revestimento alquídico aditivado com partículas de sílica contendo o inibidor dodecilamina encapsulado pelo método L-b-L aplicado sobre o aço carbono}

4.8.1 Avaliação do efeito de autorreparação por espectroscopia de impedância eletroquímica

A Figura 4.38 mostra os diagramas de Bode (log IZI vs $\log f$ e $-\varnothing$ vs $\log f)$ para o aço carbono revestido sem e com a presença de $10 \% \mathrm{~m} / \mathrm{m}$ de nanopartículas de sílica contendo dodecilamina encapsulada pelo método L-b-L nas condições com e sem defeito. Para ambos os casos ( 1 h e 4 h) é possível observar uma acentuada resposta capacitiva para as chapas sem defeito e sem nanopartículas na faixa de frequências de $100 \mathrm{kHz}$ até $10 \mathrm{~Hz}$, e uma resposta típica de resistor no final da faixa de baixas frequências. Essas respostas segundo a literatura são atribuídas à capacitância do revestimento e a resistência à entrada do eletrólito pelos poros do revestimento, respectivamente (ZHELUDKEVICH et al., 2007; TAVANDASHTI; SANJABI, 2010; MONTEMOR et al., 2012; BALASKAS et al., 2012; MEKERIDIS; KARTSONAKIS; KORDAS, 2012). Para o caso das chapas sem defeito e com nanopartículas é possível observar uma resposta resistiva bem menor na região de baixa frequência, o que indica que a adição das nanopartículas de sílica afetou o desempenho do revestimento pela criação de defeitos e poros provocados principalmente pela formação de partículas grandes e 
aglomeração na hora da aplicação da tinta (LAMAKA et al., 2008; TAVANDASHTI; SANJABI, 2010; BALASKAS et al., 2012; MEKERIDIS; KARTSONAKIS; KORDAS, 2012). A micrografia da Figura 4.24 pode-se ver claramente a formação de algumas partículas grandes, as quais prejudicaram o desempenho da tinta.

No caso dos revestimentos com defeito é observado que inicialmente (após 1 h de imersão) o valor do módulo de impedância para a condição sem nanocontainers (NCs) é maior em comparação com a condição com NCs, mas após $4 \mathrm{~h}$ de imersão esta situação é invertida devido à ação do inibidor de corrosão que é liberado a partir das paredes dos nanocontainers para as zonas menos protegidas do defeito, cuja resposta é refletida em um aumento do módulo de impedância e ângulo de fase na faixa de baixas frequências $(0,1 \mathrm{~Hz}-0,01 \mathrm{~Hz})$. Isso também foi obtido por outros autores (LAMAKA et al., 2008; ZHELUDKEVICH et al., 2007; TAVANDASHTI; SANJABI, 2010; TEDIM et al., 2010; MONTEMOR et al., 2012; BALASKAS et al., 2012; ZHELUDKEVICH et al., 2010; MEKERIDIS; KARTSONAKIS; KORDAS, 2012) usando outros tipos de inibidores de corrosão como benzotriazol, 8-hidroxiquinolina e 2-mercaptobenzotiazol e como meio agressivo uma solução de $\mathrm{NaCl} 0,05 \mathrm{~mol} / \mathrm{L}$. 

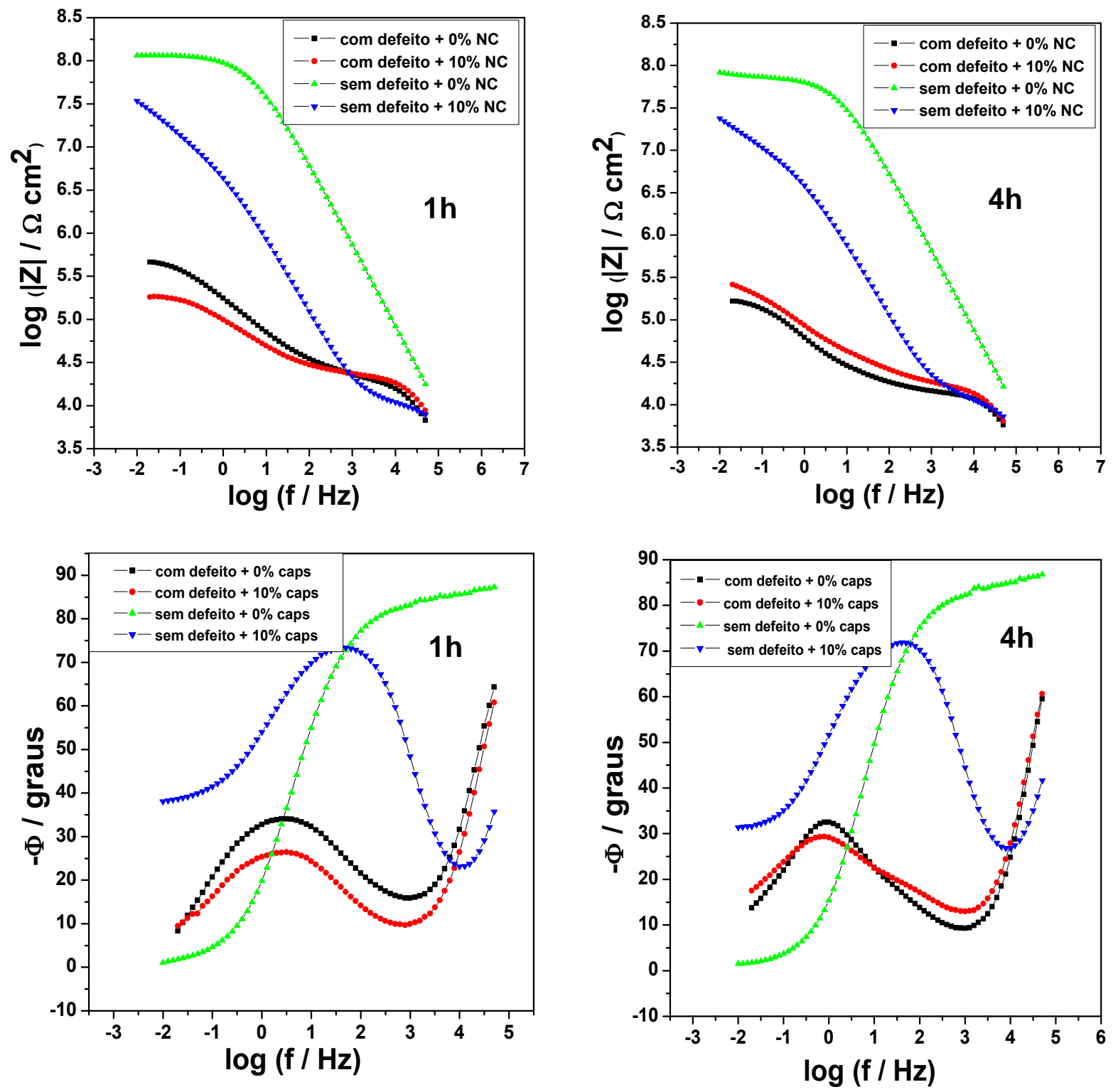

Figura 4.38 - Diagramas de Bode obtidos para as chapas de aço carbono revestidas com duas demãos de tinta alquídica e apenas a primeira camada aditivada com $0 \% \mathrm{~m} / \mathrm{m}$ e $10 \% \mathrm{~m} / \mathrm{m}$ de nanopartículas de sílica com dodecilamina encapsulada por L-b-L sem e com defeito provocado após diferentes tempos de imersão numa solução de $\mathrm{NaCl}$ 0,01 mol/L.

\subsubsection{Técnica de varredura com eletrodo vibratório (SVET)}

As medidas de SVET para o aço carbono revestido com duas demãos de uma tinta alquídica sem nanocontainers, foram obtidas após 1,5 horas, 10,5 horas, 14,5 horas e 18,5 horas de imersão em solução de cloreto de sódio $\mathrm{NaCl}$ $0,01 \mathrm{~mol} / \mathrm{L}$, como mostra a Figura 4.39. A fim de acelerar o processo de corrosão 
e avaliar o efeito da proteção desta tinta sem nanocontainers, foi feito um defeito no revestimento da amostra de aproximadamente $3 \mathrm{~mm}$ de comprimento.

Os resultados mostraram a aparição de uma região anódica ao redor do defeito depois de 1,5 horas de imersão, a qual vai aumentando com tempo até atingir um valor máximo de densidade de corrente anódica de 399,7 $\mu \mathrm{A} / \mathrm{cm}^{2}$ após 10,5 horas de imersão, onde esse pico máximo de corrente é similar ao obtido por outros autores na literatura usando como substrato aço carbono (SKORB et al., 2010). Após 14,5 horas de imersão houve uma pequena diminuição da corrente anódica devido ao grande acúmulo de produtos de corrosão sobre o defeito que atua como uma barreira física e diminui a intensidade do processo corrosivo. Notase a presença de produtos de corrosão, na região do defeito, durante todo o tempo de ensaio. 


\section{$1,5 \mathrm{~h}$ de imersão}

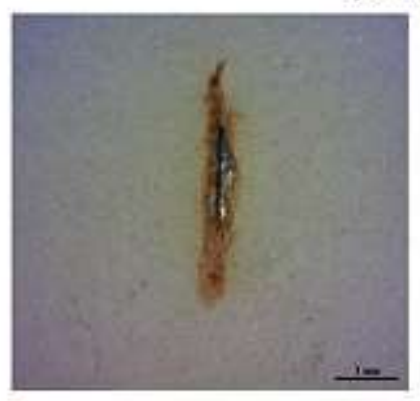

$$
400
$$

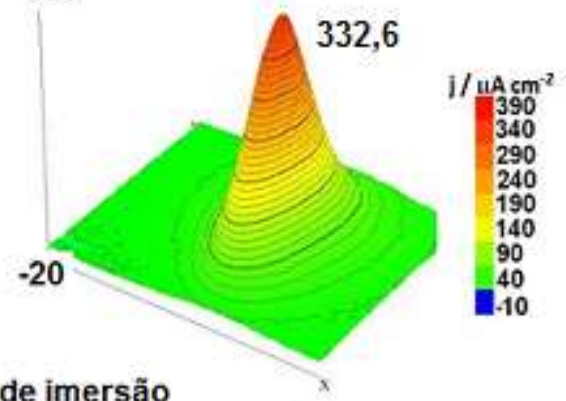

$10,5 \mathrm{~h}$ de imersão
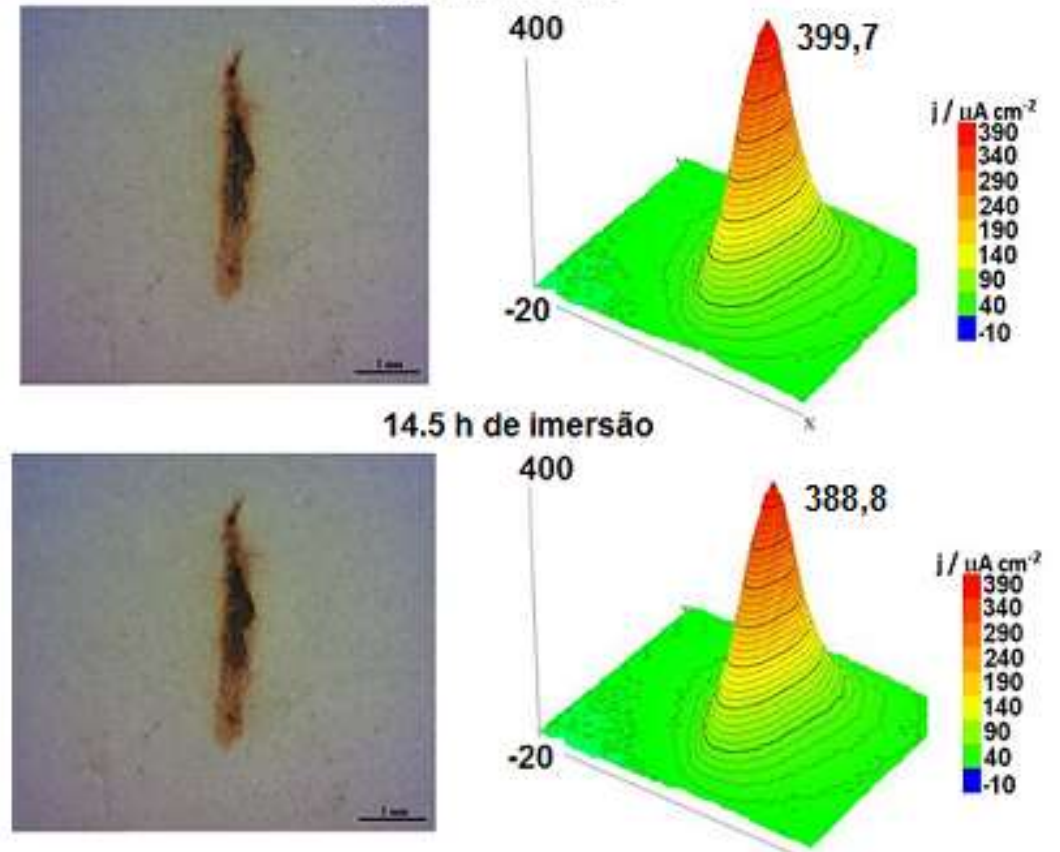

\section{$18,5 \mathrm{~h}$ de imersão}
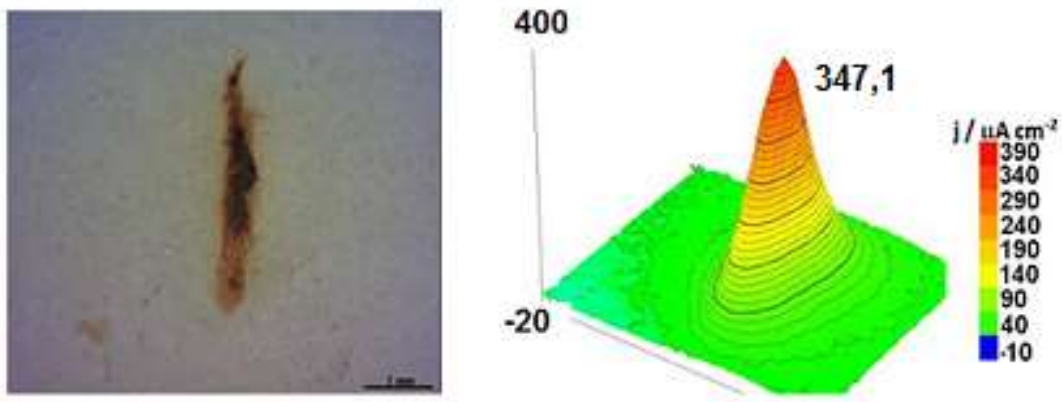

Figura 4.39 - Imagens do corpo de prova e mapas de densidade de corrente iônica obtidos para os CPs revestidos com duas demãos de tinta alquídica com defeito sem adição de nanopartículas de sílica para diferentes tempos de imersão em solução de $\mathrm{NaCl}$ 0,01 mol/L.

Para o caso da Figura 4.40, as medidas de SVET foram obtidas para o aço carbono revestido com duas demãos de uma tinta alquídica sendo apenas a primeira aditivada com $10 \% \mathrm{~m} / \mathrm{m}$ de nanocontainers em base úmida e para 
tempos de imersão de 0,5 horas, 9,5 horas, 17,5 horas e 20,5 horas em solução de $\mathrm{NaCl}$ 0,01 mol/L. Foi feito também um defeito artificial sobre amostra a fim de acelerar o processo de corrosão e avaliar o efeito da adição de nanocontainers na corrosão do substrato.

Para estas condições de ensaio, os resultados de SVET da Figura 4.39 mostraram que logo após 0,5 hora de imersão da amostra, a atividade anódica ao redor do defeito não é significativa, já que as densidades de correntes anódicas atingiram valores baixos, em torno de $63 \mu \mathrm{A} / \mathrm{cm}^{2}$, e não houve formação de produtos de corrosão sobre o defeito. Após 9,5 horas de imersão, a atividade anódica começa aumentar junto com a densidade de corrente anódica até atingir um valor máximo de $142 \mu \mathrm{A} / \mathrm{cm}^{2}$, quando depois deste tempo os valores de densidade de corrente anódica começam a diminuir até valores de $52 \mu \mathrm{A} / \mathrm{cm}^{2}$ (17,5 horas de imersão), mostrando que o processo de corrosão é retardado devido à ação do inibidor dodecilamina que é liberado sobre o defeito provocado. Após este tempo nota-se que os valores de densidade de corrente começam a aumentar novamente (20,5 horas de imersão), indicando assim uma estagnação na quantidade de inibidor liberado desde os nanocontainers.

Outro detalhe que pode ser também comentado é a pouca formação de produtos de corrosão ao redor do defeito, o qual aparece durante as primeiras horas de imersão e se mantém com o mesmo aspecto durante todo o ensaio. Estes resultados mostraram um comportamento similar ao obtido por vários autores (ZHELUDKEVICH et al., 2007; BORISOVA; MÖHWALD; SHCHUKIN, 2011; ABDULLAYEV et al., 2009; ANDREEVA; SKORB; SHCHUKIN, 2010; FIX et al., 2009), indicando o efeito da liberação do inibidor a partir dos nanocontainers provocada pela mudança de pH (ANTIPOV; SUKHORUKOV, 2004), onde este inibidor é adsorvido sobre a superfície do metal dificultando o ingresso de espécies agressivas e dificultando assim, o processo de corrosão. 


\section{$0,5 \mathrm{~h}$ de imersão}

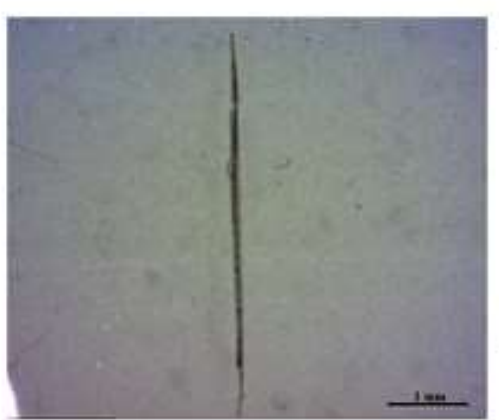

400
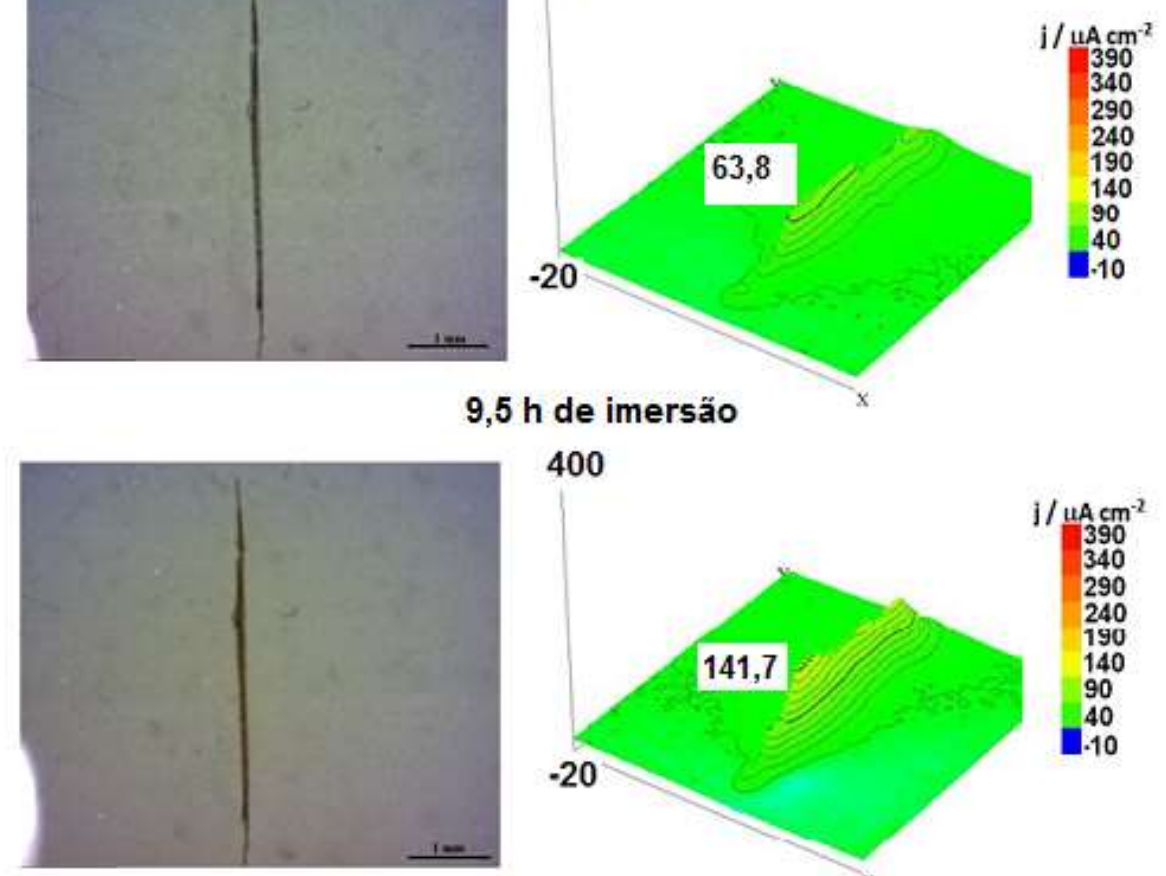

400

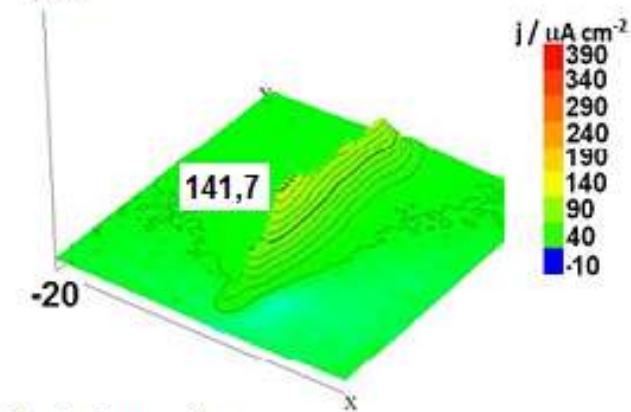

$17,5 \mathrm{~h}$ de imersão

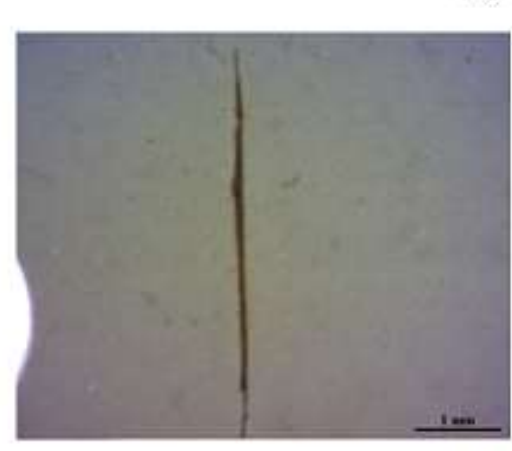

\section{0}

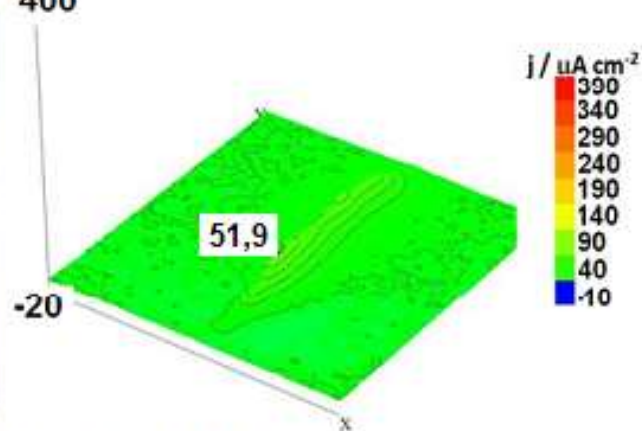

\section{$20,5 \mathrm{~h}$ de imersão}
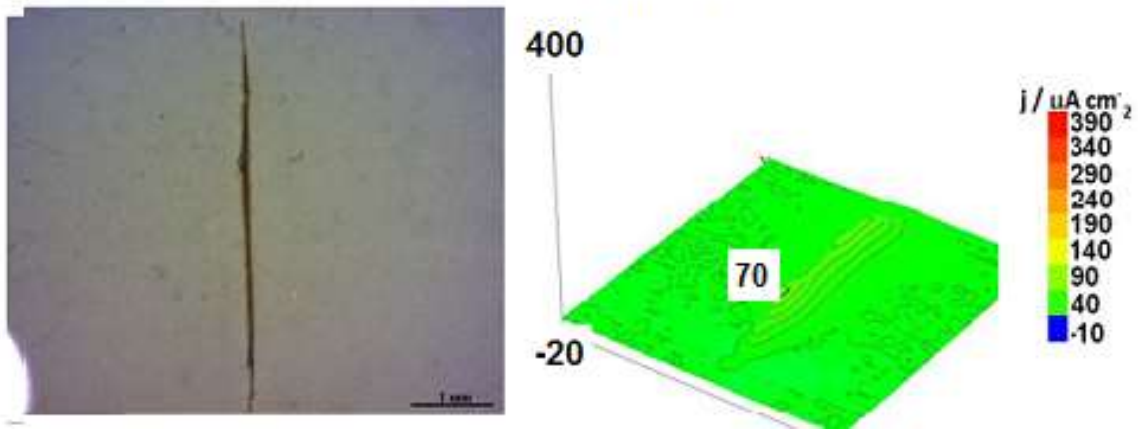

Figura 4.40 - Imagens do corpo de prova e mapas de densidade de corrente, obtidas para os CPs revestidos com duas demãos de tinta alquídica com defeito e apenas a primeira camada aditivada com $10 \%$ em massa de nanopartículas de sílica contendo dodecilamina encapsulada por L-b-L para diferentes tempos de imersão em solução de $\mathrm{NaCl}$ 0,01 mol/L. 
O inibidor de corrosão dodecilamina incorporado como um componente do filme pela técnica $L-b-L$ dentro da tinta alquídica é responsável pelo mecanismo de supressão da corrosão

\subsubsection{Ensaios acelerados em câmara de névoa salina}

Nas Figuras 4.41 e 4.42 são apresentados os resultados obtidos para os ensaios de névoa salina após de $0 \mathrm{~h}$ e $96 \mathrm{~h}$ de exposição na câmara de névoa salina e usando como corpos de prova respectivamente chapas lixadas e jateadas e pintadas com duas demãos de tinta alquídica sendo que a primeira continha $0 \%$ $\mathrm{m} / \mathrm{m}, 10 \% \mathrm{~m} / \mathrm{m}$ e $15 \% \mathrm{~m} / \mathrm{m}$, de nanopartículas de sílica com dodecilamina encapsulada por L-b-L. Durante as primeiras horas de exposição já é possível observar a presença de produtos de corrosão ao redor do defeito provocado, mas em pouca quantidade. Com o decorrer do tempo pode-se notar claramente o acúmulo de produtos de corrosão para o caso das chapas lixadas e jateadas sem NCs, enquanto que para as chapas contendo NCs $(10 \% \mathrm{~m} / \mathrm{m}$ e $15 \% \mathrm{~m} / \mathrm{m})$ a presença de produtos de corrosão é muito pequena. Já para um tempo de 96 horas, se observa uma forte corrosão especialmente para as chapas pintadas e sem nanocontainers, além disso, se vê a presença de algumas bolhas sobre a superfície dos corpos de prova pintados contendo os NCs e muitas sobre aqueles sem os NCs indicando uma certa permeação da solução agressiva através dos defeitos da tinta provocados mesmo na presença dos nanocontainers por estes terem tamanho grande numa tinta com espessura baixa $(100 \mu \mathrm{m})$. Os resultados foram muito piores para as chapas previamente jateadas em relação àquelas que foram apenas lixadas. Segundo estes resultados pode-se concluir que a adição de nanocontainers na tinta forneceu uma proteção adicional contra corrosão do aço carbono, sendo para a concentração de $15 \% \mathrm{~m} / \mathrm{m}$ de nanocontainers em base úmida onde houve menor acúmulo de produtos de corrosão na região do defeito e empolamento. O pior desempenho para as chapas jateadas pode ser explicado pelo fato do perfil de rugosidade ser de $60 \mu \mathrm{m}$, o que faz com que nos picos do perfil a tinta tenha espessura menor, da ordem de apenas $40 \mu \mathrm{m}$, justificando 0 
mau desempenho e o aparecimento de maior número de pontos de corrosão e empolamentos na tinta.

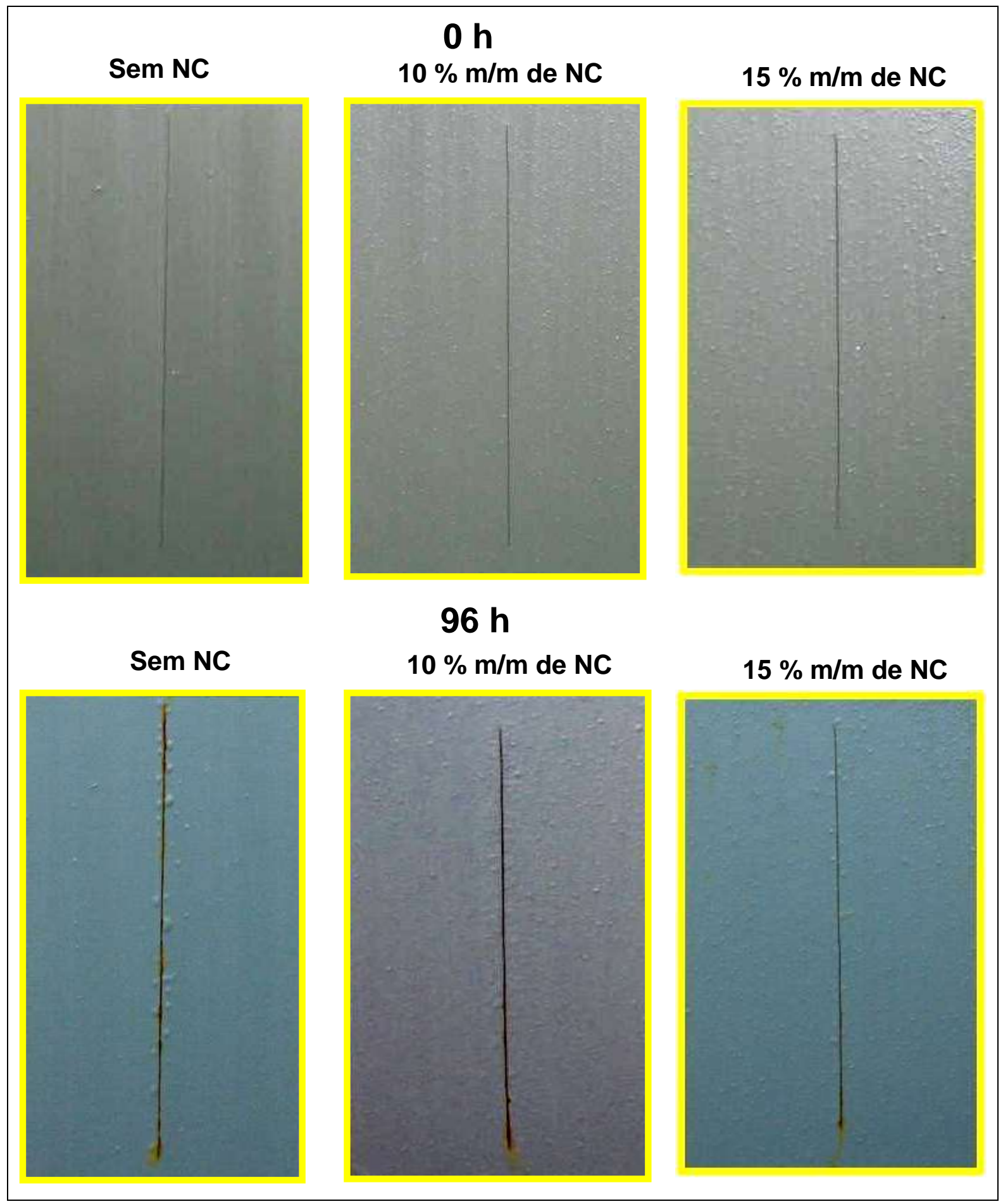

Figura 4.41 - Imagens dos corpos de prova lixados, pintados com duas demãos de tinta alquídica e apenas a primeira camada aditivada com $0 \%, 10 \%$ e $15 \%$ em massa de nanopartículas de sílica com dodecilamina encapsulada por L-b-L após $0 \mathrm{~h}$ e $96 \mathrm{~h}$ de exposição na câmara de névoa salina. 


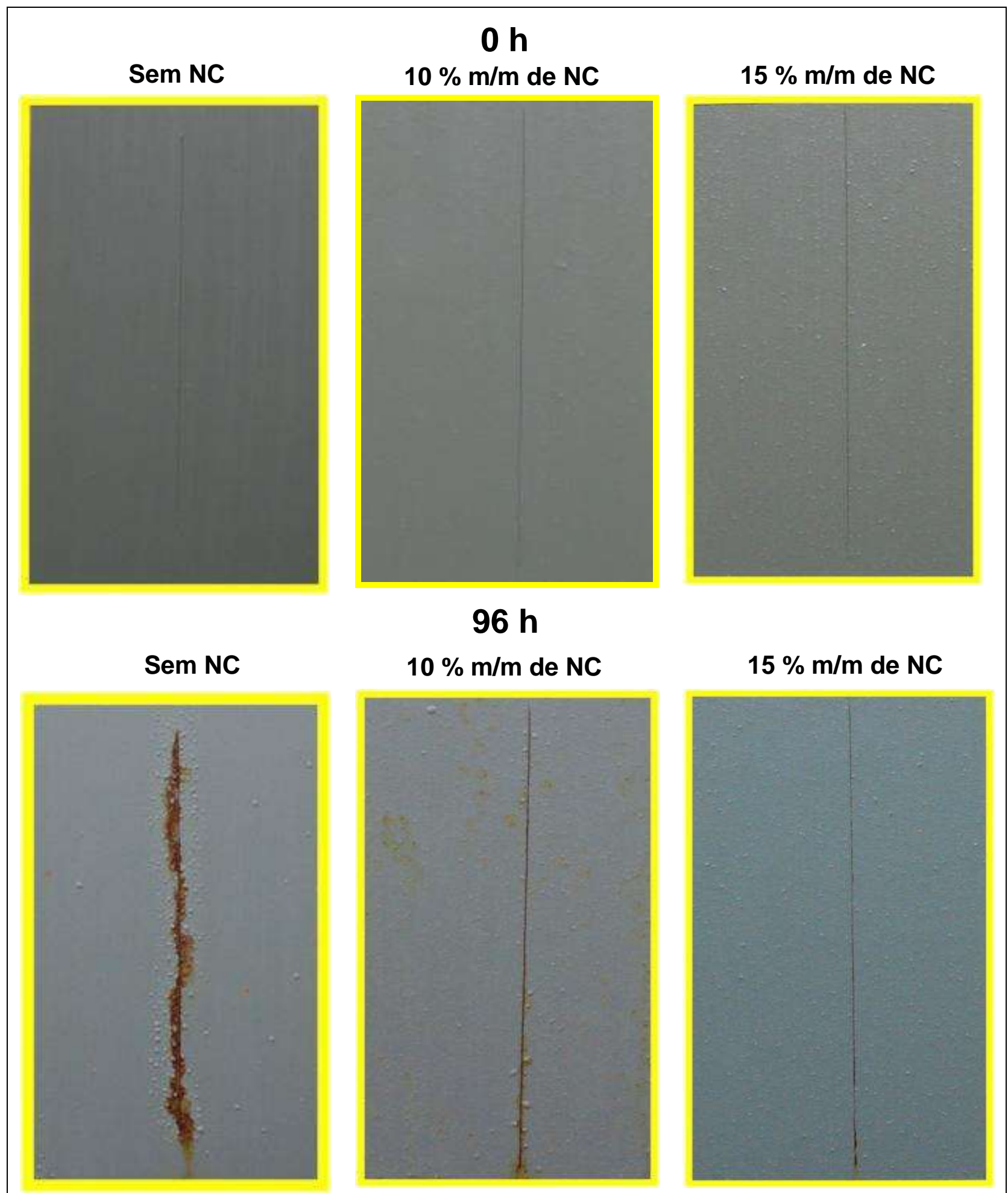

Figura 4.42 - Imagens dos corpos de prova jateados, pintados com duas demãos de tinta alquídica e apenas a primeira camada aditivada com $0 \%, 10 \%$ e $15 \%$ em massa de nanopartículas de sílica com dodecilamina encapsulada por L-b-L após 0 h e 96 h de exposição na câmara de névoa salina. 


\subsection{Avaliação por EIE e por SVET do efeito de autorreparação de um revestimento alquídico aditivado com nanotubos de haloisita contendo o inibidor dodecilamina aplicado sobre aço carbono}

\subsubsection{Medidas de espectroscopia de impedância eletroquímica (EIE)}

Os diagramas de Bode ( $\log |\mathrm{Z}|$ vs $\log f$ e $-\varnothing$ vs $\log f$ ) para os corpos de prova de aço pintado com duas camadas de tinta alquídica na situação sem e com adição dos nanotubos de haloisita somente na primeira camada são mostrados na Figura 4.43, onde é possível observar uma resposta capacitiva para as chapas sem defeito contendo $0 \% \mathrm{~m} / \mathrm{m}$ e $10 \% \mathrm{~m} / \mathrm{m}$ de NCs a qual se estende desde as altas frequências até as médias frequências, indicando que a adição dos nanotubos de haloisita não afetou o desempenho do revestimento, devido a que elas estavam bem dispersas, o qual evitou a aglomeração e permitiu uma melhor distribuição na hora da aplicação.

Com relação aos revestimentos com defeito é possível observar que após $4 \mathrm{~h}$ de imersão a adição de $10 \% \mathrm{~m} / \mathrm{m}$ de nanotubos de haloisita melhorou as propriedades de proteção contra a corrosão pelo aumento das propriedades barreira e pela liberação do inibidor desde o lúmen da haloisita nas zonas onde ocorreu o defeito. Esses resultados estão em concordância com os já reportados na literatura (SHCHUKIN et al., 2008; SHCHUKIN; MÖHWALD, 2007; ABDULLAYEV et al., 2009; FIX et al., 2009; LVOV et al., 2008; SNIHIROVA et al., 2013; ABDULLAYEV et al., 2013). Com o decorrer do tempo (8 h de imersão) uma quase autorreparação das propriedades iniciais do revestimento é atingida devido ao aumento no valor do módulo de impedância e ângulo de fase em baixas frequências provocado pela ação do inibidor o qual promove uma longa e efetiva proteção do aço contra a corrosão. 

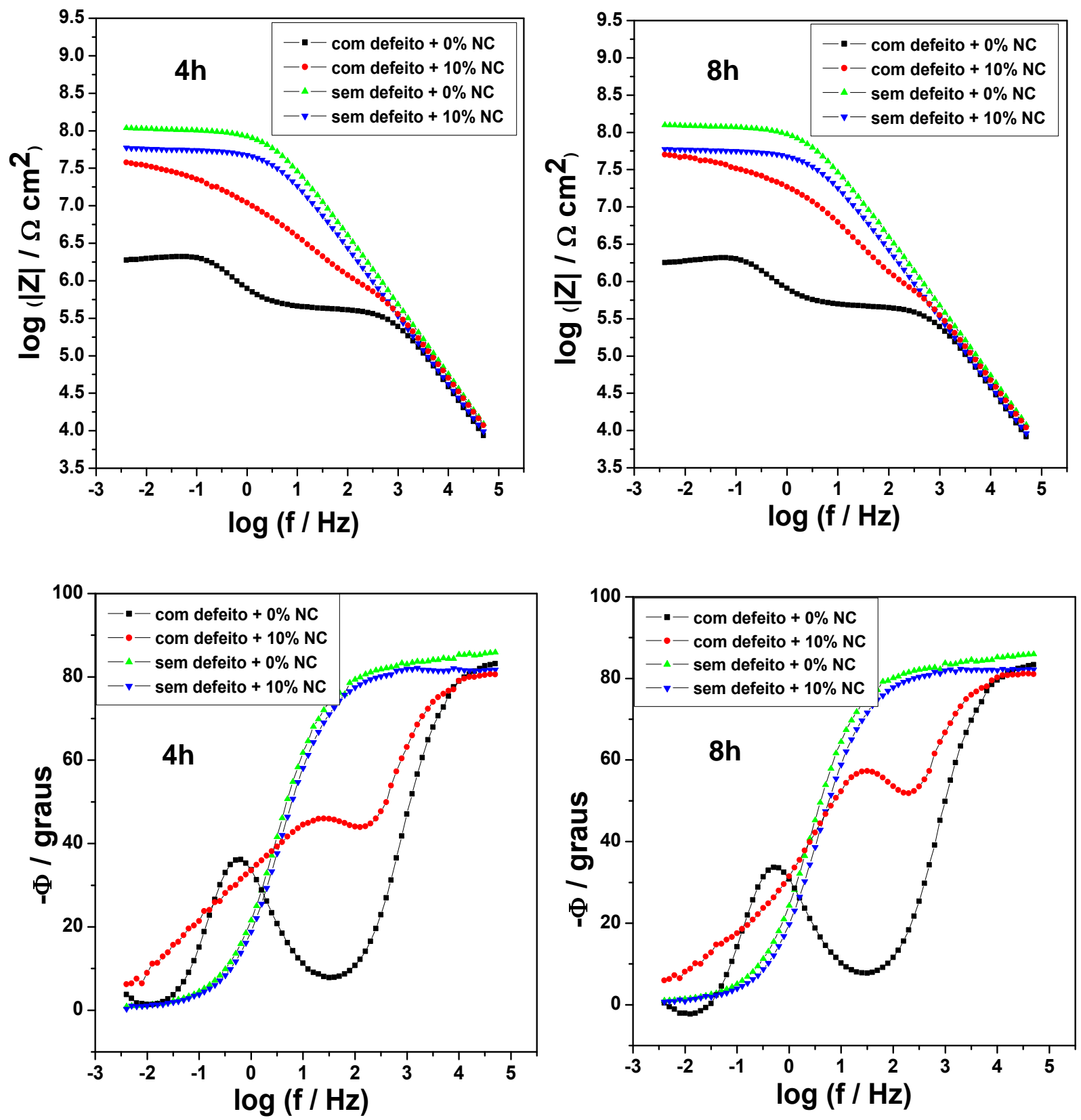

Figura 4.43 - Diagramas de Bode obtidos para as chapas de aço carbono revestidas com duas demãos de tinta alquídica e apenas a primeira camada aditivada com $0 \% \mathrm{~m} / \mathrm{m}$ e $10 \% \mathrm{~m} / \mathrm{m}$ de nanotubos de haloisita com dodecilamina encapsulada sem e com defeito provocado após diferentes tempos de imersão numa solução de $\mathrm{NaCl}$ 0,01 mol.L-1. 


\subsubsection{Técnica de varredura com eletrodo vibratório (SVET)}

As medidas de SVET para o aço carbono revestido com duas demãos de uma tinta alquídica sem nanotubos de haloisita foram obtidas após 1 h, 3 h, 4 h e $12 \mathrm{~h}$ de imersão em solução de cloreto de sódio $\mathrm{NaCl}$ 0,01 mol/L, como mostra a Figura 4.44. A fim de acelerar o processo de corrosão e avaliar o efeito da proteção desta tinta foi feito um defeito no revestimento da amostra de aproximadamente $3 \mathrm{~mm}$ de comprimento. Os resultados mostraram a aparição de uma densidade de corrente anódica alta $\left(383 \mu \mathrm{A} / \mathrm{cm}^{2}\right)$ durante a primeira hora de imersão, a qual vai diminuindo ligeiramente até o valor de $373 \mu \mathrm{A} / \mathrm{cm}^{2}$ após $3 \mathrm{~h}$ de imersão e continua até $364 \mu \mathrm{A} / \mathrm{cm}^{2}$ correspondente a $4 \mathrm{~h}$ de imersão. Isto pode ser devido a que inicialmente ( $1 \mathrm{~h}$ de imersão) a região anódica estava concentrada numa região pequena e com decorrer do tempo esta região anódica vai migrando ao longo do defeito e, portanto, a densidade de corrente anódica começa a diminuir $(i=1 / A)$ (FIX et al., 2009). Após de $12 \mathrm{~h}$ de imersão, a densidade de corrente anódica começou a aumentar em torno do defeito provocado pelo estilete até atingir um valor de densidade de corrente de $381 \mu \mathrm{A} / \mathrm{cm}^{2}$ correspondente a um tempo de imersão de $24 \mathrm{~h}$ (imagem não mostrada). 

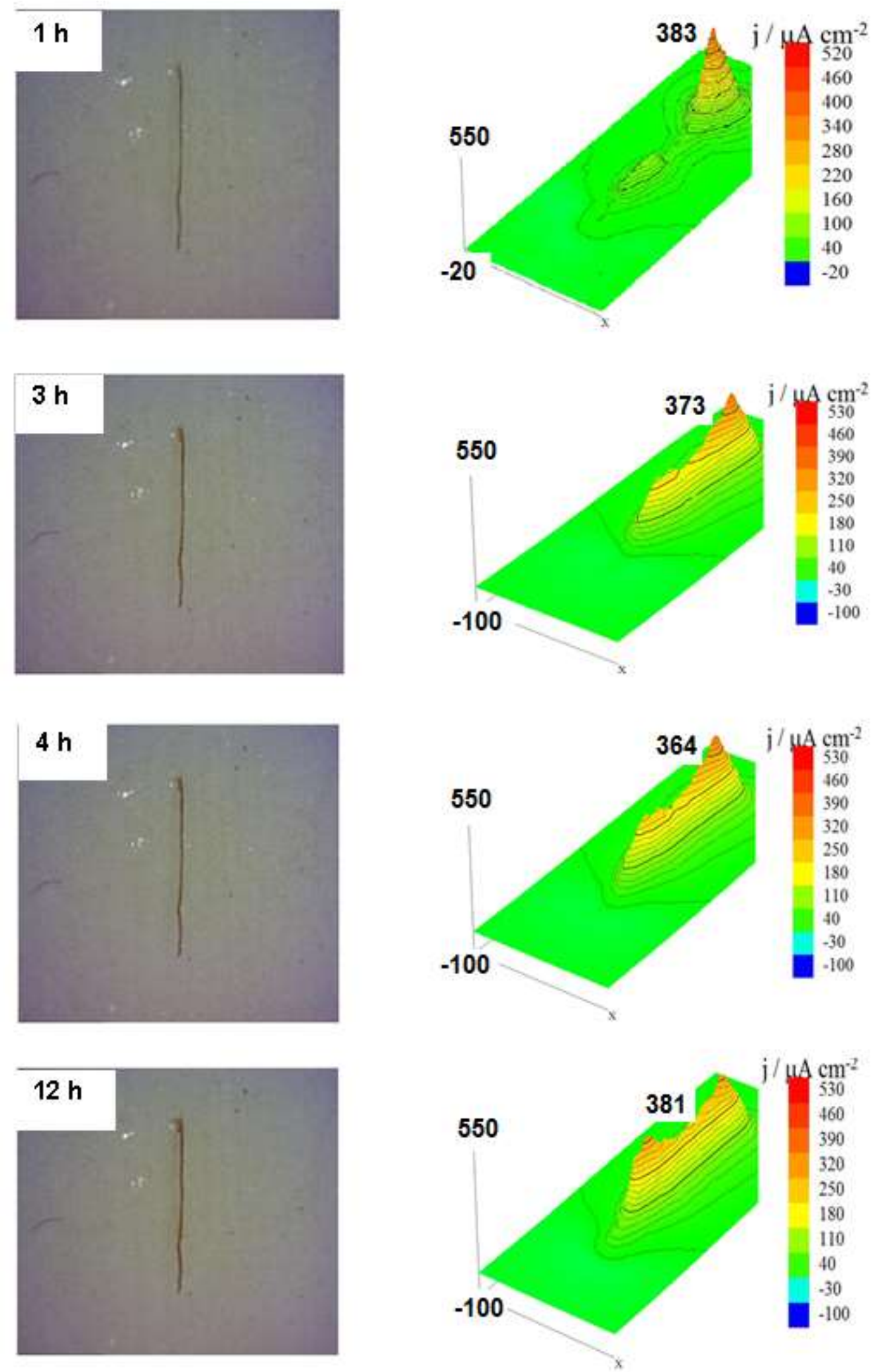

Figura 4.44 - Imagens do corpo de prova e mapas de densidade de corrente, obtidas para os CPs revestidos com duas demãos de tinta alquídica com defeito sem adição de nanotubos de haloisita para diferentes tempos de imersão em solução de $\mathrm{NaCl}$ 0,01 mol/L. 
Na Figura 4.45 são mostrados os resultados das medidas de SVET obtidas para o aço carbono revestido com duas demãos de uma tinta alquídica com a primeira camada contendo $10 \% \mathrm{~m} / \mathrm{m}$ em base úmida de nanotubos de haloisita com dodecilamina encapsulada e para tempos de imersão de $1 \mathrm{~h}, 3 \mathrm{~h}, 4 \mathrm{~h}$ e $12 \mathrm{~h}$ em solução de $\mathrm{NaCl} 0,01 \mathrm{~mol} / \mathrm{L}$. Foi feito também um defeito artificial sobre amostra a fim de acelerar o processo de corrosão e avaliar o efeito da adição desta haloisita contendo dodecilamina na corrosão do substrato.

Para estas condições de ensaio, os resultados de SVET da Figura 4.45 mostraram que inicialmente os valores de densidade de corrente começam aumentar até o valor de $552 \mu \mathrm{A} / \mathrm{cm}^{2}$ (após $3 \mathrm{~h}$ de imersão), mas depois desse tempo a atividade anódica ao redor do defeito diminuiu bruscamente até um valor de densidade de corrente anódica de $72 \mu \mathrm{A} / \mathrm{cm}^{2}$ (4 h de imersão), mostrando que o processo de corrosão é retardado devido à ação do inibidor de corrosão que é liberado do lúmen da haloisita sobre o defeito provocado (LAMAKA et al., 2008; ABDULLAYEV et al., 2009; FIX et al., 2009; LVOV et al., 2008; SNIHIROVA et al., 2013; ABDULLAYEV et al., 2013). Após $4 \mathrm{~h}$ de imersão nota-se que os valores de densidade de corrente anódica tendem a diminuir ligeiramente até atingir um valor de densidade de corrente anódica de $68 \mu \mathrm{A} / \mathrm{cm}^{2}$ (12 h de imersão), onde depois desse tempo as densidades de corrente começaram a aumentar novamente até o valor $77 \mu \mathrm{A} / \mathrm{cm}^{2}$, indicando assim que se atingiu o limite da quantidade de inibidor liberado a partir dos nanocontainers. Os nanotubos de haloisita ficaram homogeneamente distribuídos dentro do revestimento depositado sobre a superfície do aço, onde um processo de corrosão induzida pode causar mudanças significativas no $\mathrm{pH}$ local. Quando a liberação do agente anticorrosivo é significativamente acelerada em $\mathrm{pH}$ ácido, os sítios localmente ativos provocam a ação do inibidor encapsulado, que bloqueia o processo de corrosão inicial (FIX et al., 2009; LVOV et al., 2008). 

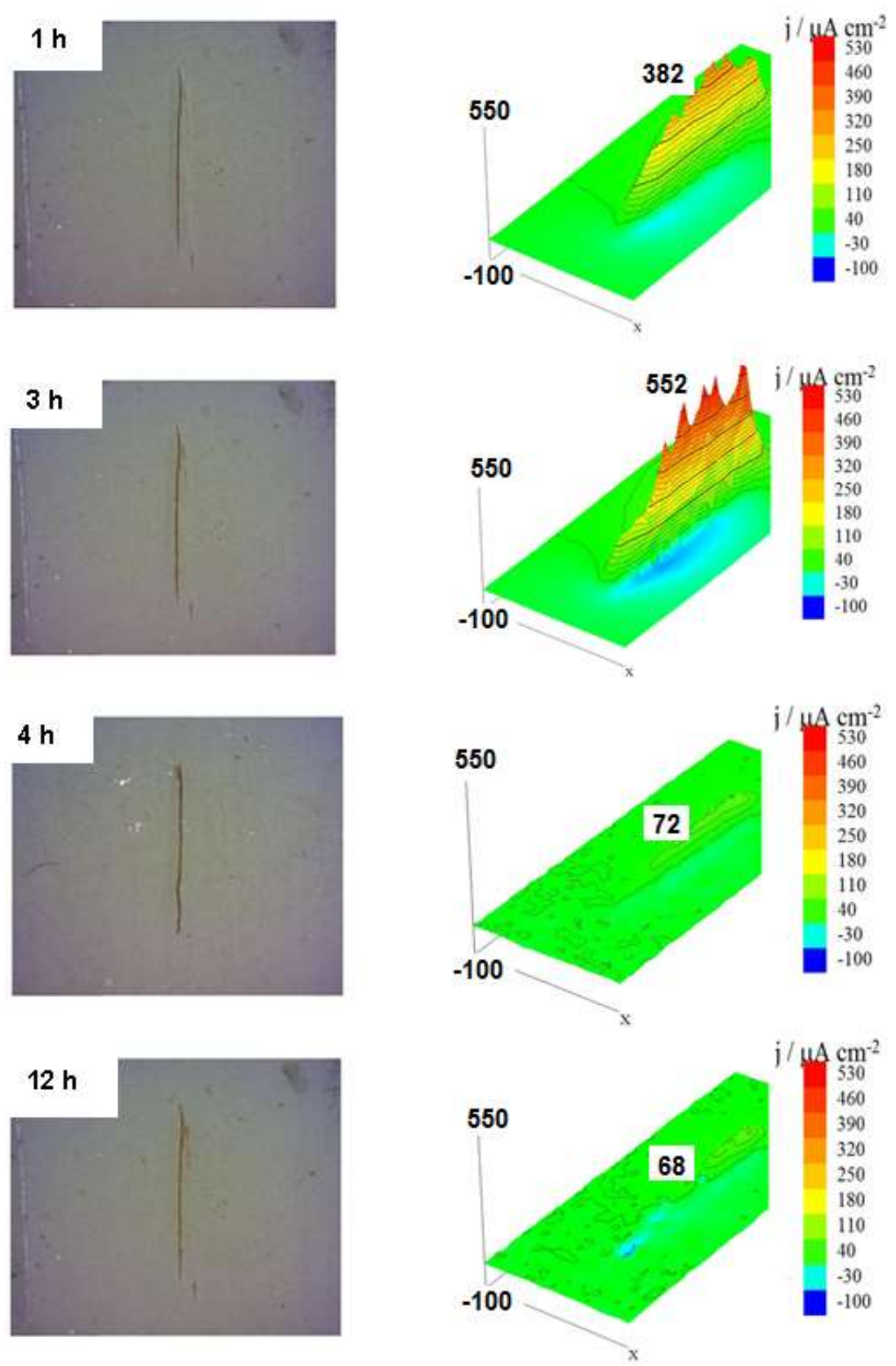

Figura 4.45 - Imagens do corpo de prova e mapas de densidade de corrente, obtidas para os CPs revestidos com duas demãos de tinta alquídica com defeito e apenas a primeira camada aditivada com $10 \% \mathrm{~m} / \mathrm{m}$ de nanotubos de haloisita com dodecilamina encapsulada para diferentes tempos de imersão em solução de $\mathrm{NaCl} 0,01 \mathrm{~mol} / \mathrm{L}$. 
A Figura 4.46 apresenta os resultados obtidos para os testes em câmara de névoa salina de chapas de aço carbono revestidas com duas demãos de tinta alquídica com defeito onde apenas a primeira camada foi aditivada com $0 \% \mathrm{~m} / \mathrm{m}$ e $10 \% \mathrm{~m} / \mathrm{m}$ de nanotubos de haloisita com dodecilamina encapsulada e para tempos de exposição de $0 \mathrm{~h}$ e $720 \mathrm{~h}$. Neste ensaio é possível observar que depois de $720 \mathrm{~h}$ o processo de corrosão é bastante severo para os corpos de prova revestidos sem haloisita $(0 \% \mathrm{~m} / \mathrm{m})$. No entanto, para as amostras revestidas com $10 \% \mathrm{~m} / \mathrm{m}$ de haloisita carregadas com dodecilamina, a formação de produtos de corrosão foi pequena e houve pouca formação de bolhas em torno do defeito, em comparação com amostras revestidas sem haloisita contendo dodecilamina, indicando assim uma melhor proteção contra o ingresso de espécies agressivas impedindo que chegassem até o metal. Com estes resultados foi possível demonstrar a coerência entre estes resultados e os obtidos previamente nos ensaios de SVET, onde a ação do inibidor de corrosão liberado do lúmen da haloisita nas zonas de defeito retardou de forma eficiente o processo de corrosão. 


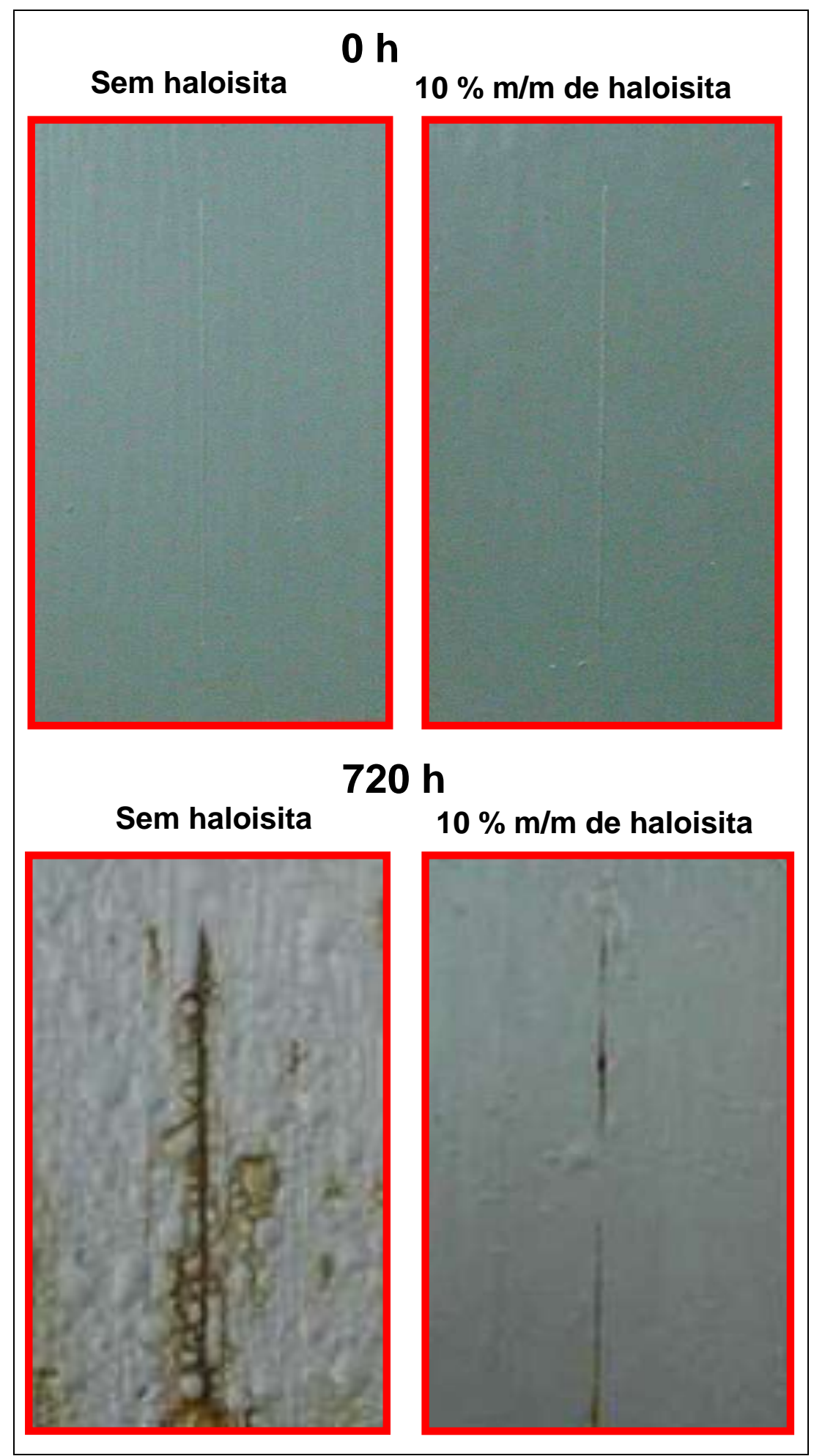

Figura 4.46 - Imagens dos corpos de prova lixados e pintados com duas demãos de tinta alquídica e apenas a primeira camada aditivada com $0 \%$ e $10 \%$ em massa de nanotubos de haloisita com dodecilamina encapsulada depois de $0 \mathrm{~h}$ e $720 \mathrm{~h}$ de exposição na câmara de névoa salina. 


\subsection{Avaliação por EIE e por SVET do efeito de autorreparação de um revestimento alquídico aditivado com partículas de sílica mesoporosa contendo o inibidor dodecilamina aplicado sobre o aço carbono}

4.10.1 Medidas de espectroscopia de impedância eletroquímica (EIE)

Os diagramas de Bode (log IZI vs $\log f$ e $-\varnothing$ vs $\log f)$ correspondentes aos corpos de prova revestidos com duas camadas de tinta alquídica com e sem defeito para as condições $0 \% \mathrm{~m} / \mathrm{m}$ e $15 \% \mathrm{~m} / \mathrm{m}$ de sílica mesoporosa com dodecilamina encapsulada, na primeira camada, são apresentados na Figura 4.47. Mesmo com uma porcentagem de $15 \% \mathrm{~m} / \mathrm{m}$ na tinta para a chapa sem defeito, pode-se observar que inicialmente ( $4 \mathrm{~h}$ de imersão) a adição da sílica mesoporosa não afetou o desempenho do revestimento pois o valores de impedância ficaram semelhantes e elevados e com comportamento capacitivo em altas frequências (BORISOVA et al., 2013), já com o decorrer do tempo (8 h de imersão) houve uma ligeira diminuição do valor do módulo de impedância para as chapas contendo sílica mesoporosa na tinta sem defeito devido ao início da entrada do eletrólito primeiro por adsorção e depois por caminhos ou poros através do revestimento, mas isso de forma bem leve e sem provocar dano na tinta. Com relação às chapas com defeito, é possível observar claramente que para ambos os tempos de imersão ( 1 h e 8 h) as chapas contendo sílica mesoporosa com dodecilamina encapsulada apresentam um maior valor de módulo de impedância e ângulo de fase em comparação com as chapas sem sílica mesoporosa, e esse efeito é mais pronunciado após um tempo maior de imersão (8h), isto ocorre como consequência da liberação do inibidor a partir dos canais internos da sílica mesoporosa sobre a região do defeito provocado pelo indentador e essa liberação aumenta com o tempo de imersão no eletrólito (BORISOVA; MÖHWALD; SHCHUKIN, 2011; SKORB et al., 2009). Além disso, esse maior valor de módulo de impedância em frequências altas e baixas representa melhores propriedades de barreira do primer e uma maior resistência de polarização do metal devido à 
presença do inibidor, respectivamente (SHCHUKIN et al., 2008; ZHELUDKEVICH et al., 2007).
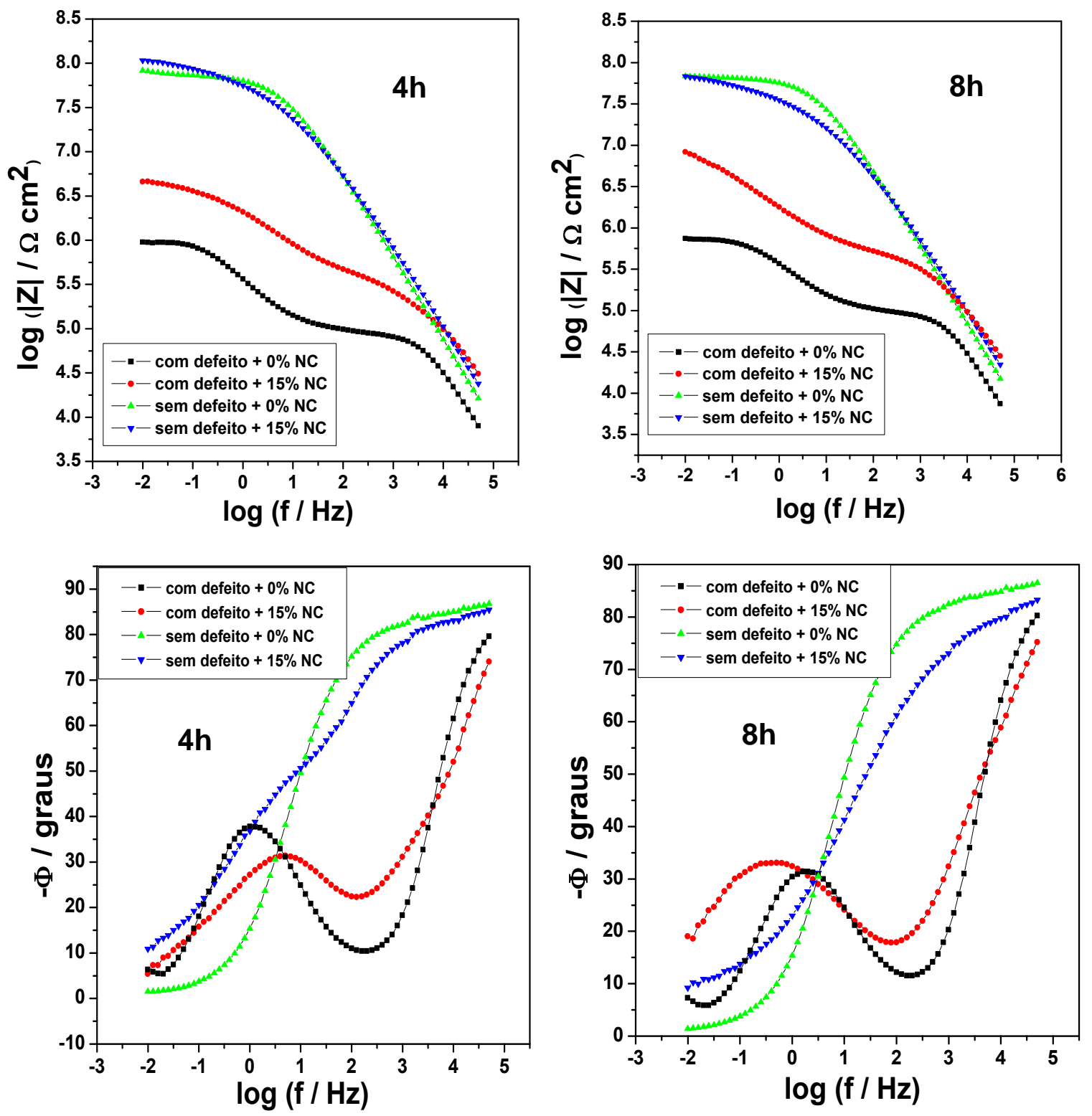

Figura 4.47 - Diagramas de Bode obtidos para as chapas de aço carbono revestidas com duas demãos de tinta alquídica e apenas a primeira camada aditivada com $0 \% \mathrm{~m} / \mathrm{m}$ e $15 \% \mathrm{~m} / \mathrm{m}$ de sílica mesoporosa com dodecilamina sem e com defeito provocado após diferentes tempos de imersão numa solução de $\mathrm{NaCl} 0,01 \mathrm{~mol} / \mathrm{L}$. 


\subsubsection{Técnica de varredura com eletrodo vibratório (SVET)}

A Figura 4.48 mostra os mapas de densidade de corrente iônica obtidos por SVET para as chapas de aço carbono revestidas com duas demãos de uma tinta alquídica sem adição de sílica mesoporosa e para tempos de imersão de 1 h, 8 h, $17 \mathrm{~h}$ e $23 \mathrm{~h}$ em solução de cloreto de sódio $\mathrm{NaCl}$ 0,05 mol/L. A fim de acelerar o processo de corrosão e avaliar o efeito da proteção desta tinta foi feito um defeito no revestimento da amostra de aproximadamente $3 \mathrm{~mm}$ de comprimento. Essa concentração de $0,05 \mathrm{~mol} / \mathrm{L}$ foi utilizada devido a que para este caso particular, quando era usada uma concentração menor $(0,01 \mathrm{~mol} / \mathrm{L})$ o defeito tornava-se catódico e só correntes catódicas apareciam sobre o defeito. Após a primeira hora de imersão é possível observar o aparecimento de um pico com densidade de corrente anódica de $46 \mu \mathrm{A} / \mathrm{cm}^{2}$ ao longo do defeito, o qual vai aumentando com o decorrer do tempo. Após de $8 \mathrm{~h}$ de imersão o aparecimento de um pico anódico intenso em uma região do defeito pode ser explicado pela presença de zonas mais ativas sobre o metal e, as quais possuem maior atividade anódica (SKORB et al., 2009). Já para tempos mais longos de imersão (23 h) este pico vai se pronunciando atingindo valores maiores de densidade de corrente anódica $\left(123 \mu \mathrm{A} / \mathrm{cm}^{2}\right)$. Esta atividade anódica medida depois da imersão dos corpos de

prova com defeito pode ser observada ao redor do defeito e confirmada pela acumulação de produtos de corrosão formados no defeito. 

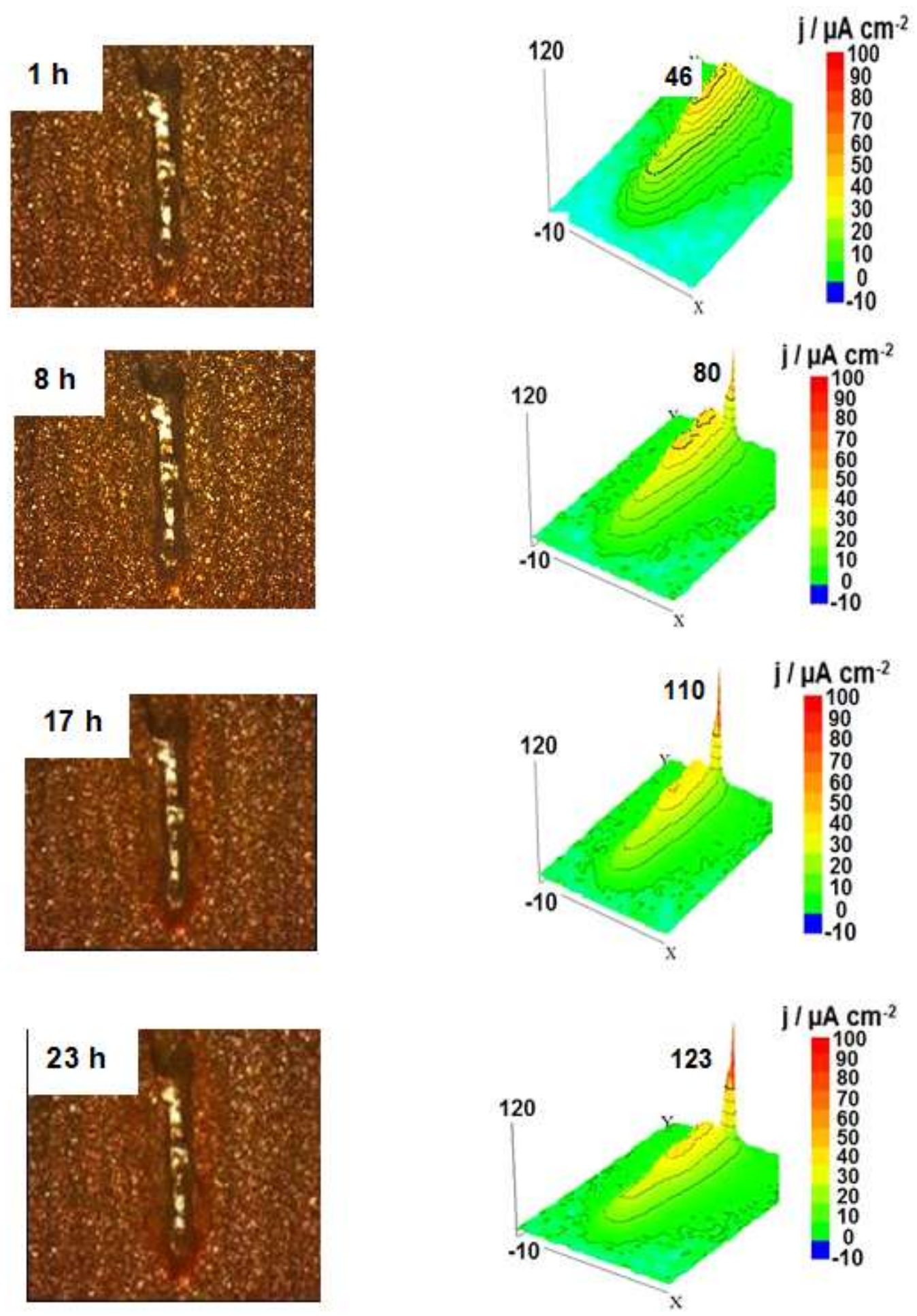

Figura 4.48 - Imagens dos corpos de prova e mapas de densidade de correntes para as chapas de aço carbono revestidas com duas demãos de tinta alquídica com defeito sem adição de partículas de sílica mesoporosa com diferentes tempos de imersão em solução de $\mathrm{NaCl}$ 0,05 mol/L. 
Já para as chapas de aço carbono revestidas com duas demãos contendo $15 \% \mathrm{~m} / \mathrm{m}$ de sílica mesoporosa e imersas numa solução de $\mathrm{NaCl} 0,05 \mathrm{~mol} / \mathrm{L}$ os resultados de SVET são mostrados na Figura 4.49. Para este caso foram feitos também defeitos artificiais sobre amostra com o objetivo de acelerar o processo de corrosão e poder avaliar as propriedades anticorrosivas do revestimento pela adição da sílica mesoporosa contendo dodecilamina.

Nestas condições é possível observar um comportamento totalmente diferente em comparação com os resultados obtidos para as chapas revestidas sem adição de sílica mesoporosa. O incremento na atividade de corrosão é insignificante ao redor do defeito, já que após 23 h de imersão em NaCl 0,05 mol/L a densidade de corrente anódica ficou em torno de 5-7 $\mu \mathrm{A} / \mathrm{cm}^{2}$ mostrando-se uma inibição do processo de corrosão devido à ação do inibidor dodecilamina que é liberado dos canais internos da sílica mesoporosa em razão do abaixamento do pH sobre o defeito provocado (BORISOVA; MÖHWALD; SHCHUKIN, 2011; SKORB et al., 2009; BORISOVA, 2012; ZHENG et al., 2013; MAIA et al., 2012). O efeito anticorrosivo do inibidor dodecilamina é baseado na formação de um filme adsorvido sobre a superfície do metal o qual age como barreira física bloqueando o contato da solução agressiva com o metal (BASTIDAS; POLO; CANO, 2000). 

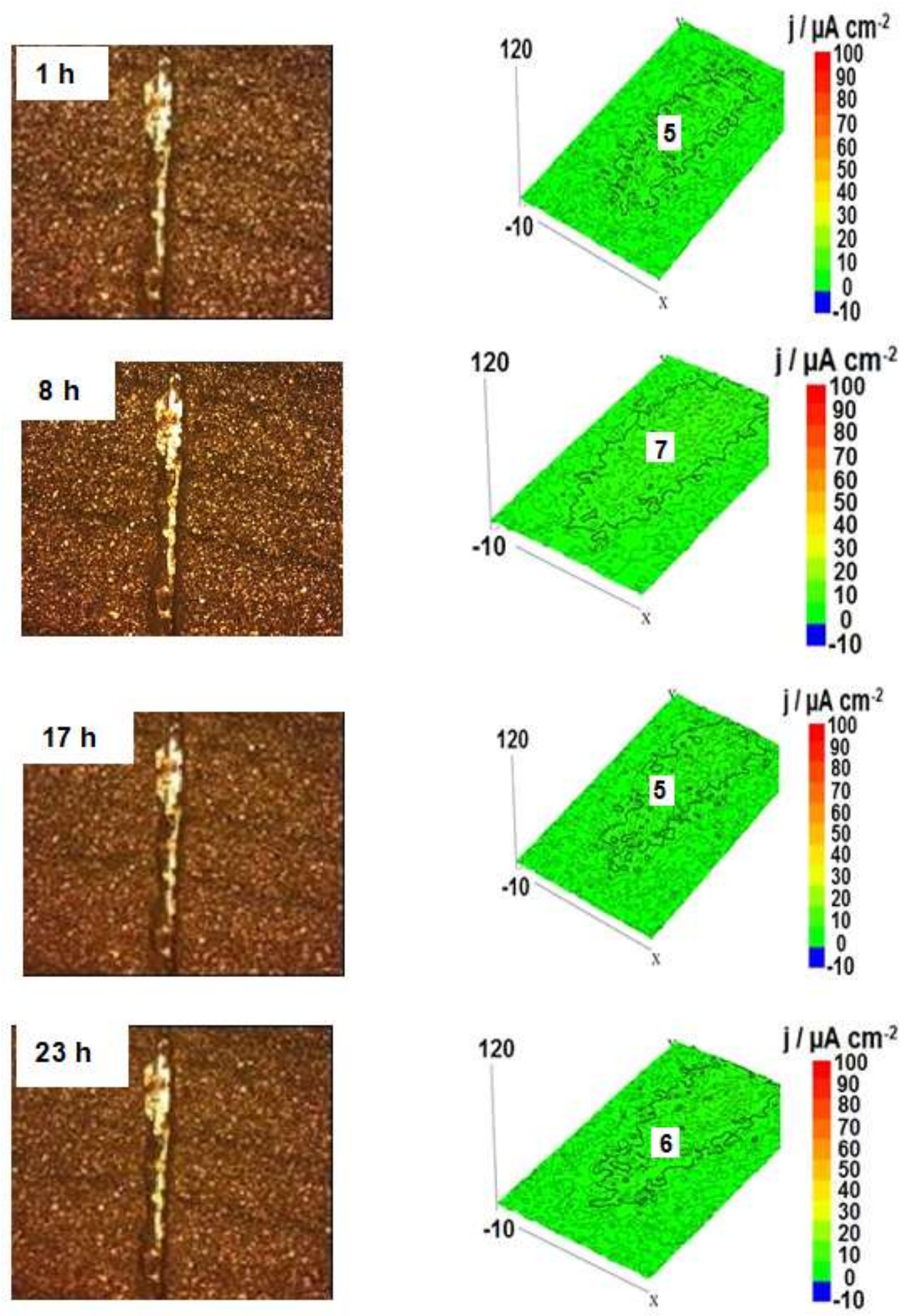

Figura 4.49 - Imagens dos corpos de prova e mapas de densidade de correntes para as chapas de aço carbono revestidas com duas demãos de tinta alquídica com defeito e apenas a primeira camada aditivada com $15 \% \mathrm{~m} / \mathrm{m}$ de sílica mesoporosa contendo dodecilamina com diferentes tempos de imersão em solução de $\mathrm{NaCl} 0,05 \mathrm{~mol} / \mathrm{L}$. 


\subsubsection{Ensaios acelerados em câmara de névoa salina}

Os resultados obtidos após exposição na câmara de névoa salina das chapas de aço carbono revestidas com tinta alquídica sem e com $15 \% \mathrm{~m} / \mathrm{m}$ de sílica mesoporosa contendo dodecilamina para tempos de exposição de $0 \mathrm{~h}$ e 720 h são apresentados na Figura 4.50. Neste ensaio é possível observar que para os corpos de prova sem adição da sílica mesoporosa o ataque foi bastante agressivo quando foram expostos durante um período de $720 \mathrm{~h}$. Por outro lado, para os corpos de prova contendo $15 \% \mathrm{~m} / \mathrm{m}$ de sílica mesoporosa carregada com inibidor dodecilamina, a formação de produtos de corrosão foi bem leve e com pouca formação de bolhas por empolamento em torno do defeito, em comparação com os corpos de prova sem sílica mesoporosa, mostrando assim uma maior eficiência na proteção contra a chegada de espécies agressivas até o metal. A partir dos ensaios de névoa salina em conjunto com os ensaios de EIS e SVET é possível confirmar o efeito self-healing ou de autorreparação do revestimento, onde a ação do inibidor de corrosão liberado dos canais internos da sílica mesoporosa na área do defeito provocado, retarda de forma eficiente o processo de corrosão. 


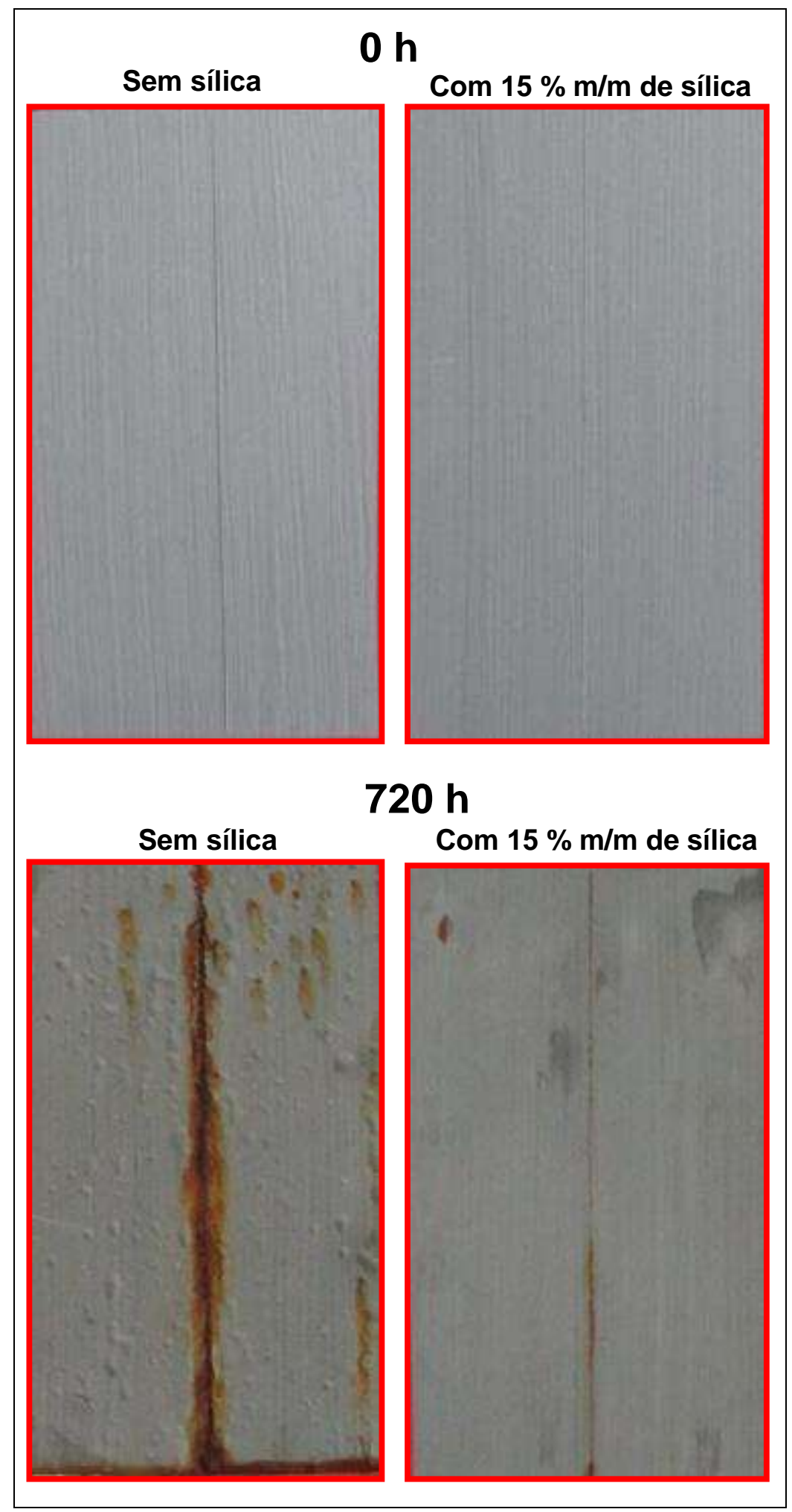

Figura 4.50 - Imagens dos corpos de prova jateados pintados com duas demãos de tinta alquídica e apenas a primeira camada aditivada com $0 \%$ e $15 \%$ em massa de sílica mesoporosa com dodecilamina encapsulada depois de $0 \mathrm{~h}$ e $720 \mathrm{~h}$ de exposição na câmara de névoa salina. 


\section{CONCLUSÕES}

Os resultados obtidos nas condições descritas neste trabalho permitem que sejam tiradas as seguintes conclusões:

As micrografias obtidas por FEG-MEV permitiram estimar como ótimo o tempo de $6 \mathrm{~h}$ para o pré-tratamento com ácido sulfúrico das nanopartículas de haloisita, já que para um tempo de $12 \mathrm{~h}$ a superfície externa foi bastante alterada por dissolução preferencial da alumina.

A partir dos resultados das diferentes técnicas como adsorção e dessorção de nitrogênio e difração de raios $X$ feitos para a sílica mesoporosa tipo SBA-15 foi possível atestar que o material obtido está dentro das especificações encontradas na literatura para considerá-lo como mesoporoso. A sílica mesoporosa desenvolvida apresentou curva de adsorção/dessorção do tipo IV, típica de materiais mesoporosos segundo a classificação de Brunauer.

Os resultados dos ensaios de espectroscopia de impedância eletroquímica mostraram o caráter inibidor da dodecilamina na proteção do aço carbono contra corrosão para condições de pH neutro e ácido, apresentando uma maior eficiência de inibição em pH 2 do que em pH neutro para uma concentração de 400 ppm.

Nos diferentes tipos de tratamentos usados para a preparação dos nanocontainers a base de nanopartículas de sílica pelo método L-b-L para encapsular a dodecilamina, foi comprovado que a melhor forma de obtê-los bem dispersos e sem uma possível fuga do inibidor dos nancontainers foi usando água destilada como dispersante, tratamento em banho de ultrassom em cada etapa de deposição dos polieletrólitos e finalmente secar as partículas obtidas ao ar.

Através das medidas de impedância eletroquímica foi possível estudar a cinética de liberação do inibidor dodecilamina, onde foi comprovado que para a 
condição de $\mathrm{pH} 2$, a velocidade de liberação do inibidor desde os três tipos de nanocontainers estudados foi maior em comparação com as outras condições de pH estudadas (6,2 e 9). Além disso, para a condição de pH 2 foi possível observar que a velocidade de liberação do inibidor foi mais lenta desde as partículas de sílica mesoporosa devido a uma maior dificuldade das moléculas do inibidor saírem desde as cavidades porosas da sílica, permitindo assim uma maior reserva do inibidor dentro da sílica e um maior tempo de proteção ao metal.

A análise química por sonda de infravermelho permitiu estudar a cinética de liberação do inibidor dodecilamina através da alteração da altura dos picos de absorção típicos da dodecilamina obtidos para diferentes tempos de imersão, Dessa forma, foi possível encontrar vários picos correspondentes à liberação da dodecilamina e dos polieletrólitos que conformam as camadas aprisionantes do inibidor dentro dos nanocontainers. Além disso, foi comprovado através de ensaios de impedância eletroquímica que esses polieletrólitos tinham pouco efeito na inibição da corrosão do aço carbono.

Os resultados de espectroscopia de impedância eletroquímica para os corpos de prova revestidos com uma tinta alquídica contendo $10 \% \mathrm{~m} / \mathrm{m}$ de nanopartículas de sílica com dedecilamina por L-b-L ou haloisita e $15 \% \mathrm{~m} / \mathrm{m}$ de sílica mesoporosa mostraram o efeito self-healing ou de autorreparação da tinta pela liberação do inibidor dodecilamina encapsulado, os quais apresentaram concordância plena com os resultados obtidos com a técnica de SVET, onde o efeito de inibição contra a corrosão na região do defeito e autorreparação da tinta ocorreu para as amostras aditivadas.

Os ensaios de névoa salina para os três tipos de nanocontainers estudados mostraram de forma inequívoca que a adição de nanocontainers na tinta forneceu propriedades de autorreparação ao revestimento, onde o inibidor é liberado dos nanocontainers retardando o processo de corrosão na região do defeito. 
A técnica de encapsulamento por Layer-by-Layer não demostrou ser muito eficiente para a produção de nanoparticulas pequenas devido à aglomeração que ocorre durante as diferentes etapas de deposição, mas mesmo assim foi possível realizar estudos através das técnicas de EIE e SVET sobre a liberação do inibidor dodecilamina a partir das nanopartículas de sílica. Dessa forma é preciso melhorar a dispersão dos nanocontainers para evitar que aglomerem na tinta e provoquem aparecimento de defeitos nela como foi o caso das nanopartículas de sílica obtidas pelo método L-b-L. Já no caso da haloisita e da sílica mesoporosa, não houve problemas de aglomeração por serem partículas bastante finas e facilmente dispersas na tinta.

Dos três tipos de nanocontainers estudados é possível concluir que todos eles foram eficientes em relação ao efeito de autorreparação proporcionado ao revestimento, mas em relação à parte estética e distribuição no revestimento, a sílica mesoporosa e a haloisita resultaram ser mais apropriadas, já que se conseguiu usar uma quantidade razoável $(10 \% \mathrm{~m} / \mathrm{m}$ ou $15 \% \mathrm{~m} / \mathrm{m})$ sem perturbar o desempenho da tinta ou criar pontos de defeitos nela. A halosita e a sílica mesoporosa são materiais muito versáteis e com relativo baixo custo de produção sendo promissora a sua aplicação em diferentes áreas da indústria química em processos de pintura de manutenção de estruturas e bens. 


\section{SUGESTÕES PARA TRABALHOS FUTUROS}

1. Usar outros tipos de polieletrólitos para a formação das camadas dos nanocontainers a base de sílica pelo método L-b-L.

2. Fazer o estudo de liberação do inibidor dodecilamina com o tempo dos nanotubos de haloisita e sílica mesoporosa para diferentes condições de $\mathrm{pH}$ usando uma sonda de infravermelho in situ.

3. Encapsular outros tipos de inibidores de corrosão dentro dos diferentes tipos de nanocontainers obtidos e estudados e avaliar seu efeito de autorreparação em diferentes tipos de tinta (epóxi e poliuretânica) aplicadas em aço carbono. 


\section{REFERÊNCIAS BIBLIOGRÁFICAS}

ABDULlAYEV, E.; ABBASOV, V.; TURSUNBAYEVA, A.; PORTNOV, V.; IBRAHIMOV, H.; MUKHTAROVA, G.; LVOV, Y. Self-healing coatings based on halloysite clay polymer composites for protection of copper alloys. Applied Materials \& Interfaces, v. 5, p. 4464-4471, 2013.

ABDULLAYEV, E.; JOSHI, A.; WEI, W.; ZHAO, Y.; LVOV, Y. Enlargement of halloysite clay nanotube lumen by selective etching of aluminium oxide. ACS Nan, v. 6, p. 7216-7226, 2012.

ABDULLAYEV, E.; PRICE, R.; ; SHCHUKIN, D. LVOV, Y. M. Halloysite tubes as nanocontainers for anticorrosion coating with benzotriazole. Applied Materials \& Interfaces, v. 1, p. 1437-1443, 2009.

AKID, R., GARMA, M. Scanning vibrating reference electrode technique: a calibration study to evaluate the optimum parameters for maximum signal detection of point source activity. Electrochimica acta, v. 49, p. 2873-2879, 2004.

ALVES, M. Parâmetros texturais de pós analisados por técnicas de adsorção de gases. Exame de Qualificação Geral de Doutorado, Instituto de Química, Unicamp, 1999.

ANDREEVA, D. V.; FIX, D.; MOHWALD, H.; SHCHUKIN, D. G. Buffering polyelectrolyte multilayers for active corrosion protection. Journal of Materials Chemistry, v. 18, p. 1738-1740, 2008.

ANDREEVA, D. V.; SKORB, E. V.; SHCHUKIN, D. Layer-by-layer polyelectrolyte/inhibitor nanostructures for metal corrosion protection. Applied Materials \& Interfaces, v. 2, p. 1954-1962, 2010.

ANDREEVA, D.V.; FIX, D.; MÖHWALD, H.; HACK, T.; SHCHUKIN, D. Selfhealing anticorrosion coatings based oh $\mathrm{pH}$-sensitive polyelectrolyte/inhibitor sandwichlike nanostructures, Advanced Materials, v. 20, p. 2789-2794. 2008.

ANTIPOV, A. A.; SUKHORUKOV, G. B. Polyelectrolyte multilayer capsules as vehicles with tunable permeability. Advance in Colloid and Interface Science. v. 111, p. 49-61, 2004.

ANZAI, J. I.; KOBAYASHI, Y.; NAKAMURA, N.; NISHIMURA, M.; HOSHI, T. Layer-by-Layer construction of multilayer thin films composed of avidin and blotin-labeled poly(amine)s. Langmuir, v. 15, p. 221-226, 1999.

AOKI, I. V., DE MELO, H. G., Fundamentos da Técnica de Espectroscopia de Impedância Eletroquímica (EIE), Metalúrgica \& Materiais, v. 66, p. 201-206, 2009.

ARAÚJO, A.C.; PERES, A.E.C.; BRANDÃO, P.R.G. Determinação do Potencial Zeta. In: SIMPÓSIO EPUSP DE CARACTERIZAÇÃO TECNOLÓGICA NA 
ENGENHARIA E INDÚSTRIA MINERAL, 1990, São Paulo, Anais. São Paulo: p. 231-247.

ARAUJO, A.S.; JERONIEC, M. Thermogravimetric monitoring of the MCM-41 synthesis. Thermochimica Acta, v. 363, p. 175-180, 2000.

ASHASSI - SORKHABI, H.; NABAVI - AMRI, S. A. Polarization and impedance methods in corrosion inhibition study of carbon steel amines in petroleum water mixtures. Electrochimica Acta, v. 47, p.2239-2244, 2002.

AYERS, R.C.; HACKERMAN, N. Corrosion inhibition in $\mathrm{HCl}$ using methyl pyridines. Journal of the Electrochemical Society, v. 110, p.507-513. 1962.

BADIEA, A. M.; KIKKERI, N. M. The effect of sodium benzoate and sodium 4(phenylamino)benzenesulfonate on the corrosion behaviour of low carbon steel. Monatsh Chemical, v. 40, p.1-8, 2009.

BALASKAS, A. C.; KARTSONAKIS, I. A.; TZIVELEKA, L. A.; KORDAS, G. C. Improvement of anti-corrosive properties of epoxy-coated AA 2024-T3 with $\mathrm{TiO}_{2}$ nanocontainers loaded with 8-hydroxyquinoline. Progress in Organic Coatings, v. 74, p. 418-426, 2012.

BARRETT, E. P.; JOIYNER, L. G.; HALENDA, P. P. The determination of pore volume and area distributions in porous substances. I. Computations from nitrogen isotherms. Journal of American Chemical Society, v. 73, p. 373, 1953.

BASTIDAS, J. M.; DAMBORENEA, J.; VÁZQUEZ, A. J. Butyl substituents in nbutylamine and their influence on mild steel corrosion inhibition in hydrochloric acid. Journal of Applied Electrochemistry, v. 27, p.345-349. 1997.

BASTIDAS, J. M.; POLO, J. L.; CANO. E. Substitutional inhibition mechanism of mild steel hydrochloric acid corrosion by hexylamine and dodecylamine. Journal of Applied Electrochemistry, v. 30, p.1173-1177, 2000.

BASTIDAS, J. M.; POLO, J. L.; CANO. E.; TORRES, C. L. Tributylamine as corrosion inhibitor for mild steel in hydrochloric acid. Journal of Materials Science, v. 35, p.2637-2642, 2000.

BECK, F.; KRÜGER, U. A.; BLECHER, A.; KURZMANN, P. Corrosion of pretreated aluminium after cathodic electrodeposition of paint. Materials and Corrosion, v. 46, p. 447-459, 1995.

BECK, J. S.; VARTULI, J. C.; ROTH, W. J.; LEONOWICZ, M. E; KRESGE, C. T.; SCHMITT, K. D.; CHU, C, T-W.; OLDSON, D. H.; SHEPPARD, E. W.; MCCULLEN, S. B.; HIGGINS, J. B.; SCHLENKER, J. L. A new family of mesoporous molecular sieves prepared with liquid crystal templates. Journal of the American Chemical Society, v. 114, p. 10834-10843, 1992.

BODEEPONG, S.; BHONGSUWAN, D.; PUNGRASSAMI, T.; BHONGSUWAN, T. Characterization of halloysite from Thung Yai Distric, Nackon Si Thammarat 
Province, in Shouthern Thailand. Songklanakarin Journal of Science and Technology, v. 33, p. 509-607, 2011.

BORISOVA, D.; AKÇAKAYAIRAN, D.; SHENDERLEIN, M.; MÖHWALD, H.; SHCHUKIN, D. G. Nanocontainer-based anticorrosive coatings: Effect of the container size on the self-healing performance. Materials Views, v. 23, p. 3799-3812, 2013.

BORISOVA, D.; MÖHWALD, H.; SHCHUKIN, D. G. Influence of embedded nancontainers on the efficiency of active anticorrosion coatings for aluminum alloys part I: Influence of nanocontainers concentration. Applied Materials \& Interfaces, v. 4, p. 2931-2939, 2012.

BORISOVA, D.; MÖHWALD, H.; SHCHUKIN, D. G. Mesoporous sílica nanoparticles for active corrosion protection. American Chemical Society nanotechnology, v. 5, p. 1939-1946, 2011.

BORIVOSA, D. Feedback active coatings based on mesoporous sílica nanocontainers. Doctoral Dissertation. University of Potsdam. Potsdam, Germany, 2012.

BRAUN, R. D.; LOPEZ, E. L.; VOLLMER, D. P. Low molecular weight straingchain amines as corrosion inhibitors. Corrosion Science, v. 34, p. 1251-1257, 1993.

BRUNAUER, S.; EMMETT, P. H.; TELLER, E. Adsorption of gases in multimolecular layers. Journal of American Chemical Society, v. 60, p. 309319, 1938.

CABRERA, S.; MARIN, J.; GONZÁLEZ, I. La utilización de la espectroscopia de impedancia electroquímica (EIS) para identificar diferentes estados superficiales en el proceso de corrosión del acero al carbono en medios amargos. Boletín de la Sociedad Química de México, v. 1, p. 32-41, 2007.

Caracterização de partículas, 2011. Disponível em: http://br.mt.com/br/pt/home/products/L1 AutochemProducts/FBRM/PVMParticle-System-Characterization.html. Acessado em: 12 de Fevereiro de 2014.

CHAIYASAT, P.; ISLAM, M. Z.; CHAIYASAT, A. Preparation of poly(divinylbenzene) microencapsulated octadecane by microsuspensionpolymerization: oil droplets generated by phase inversion emulsification. Royal Society of Chemistry, v. 3, p. 10202-10207, 2013.

CHAO, M.C.; LIN, H. P.; SHEU, H. S.; MOU, C. Y. A study of morphology of mesoporous silica SBA-15. Studies in Surface Science and Catalysis, v. 141, p.387-394, 2002.

CHAUDAHARI, H. G.; MAHIDA, M. M. Aliphatic amines as corrosión inhibitors for zinc in hydrochloric acid. Der Pharma Chemica, v. 4, p. 2305 -2312, 2012. 
CHEN, T.; FU, J. An intelligent anticorrosion coating based on $\mathrm{pH}$-responsive supramolecular nanocontainers. Journal of Nanotechnology, v. 23, p. 1-12, 2012.

CHEN, T.; FU, J. pH-responsive nanovalves base on hollow mesoporous silica spheres for controlled release of corrosion inhibitor. Journal of Nanotechnology, v. 23, p. 1-8, 2012b.

CONLEY, R. T. Infrared Spectroscopy. Second Edition. Allyn and Bacon, INC. Boston. 1972. 355p.

CULLITY, B.D. Elements of X-ray diffraction. Second Edition. Massachusetts: Addison-Wesley Publishing Company Inc. 1956. 569 p.

DA SILVA, J. Estudo da corrosão de revestimentos de zinco-ligas obtidos por imersão a quente sobre aços baixos-carbono. Dissertação de Mestrado. Porto Alegre, Brasil, 2011.

DALTIN, D. Tensoativos. Química, propriedades e aplicações. Blucher. 2011. 330p.

DAMBORENEA, J.; BASTIDAS, J.M.; VAZQUEZ, A.J. Adsorption and inhibitive properties of four primary aliphatic amines on mild steel in $2 \mathrm{M}$ hydrochloric acid. Electrochimica Acta, Vol. 45, p. 455-459, 1997.

DANIILIDIS, I.; KARTSONAKIS, I.; KORDAS, G.; PAPPAS, G. S. Encapsulation and Release of corrosion inhibitor into titiana nanocontainers. Journal of Nanoscience and Nanotechnology, v. 10, p. 5912-5920, 2010.

DAUTZENBERG, H.; JAEGER, W.; KÖTZ, J.; PHILIPP, B.; SEIDEL, CH.; STSCHERBINA. Polyelectrolytes: Formation, Characterization and Application. New York: Hanser/Gardner Publications, Inc. 1994. 343p.

DE SOUZA, A. F. Sílicas mesoporosas modificadas com grupos contendo nitrogênio e enxofre como adsorventes para íons metálicos em solução. Dissertação de Doutorado. João Pessoa - PB. Brasil, 2012.

DE SOUZA, H. Estudo da adsorção de polieletrólitos e do ordenamento molecular de filme molecular de filmes poliméricos automontados através da óptica não-linear. Dissertação de Doutorado. São Carlos, São Paulo, Brasil, 2010.

DE SOUZA, K. C. Síntese e caraterização de nanocompósitos de sílica mesoporosa com partículas magnéticas para dispositivos de liberação controlada de fármacos. Dissertação de Mestrado. Belo Horizonte. Brasil, 2007.

DENARI, G.B. Princípios e aplicações de análise térmica. São Paulo: Instituto de Química de São Carlos, 2012./ Material de apoio - Curso teórico prático.

DHAR, G. M.; KUMARAN, G. M.; KUMAR, M.; RAWAT, K. S.; SHARMA, L. D.; RAJU, B. D.; RAMA RAO, K. S. Physico-chemical characterization and 
catalysis on SBA-15 supported molybdenum hydrotreating catalysis. Catalysis Today, v. 99, p. 309-314, 2005.

DIAS, S. A. S.; LAMAKA, S. V.; NOGUEIRA, C. A.; DIAMANTINO, T. C.; FERREIRA, M. G. S. Sol - Gel coatings modified with fillers active corrosion protection. Corrosion Science, v. 62, p. 153-162, 2012.

DISTRIBUTION, P. S.; INTER, J. C. (2002). 738 3.1, 738-765.

ELACHOURI, M.; HAJJI, M. S.; KERTIT, S.; ESSASSI, E. M.; SALEM, M.; COUDERT, R. Some surfactants in the series of 2 (alkyldimethylammonio) alkanol bromides as inhibitors of the corrosion of iron in acid chloride solution. Corrosion Science, v. 37, p. 381-389, 1995.

Electrochemical Impedance Spectroscopy (EIS): A Powerful and Cost Effective Tool for Fuel Cell Diagnostics, 2007. Disponível em: http://www.scribner.com/files/tech-papers/Scribner/Research.pdf. Acessado em: 03 de Agosto de 2012.

Espectroscopia Infravermelho, 2009. Disponível em: http:// www.maxwell.lambda.ele.puc. Acessado em: 29 de Julho de 2012.

FIX, D.; ANDREEVA, D. V.; LVOV, Y. M.; SHCHUKIN, D. G.; MOHWALD, H. Application of inhibitor-loaded halloysite nanotubes in active-corrosive coatings. Advanced Functional Materials, v. 19, p. 1720-1727, 2009.

FU, J.; CHEN, T.; WANG, M.; YANG, N.; LI, S.; WANG, Y.; LIU, X. Acid and alkaline dual stimuli-responsive mechanized hollow mesoporous silica nanoparticles as smart nanocontainers for intelligent anticorrosion coatings. ACS Nano, v. 12, p. 11397-11408, 2013.

FU, S.; XU, C.; DU, C.; TIAN, A.; ZHANG, M. Encapsulation of C.I. pigment blue 15:3 using a polymerizable dispersant via emulsion polymerization. Colloids and Surfaces A: Physicochemical and Engineering Aspects. v. 384, p.68-74, 2011.

FUERSTENAU, D.W. Mineral-Water and electrical double layer In: PERES, A. E.C.C; MONTE, M. B. M. Química de superfície na flotação; tratamento de minérios. 4 ed. Rio de janeiro: Cetem/MCT, 2004.

GALARNEAU, A.; CAMBON, H.; RENZO, F. D.; FAJULA, F. True Microporosity and Surface Area of Mesoporous SBA-15 Silicas as a Function of Synthesis Temperature. Langmuir, v. 17, p. 8328-8335, 2001.

GENTIL, V. Corrosão. Terceira edição. Rio de Janeiro: LTC - Livros Técnicos e Científicos Editora S.A. 1996. 335p.GHOSH, S. K. Functional Coatings. Weinheim: Wiley-VCH, 2006.

GRIGORIEV, D. O.; BUKREEVA, T.; MÖHWALD, H.; SHCHUKIN, D. New method for fabrication of loaded micro- and nanocontainers: emulsion encapsulation by polyelectrolyte layer-by-layer deposition on the liquid core. Langmuir, v. 24, p. 999-1004, 2008. 
HAMDY, A. S.; SHENAWY, E. E; BITAR, T. E.; Electrochemical impedance spectroscopy study of the corrosion behaviour of some niobium bearing stainless steels in $3.5 \% \mathrm{NaCl}$. International Journal of Electrochemical Science, v. 1, p. 171-180, 2006.

HAN, Y, J.; KIM, J. M.; STUCKY, G. D. Preparation of nobel metal nanowires using hexagonal mesoporous silica SBA-15. Chemistry of Materials, v. 12, p. 2068-2069, 2000.

HARA, M. Polyelectrolytes. Science and Technology. New Jersey: Marcel Decker, Inc. 1993. 399p.

HATTON, B.; LANDSKRON, K., WHITNALL, W.; PEROVIC, D.; OZIN, G. A. Past, Present, and Future of Periodic Mesoporous Organosilicas (PMOs), Accounts of Chemical Research, v. 38, p. 305-312, 2005.

HUNTER, R. J. Zeta Potential in Colloids. Academic Press. New York. 1981. $386 p$.

Inibidores Orgânicos de Adsorção, 2005, Disponível em: http://www.ufrgs.br/lapec/cariboos files/inibidores 20org c3 a2nicos.pdf. Aces sado em : 18 de Julho de 2012.

KARTSONAKIS, I. A.; BALASKAS, A. C.; KOUMOULOS, E. P.; CHARITIDIS, C. A.; KORDAS, G. C. Incorporation of ceramic nanocontainers into epoxy coatings for the corrosion protection of hop dip galvanized steel. Corrosion Science, v. 57, p. 30-41, 2012.

KARTSONAKIS, I.; DANIILIDIS, I.; KORDAS, G. Encapsulation of the corrosion inhibitor 8-hydroxyquinoline into ceria nanocontainers. Journal Sol Gel science Technological, v. 48, p. 24-31, 2008.

KATIJAR, A.; YADAV, S.; SMIRNIOTS, P. G.; PINTO, N. G. Syntheses of ordered large pore SBA-15 spherical particles for adsorption of biomolecules. Journal of Chromatography A, v. 1122, p. 13-20, 2006.

KAVANOV, A. V.; LEMIEUX, P.; VINOGRADOV, S.; ALAKHOV. Pluronic $\circledast$ block copolymers: novel functional molecules for genetherapy. Advance Drug Delivery Reviews, v. 54, p. 223-233, 2002.

KIWILSZA, A.; MIELCAREK, J.; PAJZDERSKA, A.; WASICKI, J. Ordered mesoporous silica material SBA-15: loading of new calcium channel blocker lacidipine. Journal of Microencapsulation, v. 30, p. 21-27, 2013.

KO, C. H.; RYOO, R. Characterization of the porous structure of SBA-15. Chemistry of Materials, v. 12, p. 1961-1968, 2000.

KOOT, V.; ERDEN, A. M. J. V. D.; WECKHUYSEN, B. M.; KONINGSBERGER, D. C.; RAMARKER, D. E.; BOKHOVEN, J. A. V.; MILLER, J. T. As the old adage goes, 2007, A picture is worth a thousand. 
KOUMOULOS, E. P.; KARTSONAKIS, I. A.; BALASKAS, A. C.; PAPPAS, G. S.; CHARITIDIS, C. A.; KORDAS, G. C. Hibrid organic-inorganic multilayer coatings including nanocontainers for corrosion protection of metal alloys. Corrosion Science, v. 57, p. 56-66, 2012.

KUANG, F.; SHI, T.; WANG, J.; JIA, F. Microencapsulation technology for thiourea corrosion inhibitor. Journal solid state electrochemical, v. 13, p. 1729-1735, 2009.

KUMARAN, G. M.; GARG, S.; SONI, K.; KUMAR, M.; SHARMA, L. D.; DHAR, G. M.; RAO, K. S. R. Effect of Al-SBA-15 support on catalytic functionalities of hydrotreating catalysis I. Effect of variation of $\mathrm{Si} / \mathrm{Al}$ ratio on catalytic functionalities. Applied Catalysis A, v. 305, p. 123-129, 2006.

LAMAKA, S. V.; SHCHUKIN, D.; ANDREEVA, D. V.; ZHELUDKEVICH, M. L.; MÖHWALD, H.; FERREIRA, M. G. S. Sol-Gel/polyelectrolyte active corrosion protection system. Advanced Functional Materials, v. 18, p. 3137-3147, 2008.

LAMAKA, S. V.; ZHELUDKEVICH, M. L.; YASAKU, K. A.; SERRA, R.; POZNYAK, S. K.; FERREIRA, M. G. S. Nanopouros titiana interlayer as reservoir of corrosion inhibitors for coatings with self-healing ability. Process in Organic Coatings, v. 58, p. 127-135, 2007.

LANKALAPALLI, S.; KOLAPALLI, V.R.M. Polyelectrolyte complexes. A review of their applicability in drug delivery. Indian Journal of Pharmaceutical Sciences, v. 71, p. 481-487, 2009.

LEE, D.; GEMICI, Z.; RUBNER, M. F.; COHEN, R.E. Multilayers of oppositely charged $\mathrm{SiO}_{2}$ nanoparticles: effect of surface charge on multilayer assembly. Lagmuir, v. 23, p.8833-8837, 2007.

LEROY, P.; TOURNASSAT, C.; BIZI, M. The influence of surface conductivity on the apparent zeta potential of $\mathrm{TiO} 2$ nanoparticles. Journal of Colloid and Interface Science, v. 356, p. 442-453, 2011.

LI, G. L.; ZHENG, Z.; MÖHWALD, H.; SHCHUKIN, D. G. Silica/polymer doublewalled hybrid nanotubes: synthesis and application as stimuli-responsive nanocontainers in self-healing coatings. ACS Nano, v. 7, p. 2470-2478, 2013.

LIU, H.; WANG, C.; GAO, Q.; LIU, X.; TONG, Z. Magnetic hydrogels with supracolloidal structures prepared by suspension polymerization stabilized by $\mathrm{Fe}_{2} \mathrm{O}_{3}$ nanoparticle. Acta Biomaterialia, v.6, p.275-281, 2010.

LIU, M.; WU, C.; JIAO, Y.; XIONG, S.; ZHOU, C.; Chitosan-halloysite nanotubes nanocomposite scaffolds for tissue engineering. Journal of Materials Chemistry B, v. 1, p. 2078-2089, 2013.

LOVEDAY, D.; PETERSON, P.; RODGERS, B. Evaluation of organic coating with electrochemical impedance spectroscopy. Part 2: Application of EIS to Coatings. Journal of Coatings Technology, p. 88-93, 2004. 
LUO, Z. ; WANG, A.; WANG, C.; QIN, W.; ZHAO, N.; SONG, H.; GAO, J. Liquid crystalline phase behavior and fiber spinning of cellulose/ionic liquid/halloysite nanotubes dispersions. Journal of Materials Chemistry A, v. 2, p. 7327-7336, 2014.

LVOV, Y. M. Nanofabrication of ordered multilayers by alternative adsorption of polyions, nanoparticles and proteins: from planar films to microtemplates. Multiple layered functional thin films, v. 21, p. 1-13, 2000.

LVOV, Y. M.; SHCHUKIN, D. G.; MOHWALD, H.; PRICE, R. R. Halloysite clay nanotubes for controlled release of protective agents. ACS Nano, v. 2, p. 814820, 2008.

MAIA, F.; TEDIM, J.; LISENKOV, A. D.; SALAK, A. N.; ZHELUDKEVICH, M. L.; FERREIRA, M. G. S. Silica nanocontainers for active corrosion protection. Nanoscale - The Royal Society of Chemistry, v. 4, p. 1287-1298, 2012.

MEKERIDIS, E. D.; KARTSONAKIS, I. A.; KORDAS, G. C. Multilayer organicinorganic coating incorporating $\mathrm{TiO}_{2}$ nanocontainers loaded with inhibitors for corrosion protection of AA2024-T3. Progress in Organic Coatings, v. 73, p.142-148, 2012.

MEKERIDIS, E. D.; KARTSONAKIS, I. A.; PAPPAS, G. S.; KORDAS, G. C. Release studies of corrosion inhibitors from cerium titanium oxide nanocontainers. Journal Nanoparticules Research, v. 13, p. 541-554, 2011.

MERNARI, B.; ATTARI, H. E.; TRAISNEL, M.; BENTISS, F.; LAGRENEE, M. Inhibiting effects of 3,5-bis(n-pyridyl)-4-amino-1,2,4-triazoles on the corrosion for mild steel in $1 \mathrm{M} \mathrm{HCl}$ medium. Corrosion Science, v. 40, p. 391-399, 1998.

Methods of Micro Encapsulation, $2010 . \quad$ Disponível em: http://pt.scribd.com/doc/28977603/Methods-of-Micro-Encapsulation Acessado em: 22 de Julho de 2012.

MEYNEN, V.; COOL, P.; VANSANT, E. F. Verified syntheses of mesoporous materials. Microporous and Mesoporous Materials, v. 125, p. 170-223, 2009.

Microscopia Eletrônica de Transmissão, 2002. Disponível em: http://www.cetene.gov.br/pdf/met.pdf. Acessado em: 16 de Outubro de 2013.

MINATTI, E.; CAMPESTRINI, I.; BELLETTINI, I.C.; FELIPPE, A. C.; MICKE, G. A. Coagulação de soluções aquosas de PEI (um policátion) promovida pela adição de SDS (um surfactante aniônico) investigadas por espalhamento de raios-X, turbidimetria e mobilidade eletroforética. In: 30ำ Reunião Anual da Sociedade Brasileira de Química, 2007, Águas de Lindóia - SP.

MISSIRLIS, D.; KAWAMURA, R.; TIRELLI, N.; HUBBEL, J. A. Doxorubicin encapsulation and diffusional release from stable, polymeric, hydrogel nanoparticles. European Journal of Pharmaceutical Sciences, v. 29, p.120129, 2006. 
MONTEMOR, M. F.; SNIHIROVA, D. V.; TARYBA, M. G.; LAMAKA, S. V.; KARTSONAKIS, I. A.; BALASKAS, A. C.; KORDAS, G. C.; TEDIM, J.; KUZNETSOVA, A.; ZHELUDKEVICH, M. L.; FERREIRA, M. G. S. Evaluation of self-healing ability in protective coatings modified with combinations of layered double hydroxides and cerium molibdate nanocontainers filled with corrosion inhibitors. Electrochimica Acta, v. 60, p. 31-40, 2012.

MOTHÉ, C. G.; AZEVEDO, A. D. Análise térmica de materiais. 1 ed. Editora Artliber. 2009. 322p.

MULDER, W. H.; SLUYTERS, J. H. An explanation of depressed semicircular arcs in impedance plots for irreversible electrode reactions. Electrochimica Acta, v. 33, p. 303-310, 1988.

MURRAY, J. N.; MORAN, P. J.; GILEADI, E. Utilization of the specific pseudocapacitance for determination of the area of corroding steel surfaces. Corrosion Science, v. 44, p. 533-538, 1988.

NEIMARK, A. V.; SING, K. S. W. Characterization of solid catalysts. Handbook of Heterogeneous Catalysts, 2008.

NEIVA, A. C. Caracterização de materiais por espectroscopia, difração. São Paulo. EPUSP, 2004. Apostila para a disciplina de pós-graduação do Departamento de Engenharia Química, PQI - 5841- Caracterização de materiais por espectroscopia, difração.

OLIVARES, O.; LIKHANOVA, N.V.; DOMINGUEZ, M. A.; ARCE, E.; DORANTES, H.; ARELLANES, P. Synthesis and corrosion inhibition of amino acids alkylamides for mild steel in acidic environment. Materials Chemistry and Physics, v.110, p. 344-351, 2008.

OSCIK,J., Adsorption. Wiley, New York, 1982. 206p.

PADILHA, A. F. Microscopia Eletrônica de Transmissão. São Paulo. EPUSP, 2004. Apostila para a disciplina de graduação do Departamento de Engenharia Metalúrgica e de Materiais, PMI - 2201.

PASCUALI, R. C.; CHIAPPETTA, D. A.; BREGNI, C. Los copolimeros em bloques anfifílicos y sus propiedades farmacéuticas. Acta Farmacia Bonaerense, v. 24, p. 610-618, 2005.

PASHLEY, R. M.; KARAMAN, M. E. Applied Colloid and Surface Chemistry. Nova York: John Wiley \& Sons, 2004. 188 p.

PATERNO, L.G.; MATOSSO, L. H. C.; OLIVEIRA, J. O. N. Filmes poliméricos ultrafinos produzidos pela técnica de automontagem: preparação, propriedades e aplicações. Química Nova, v. 24, p. 228-235, 2001.

POZNYAK, S. K.; TEDIM, J. RODRIGUES. L. M.; SALAK, A. N.; ZHELUDKEVICH, M. L.; DICK, L. F. P., FERREIRA, M. G. S. Novel inorganic host layered double hydroxides intercalated with guest organic inhibitors for 
anticorrosion applications. Applied Materials \& Interfaces, v. 1, p. 2353-2362, 2009.

PRICE, R. R.; GABER, B. P; LVOV, Y. In-vitro release characteristics of tetracycline $\mathrm{HCl}$, khellin and nicotinamide adenine dineculeotide from halloysite; a cylindrical mineral. Journal of Microencapsulation, v. 18, p. 713-722, 2001.

QUINTELLA, S. A. Síntese, caracterização e propriedades catalíticas da peneira molecular nanoestructurada modificada com lantânio. Dissertação de Doutorado. Rio Grande do Norte, Natal, Brasil, 2009.

RÁMILA, A.; MUÑOZ, B.; PÉREZ-PARIENTE, J.; VALLET-REGÍ, M. Mesoporous MCM-41 as drug host system. Journal of Sol-Gel Science and Technology, v. 26, p. 1199-1202, 2003.

RAMMELT, U.; REINHARD, G. Impedance analysis of conversion layers on iron. Electrochimica Acta, v. 40, p. 505-511, 1995.

RAMMELT, U.; REINHARD, G. The influence of surface roughness on the impedance data for iron electrodes in acid solutions. Corrosion Science, v. 27, p. 373-382, 1987.

REED, J. S. Principles of Ceramics Processing. 2. ed. New York: John Wiley \& Sons. 1995. $658 \mathrm{p}$.

ROA, D. B. Nanofibras de carbono verticalmente alinhadas: estudo do crescimento por microscopia eletrônica de transmissão. Dissertação de Mestrado, Belo Horizonte, Minas Gerais, Brasil, 2008.

ROBERGE, P. R. Handbook of Corrosion Engineering. New York: Mcgraw Hill. 2000. 1128p.

ROSS, S.; MORRISON, I. D. Colloidal Systems and Interfaces. New York: John Wiley \& Sons. 1988. 422p.

SAEED, T. M.; ALI, A.; RAHMAN, S. U. The cyclic hydroxylamines: a new class of corrosion inhibitors of carbon steel in acidic medium. Anticorrosion Methods and Materials, v.50, p. 201-207, 2003.

SASTRI, V.S. Corrosion Inhibitors: principles and applications. West Sussex: John Wiley \& Sons. 1998. 926p.

SEGOVIA, D. B.; DUTRA, W. E. Análise térmica - termogravimétrica (TGA) análise térmica diferencial (DTA), calorimetria exploratória diferencial (DSC). São Mateus. UFES, 2009. Apostila para o curso de farmácia do Departamento de Ciência da Saúde, Biológicas e Agrarias.

Self-healing nanotechnology coatings as alternative to toxic chromium, 2008. Disponível em:http://www.nanowerk.com/spotlight/spotid=6555.php.

Acessado em: 06 de Agosto de 2012. 
SELVAN, S.T.; SPATZ, J. P.; KLOCK, H. A.; MOLLER, M. Gold-polypyrrole core-shell particles in diblock copolymer. Advance Functional Materials, v. 10, p. 132-134, 1998.

SETTLE, F. Handbook of Instrumental Techniques for Analytical Chemistry. USA. Prentice Hall, 1997.

SHCHUKIN, D.; LAMAKA, S. V.; YASAKAU, K. A.; ZHELUDKEVICH , M. L.; FERREIRA, M. G. S.; MÖHWALD, H. Active anticorrosion coatings with halloysite nanocontainers. The Journal of Physical Chemistry C, v. 112, p. 958-964, 2008.

SHCHUKIN, D.; MÖHWALD, H. Self-repairing coatings containing active nanoreservoirs. Small, v. 3, p. 926-943, 2007.

SHCHUKIN, D.; MÖHWALD, H. Surface-Engineered nanocontainers for entrapment of corrosion inhibitors. Advanced Functional Materials, v. 17, p. 1451-1458, 2007.

SHIMAZAKI, Y. Preparation of the layer-by-layer deposited ultrathin film based on the charge-transfer interaction. Langmuir, v. 13, p. 1385-1387, 1997.

SILVA, M.C. Propriedades ópticas do poliestireno sulfonado dopado com íons de neodímio. Dissertação de Mestrado. Minas Gerais, Brasil, 2006.

SILVERMAN, D. C.; CARRICO, J. E. Electrochemical impedance technique - A practical tool for corrosion prediction. Corrosion, v. 44, p. 280-287, 1988.

SILVERSTEIN, R. M.; BASSIER, G. C.; MORRIL, T. C. Identificação Espectrométrica de Compostos Orgânicos Trad. de Ricardo Bicca de Alencastro e Roberto de Barros Faria. Rio de Janeiro: Ed. Guanabara Dois S.A., 1979. p. 65-122.

SIMOES, A. M.; BASTOS, A. C.; FERREIRA, M. G. S.; GONZALEZ-GARCIA, Y.; GONZALEZ, S.; SOUTO, R. M. Use of SVET and SECM to study the galvanic corrosion of an iron-zinc cell. Corrosion Science, v. 49, p. 726-739, 2007.

SING, K. S. W.; EVEREN D. H.; HAUL, R. A. W.; MOSCOU, R. A.; PIEROTTI, J. R.; SIEMIENIEWSKA, T. IUPAC Recommendations. Handbook of Heterogeneous Catalysts, 2002.

SING, K. S.; EVERETT, D. H.; HAUL, R. A. W.; MOSCOW, L.; PIEROTTI, R. A.; ROUQUEROL. J.; SIEMIENIEWSKA, T. Reporting physisorption data gas/solid systems with special reference to the determination of surface area and porosity. Pure Applied Chemistry, v. 57, p. 603-619, 1985.

SKOOG, D. A.; HOLLER, F. J.; NIEMAM, T. A. Princípios de análise instrumental. 5 ed, Editora Bookman, 2002, 836p.

SKORB, E. V.; ANDREEVA, D. V. Layer-by-Layer approaches for formation of smart self-healing materials. Polymer Chemistry, v. 4, p. 4834-4845, 2013. 
SKORB, E. V.; ANDREEVA, D. V.; SHCHUKIN, D. G.; MOHWALD, H. Ultrasound-driven design of metal surface nanofoams. Nanoscale, v. 2, p. 722 727, 2010.

SKORB, E. V.; FIX, D.; ANDREEVA, D. V.; MÖHWALD, H.; SHCHUKIN, D. Surface-Modified mesoporous $\mathrm{SiO}_{2}$ containers for corrosion protection. Advanced Functional Materials, v. 19, p. 2373-2379, 2009.

SNIHIROVA, D.; LIPHARDT, L.; GRUNDMEIER, G. MONTEMOR, F. Electrochemical study of the corrosion inhibition ability of "smart" coatings ,applied on AA2024. Journal of Solid State Electrochemical, v. 17, p. 21832192, 2013.

SOARES, V. F. Dispersão e estabilização de partículas submicrométricas de óxido de alumínio em sistemas líquidos destinados à produção de materiais refratários. Dissertação de Mestrado. Belo Horizonte. Brasil, 2009.

SONAWANE, S.H.; BHANVASE, B. A.; JAMALI, A. A.; DUBEY, S. K.; KALE, S. S.; PINJARI, D. V.; KULKARNI, R. D.; GOGATE, P.R.; PANDIT, A. B. Improve active anticorrosion coatings using layer-by-layer assembled $\mathrm{ZnO}$ nanocontainers with benzotriazole. Chemical Engineering Journal, v. 10, p. 464-472, 2012.

SRHIRI, A.; ETMAN, M.; DABOSI, F. Electro and physicochemical study of corrosion inhibition of carbon steel in $3 \% \mathrm{NaCl}$ by alkymidazoles. Electrochimica Acta, v. 41, p.429-437, 1996.

STANKIEWICZ, A.; SZCZYGIEL, I.; SZCZYGIEL, B. Self-healing coatings in anticorrosion applications. Journal of Materials Science, v. 48, p. 8041-8051, 2013.

SUKHORUKOV, G. B.; DONATH, S.; SUSHA, A. S.; VOIGT, A.; HARTMANN, J.; MÖHWALD, $H$. Microencapsulation by means of step-wise adsorption of polyelectrolytes. Journal of Microencapsulation, v. 17, p. 177-185, 2000.

SYRETT, J.; BECER, C.; HADDLETON, D. Self-healing and self-mendable polymers. Polymer Chemistry, v. 1, p. 978-987, 2010.

SZAUER, T.; BRANDT, A. On the role of fatty-acid in adsorption and corrosion inhibition of iron by amine fatty-acid salts in acidic solution. Electrochimica Acta, v. 26, p.1219-1224, 1981.

TAGUCHI, A.; SCHÜTH, F. Ordered mesoporous materials in catalysis. Microporous and Mesoporous Materials, v. 77, p. 1-45, 2005.

TAN, B.; RANKIN, S. E. Dual latex/surfactant templating of hollow spherical silica particles with ordered mesoporous shells. Langmuir, v. 21, p. 8180-8187, 2005.

TAVANDASHTI, N. P.; SANJABI, S. Corrosion study of hibrid sol-gel coatings containing boehmite nanoparticles loaded with cerium nitrate corrosion inhibitor. Process in Organic Coatings, v. 69, p. 384-391, 2010. 
TEDIM, J.; POZNYAK, S. K.; KUZNETSOVA, A.; RAPS, D.; HACK, T.; ZHELUDKEVICH, M. L.; FERREIRA, M. G. S. Enhancement of active corrosion protection via combination of inhibitor-loaded nanocontainers. Applied Materials \& Interfaces, v. 2, p.1528-1535, 2010.

THIELEMANN, J. P.; GIRGSDIES, F.; SCHLOGL, R.; HESS, C. Pore structure and surface area of silica SBA-15: influence of washing and scale-up. Beilstein Journal of Nanotechnology, v. 2, p. 110-118, 2011.

TUEL, A.; HUBERT-PFALZGRAF, L. G. Nanometric monodispersed titanium oxide particles on mesoporous silica: synthesis, characterization and catalytic activity in oxidation reactions in the liquid phase. Journal of Catalysis, v. 217, p. 343-353, 2003.

TWITE, R. L.; BIERWAGEN, G. P. Review of alternatives to chromate for corrosion protection of aluminum aerospace alloys. Progress in Organic Coatings. v. 33, p. 91-100, 1998.

UHLIG, H. H.; REVIE, R. W. Corrosion and Corrosion Controle. An introduction to corrosion science and engineering. Third edition. New York: John Wiley \& Sons. 1985. 441p.

VALLET-REGÍ, M.; DOADRIO, J. C.; DOADRIO, R. P.; IZQUIERDO-BARBA, I.; RAMILA, A.; DEL REAL, R. P.; PÉREZ-PARIENTE, J. A new property of MCM41: Hexagonal ordered mesoporous materials as a matrix for the amoxicillin. Solid State Ionics, v. 172, p. 435-439, 2004.

VALLET-REGí, M.; RAMILA, A.; DEL REAL, R. P.; PÉREZ-PARIENTE, J. A new property of MCM-41: Drug delivery system. Chemistry of Materials, v. 13, p. 308-311, 2001.

VAN DER MEER, J.; BARDEZ-GIBOIRE, I.; MERCIER, C.; REVEL, B.; DAVIDSON, A.; DENOYEL, R. Mechanism of metal oxide nanoparticle loading in SBA-15 by the double solvent technique. The Journal of Physical Chemistry, v. 114, p. 3507-3515, 2010.

VENKATARAMAN, M. The effect of colloidal stability on the heat transfer characteristics of nanosilica dispersed fluids. Master Dissertation. University of Madras. Orlando. USA, 2002.

VERMA, A.; VERMA, A. Polyelectrolyte complex - An overview. Indian Journal of Pharmaceutical Sciences, v. 4, p. 1684-1691, 2013.

VIEIRA, J. Estudos de interfaces eletroquímicas envolvendo aço carbono, aço galvanizado e zinco em meios eletrólitos, na ausência e presença de benzotriazole. Dissertação de Doutorado. São Paulo. Brasil, 2010.

W. J. Effects of addition of corrosion inhibitors to silane films on the performance of AA2024-T3 in a $0.5 \mathrm{M} \mathrm{NaCl}$ solution. Progress in Organic Coatings, v. 53, p. 153-158, 2005. 
WANG, W.; XU, L.; LI, X.; LIN, Z.; YANG, Y.; AN, E. Self-healing mechanisms of water triggered smart coating in seawater. Journal of Materials Chemistry A, v. 2, p. 1914-1921, 2014.

WOLYNEC, S. Técnicas Eletroquímicas em Corrosão, Editora da Universidade de São Paulo, São Paulo, Brasil, 2003.

WOOL, R. P.; Self-healing Materials: a review. Soft Matter, v. 4, p. 400-418, 2008.

WU, D. Y.; MEURE, S.; SOLOMON, D. Self-healing polymeric materials: a review of recent developments. Progress in Polymeric Science, v. 33, p. 479522, 2008.

YABUKI, A.; OKUMURA, K. Self-healing coatings using superabsorbent polymers for corrosion inhibition in carbon steel. Corrosion Science, v. 59, p. 258-262, 2012.

YAMADA, Y.; MIZUTANI, M.; NAKAMURA, T.; YANO, K. Mesoporous microcapsules with decorated inner surface: fabrication and photocatalytic activity. Chemistry of Materials, v. 22, p. 1695-1703, 2010.

ZAYID, A. Factors effecting the electrical conductivity and zeta potential of alumina nanofluids. Master Dissertation. Dalhousie University. Halifax. Nova Scotia, 2014.

Zeta potential an introduction in 30 minutes, 2004. Disponível em: http://www.malvern.com/br/support/resource-center/technical/notes/TN10 1104ZetaPotentiallntroduction.aspx. Acessado em: 24 de Outubro de 2013.

ZHANG, A. B.; PAN, L. ZHANG, H. Y.; LIU, S. T.; YE, Y.; XIA, M. S.; CHEN, X. $G$. Effects of acid treatment on the physic-chemical and pore characteristics of halloysite. Colloids and Surfaces A: Physicochemical and Engineering Aspects, v. 396, p. 182-188, 2012.

ZHANG, S. H.; LYON, S. B. Anodic processes on iron covered by thin dilute electrolyte layers (II) - A. C. Impedance Measurements. Corrosion Science, v. 36, p. 1309-1321, 1994.

ZHAO, D.; HUO, Q.; FENG, J.; CHMELKA, B. F.; STUCKY, G. D. Nonionic triblock and star diblock copolymer and oligomeric surfactant syntheses of highly ordered, hydrothermally stable, mesoporous silica structures. Journal of the American Chemical Society, v. 120, p.6024-6036, 1998a.

ZHAO, D.; FENG, J.; HUO, Q.; MELOSH, N.; FREDRICKSON, G. H.; CHMELKA, B. F.; STUCKY, G. D. Triblock copolymer syntheses of mesoporous silica with periodic 50 to 300 angstrom pores. Science, v. 279, p. 548-552, $1998 \mathrm{~b}$.

ZHELUDKEVICH, M. L.; POZNYAK, S. K.; RODRIGUES, L. M.; RAPS, D.; HACK, T.; DICK, L. F.; NUNES, T.; FERREIRA, M. G. S. Active protection 
coatings with layered double hydroxides nanocontainers of corrosion inhibitor. Corrosion Science, v. 52, p. 602-611, 2010.

ZHELUDKEVICH, M. L.; SHCHUKIN, D.; YASAKAU, K. A.; MÖHWALD, H.; FERREIRA, M. G. S. Anticorrosion coatings with self-healing effect based on nanocontainers impregnated with corrosion inhibitor. Chemical Materials, v. 19, p. 402-411, 2007.

ZHENG, Z.; HUANG, X.; SCHENDERLIEN, M.; BORISOVA, D.; CAO, R.; MÖHWALD, H.; SHCHUKIN, D. G. Self-healing and antifouling multifunctional coatings based on $\mathrm{pH}$ and sulfide ion sensitive nancontainers. Materials Views, v. 23, p. 3307-3314, 2013.

ZUCOLOTTO, V. Compósitos poliméricos nanoestruturados de azocorantes, ftalocianinas e polímeros luminescentes. Dissertação de Doutorado. São Carlos, São Paulo, Brasil, 2003.

ZWAAG, S. Self-healing Materials. An alternative approach to 20 centuries of materials science. Springer, Verlag, 2007. 400p. 